\title{
Solar Thermal Bowl Concepts and Economic Comparisons for Electricity Generation
}
T. A. Williams
E. P. Coomes
J. A. Dirks
S. N. Craig
D. R. Brown
M. K. Drost
Z. I. Antoniak
K. K. Humphreys
R. T. Allemann
K. K. Nomura

April 1988

Prepared for the U.S. Department of Energy under Contract DE-AC06-76RLO 1830

Pacific Northwest Laboratory Operated for the U.S. Department of Energy by Battelle Memorial Institute 


\title{
DISCLAIMER
}

This report was prepared as an account of work sponsored by an agency of the United States Government. Neither the United States Government nor any agency thereof, nor Battelle Memorial Institute, nor any or their employees, makes any warranty, expressed or implied, or assumes any legal liability or responsibility for the accuracy, completeness, or usefulness of any information, apparatus, product, or process disclosed, or represents that its use would not infringe privately owned rights. Reference herein to any specific commercial product, process, or service by trade name, trademark, manufacturer, or otherwise does not necessarily constitute or imply its endorsement, recommendation, or favoring by the United States Government or any agency thereof, or Battelle Memorial Institute. The views and opinions of authors expressed herein do not necessarily state or reflect those of the United States Government or any agency thereof, or Battelle Memorial Institute.

\author{
PACIFIC NORTHWEST LABORATORY \\ operated by \\ BATTELLE MEMORIAL INSTITUTE \\ for the \\ UNITED STATES DEPARTMENT OF ENERGY \\ under Contract DE-AC06-76RLO 1830
}

\begin{tabular}{|c|c|}
\hline \multirow{2}{*}{\multicolumn{2}{|c|}{ Printed in the United States of America }} \\
\hline & \\
\hline \multicolumn{2}{|c|}{$\begin{array}{l}\text { Available from } \\
\end{array}$} \\
\hline \multicolumn{2}{|c|}{$\begin{array}{l}\text { National Technical Information Service } \\
\text { United States Department of Commerce }\end{array}$} \\
\hline \multicolumn{2}{|c|}{$\begin{array}{l}5285 \text { Port Royal Road } \\
\text { Springfield, Virginia } 22161\end{array}$} \\
\hline \multicolumn{2}{|c|}{ Springfield, Virginia 22161} \\
\hline \multirow{2}{*}{\multicolumn{2}{|c|}{$\begin{array}{l}\text { NTIS Price Codes } \\
\text { Microfiche A01 }\end{array}$}} \\
\hline & \\
\hline \multicolumn{2}{|c|}{ Printed Copy } \\
\hline Рagec & Price \\
\hline rages & \\
\hline $001-025$ & A02 \\
\hline 026-050 & A03 \\
\hline 051-075 & A04 \\
\hline $076-100$ & A05 \\
\hline $101-125$ & A06 \\
\hline $126-150$ & A07 \\
\hline $151-175$ & $A(1 B$ \\
\hline $176-200$ & $A 09$ \\
\hline $201-225$ & A010 \\
\hline $226-250$ & A011 \\
\hline $251-275$ & A012 \\
\hline $276-300$ & A013 \\
\hline
\end{tabular}


PNL -6129

UC -236

SOLAR THERMAL BOWL CONCEPTS AND ECONOMIC

COMPARISONS FOR ELECTRICITY GENERATION
T. A. Williams
J. A. Dirks
D. R. Brown
Z. I. Antoniak
R. T. Allemann
E. P. Coomes
S. N. Craig
M. K. Drost
K. K. Humphreys
K. K. Nomura

April 1988

Prepared for the U.S. Department of Energy under Contract DE-AC06-76RLO 1830

Pacific Northwest Laboratory

Richland, Washington 99352 


\section{PREFACE}

The research and development (R\&D) described in this document was conducted within the U.S. Department of Energy's (DOE) Solar Thermal Technology Program. The goal of the Solar Thermal Technology Program is to advance the engineering and scientific understanding of solar thermal technology, and to establish the technology base from which private industry can develop solar thermal power production options for introduction into the competitive energy market.

Solar thermal technology concentrates solar radiation by means of tracking mirrors or lenses onto a receiver where the solar energy is absorbed as heat and converted into electricity or incorporated into products as process heat. The two primary solar thermal technologies, central receivers and distributed receivers, employ various point and line-focus optics to concentrate sunlight. Current central receiver systems use fields of heliostats (two-axis tracking mirrors) to focus the sun's radiant energy onto a single tower-mounted receiver. Parabolic dishes up to 17 meters in diameter track the sun in two axes and use mirrors or Fresnel lenses to focus radiant energy onto a receiver. Troughs and bowls are line-focus tracking reflectors that concentrate sunlight onto receiver tubes along their focal lines. Concentrating collector modules can be used alone or in a multi-module system. The concentrated radiant energy absorbed by the solar thermal receiver is transported to the conversion process by a circulating working fluld. Receiver temperatures range from $100^{\circ} \mathrm{C}$ in lowtemperature troughs to over $1500^{\circ} \mathrm{C}$ in dish and central receiver systems.

The Solar Thermal Technology Program is directing efforts to advance and improve each system concept through the research and development of solar thermal materials, components, and subsystems, and the testing and performance evaluation of subsystems and systems. These efforts are carried out through the technical direction of DOE and its network of national laboratories who work with private industry. Together they have established a comprehensive, goal directed program to improve performance and provide technically proven options for eventual incorporation into the Nation's energy supply.

To be successful in contributing to an adequate national energy supply at a reasonable cost, solar thermal energy must eventually be economically 
competitive with a variety of other energy sources. Components and systemlevel performance targets have been developed as quantitative program goals. The performance targets are used in planning research and development activities, measuring progress, assessing alternative technology options, and making optimal component developments. These targets will be pursued vigorously to ensure a successful program.

This study is aimed at providing a relative comparison of the thermodynamic and economic performance in electric applications for Fixed Mirror Distributed Focus (FMDF) solar thermal concepts which have been studied and developed in the DOE solar thermal program. Following the completion of earlier systems comparison studies in the late 1970s there have been a number of years of progress in solar thermal technology. This progress includes developing new solar components, improving component and system design details, constructing working systems, and collecting of operating data on the systems. This study provides an update of the expected performance and cost of the major components, and an overall system energy cost for the FMDF concepts evaluated. The projections in this study are for the late 1990s, based on the capabilities of the technologies which could be expected to be achieved with further technology development. The results of the analyses performed in this study are compared with the results of another recently completed study that evaluated four central receiver systems, one parabolic dish system, and a parabolic trough system (Williams et al, 1987). 


\section{ABSTRACT}

This study is aimed at providing a relative comparison of the thermodynamic and economic performance in electric applications for fixed mirror distributed focus (FMDF) solar thermal concepts which have been studied and developed in the DOE solar thermal program. Following the completion of earlier systems comparison studies in the late 1970s there have been a number of years of progress in solar thermal technology. This progress includes developing new solar components, improving component and system design details, constructing working systems, and collecting operating data on the systems. This study provides an update of the expected performance and cost of the major components, and an overall system energy cost for the FMDF concepts evaluated. The projections in this study are for the late 1990s and are based on the potential capabilities that might be achieved with further technology development. 



\section{SUMMARY}

The fixed mirror distributed focus (FMDF) hemispherical bowl is a solar thermal power technology which has been studied for several years as a potential means of producing electricity. The goal of this study is to evaluate the technology relative to the Solar Thermal Technology Program goals of the U.S. Department of Energy (DOE), and relative to other solar thermal technologies. Data for other solar thermal technologies are taken from a companion document in which dish, trough, and central receiver concepts were analyzed using assumptions and methods identical to those used for this study (Williams et a). 1987). This study develops projections of the performance and cost that could be achieved by the FMDF technology, based on the assumption of continued technology development and high volume production of solar components.

The bowl technology uses a fixed, non-tracking concentrator which produces focal line within the concentrator. A two-axis tracking receiver moves within the bowl to follow the movement of the focal line throughout the day. Five variations of the bowl technology were analyzed in this study. The first four concepts were configured from variations in the concentrator rim angle and the working fluid used in the receiver and transport subsystem. Each of these concepts used a centrally located steam-Rankine heat engine for conversion of thermal energy into electricity. The fifth concept represented an innovative approach to the bowl technology, and used a tracking mirror panel section on the concentrator (the tracking section is referred to as the iris) and a distributed energy conversion system that used stirling cycle heat engines.

Key annual efficiency, cost, and economic results of the study are highlighted in Table S.1 for the 100-MWe designs. The data provided are for the designs that resulted in the lowest levelized energy cost (LEC) over the analysis range. The lowest LECs for the cases analyzed occurred for the 60degree bowl cases. The 30-degree bowl results as we1l as the iris case had markedly higher LECs. 
IABLE S.1. Summary of Key Results for Lowest Energy Cost Systems (minimum LEC cases)

\begin{tabular}{|c|c|c|c|c|c|c|c|c|c|c|c|}
\hline & & & $\begin{array}{l}\text { 6e Degreo } \\
\text { teer/Staan }\end{array}$ & & $\begin{array}{c}86 \text { Degroe } \\
\text { Salt }\end{array}$ & & $\begin{array}{l}\text { De Degree } \\
\text { ter/Stese }\end{array}$ & & $\begin{array}{l}30 \text { Degree } \\
\text { Salt }\end{array}$ & & Iris \\
\hline & $\begin{array}{l}\text { Plant Size } \\
\text { Pfant Capacily Factor }\end{array}$ & & $\begin{array}{l}100 \text { wite } \\
17 \pi\end{array}$ & & $\log _{\text {Bex }}$ & & ${ }_{13 x}^{160} \mathrm{wa}$ & & $100 \mathrm{w1}$ & & ${ }_{68 \mathrm{x}}^{108 \mathrm{w}}$ \\
\hline & Component & Eir. & Cost & Eff. & Cost & Eff. & Cost & Eff. & cost & Eff. & Cost \\
\hline & Concentrator & .56 & $1138 / \mathrm{m}^{2}$ & .58 & $3139 / 4^{2}$ & .44 & $397 / \mathrm{r}^{2}$ & .44 & $197 / \mathrm{n}^{2}$ & .39 & $\$ 89 / 0^{2}$ \\
\hline & Recoivor & .78 & $262 / m^{2}$ & .81 & $376 / 4^{2}$ & .79 & $\$ 132 / 4^{2}$ & .39 & $1173 / m^{2}$ & .39 & $388 / \mathrm{s}^{2}$ \\
\hline & Iransport & .98 & $271 / 0^{2}$ & .88 & $s 79 / m^{2}$ & .86 & $265 / 0^{2}$ & .77 & $882 / 0^{2}$ & .98 & $88 / 4^{2}$ \\
\hline & Storagu & NA & MA & .89 & $\$ 12 / \mathrm{ktht}$ & MA & MA & .80 & $\$ 11 / \mathrm{k} / \mathrm{ht}$ & NA & MA \\
\hline & Conversion & .35 & $2310 / \mathrm{kW0}$ & .41 & $\$ 380 / \mathrm{kll}$ & .35 & $\$ 310 / \mathrm{kl}$ & .41 & $2370 / k 16$ & .32 & $3210 / k^{w e}$ \\
\hline & $\begin{array}{l}\text { Dalance of } \\
\text { Plant }\end{array}$ & NA & $127 / \mathrm{m}^{2}$ & HA & $\$ 16 / \mathrm{a}^{2}$ & NA & $325 / \mathrm{*}^{2}$ & MA & $115 / n^{2}$ & MA & $315 / 4^{2}$ \\
\hline & Systen & .11 & $2580 / \mathrm{kWO}$ & .10 & 395चe/k10 & .68 & $82960 / \mathrm{kTe}$ & .05 & $815,880 / \mathrm{kJe}$ & .03 & 12100/kle \\
\hline & Detu & HA & $37 / m^{2}$-Year & NA & $31 / \star^{2}$-Year & MA & $39 / \triangle^{2}$-Year & NA & $s 10 / \star^{2}$-Year & MA & $118 / \mathrm{m}^{2}-$ Year \\
\hline & $\begin{array}{l}\text { Levelized } \\
\text { Energy Cost }\end{array}$ & $\mathrm{MA}$ & 1.13/kWhe & Wh & 2.14/kWho & NA & S.21/kWho & NA & $8.37 / \mathrm{knhe}$ & NA & 8.31/kthe \\
\hline
\end{tabular}


Basic design information on the bowl concepts was provided to Pacific Northwest Laboratory (PNL) by the principal investigator of the bowl technology, Texas Tech University (TTU). TTU also provided PNL with data on the component performance (such as receiver thermal losses) or with estimates of component performance when such information was available. An independent review was performed on these estimates; where necessary the performance estimates were revised to be consistent with the approaches and assumptions used in previous evaluations of other solar thermal concepts. Independent component cost estimates were developed for all cases to ensure comparability of cost estimates between the bow1 cases and other solar thermal technologies.

The annual plant energy output and LEC were determined using the SOLSTEP computer code. The energy analysis routines within SOLSTEP used hourly weather data to model the performance of the key plant subsystems over the course of a year (1976 climatic data for Barstow, California were used in the analysis). The economic routines in SOLSTEP developed estimates of the capital and operating costs for solar thermal plants, and calculated their LECs. For each of the plant sizes and capacity factors analyzed, SOLSTEP determined the optimum collector field and energy storage size based upon an economic optimization. LECs are calculated using an approach consistent with the calculation of the DOE energy cost goals for solar thermal technologies (DOE 1986).

Each of the five bowl concepts was analyzed over a range of plant sizes from 0.5 MWe to 100 MWe, to identify any particular plant size where the concept might have advantages over other solar thermal technologies. Two of the bowi cases used molten salt energy storage systems to assess the plant's performance over a range of capacity factors.

For the cases analyzed, the annual average plant efficiency was highest for 100-MWe plants. Table S.1 provides a summary of key plant component efficiencies, as well as the overall plant efficiency. Annual efficiencies at this size for designs without energy storage ranged from $3 \%$ to $11 \%$ for the 5 cases. In comparison, annual average efficiencies for several central receiver concepts at the same plant size ranged from $14 \%$ to $19 \%$, and for the dish-Stirling technology were 21\% (see Williams et al. 1987). 
None of the bowl components had any significant cost advantages over other solar technologies for any of the cases analyzed. In some cases (such as the receiver subsystem) the bowl components were significantly more expensive than the other technologies. The combination of lower plant performance and generally higher plant costs resulted in much higher LECS for the bowl cases than for other solar thermal technologies. The lowest LEC at each plant size is plotted in Figure S.1 for the bowl cases and also for two other solar thermal technologies.
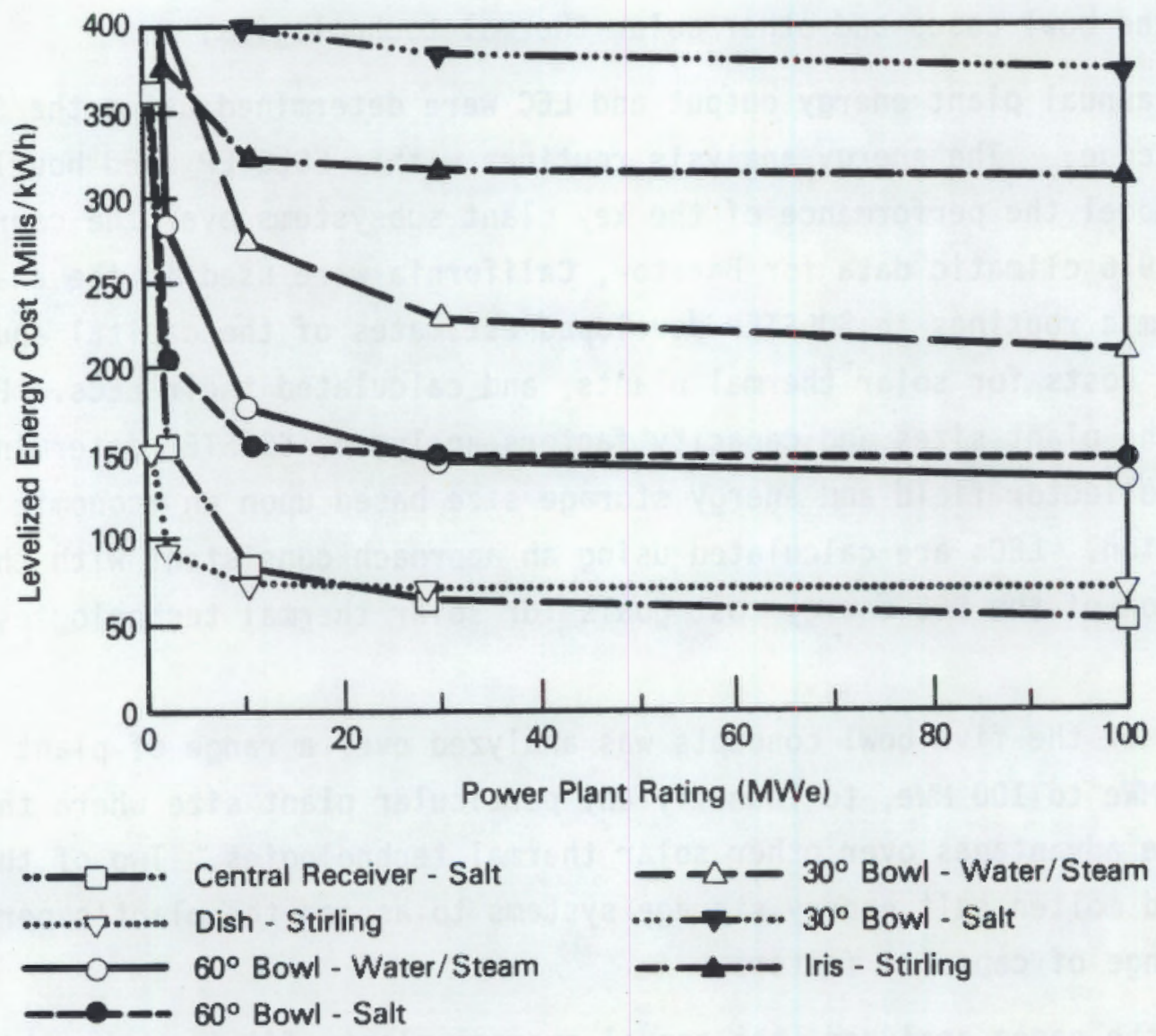

FIGURE S.1. Minimum LEC for Bowls, Central Receiver-Salt, and Dish-Stirling 
Although they were not analyzed in this study, a number of other possible FMDF bowl concepts could be configured. Sensitivity analyses of the key cost parameters in the study indicate that cost reductions alone would not make bowl concepts competitive with other solar thermal technologies; annual performance would have to be increased in conjunction with decreasing the system cost. Further design optimization (such as receiver size, rim angle, working fluid temperature, etc.) of basic bowl configurations considered in Cases I through IV is not expected to significantly improve the concepts' performance. Revolutionary design changes to improve concentrator efficiency (which would have to involve tracking) and to increase receiver performance (such as reducing receiver size to reduce thermal losses) are already features that are incorporated in central receiver and dish technologies. The overall conclusion is that the bowl concepts that were analyzed do not appear to be competitive with either the central receivers or dish-Stirling technologies. Therefore, further development of the FMDF bowl concept for electric power applications is not recommended. 

• 


\section{ACKNOWLEDGMENTS}

In addition to the primary report authors, we would like to acknowledge the technical contribution of PNL staff member Bill Doggett. Additionally, we extend our thanks to the following Texas Tech University staff members that provided information and technical reviews: Ed 0'Hair, Travis Simpson, Ron Anderson, Bobby Green, Jim Jonish, Tim Maxwell, Penington Vann, Steve Calico, and Tom Harper. 


\section{ACRONYMS}

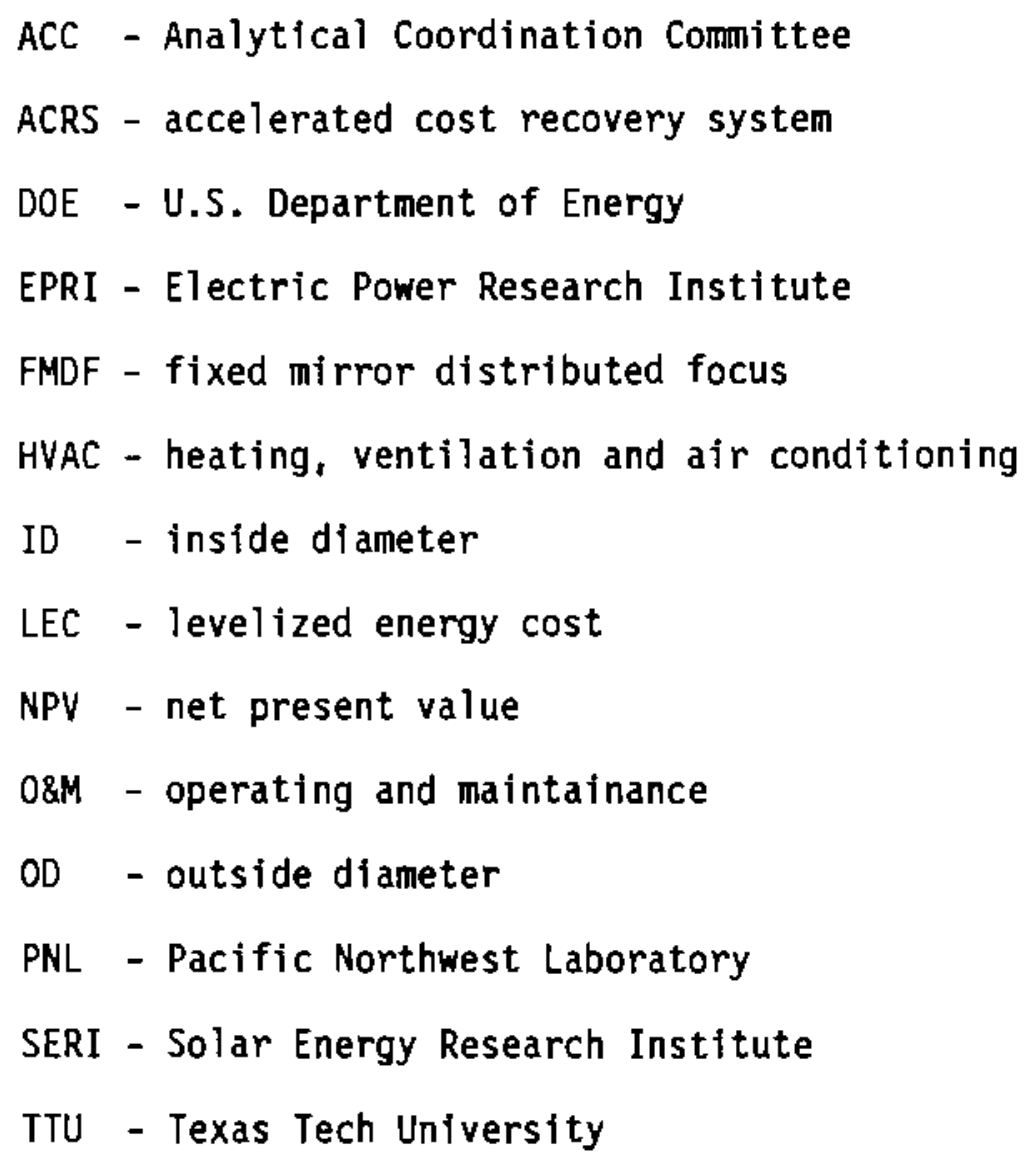




\section{CONTENTS}

PREFACE

ABSTRACT

v

SUMMARY

vi i

ACKNOWLEDGMENTS

$x i i$

ACRONYMS

XV

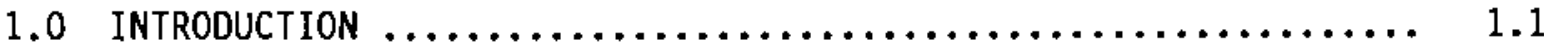

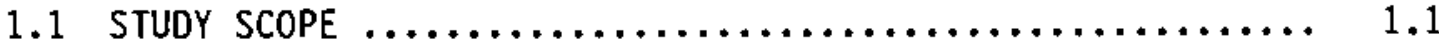

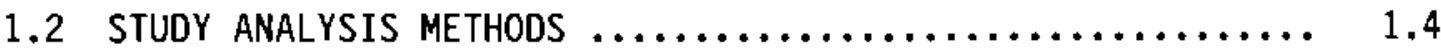

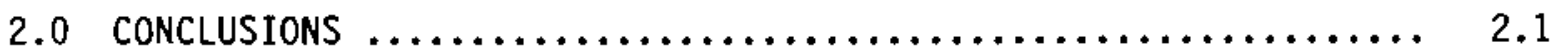

2.1 PERFORMANCE CONCLUSIONS $\ldots \ldots \ldots \ldots \ldots \ldots \ldots \ldots \ldots \ldots \ldots \ldots \ldots \ldots \ldots$

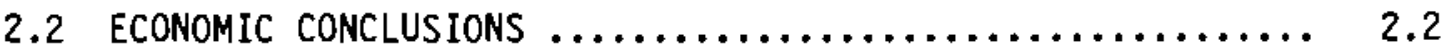

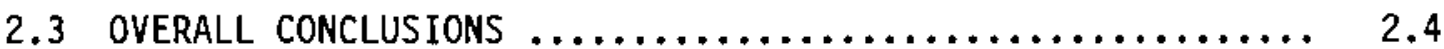

3.0 STUDY APPROACH AND GROUND RULES $\ldots \ldots \ldots \ldots \ldots \ldots \ldots \ldots \ldots \ldots \ldots \ldots . \ldots \ldots$

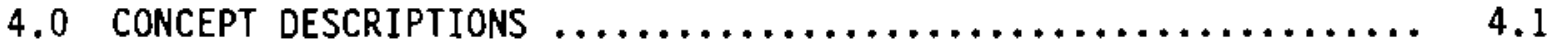

4.1 CASE I: 60-DEGREE BOWL WITH A WATER/STEAM RECEIVER

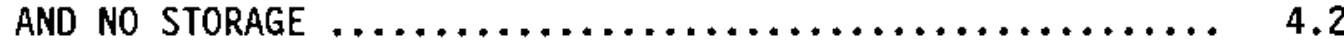

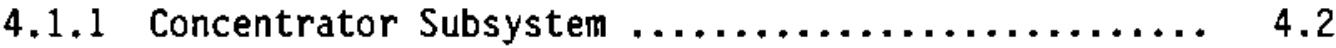

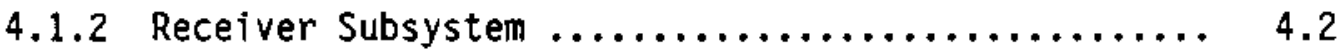

4.1.3 Energy Transport Subsystem ............... 4.3

4.1 .4 Energy Storage Subsystem ................ 4.3

4.1 .5 Energy Conversion Subsystem $\ldots \ldots \ldots \ldots \ldots \ldots \ldots \ldots .4 .3$

4.2 CASE II: 60-DEGREE BOWL WITH A MOLTEN SALT RECEIVER

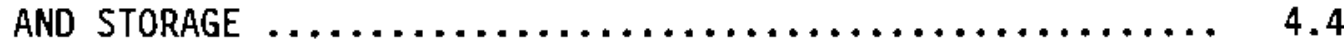

4.2 .1 Concentrator Subsystem $\ldots \ldots \ldots \ldots \ldots \ldots \ldots \ldots \ldots \ldots .4 .4$

4.2 .2 Receiver Subsystem $\ldots \ldots \ldots \ldots \ldots \ldots \ldots \ldots \ldots \ldots \ldots, 4.4$

4.2.3 Energy Transport Subsystem ................ 4.4 


\section{CONTENTS (contd)}

4.2.4 Energy Storage Subsystem $\ldots \ldots \ldots \ldots \ldots \ldots \ldots \ldots, 4.5$

4.2.5 Energy Conversion Subsystem $\ldots \ldots \ldots \ldots \ldots \ldots \ldots \ldots, \quad 4.5$

4.3 CASE III: 30-DEGREE BOWL WITH A WATER/STEAM RECEIVER AND NO STORAGE $\ldots \ldots \ldots \ldots \ldots \ldots \ldots \ldots \ldots \ldots \ldots \ldots \ldots \ldots \ldots \ldots, \quad 4.6$

4.3.1 Concentrator Subsystem $\ldots \ldots \ldots \ldots \ldots \ldots \ldots \ldots \ldots, \quad 4.6$

4.3.2 Receiver Subsystem $\ldots \ldots \ldots \ldots \ldots \ldots \ldots \ldots \ldots \ldots, \quad 4.6$

4.3.3 Energy Transport Subsystem $\ldots \ldots \ldots \ldots \ldots \ldots \ldots \ldots, 4.7$

4.3.4 Energy Storage Subsystem $\ldots \ldots \ldots \ldots \ldots \ldots \ldots \ldots, 4.7$

4.3.5 Energy Conversion Subsystem $\ldots \ldots \ldots \ldots \ldots \ldots \ldots \ldots, 4.7$

4.4 CASE IV: 30-DEGREE BOWL WITH A MOLTEN SALT RECEIVER

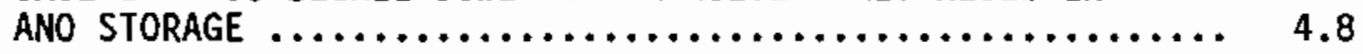

4.4.1 Concentrator Subsystem $\ldots \ldots \ldots \ldots \ldots \ldots \ldots \ldots \ldots, 4.8$

4.4.2 Receiver Subsystem $\ldots \ldots \ldots \ldots \ldots \ldots \ldots \ldots \ldots \ldots, 4.8$

4.4.3 Energy Transport Subsystem $\ldots \ldots \ldots \ldots \ldots \ldots \ldots \ldots, 4.8$

4.4.4 Energy Storage Subsystem $\ldots \ldots \ldots \ldots \ldots \ldots \ldots \ldots \ldots, 4.9$

4.4.5 Energy Conversion Subsystem ................ 4.9

4.5 CASE V: 30-DEGREE BOWL WITH AN IRIS, HEAT PIPE RECEIVER, STIRLING ENGINE AND NO STORAGE $\ldots \ldots \ldots \ldots \ldots \ldots \ldots \ldots \ldots, 4.9$

4.5.1 Concentrator Subsystem $\ldots \ldots \ldots \ldots \ldots \ldots \ldots \ldots \ldots, 4.9$

4.5 .2 Receiver Subsystem $\ldots \ldots \ldots \ldots \ldots \ldots \ldots \ldots \ldots \ldots, 4.10$

4.5.3 Energy Transport Subsystem $\ldots \ldots \ldots \ldots \ldots \ldots \ldots \ldots, 4.10$

4.5.4 Energy Storage Subsystem $\ldots \ldots \ldots \ldots \ldots \ldots \ldots \ldots \ldots, 4.11$

4.5.5 Energy Conversion Subsystem $\ldots \ldots \ldots \ldots \ldots \ldots \ldots, 4.11$

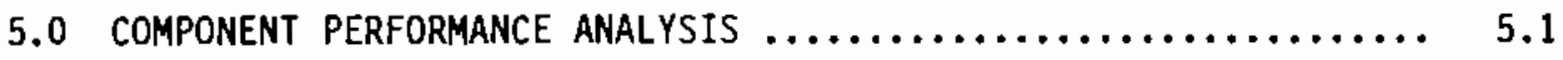

5.1 CASE I: 60-DEGREE CONCENTRATOR WITH A WATER/STEAM

RECEIVER AND NO STORAGE $\ldots \ldots \ldots \ldots \ldots \ldots \ldots \ldots \ldots \ldots \ldots, 5.3$

5.1.1 Concentrator Subsystem $\ldots \ldots \ldots \ldots \ldots \ldots \ldots \ldots \ldots, 5.3$ 
CONTENTS (contd)

5.1.1.1 Design-Point Performance $\ldots \ldots \ldots \ldots \ldots \ldots$. 5.4

5.1.1.2 Annual Average Concentrator Performance .. 5.6

5.1 .2 Receiver Subsystem $\ldots \ldots \ldots \ldots \ldots \ldots \ldots \ldots \ldots \ldots, 5.7$

5.1.2.1 Design-Point Performance ............. 5.7

5.1.2.2 Annual Average Receiver Efficiency ...... 5.7

5.1 .3 Transport Subsystem $\ldots \ldots \ldots \ldots \ldots \ldots \ldots \ldots \ldots \ldots, 5.8$

5.1.3.1 Design-Point Performance $\ldots \ldots \ldots \ldots \ldots \ldots . \quad 5.8$

5.1.3.2 Annual Average Transport Performance ..... 5.8

5.1 .4 Storage Subsystem $\ldots \ldots \ldots \ldots \ldots \ldots \ldots \ldots \ldots \ldots, \quad 5.9$

5.1 .5 Energy Conversion Subsystem $\ldots \ldots \ldots \ldots \ldots \ldots \ldots \ldots, 5.9$

5.1.5.1 Design-Point Performance ............. 5.10

5.1.5.2 Annual Average Energy Conversion
Efficiency ................................. 5.11

5.1.6 Parasitic Losses .......................... $\quad 5.12$

5.1.6.1 Design-Point Performance ............ 5.12

5.1.6.2 Annual Average Parasitic Losses ....... 5.12

\subsection{CASE II: 60-DEGREE CONCENTRATOR WITH A MOLTEN SALT}

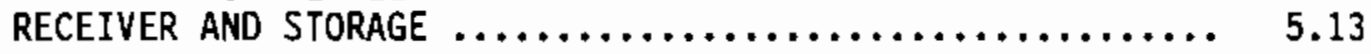

5.2.1 Concentrator Subsystem $\ldots \ldots \ldots \ldots \ldots \ldots \ldots \ldots \ldots, 5.13$

5.2.2 Receiver Subsystem $\ldots \ldots \ldots \ldots \ldots \ldots \ldots \ldots \ldots \ldots, \quad 5.13$

5.2.2.1 Design-Point Performance ............. 5.14

5.2.2.2 Annual Average Receiver Efficiency ...... 5.14

5.2.3 Transport Subsystem $\ldots \ldots \ldots \ldots \ldots \ldots \ldots \ldots \ldots \ldots \ldots .6 .14$

5.2.3.1 Design-Point Performance ............. 5.15

5.2.3.2 Annual Average Transport Performance .... 5.15

5.2.4 Storage Subsystem $\ldots \ldots \ldots \ldots \ldots \ldots \ldots \ldots \ldots \ldots \ldots, \quad 5.15$

$$
x i x
$$


CONTENTS (contd)

5.2.4.1 Design-Point Performance ............. 5.16

5.2.4.2 Annual Average Storage Performance ...... 5.16

5.2.5 Energy Conversion Subsystem $\ldots \ldots \ldots \ldots \ldots \ldots \ldots, 5.18$

5.2.5.1 Design-Point Performance ............. 5.18

5.2.5.2 Annual Average Energy Conversion
Efficiency .......................... 5.20

5.2.6 Parasitic Losses $\ldots \ldots \ldots \ldots \ldots \ldots \ldots \ldots \ldots \ldots \ldots . \quad 5.20$

5.2.6.1 Design-Point Performance ............. 5.21

5.2.6.2 Annual Average Parasitic Losses ........ 5.21

5.3 CASE III: 30-DEGREE CONCENTRATOR WITH A WATER/STEAM

RECEIVER AND NO STORAGE $\ldots \ldots \ldots \ldots \ldots \ldots \ldots \ldots \ldots \ldots \ldots \ldots, \quad 5.22$

5.3.1 Concentrator Subsystem $\ldots \ldots \ldots \ldots \ldots \ldots \ldots \ldots \ldots, 5.22$

5.3.1.1 Design-Point Performance ............. 5.22

5.3.1.2 Annual Average Concentrator Performance .. 5.24

5.3 .2 Receiver Subsystem $\ldots \ldots \ldots \ldots \ldots \ldots \ldots \ldots \ldots \ldots . \ldots \ldots .24$

5.3.2.1 Design-Point Performance ............ 5.25

5.3.2.2 Annual Average Receiver Efficiency ...... 5.25

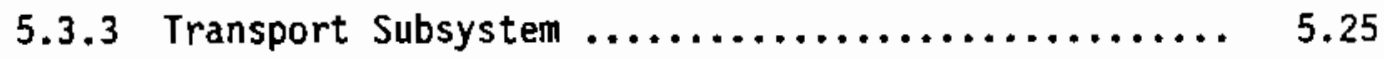

5.3.3.1 Design-Point Performance ............. 5.26

5.3.3.2 Annual Average Transport Performance .... 5.26

5.3 .4 Storage Subsystem $\ldots \ldots \ldots \ldots \ldots \ldots \ldots \ldots \ldots \ldots, \quad 5.26$

5.3 .5 Energy Conversion Subsystem $\ldots \ldots \ldots \ldots \ldots \ldots \ldots \ldots, 5.27$

5.3.5.1 Design-Point Performance $\ldots \ldots \ldots \ldots \ldots \ldots, 5.27$

5.3.5.2 Annual Average Energy Conversion
Efficiency ......................... 5.27

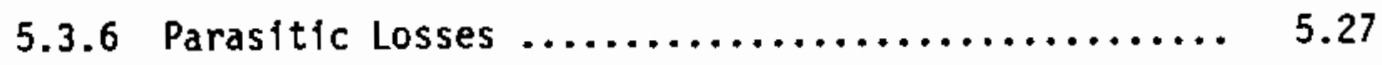

5.3.6.1 Design-Point Performance $\ldots \ldots \ldots \ldots \ldots \ldots, 5.28$ 


\section{CONTENTS (contd)}

5.3.6.2 Annual Average Parasitic Losses ........ 5.28

5.4 CASE IV: 30-DEGREE CONCENTRATOR WITH A MOLTEN SALT

RECEIVER AND STORAGE $\ldots \ldots \ldots \ldots \ldots \ldots \ldots \ldots \ldots \ldots \ldots \ldots, 5.29$

5.4.1 Concentrator Subsystem..$\ldots \ldots \ldots \ldots \ldots \ldots \ldots \ldots \ldots .6 .29$

5.4.2 Receiver Subsystem $\ldots \ldots \ldots \ldots \ldots \ldots \ldots \ldots \ldots \ldots \ldots, \quad 5.29$

5.4.2.1 Design-Point Performance ............. 5.29

5.4.2.2 Annual Average Receiver Efficiency ...... 5.30

5.4.3 Transport Subsystem $\ldots \ldots \ldots \ldots \ldots \ldots \ldots \ldots \ldots \ldots, \quad 5.30$

5.4.3.1 Design-Point Performance ............. 5.30

5.4.3.2 Annual Average Transport Performance ..... 5.31

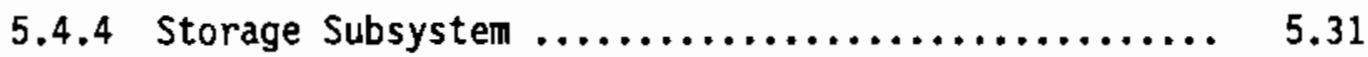

5.4.4.1 Design-Point Performance...$\ldots \ldots \ldots \ldots .6 .31$

5.4.4.2 Annua 1 Average Storage Performance ...... 5.32

5.4.5 Energy Conversion Subsystem $\ldots \ldots \ldots \ldots \ldots \ldots \ldots \ldots, 5.32$

5.4.5.1 Design-Point Performance ............. 5.32

5.4.5.2 Annual Average Energy Conversion
Efficiency ......................... 5.32

5.4.6 Parasitic Losses $\ldots \ldots \ldots \ldots \ldots \ldots \ldots \ldots \ldots \ldots \ldots . \quad 5.33$

5.4.6.1 Design-Point Performance ............. 5.33

5.4.6.2 Annual Average Parasitic Losses ........ 5.34

5.5 CASE V: IRIS CONCENTRATOR, HEAT PIPE RECEIVER, STIRLING

ENGINE, AND NO STORAGE $\ldots \ldots \ldots \ldots \ldots \ldots \ldots \ldots \ldots \ldots \ldots, \quad 5.35$

5.5.1 Concentrator Subsystem $\ldots \ldots \ldots \ldots \ldots \ldots \ldots \ldots \ldots \ldots, \quad 5.35$

5.5.1.1 Design-Point Performance $\ldots \ldots \ldots \ldots \ldots \ldots .5 .36$

5.5.1.2 Annual Average Concentrator Performance .. 5.38

5.5.2 Receiver Subsystem $\ldots \ldots \ldots \ldots \ldots \ldots \ldots \ldots \ldots \ldots \ldots, 5.38$

5.5.2.1 Design-Point Performance $\ldots \ldots \ldots \ldots \ldots \ldots . \quad 5.38$ 


\section{CONTENTS (contd)}

5.5.2.2 Annual Average Receiver Efficiency ...... 5.38

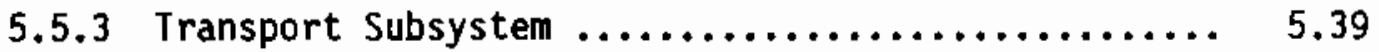

5.5.3.1 Design-Point Performance ............. 5.39

5.5.3.2 Annual Average Transport Performance .... 5.39

5.5 .4 Storage Subsystem $\ldots \ldots \ldots \ldots \ldots \ldots \ldots \ldots \ldots \ldots, \quad 5.40$

5.5 .5 Energy Conversion Subsystem $\ldots \ldots \ldots \ldots \ldots \ldots \ldots \ldots, \quad 5.40$

5.5.5.1 Design-Point Performance ............ 5.40

5.5.5.2 Annual Average Energy Conversion
Efficiency ......................... 5.41

5.5.6 Parasitic Losses ........................ $\quad 5.42$

5.5.6.1 Design-Point Performance $\ldots \ldots \ldots \ldots \ldots \ldots . \quad 5.42$

5.5.6.2 Annual Average Parasitic Losses ........ 5.43

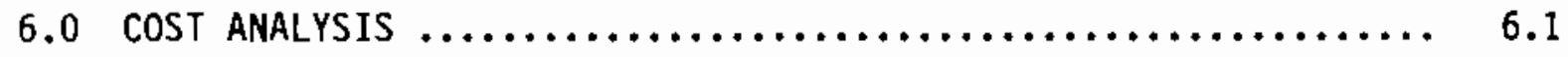

6.1 CONCENTRATOR COSTS $\ldots \ldots \ldots \ldots \ldots \ldots \ldots \ldots \ldots \ldots \ldots \ldots \ldots \ldots \ldots \ldots \ldots \ldots, 6.1$

6.1.1 Baseline (Case I \& II) Concentrator ............ 6.1

6.1 .2 Case III \& IV Concentrators $\ldots \ldots \ldots \ldots \ldots \ldots \ldots \ldots, 6.5$

6.1 .3 Iris Concentrator $\ldots \ldots \ldots \ldots \ldots \ldots \ldots \ldots \ldots \ldots, 6.6$

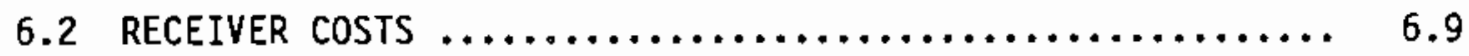

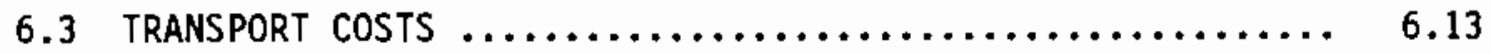

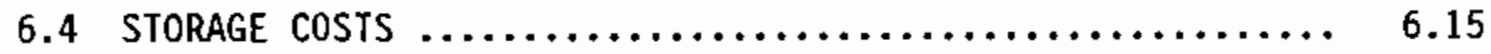

6.5 ENERGY CONVERSION COSTS $\ldots \ldots \ldots \ldots \ldots \ldots \ldots \ldots \ldots \ldots \ldots, 6.16$

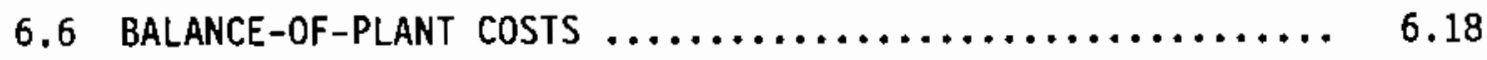

6.7 OPERATIONS AND MaintenanCe COSTS $\ldots \ldots \ldots \ldots \ldots \ldots \ldots \ldots, 6.21$

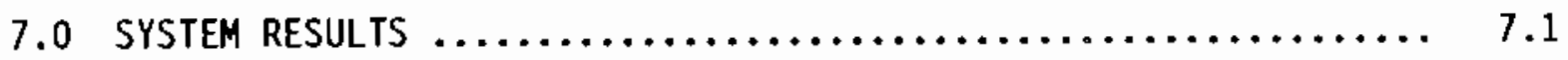

7.1 PLANT DESIGN POINTS $\ldots \ldots \ldots \ldots \ldots \ldots \ldots \ldots \ldots \ldots \ldots \ldots \ldots \ldots \ldots \ldots \ldots \ldots, 7.1$

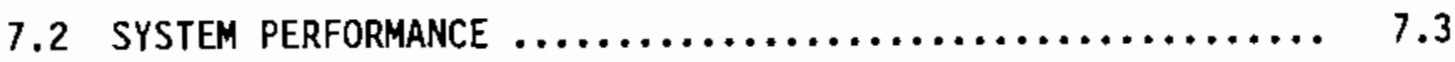




\section{CONTENTS (contd)}

7.2.1 Overall Plant Efficiency $\ldots \ldots \ldots \ldots \ldots \ldots \ldots \ldots, 7.3$

7.2.2 System Energy Losses $. . \ldots \ldots \ldots \ldots \ldots \ldots \ldots \ldots . .7 .5$

7.3 SYSTEM CAPITAL AND O\&M COST RESULTS $\ldots \ldots \ldots \ldots \ldots \ldots \ldots . \ldots \ldots \ldots$

7.4 SYSTEM LEC RESULTS $\ldots \ldots \ldots \ldots \ldots \ldots \ldots \ldots \ldots \ldots \ldots \ldots \ldots \ldots \ldots \ldots \ldots, 7.14$

7.5 COMPARISON TO SOLAR THERMAL ENERGY COST GOALS $\ldots \ldots \ldots \ldots .7 .18$

7.6 COMPARISON TO OTHER SOLAR THERMAL CONCEPTS $\ldots \ldots \ldots \ldots \ldots .7 .19$

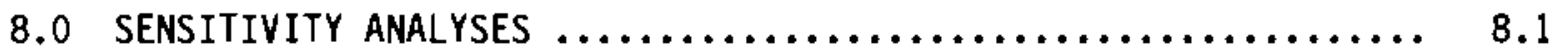

8.1 KEY PERFORMANCE ANALYSIS UNCERTAINTIES $\ldots \ldots \ldots \ldots \ldots \ldots . .8 .1$

8.1.1 Receiver Thermal Losses $\ldots \ldots \ldots \ldots \ldots \ldots \ldots \ldots \ldots, 8.2$

8.1 .1 .1 Wind Speed Impact $\ldots \ldots \ldots \ldots \ldots \ldots \ldots \ldots, 8.3$

8.1.1.2 Total Loss Uncertainties ............. 8.4

8.2 KEY COST UNCERTAINTIES $\ldots \ldots \ldots \ldots \ldots \ldots \ldots \ldots \ldots \ldots \ldots \ldots, 8.5$

8.2.1 Concentrator Cost Uncertainties ............. 8.6

8.2.2 Receiver Cost Uncertainties ................ 8.6

8.2.3 Other Component Uncertainties .............. 8.6

8.3 ALternative CONCENTRATOR DESignS $\ldots \ldots \ldots \ldots \ldots \ldots \ldots \ldots, 8.7$

APPENDIX A - STUDY PROCESS AND GROUND RULES $\ldots \ldots \ldots \ldots \ldots \ldots \ldots \ldots$ A.1

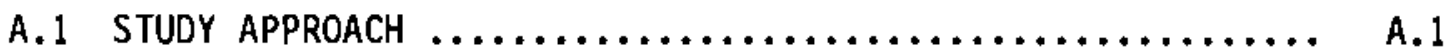

A.2 STUDY GROUND RULES AND ASSUMPTIONS $\ldots \ldots \ldots \ldots \ldots \ldots \ldots \ldots$ A.2

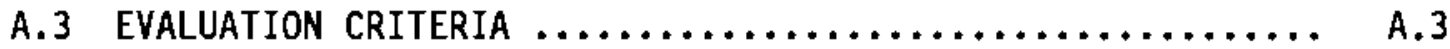

APPENDIX B - LEVELIZED ENERGY COST CALCULATIONS $\ldots \ldots \ldots \ldots \ldots \ldots \ldots$ B. 1

B.1 GENERAL ECONOMIC PRINCIPLES $\ldots \ldots \ldots \ldots \ldots \ldots \ldots \ldots \ldots \ldots \ldots \ldots \ldots \ldots \ldots \ldots$, B. 1

B.2 USING LEVELIZED ENERGY COST ANALYSIS $\ldots \ldots \ldots \ldots \ldots \ldots \ldots$, B.3

B.3 LEVELIZED ENERGY COST APPROACH $\ldots \ldots \ldots \ldots \ldots \ldots \ldots \ldots \ldots$, B. 3

B.4 ECONOMIC ASSUMPTIONS $\ldots \ldots \ldots \ldots \ldots \ldots \ldots \ldots \ldots \ldots \ldots \ldots \ldots \ldots \ldots \ldots, \quad$ B. 9 
CONTENTS (contd)

APPENDIX $c-$ CONCENTRATOR PERFORMANCE DATA $\ldots \ldots \ldots \ldots \ldots \ldots \ldots \ldots, c .1$

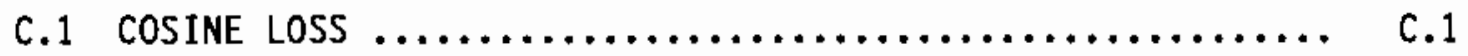

C.2 END LOSS $\ldots \ldots \ldots \ldots \ldots \ldots \ldots \ldots \ldots \ldots \ldots \ldots \ldots \ldots \ldots \ldots \ldots \ldots \ldots \ldots, c .2$

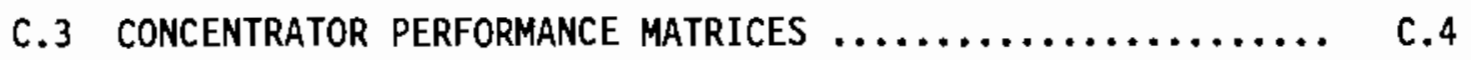

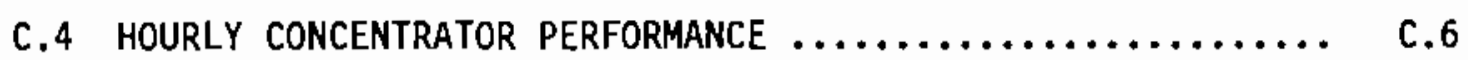

APPENDIX D - RECEIVER THERMAL LOSS CALCULATIONS $\ldots \ldots \ldots \ldots \ldots \ldots$ D. 1

D.1 CASE I: 60-DEgREE CONCENTRATOR WATER/STEAM RECEIVER .... 0.2

D.2 CASE II: 60-DEgREE CONCENTRATOR SALT RECEIVER ......... D. 3

D.3 CASE III: 30-DEgREE CONCENTRATOR WATER/STEAM RECEIVER ... 0.3

D. 4 CASE IV: 30-DEgREE CONCENTRATOR SALT RECEIVER $\ldots \ldots \ldots \ldots .0 .6$

D.5 CASE 5 - IRIS/STIRLING RECEIVER $\ldots \ldots \ldots \ldots \ldots \ldots \ldots \ldots \ldots \ldots \ldots \ldots \ldots \ldots, 0.7$

APPENDIX E - TRANSPORT SYSTEM PERFORMANCE ANALYSIS $\ldots \ldots \ldots \ldots \ldots \ldots$ E. 1

E.1 SYSTEM DEFINITION $\ldots \ldots \ldots \ldots \ldots \ldots \ldots \ldots \ldots \ldots \ldots \ldots \ldots \ldots \ldots \ldots \ldots \ldots \ldots \ldots$

E.2 FIELD LAYDUT $\ldots \ldots \ldots \ldots \ldots \ldots \ldots \ldots \ldots \ldots \ldots \ldots \ldots \ldots \ldots \ldots \ldots \ldots \ldots \ldots \ldots$

E.3 PIPING SYSTEM DETAILS $\ldots \ldots \ldots \ldots \ldots \ldots \ldots \ldots \ldots \ldots \ldots \ldots$, E.7

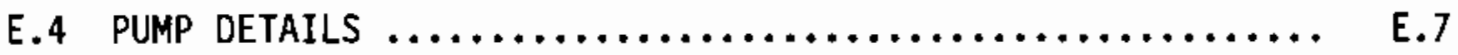

E.5 SYSTEM PERformance CALCULATIONS $\ldots \ldots \ldots \ldots \ldots \ldots \ldots \ldots \ldots$ E. 8

E. 6 HEAT LOSS CALCULATION $\ldots \ldots \ldots \ldots \ldots \ldots \ldots \ldots \ldots \ldots \ldots \ldots \ldots \ldots \ldots \ldots \ldots$

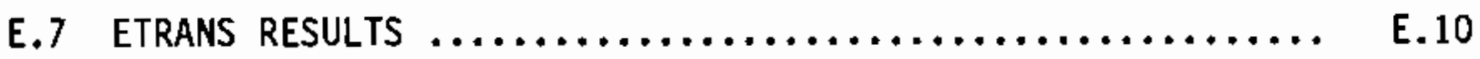

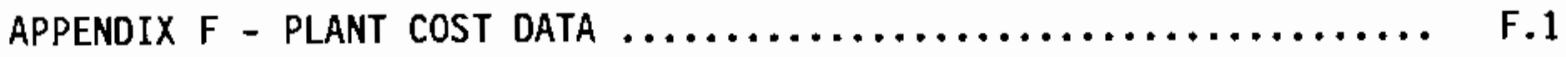

APPENDIX $G$ - PARASITIC POWER REQUIREMENTS $\ldots \ldots \ldots \ldots \ldots \ldots \ldots \ldots \ldots, G .1$

G.1 METHODOLOGY $\ldots \ldots \ldots \ldots \ldots \ldots \ldots \ldots \ldots \ldots \ldots \ldots \ldots \ldots, G .2$

G.2 CALCULATIONS $\ldots \ldots \ldots \ldots \ldots \ldots \ldots \ldots \ldots \ldots \ldots \ldots \ldots, G .5$

G.2.1 Concentrator Tracking Power ................ G.6

G.2.2 Fixed Operating Power Requirements $\ldots . \ldots \ldots \ldots \ldots$ G.6. G.6 


\section{CONTENTS (contd)}

G.2.3 Standby Power Requi rements $\ldots \ldots \ldots \ldots \ldots \ldots \ldots \ldots$, G.8

G.2.4 Heat Tracing Power Requirements $\ldots \ldots \ldots \ldots \ldots \ldots$ G........ G

APPENDIX H - IRIS CONCENTRATOR WITH ORGANIC RANKINE CYCLE ENERGY CONVERSION

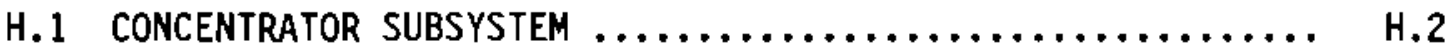

H.1.1 Design-Point Performance $\ldots \ldots \ldots \ldots \ldots \ldots \ldots \ldots$, H.2

H.1.2 Average Annual Concentrator Performance .......... H.4

H.1.3 Concentrator Cost ............................. H.5

H.2 RECEIVER SUBSYSTEM $\ldots \ldots \ldots \ldots \ldots \ldots \ldots \ldots \ldots \ldots \ldots \ldots \ldots \ldots$, H.5

H.2.1 Design-Point Performance $\ldots \ldots \ldots \ldots \ldots, \ldots, \ldots, \ldots$, H.5

H.2.2 Average Annual Receiver Efficiency .............. H.6

H.2.3 Receiver Cost $\ldots \ldots \ldots \ldots \ldots \ldots \ldots \ldots \ldots \ldots \ldots \ldots$, H.7

H.3 TRANSPORT SUBSYSTEM $\ldots \ldots \ldots \ldots \ldots \ldots \ldots \ldots \ldots \ldots \ldots \ldots \ldots$, H. 7

H.3.1 Design-Point Performance ..................... H.7

H.3.2 Average Annual Transport Performance ............ H.7

H.3.3 Transport System Cost $\ldots \ldots \ldots \ldots \ldots \ldots \ldots \ldots \ldots$ H.7

H.4 STORAGE SUBSYSTEM $\ldots \ldots \ldots \ldots \ldots \ldots \ldots \ldots \ldots \ldots \ldots \ldots, \quad$ H.7

H.5 ENERGY CONVERSION SUBSYSTEM $\ldots \ldots \ldots \ldots \ldots \ldots \ldots \ldots \ldots \ldots \ldots \ldots \ldots$, H.8

H.5.1 Design-Point Performance ..................... H.8

H.5.2 Average Annual Energy Conversion Efficiency ....... H.8

H.5.3 Energy Conversion Cost $\ldots \ldots \ldots \ldots \ldots \ldots \ldots \ldots \ldots$ H.

H.6 BALANCE OF PLANT, PARASITICS, AND OPERATING AND

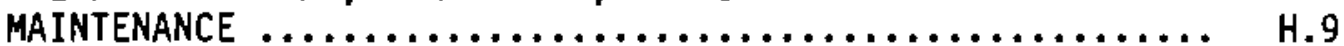

H.6.1 Parasitics ................................. H.9

H.6.2 Balance-of-Plant Costs ....................... H.9

H.6.3 O\&M Costs $\ldots \ldots \ldots \ldots \ldots \ldots \ldots \ldots \ldots \ldots \ldots \ldots, \quad H .9$ 


\section{CONTENTS (contd)}

H.7 SYSTEM PERFORMANCE AND ANNUAL OUTPUT $\ldots \ldots \ldots \ldots \ldots \ldots \ldots, \mathrm{H} . \mathrm{g}$

H.7.1 Optimistic Case Estimate ..................... H.9

H.7.2 Realistic Case Estimate of Annual Output ........... H.10

H.8 SYSTEM COST $\ldots \ldots \ldots \ldots \ldots \ldots \ldots \ldots \ldots \ldots \ldots \ldots \ldots \ldots \ldots$, H. 12

H.9 LeVELIZEd EnERGy COST $\ldots \ldots \ldots \ldots \ldots \ldots \ldots \ldots \ldots \ldots \ldots \ldots$, H.12

APPENDIX I - CAPITAL COST ESTIMATES FOR INNOVATIVE BOWL CONCENTRATORS I.1

I.1 GLASS ON CAST-IN-PLACE CONCRETE CONCENTRATOR $\ldots \ldots \ldots \ldots \ldots$ I.2

I. 2 GLASS ON PRE-CAST CONCRETE CONCENTRATOR .............. I.3

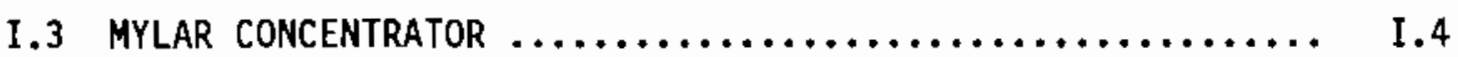

I.4 MEMBRANE CONCENTRATOR $\ldots \ldots \ldots \ldots \ldots \ldots \ldots \ldots \ldots \ldots \ldots \ldots \ldots \ldots \ldots \ldots \ldots$ 


\section{FIGURES}

S.1 Minimum LEC for Bowls, Central Receiver-Salt, and Dish-Stirling $x$

5.1 Part-Load Efficiency for Five Stirling Engines in Series ..... 5.41

5.2 Ambient Temperature Correction for the Energy Conversion Subsystem in an Iris-Stirling System ................... 5.42

6.1 Transport Cost Results: Cases I-IV ..................... 6.15

7.1 Annual System Efficiency for No-Storage Designs $\ldots \ldots \ldots \ldots \ldots, 7.4$

7.2 Annual Energy Losses for a 100-MWe, 60-Degree-Water/Steam Plant

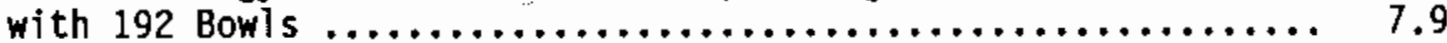

7.3 Annual Energy Losses for a 100-MWe, 60-Degree-Salt Plant with 192 Bowls ........................................... 7.10

7.4 Annual Energy Losses for a 100-MWe, 30-Degree-Water/Steam Plant

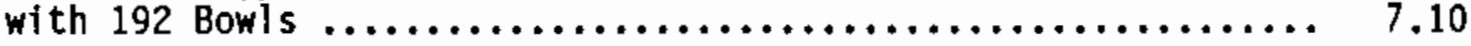

7.5 Annual Energy Losses for a 100-MWe, 30-Degree-Salt Plant with 192 Bowls

7.6 Annual Energy Losses for a 100-MWe, 30 iris-Stirling Plant with 192 Bowls

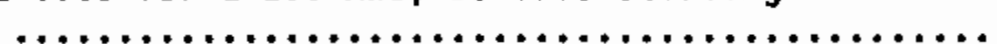

7.7 Initial Capital Cost of No-Storage Designs $\ldots \ldots \ldots \ldots \ldots \ldots \ldots . .1 .14$

7.B O\&M Cost Fractions of No-Storage Designs ................. 7.15

7.9 LEC vs. Plant Size for No-Storage Designs $\ldots \ldots \ldots \ldots \ldots \ldots \ldots .7 .15$

7.10 LEC vs. Plant Size for No-Storage Designs $\ldots \ldots \ldots \ldots \ldots \ldots \ldots . \ldots . . .16$

7.11 LEC vs. Plant Size for Minimum LEC Designs $\ldots \ldots \ldots \ldots \ldots \ldots . . . . .17$

7.12 LEC vs. Plant Size for Minimum LEC Designs $\ldots \ldots \ldots \ldots \ldots \ldots \ldots 7.18$

7.13 LEC for Bowls, Central Receiver-Salt and Dish-Stirling No-Storage

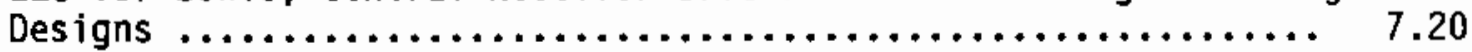

7.14 Minimum LEC for Bowls, Central Receiver-Salt, and Dish-Stirling 7.21

8.1 LEC for Alternative Concentrators $\ldots \ldots \ldots \ldots \ldots \ldots \ldots \ldots \ldots .8 .8$

8.2 Concentrator Cost Sensitivity for 100-MWe Minimum LEC Designs • 8.9

8.3 Receiver Cost Sensitivity for 100-MWe Minimum LEC Designs .... 8.9 


\section{FIGURES (contd)}

C.1 Capture as a Function of Incident Angle for Iris Collector .... C.3

C.2 60-Degree Concentrator Hourly Efficiency $\ldots \ldots \ldots \ldots \ldots \ldots \ldots$ c.5

C.3 30-Degree Concentrator Hourly Efficiency $\ldots \ldots \ldots \ldots \ldots \ldots \ldots$ c. 7

C.4 Iris Concentrator Hourly Efficiency $\ldots \ldots \ldots \ldots \ldots \ldots \ldots \ldots$, c.7

E.1 General Bowl Field Arrangement $\ldots \ldots \ldots \ldots \ldots \ldots \ldots \ldots \ldots \ldots$ E.3

E.2 Parabolic Dish Collector Field Layout $\ldots \ldots \ldots \ldots \ldots \ldots \ldots \ldots \ldots$ E.5

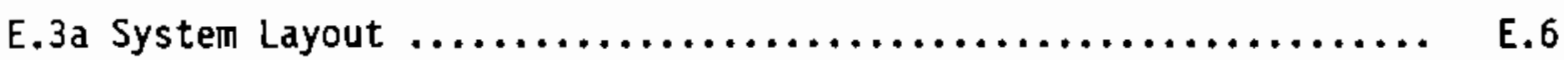

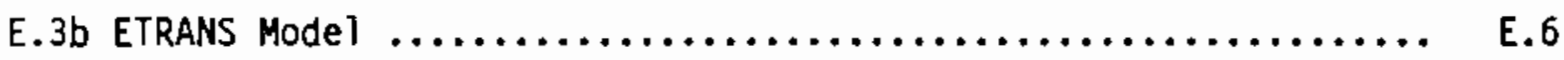




\section{$\underline{\text { TABLES }}$}

S.1 Summary of Key Results for Lowest Energy Cost Systems ....... vili

1.1 Key Design Features for Bowl Cases Analyzed $\ldots \ldots \ldots \ldots \ldots \ldots \ldots$

5.1 Case I Transport System Annual Average Figure of Merit ...... 5.9

5.2 Case I Turbine Inlet Steam Conditions $\ldots \ldots \ldots \ldots \ldots \ldots \ldots \ldots \ldots . \ldots \ldots$

5.3 Water/Steam Energy Conversion Subsystem Design Point ....... 5.11

5.4 Case I Annual Average Energy Conversion Efficiency ......... 5.12

5.5 Design-Point Parasitic Losses for Case I ............... 5.13

5.6 Case I Annual Average Parasitics As a Fraction of Gross Output 5.13

5.7 Case II Transport System Annual Average Figure of Merit ..... 5.16

5.8 Molten Salt Storage Design-Point Performance ............ 5.17

5.9 Case II Annual Average Storage Figure of Merit for 0.4 Capacity Factor Plants ............................... 5.18

5.10 Steam Generator Design Information $\ldots \ldots \ldots \ldots \ldots \ldots \ldots \ldots \ldots . . \ldots . \ldots$

5.11 Case II Design-Point Energy Conversion Efficiency ......... 5.19

5.12 Case II Annual Average Energy Conversion Efficiency ........ 5.20

5.13 Design-Point Parasitic Losses for Case II .............. 5.21

5.14 Case II Annual Average Parasitics As a Fraction of Gross Output 5.22

5.15 Case III Transport System Annual Average Figure of Merit .... 5.26

5.16 Case III Annual Average Energy Conversion Efficiency ....... 5.27

5.17 Design-Point Parasitic Losses for Case III ............ 5.28

5.18 Case III Annual Average Parasitics As a Fraction of Gross Output 5.29

5.19 Case IV Transport System Annual Average Figure of Merit ...... 5.31

5.20 Case IV Annual Average Storage Figure of Merit for 0.4 Capacity Factor Plants .................................. 5.32

5.21 Case IV Annual Average Energy Conversion Efficiency ........ 5.33

5.22 Design-Point Parasitic Losses for Case IV ............. 5.34 $x x i x$ 


\section{TABLES (contd)}

5.23 Case IV Annual Average Parasitics As a Fraction of Gross Output 5.34

5.24 Case $\vee$ Transport System Design-Point Efficiency .......... 5.39

5.25 Case $V$ Transport System Annual Average Efficiency ......... 5.40

5.26 Design-Point Parasitic Losses for Case $\vee \ldots \ldots \ldots \ldots \ldots \ldots \ldots \ldots . . \ldots 3$

5.27 Case $V$ Annual Average Parasitics As a Fraction of Gross Output 5.43

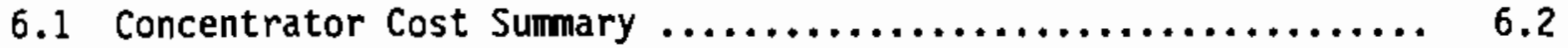

6.2 Main Concentrator Cost Components $\ldots \ldots \ldots \ldots \ldots \ldots \ldots \ldots \ldots \ldots .6 .2$

6.3 Pier Construction Component Costs $\ldots \ldots \ldots \ldots \ldots \ldots \ldots \ldots \ldots \ldots . \ldots . \ldots$

6.4 Baseline Concentrator Component Cost Estimates ........... 6.5

6.5 Component Cost Relationships Relative to the Baseline Bowl ... 6.5

6.6 30-Degree Concentrator Component Cost Estimate ........... 6.6

6.7 Iris Concentrator Component Costs $\ldots \ldots \ldots \ldots \ldots \ldots \ldots \ldots \ldots \ldots . .6 . \ldots$

6.8 Cases I through IV Receiver Estimates .................. 6.9

6.9 Receiver Material Unit Costs $\ldots \ldots \ldots \ldots \ldots \ldots \ldots \ldots \ldots \ldots \ldots \ldots . \ldots \ldots \ldots$

6.10 Manufacturing Cost Assumptions $\ldots \ldots \ldots \ldots \ldots \ldots \ldots \ldots \ldots \ldots \ldots \ldots \ldots \ldots \ldots$

6.11 Receiver Absorber Weights $\ldots \ldots \ldots \ldots \ldots \ldots \ldots \ldots \ldots \ldots \ldots \ldots \ldots . \ldots \ldots$

6.12 Iris Receiver Cost Estimate $\ldots \ldots \ldots \ldots \ldots \ldots \ldots \ldots \ldots \ldots \ldots \ldots .6 .12$

6.13 Transport Costs $\ldots \ldots \ldots \ldots \ldots \ldots \ldots \ldots \ldots \ldots \ldots \ldots \ldots \ldots \ldots \ldots \ldots \ldots \ldots \ldots$

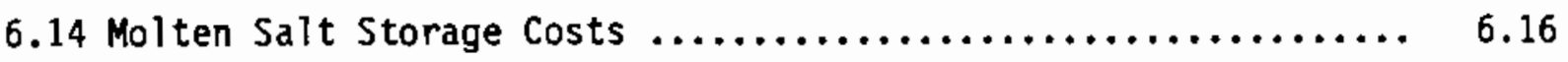

6.15 Rankine Energy Conversion Costs ................... 6.17

6.16 Stirling Engine Cost Adjustment Factors .............. 6.17

6.17 Balance-of-Plant Cost Results: Rankine Bowl Systems ........ 6.21

6.18 Balance-of-Plant Cost Results: Stirling Bowl System ........ 6.21

6.19 Bowl System Operating Labor Requirements ................ 6.22

6.20 Bow System $08 M$ Costs $\ldots \ldots \ldots \ldots \ldots \ldots \ldots \ldots \ldots \ldots \ldots \ldots \ldots \ldots \ldots . \ldots . \ldots \ldots$ 


\section{TABLES (contd)}

8.1 SOLSTEP LEC Sensitivity to Assumed Wind Speed $\ldots \ldots \ldots \ldots \ldots . . . .3$

8.2 Receiver Losses Sensitivity Analysis Results ............. 8.5

8.3 Alternative Concentrator Unit Costs $\ldots \ldots \ldots \ldots \ldots \ldots \ldots \ldots . . .6 .7$

A.1 Economic Assumptions $\ldots \ldots \ldots \ldots \ldots \ldots \ldots \ldots \ldots \ldots \ldots \ldots \ldots \ldots \ldots \ldots \ldots \ldots \ldots$, A.4

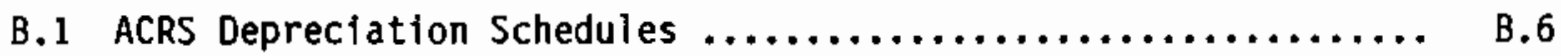

B.2 Power Plant Economic Ground Rules ...................... B. 10

C.1 60-Degree Concentrator Performance Matrix $\ldots \ldots \ldots \ldots \ldots \ldots \ldots$ C.4

C.2 30-Degree Concentrator Performance Matrix $\ldots \ldots \ldots \ldots \ldots \ldots \ldots$ C.4

C.3 Iris Concentrator Performance Matrix ................... C.5

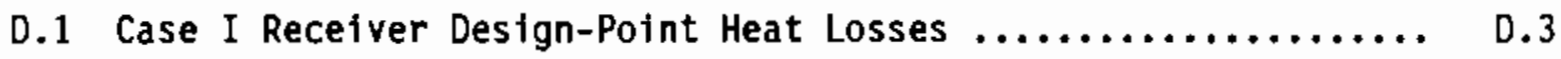

D.2 Case II Receiver Design Assumptions $\ldots \ldots \ldots \ldots \ldots \ldots \ldots \ldots \ldots$ D.4

D.3 Case II Receiver Design-Point Heat Losses $\ldots \ldots \ldots \ldots \ldots \ldots \ldots$ D.4

D.4 Case III Receiver Design Assumptions $\ldots \ldots \ldots \ldots \ldots \ldots \ldots \ldots$. D.5

D.5 Calculational Procedure for Case III Receiver $\ldots \ldots \ldots \ldots \ldots \ldots$. 0.6

D.6 Case III Receiver Design-Point Heat Losses $\ldots \ldots \ldots \ldots \ldots \ldots \ldots$. 0.6

D.7 Case IV Receiver Design Assumptions $\ldots \ldots \ldots \ldots \ldots \ldots \ldots \ldots \ldots$ D.7

D.8 Calculational Procedure for Case IV Receiver $\ldots \ldots \ldots \ldots \ldots \ldots$ D.8

D.9 Case IV Receiver Design-Point Heat Losses $\ldots \ldots \ldots \ldots \ldots \ldots \ldots$. 0.8

D.10 Case $\vee$ Receiver Design Assumptions $\ldots \ldots \ldots \ldots \ldots \ldots \ldots \ldots \ldots \ldots \ldots \ldots \ldots, 0.8$

D.11 Case $\vee$ Receiver Design-Point Heat Losses $\ldots \ldots \ldots \ldots \ldots \ldots \ldots$ D. 8

E.1 FMDF Bowl Field Specificattons $\ldots \ldots \ldots \ldots \ldots \ldots \ldots \ldots \ldots \ldots \ldots$ E.2

E.2 FMDF Bow1 Transport System Conditions $\ldots \ldots \ldots \ldots \ldots \ldots \ldots \ldots$ E.11

E.3 FMDF Bowl Transport System Conditions $\ldots \ldots \ldots \ldots \ldots \ldots \ldots \ldots \ldots$ E.12

E.4 FMDF Bow1 Transport System Conditions $\ldots \ldots \ldots \ldots \ldots \ldots \ldots \ldots$ E.13

E.5 FMDF Bowl Transport System Conditions $\ldots \ldots \ldots \ldots \ldots \ldots \ldots \ldots$ E.14 


\section{TABLES (contd)}

F.1 Plant Cost Breakdown for 60-Degree-W/S System at 0.5 Me ..... F.2

F.2 Plant Cost Breakdown for 60-Degree-W/S System at 2 Wwe ...... F.2

F.3 Plant Cost Breakdown for 60 -Degree-W/S System at 10 MWe ....... F.3

F.4 Plant Cost Breakdown for 60 -Degree-W/S System at 30 WWe ...... F.3

F.5 Plant Cost Breakdown for 60-Degree-W/S System at 100 Mwe ..... F.4

F.6 Plant Cost Breakdown for Two 60-Degree-Salt Systems at 0.5 MWe F.5

F.7 P1ant Cost Breakdown for Two 60-Degree-Salt Systems at 2 MWe .. F.6

F.8 Plant Cost Breakdown for Two 60-Degree-Salt Systems at 19 Mwe . F.7

F.9 Plant Cost Breakdown for Two 60-Degree-Salt Systems at 30 MWe . F.8

F.10 Plant Cost Breakdown for Two 60-Degree-Salt Systems at 100 WWe F.9

F.11 Plant Cost Breakdown for 30-Degree-W/S System at 0.5 MWe ..... F.10

F.12 Plant Cost Breakdown for 30-Degree-W/S System at 2 Mwe ....... F.10

F.13 Plant Cost Breakdown for 30-Degree-W/S System at 10 MWe $\ldots \ldots$ F.11

F.14 Plant Cost Breakdown for 30-Degree-W/S System at 30 Whe ...... F.11

F.15 Plant Cost Breakdown for 30-Degree-W/S System at 100 MWe ..... F.12

F.16 Plant Cost Breakdown for Two 30-Degree-Salt Systems at 0.5 Mwe F.13

F.17 P1ant Cost Breakdown for Two 30-Degree-Salt Systems at 2 MWe .. F.14

F.18 Plant Cost Breakdown for Two 30-Degree-Salt Systems at 10 MWe . F.15

F.19 Plant Cost Breakdown for Two 30-Degree-Salt Systems at 30 MWe . F.16

F.20 Plant Cost Breakdown for Two 30-Degree-Salt Systems at 100 MWe F.17

F.21 Plant Cost Breakdown for Iris/Stirling System at 0.5 MWe $\ldots . \ldots$ F.18

F.22 Plant Cost Breakdown for Iris/Stirling System at 2 MWe ....... F.18

F.23 Plant cost Breakdown for Iris/Stirling System at 10 MWe ...... F.19

F.24 Plant Cost Breakdown for Iris/Stirling System at 30 Mwe ...... F.19

F.25 Plant Cost Breakdown for Iris/Stirling System at 100 MWe ..... F.20 


\section{$\underline{\text { TABLES }}$ (contd)}

G.1 Differential Analysis $\ldots \ldots \ldots \ldots \ldots \ldots \ldots \ldots \ldots \ldots \ldots \ldots$, G.3

G.2 Lighting Requirement for Crosbyton 5-MWe Design ............ G.7

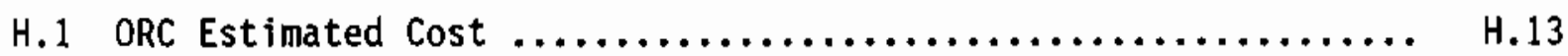

H.2 Levelized Energy Cost of ORC System $\ldots \ldots \ldots \ldots \ldots \ldots \ldots \ldots \ldots$ H.13

1.1 Cast-in-Place Concentrator Estimate $\ldots \ldots \ldots \ldots \ldots \ldots \ldots \ldots$ I. 3

I.2 Pre-Cast Concrete Concentrator Cost Estimate .............. I.4

I.3 Mylar Concentrator Cost Estimate ..................... I.5

I.4 Membrane Concentrator Cost Estimate $\ldots \ldots \ldots \ldots \ldots \ldots \ldots \ldots \ldots$ I.6 


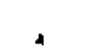




\subsection{INTRODUCTION}

Solar thermal energy systems are promising technologies for providing energy in a number of different forms. The fixed mirror distributed focus (FMDF) hemispherical bowl is a solar thermal power technology which has been studied for several years as a potentially attractive means of producing electricity. This study develops projections (of the performance and cost) that could be achieved by the bowl technology, based on the assumption of continued technology development and high volume production of solar components.

The goal of this study is to evaluate the attractiveness of the bowl technology relative to other solar thermal concepts currently being pursued by the U.S. Department of Energy (DOE) Solar Thermal Technology Program. This evaluation was based on developing projections of the levelized energy cost (LEC) of the bowl technology in commercial applications. The LEC approach for comparing alternative systems is an economically correct method that considers both system performance and life cycle costs. The LECs estimated for bowl concepts are compared to data for other solar thermal technologies and to long-term goals established by the DOE Solar Thermal Technology Program for solar thermal electric systems (DOE 1986). Data for other solar thermal technologies are taken from a companion document which analyzed the concepts using assumptions and methods identical to those used for this study (Williams et al. 1987).

\subsection{STUDY SCOPE}

Many alternative configurations of the FMDF bowT technology are possible, and it was not clear at the start of this study which of these concepts would represent the optimal system design. For this reason, several different bowl concepts were selected to be analyzed. These concepts were selected by Texas Tech University (TTU) to represent the bowl concepts most likely to be economically competitive with other solar thermal technologies.

The important decisions in selecting the concepts to be analyzed were as follows: 
- Concentrator Rim Angle. The bowl concept which had been most extensively studied used a 60-degree rim angle. Shallower bowls, such as the 30-degree rim angle design, held the promise of having significantly less expensive concentrators. The trade-off with shallow bowls is that they would have somewhat lower off-peak performance than the 60-degree rim angle concentrator.

- Receiver Working Fluid. The bowl concept which had been most extensively studied used a water/steam working fluid in the receiver and a thermal transport system. Other solar technologies (such as the central receiver) had been shown to have significant advantages when using working fluids (such as moiten salt), particularly when energy storage was desired.

- Innovative Concepts. Several innovative concepts for the bowl system had been proposed, including the use of distributed heat engines and a concentrator with a tracking panel (iris design).

Based on these design considerations, five cases were chosen for consideration in this study. The first four cases consisted of variations in the concentrator design and receiver working fluid. Concentrators considered in these cases included a 60-degree rim angle concentrator and a 30-degree rim angle concentrator. Both water/steam and molten salt were considered as the working fluids for the receiver. The fifth case combined the iris concentrator design with the use of distributed heat engines for energy conversion. (a) Key design features of the five cases are summarized in Table 1.1.

Each of the concepts in this study was analyzed over a range of plant power ratings from 0.5 Mwe to 100 Mwe. The molten salt concepts (Cases II and IV) were also analyzed with thermal energy storage systems. This extended the capacity factor over a range that included no-storage cases up to intermediate load capacity factors. The water/steam concepts (Cases I and III) and the distributed engine concept (Case $V$ ) were not analyzed with energy storage because previous work had shown that energy storage would not improve the LEC

(a) The iris concentrator is combined with a heat pipe receiver and a stirling engine. This case is part of the sensitivity study and is unofficially identified as case $v$. 
IABLE 1.1. Key Design Features for Bowl Cases Analyzed

\begin{tabular}{|c|c|c|c|c|c|}
\hline & $\begin{array}{l}\text { Cose I } \\
\text { 80 Dogree- } \\
\text { Nater/Steat }\end{array}$ & $\begin{array}{l}\text { Caso II } \\
\text { 6i Dogreo- } \\
\text { Salt }\end{array}$ & $\begin{array}{l}\text { Case III } \\
\text { 31 Dogroe- } \\
\text { Weter/Stean }\end{array}$ & $\begin{array}{l}\text { Case IV } \\
\text { 3o Dogroo- } \\
\text { Salt } \\
\end{array}$ & $\begin{array}{l}\text { Case } Y \\
\text { Irig-stirling }\end{array}$ \\
\hline Concontrator & $\begin{array}{l}\text { 68 Degreo Rin Anglo } \\
2923 \text { "n }^{2} \\
\text { glass-metal }\end{array}$ & $\begin{array}{l}\text { Be Degree Rie Angle } \\
2923 \text { an }^{2} \\
\text { gl ass-netal }\end{array}$ & $\begin{array}{l}36 \text { Dogree Fin Anglo } \\
2960-^{2} \\
\text { glags-notel }\end{array}$ & $\begin{array}{l}31 \text { Dogreo Riu Angle } \\
2956 \otimes^{2} \\
\text { oluss-notal }\end{array}$ & $\begin{array}{l}15 \text { Dogree Iracking Iris } \\
30 \text { Dogree Rin Angle } \\
3725 \Omega^{2} \\
\text { gloss-eotal/Lylar }\end{array}$ \\
\hline Recoivor & Full Length & Fulf Length & sex of Full Length & 68X of Full Langth & 20x of Full Length \\
\hline $\begin{array}{l}\text { Recoivor Exit } \\
\text { Toapp }{ }^{\circ} \mathrm{C}\left({ }^{\circ} \mathrm{F}\right)\end{array}$ & $\begin{array}{l}538 \\
\text { (1808) }\end{array}$ & $\begin{array}{l}588 \\
\text { (1858) }\end{array}$ & $\begin{array}{l}538 \\
(1800)\end{array}$ & $\begin{array}{l}\text { 688 } \\
(1050)\end{array}$ & $\begin{array}{l}849 \\
(1260)\end{array}$ \\
\hline $\begin{array}{l}\text { Transport } \\
\text { Subsystoen }\end{array}$ & Water/Stean & Wolten Salt & Dotor/Stean & Holten Solt & Eloctric \\
\hline Storaja Subsygton & Norie & Mottan Salt & Hone & Molten salt & Nono \\
\hline $\begin{array}{l}\text { Enargy Conversion } \\
\text { Subsysten }\end{array}$ & Stoar Ranking & Stean Rankino & Stoan Rankino & Stean Rankine & Stirling \\
\hline $\begin{array}{l}\text { Eneray Conyornion } \\
\text { Cycle Uax foup } \\
{ }^{\circ} \mathrm{C}(\mathrm{C})\end{array}$ & $\begin{array}{l}616 \\
(950)\end{array}$ & $\begin{array}{l}538 \\
\text { (1680) }\end{array}$ & $\begin{array}{l}618 \\
(950)\end{array}$ & $\begin{array}{l}538 \\
(1000)\end{array}$ & $\begin{array}{l}649 \\
\text { (1286) }\end{array}$ \\
\hline
\end{tabular}


of these technologies (Williams et al. 1987). The concepts were analyzed over a broad range of configurations to give an indication of any application niches (such as small, no-storage plants, or large, high-capacity-factor plants) where a particular concept might appear to have significant advantages relative to other solar thermal concepts.

\subsection{STUDY ANALYSIS METHODS}

The analysis performed in this study has three essential objectives: to characterize the annual performance of the solar technologies when configured in working systems, to estimate the costs of constructing and operating the systems, and to determine the optimum combination of collector field size and energy storage size for plants of different power ratings and capacity factors. These activities were addressed in this analysis with the use of the computer code SOLSTEP.

SOLSTEP was developed at Pacific Northwest Laboratory (PNL) and designed as a general solar thermal systems analysis tool (Bird 1980). It has been used in the past to analyze a wide range of solar thermal technologies for both electricity and industrial process heat applications. Key features of SOLSTEP are its ability to quickly analyze plants over a wide range of sizes and capacity factors, provide an annual simulation of the system performance using actual weather data, and calculate capital, operating and maintenance (O\&M), and LEC for the plant.

System performance is modeled in SOLSTEP by evaluating the performance of each component using a number of steady-state calculations over small time steps. One-hour time steps are typically used in the performance analysis for a one-year period. The plant energy output is calculated by SOLSTEP for each time step based on the insolation available, component performance characteristics during the time step, plant parasitics, and the plant operating mode. Following the performance analysis of the plant, SOLSTEP performs an economic analysis. The economic portion of the code estimates the capital and operating costs of the solar thermal plant based upon user supplied cost models. The code then uses the cost and performance assessment to calculate an LEC. 


\subsection{CONCLUSIONS}

This chapter highlights the most significant conclusions resulting from the study. Conclusions regarding the performance of the fixed mirror distributed focus (FMDF) bowl technology are presented in Section 2.1. Economic conclusions regarding capital investment costs and levelized energy cost (LEC) for the technology are provided in Section 2.2. Overall conclusions are given in Section 2.3. Where the conclusions compare the bowl technology to central receiver or dish systems, the data are taken from a companion study where central receiver, dish and trough systems were analyzed using assumptions and approaches identical to those used in this analysis (williams et al. 1987).

\subsection{PERFORMANCE CONCLUSIONS}

The annual efficiencies of the bowl concepts were significantly lower than efficiencies for central receiver or dish systems. For each of the bowl cases, the annual average plant efficiency was highest for the 100-Mwe designs. Annual efficiencies at this size for designs without energy storage ranged from $3 \%$ to $11 \%$ for the 5 bowl cases. In comparison, annual average efficiencies for several central receiver concepts at the same plant size ranged from $14 \%$ to $19 \%$, and for the dish-Stirling technology were $21 \%$ (Williams et al. 1987).

One of the larger contributors to the poor system efficiency was the concentrator. The bowl concentrator had good design-point efficiency (when the sun was directly normal to the bowl), but the efficiency fell dramatically at other solar positions. For the 60-degree concentrators, the decrease in efficiency for other sun positions was the result of cosine losses, which could not be avoided in a non-tracking concentrator. In addition to the cosine losses, the 30-degree concentrators had significant end losses (where concentrated insolation misses the receiver because of the less-than-full-length receiver design) during off-design conditions. This effect caused the annual efficiency of the 30-degree concentrators to be much lower than the 60-degree concentrators. The receiver used in the iris-stirling case was very short to 
limit thermal losses. The result was that the fris concentrator had the highest end losses and the lowest annual concentrator efficiency.

Another major contributor to the poor system efficiency of the bow technology is the receiver. The power on the receiver varies significantly over its length, with much of the receiver at very low flux levels; this causes the full-length receiver to inherently have a low average flux design. The low average flux requires large receiver surface areas for a given power level, which results in large thermal losses. The average receiver flux can be increased by reducing the receiver length, but this approach introduces receiver end losses.

Working fluids that require high receiver inlet temperatures do not appear desirable for the bowl technology. Because the receiver flux is very low where the working fluid enters the flux zone, thermal input may not balance thermal losses for fluids with high temperatures in this region. Effective use of the low flux areas of the receiver requires low temperature working fluids in these areas. This was the principal reason for the poor performance of the iris-Stirling concept: the high-temperature, isothermal receiver required for the Stirling engine had very high thermal losses because of the low average flux.

Both the low concentrator performance and low receiver performance appear to be inherent with the bowl technology. Although further optimization of the concentrator and receiver designs is possible, it does not appear that optimization would result in system performance levels near those of central receiver or dish technologies.

\subsection{ECONOMIC CONCLUSIONS}

The principal attractive features of the bow 1 technology are the fixed concentrators. Elimination of tracking mechanisms could reduce costs relative to tracking concentrators, and the capability of constructing the concentrators in larger sizes (203 ft, $62 \mathrm{~m}$ diameter) could show economies of scale. The results of this study indicate that these benefits would not, in actuality, provide the bowl concentrators with any significant cost advantages over other 
solar technologies. The installed concentrator costs estimated for the 60degree bowls were higher than the concentrator costs for central receivers and dishes. The costs for 30-degree bowls were estimated to be roughly the same as for the central receiver concentrator.

Several innovative concentrators that were intended to provide significant concentrator cost reductions for 30-degree bowls were analyzed as part of a sensitivity analysis. The results of the cost analysis indicated that the concentrators did not offer the potential for significant cost reductions compared with the baseline concentrator. In addition, concentrator performance and lifetime concerns do not make these concepts appear attractive.

Receiver unit costs (in $\$ / \mathbb{m}^{2}$ of aperture area) for the bowl concepts tended to be much higher than for the central receiver or dish, and were a major component of the plant cost. The major factor in the high costs of receivers is that the large focal line requires a large (and expensive) receiver. Although the receiver costs could probably be reduced by further design optimization (an example is in receiver tube wall thicknesses), these cost reductions would not significantly affect the comparisons of the bowl concepts with each other or with other solar technologies.

Thermal energy transport costs are a significant cost element for all the bowl concepts except the iris-Stirling, which uses electrical energy transport. The high costs for thermal transport are due to the extensive piping needed to supply working fluid to each bowl and to return heated fluid to the centrally located energy conversion subsystem. The unit costs for thermal energy transport increases for larger plant sizes; for very small plant sizes the impact of the thermal transport cost is minimized.

The LECS of the bowl concepts were substantially higher than both U.S. Department of Energy (DOE) energy cost goals for solar thermal technology and projections for the central receiver and dish technologies. In comparing the bowl concepts, the lowest LEC for no-storage conditions was obtained by the 60-degree water/steam (Case I) concept. The LECs of the 60-degree concentrator cases were much lower than for either of the 30-degree concentrator cases, even though the 30-degree concentrators were less expensive than the 60-degree 
concentrators. The 60-degree cases held the LEC advantage because the receivers for the 30-degree cases were more expensive, and the system efficiency was substantially less for the 30 -degree cases.

LECs for all concepts decreased as plant size increased. This trend was particularly pronounced for plant sizes below 10 MWe. As plant size decreased, the LEC increased because of decreasing turbine efficiency and increasing unit costs for turbines, balance-of-plant components, and plant 08M.

\subsection{OVERALL CONCLUSIONS}

None of the bowl concepts analyzed in this study appear to show the potential to be economically competitive, electricity-producing technologies. The projected energy costs for every bowl concept were much higher than the $\$ 0.05 / \mathrm{kWh}$ energy cost goal for solar thermal electric plants established by DOE (DOE 1986).

The results of this study show that the bowl concept will not be economically competitive with the central receiver or dish-Stirling technologies. The LECs of the bowl concepts were much higher than for the central receiver or dish concepts. In addition, the bowl concepts showed no other inherent advantages over central receivers or dish-Stirling systems, which would indicate that they would be the preferred systems in other types of applications or under different study assumptions.

Sensitivity analyses indicated that cost reductions alone would not make any of the bowl concepts competitive with central receivers or with the dishStirling technology. Even with a zero-cost concentrator or zero-cost receiver, the bowl concepts do not approach the LEC of the central receivers or the dish-Stirling technology. 


\subsection{STUDY APPROACH AND GROUND RULES}

An Analytical Coordination Committee (ACC), that was established to guide and review this study, agreed to the study approaches, ground rules, and concept selections. Members of the ACC included staff from Texas Tech University (TTU), the principal investigator of the bowl technology, Solar Energy Research Institute (SERI), and Pacific Northwest Laboratory (PNL). This section provides an overview of key assumptions and ground rules; formal assumptions and ground rules agreed to by the ACC are documented in Appendix $A$.

Basic design information on the bowl concepts was provided by TTU. TTU also provided data on the component performance (such as receiver thermal losses) or provided estimates of component performance when such information was available. An independent review of the performance estimates was performed: where necessary the performance estimates were revised to be consistent with the approaches and assumptions used by PNL in evaluating other solar thermal concepts. Independent component costs were estimated for all cases to ensure comparability of cost estimates between the bow 1 cases and other solar thermal technologies.

Several ground rules were established to provide a framework for the cost and economic analysis. These ground rules help to ensure that the analysis factored out the state of development of the bowl concepts, so that concepts that are currently in conceptual stages are not penalized when compared with concepts for which operational data already exists. The analysis was based on a "commercial" solar thermal industry that could be developed by the late 1990 's. The industry is assumed to be installing several hundred megawatts per year of electrical capacity, and is assumed to have improved the maturity of solar thermal components so that technical and economic risks are similar to other energy systems. The implications of these assumptions are:

- Cost estimates are based on construction of a plant where severat commercial plants of a similar design have previously been built.

- The annual installation rate of solar thermal capacity allows stable mass production of solar thermal components. 
- Plant financing is based on standard utility economics.

- Standard construction techniques will have been developed which preclude extraordinary indirect and contingency costs.

- Developmental costs required to achieve a "commercial" industry are excluded.

A levelized energy cost (LEC) is calculated for each solar thermal system evaluated. The LEC serves as the sumary figure of merit for making comparisons among alternative solar thermal systems. The LEC is calculated consistently with the method used in establishing technology goals for the solar thermal program (Williams, Dirks and Brown 1985). LECs were calculated in real (constant) dollar terms. Economic assumptions used in the analysis are based on recommendations for calculations to be compared with the long-term technology goals for solar thermal systems (Williams and Dirks 1985). 


\subsection{CONCEPT DESCRIPTIONS}

To characterize the key differences among the five cases analyzed in this study, each concept was organized into five subsystems:

- concentrator

- receiver

- energy transport

- energy storage

- energy conversion.

Unlike most other high-temperature solar thermal concepts, which have tracking concentrators, the fixed mirror distributed focus (FMDF) solar thermal concept has a fixed concentrator. This fixed concentrator reflects and concentrates the incident solar radiation on a sun-tracking receiver, where it is converted to thermal energy. The transport subsystem then moves thermal energy from the receiver to the thermal energy storage subsystem (when present) or directly to the energy conversion subsystem when there is no storage. The thermal energy storage subsystem stores excess energy collected during periods of high insolation for use when the field cannot supply adequate energy to the turbine. The energy conversion subsystem converts the collected thermal energy to electricity. This is the general arrangement of Cases I through IV.

Case $V$ uses a slightly different arrangement; in addition to the fixed concentrator, a portion of the concentrator tracks the sun (the tracking section is referred to as the iris). The receiver also tracks the sun and converts the concentrated solar insolation to thermal energy. This thermal energy is then supplied directly to the Stirling engines. The transport subsystem transports electric energy from the energy conversion subsystem to the utility grid. There is no storage with this case.

In the following sections, the five subsystems for each case are described in detail. All of the configurations for the five cases were specified by Texas Tech University (TTU). 


\subsection{CASE I: 60-DEGREE BOWL WITH A WATER/STEAM RECEIVER AND NO STORAGE}

This case consists of a field of 60-degree bowls that use water/steam as the heat transport fluid. The steam is used in a Rankine cycle heat engine to produce electricity; this case has no energy storage.

\subsubsection{Concentrator Subsystem}

The Case I concentrator design is generally the same as described in Volume VIII: Preliminary Design of 5 MWe Solar-Fossil Hybrid Electric Power Plant at Crosbyton, Texas. This concentrator has a 60-degree rim angle (a) and an aperture diameter of 203 feet $(61.9 \mathrm{~m})$; the resulting gross aperture area is $32,365 \mathrm{ft}^{2}\left(3007 \mathrm{~m}^{2}\right)$. The radius of curvature for the concentrator is 117.2 feet $(35.7 \mathrm{~m})$ which yields a theoretical surface area of $43,154 \mathrm{ft}^{2}$ $\left(4009 \pi^{2}\right)$ for a perfect surface. Therefore, the theoretical surface area is one-third larger than the gross aperture area.

The concentrators face to the south, are partialiy sunk into the ground, and are tilted at 15 degrees. In an east-west direction it is assumed that there is no space between the concentrators; therefore, the center-to-center spacing in the east-west direction is $203 \mathrm{ft}(61.87 \mathrm{~m})$. In the north-south direction the concentrators are spaced apart $322 \mathrm{ft}(98.1 \mathrm{~m})$ center-to-center to prevent one concentrator from shadowing the other, which is to the north of it.

\subsubsection{Receiver Subsystem}

The receiver/boiler is a cylinder with a length approximately equal to one-half the concentrator radius of curvature. It consists of a Schedule 40 , 316 stainless steel support tube, 58 feet in length, with an 18 inch diameter. This support tube is spirally wrapped with twenty parallel 0.375 -inch outside diameter (OD), 0.245-inch inside diameter (ID), tubes. There are two types of tube materials used. The bottom $60 \%$ of the receiver (low flux area) uses 316 stainless steel tubes. The heated water from these tubes enters a plenum and

(a) The rim angle is defined as the half angle of an arc that extends from one rim to the other through the center of the bowl; therefore, a full hemisphere would have a rim angle of 90 degrees. 
then exits into twenty Inconel 617 tubes of the same size. Inconel 617 is used for the top $40 \%$ of the receiver because this region experiences the highest temperature and flux concentrations. The receiver tubes are painted with black Pyromark paint to reduce reflection and to aid in the absorption of the concentrated solar flux.

The receiver is attached to a cantilevered boom which pivots about the center of curvature of the concentrator. Thus, the receiver is able to track the focal line in two axes and to intercept most of the specularly reflected solar flux.

\subsubsection{Energy Transport Subsystem}

The energy transport subsystem includes the collector field supply and return piping, and the field supply pump. The transport system supplies the receivers with $100^{\circ} \mathrm{F}$ water at $1175 \mathrm{psi}$. Steam exits the receiver at $1000^{\circ} \mathrm{F}$ and $1000 \mathrm{psi}$, and is returned to the turbine. The receiver supply piping and pumps were carbon steel and the insulation was fiberglass. On the return side, stainless steel piping and calcium silicate insulation were used.

The actual layout of the piping was done by using the ETRANS computer code. Two different layouts were used depending on the number of bowls in the field. These layouts are explained in Appendix $E$.

\subsubsection{Energy Storage Subsystem}

There was no storage considered with this 60-degree concentrator, water/steam receiver case.

\subsubsection{Energy Conversion Subsystem}

The energy conversion subsystem takes thermal energy (steam) from the transport system and converts it to electrical energy. This subsystem consists of the Rankine cycle heat engine, electric generator, condenser, and an evaporative cooling tower. Rankine cycle engine accessories include lube systems, steam seal system, and controls. Main feed pumps are not required because this job is done by the field circulation pumps (included in the transport subsystem). The generator is a three-phase, four-pole synchronous 
unit. The heat rejection unit includes the circulating water piping, circulating water pumps and cooling tower.

The temperature and pressure will vary depending on the collector field size. Larger field sizes will have lower temperatures and pressures because of greater losses in the energy transport system.

\subsection{CASE II: 60-DEGREE BOWL WITH A MOLTEN SALT RECEIVER AND STORAGE}

This case consists of a field of 60-degree bowls which use molten salt as both the heat transport fluid and the thermal energy storage medium. The molten salt is used to raise steam for a Rankine cycle heat engine to produce electricity.

\subsubsection{Concentrator Subsystem}

The concentrator for Case II is identical to that described in Section 4.1.1.

\subsubsection{Receiver Subsystem}

The Case II receiver is a cylinder with a length approximately equal to one-half the radius of curvature of the concentrator. It consists of a Schedule 40,316 stainless stee 1 support tube, $58 \mathrm{ft}$ in length, with a 17-in. diameter. This support tube is spirally wrapped with ten parallel 0.875-in. 0D, 0.5-in. ID, tubes. The tube material used was Incoloy $800 \mathrm{H}$. The receiver tubes are painted with black Pyromark paint to reduce reflection and aid in the absorption of the concentrated solar flux.

The receiver is attached to a cantilevered boom which pivots about the center of curvature of the concentrator. Therefore, the receiver is able to track the focal line in two axes and to intercept most of the specularly reflected solar flux.

\subsubsection{Energy Transport Subsystem}

The energy transport subsystem includes the collector field supply and return piping, and the field supply pump. The transport system supplies the receivers with $550^{\circ} \mathrm{F}$ molten salt at $300 \mathrm{psi}$. The heated salt exits the receiver at $1050^{\circ} \mathrm{F}$ and $235 \mathrm{psi}$, and is returned to the storage subsystem. The receiver 
supply pumps and piping were carbon steel; the return side piping was stainless steel. Fiberglass insulation was used on the supply side and calcium silicate insulation was used on the return side.

Layouts for the field piping were done using ETRANS and are explained in Appendix E.

The storage discharge section of the transport system sends hot salt to the steam generator and returns the cooled salt to the storage subsystem.

\subsubsection{Energy Storage Subsystem}

The energy storage subsystem stores thermal energy as sensible heat, and molten salt acts as the storage medium. The subsystem consists of a "hot" tank for storing the hot molten salt at $1050^{\circ} \mathrm{F}$, a "cold" tank for storing salt at $550^{\circ} \mathrm{F}$, and a salt treatment and makeup system. A charging loop is not required because the same fluid is used for transport and storage. During periods of available insolation, molten salt is pumped from the cold tank to the receivers, where it is heated. The hot molten salt is returned to the hot storage tank. Storage is discharged by pumping molten salt from the hot tank through the discharge piping to the steam generator. The low-temperature molten salt is then returned to the cold tank.

\subsubsection{Energy Conversion Subsystem}

The energy conversion subsystem takes thermal energy supplied from the storage subsystem and converts it to electrical energy. This subsystem consists of the steam generator, a Rankine-cycle heat engine, an electric generator, and an evaporative cooling tower.

The concept uses a three- or four-shell recirculating steam generator. The steam generator, which consists of preheating, evaporating, and superheating heat exchangers, is used to generate steam. The $100 \mathrm{MW}$ design also includes a reheater. Accessories include feedwater heaters, feedwater booster pump, feedwater pump, lubrication systems, steam seal system, and controls.

The generator is a three-phase, four-pole synchronous unit. The generator is assumed to be air-cooled and equipped with a brushless exciter. 
Waste heat from the Rankine cycle is rejected to the atmosphere through a conventional evaporative cooling tower. The heat rejection unit includes the circulating-water piping, circulating-water pumps, and a cooling tower.

\subsection{CASE III: 30-DEGREE BOWL WITH A WATER/STEAM RECEIVER AND NO STORAGE}

This case consists of a field of 30-degree bowls which use water/steam as the heat transport fluid. The steam is used in a Rankine cycle heat engine to produce electricity; this case has no energy storage.

\subsubsection{Concentrator Subsystem}

The Case III concentrator design has a 30-degree rim angle ${ }^{(a)}$ and an aperture diameter $(203 \mathrm{ft})$ and gross area $\left(32,365 \mathrm{ft}^{2}\right)$ identical to the 60degree concentrators used in Cases I and II. However, at $203 \mathrm{ft}$, the radius of curvature of this concentrator is considerably larger than that of the 60-degree concentrator $(117.2 \mathrm{ft})$. This yields a much shallower concentrator and a theoretical surface area of $34,689 \mathrm{ft}^{2}\left(3222.7 \mathrm{~m}^{2}\right)$ for a perfect surface. Therefore, the theoretical surface area of this "shallow" concentrator is only about $7.2 \%$ larger than its gross aperture area.

Just as with the 60-degree concentrators, these concentrators are partially sunk into the ground and are tilted at 15 degrees facing south. In an eastwest direction it is assumed that there is no space between the concentrators; therefore, the center-to-center spacing in the east-west direction is $203 \mathrm{ft}$ $(61.87 \mathrm{~m})$. In the north-south direction the concentrators are spaced apart $322 \mathrm{ft}(9 \mathrm{~B} .1 \mathrm{~m})$ center-to-center to prevent one concentrator from shadowing the other which is to the north of $i t$.

\subsubsection{Receiver Subsystem}

The receiver/boller is a cylinder with a length approximately equal to $60 \%$ of one-half of the radius of curvature of the concentrator. It consists of a Schedule 40, 316 stainless steel support tube, $60.9 \mathrm{ft}$ in length, with a

(a) The rim angle is defined as the half angle of an arc that extends from one rim to the other through the center of the bowl; therefore, a full hemisphere would have a rim angle of 90 degrees. 
32.4-inch diameter. This support tube is spirally wrapped with thirty-two parallel 0.536-1nch 0D, 0.368-inch ID, tubes. There are two types of tube materials used. The bottom $60 \%$ of the receiver (lower flux area) uses 316 stainless steel tubes. The heated water from these tubes enters a plenum and then exits into thirty-two Inconel 617 tubes of the same size. Inconel 617 is used for the top $40 \%$ of the receiver because this region experiences the highest temperature and flux concentrations. The receiver tubes are painted with black Pyromark paint to reduce reflection and to aid in the absorption of the concentrated solar flux.

The receiver is attached to a cantilevered boom which pivots about the center of curvature of the concentrator. Therefore, the receiver is able to track the focal line in two axes and to intercept much of the specularly reflected solar flux. However, since the receiver is only $60 \%$ of full length, some of the reflected flux will miss the receiver and this effect will vary with solar position.

\subsubsection{Energy Transport Subsystem}

The energy transport subsystem includes the collector field supply and return piping and the field supply pump. The transport system supplies the receivers with $100^{\circ} \mathrm{F}$ water at $1175 \mathrm{psi}$. Steam exits the receiver at $1000^{\circ} \mathrm{F}$ and $1000 \mathrm{psi}$, and is returned to the turbine. The receiver supply piping and pumps were carbon steel and the insulation was fiberglass. On the return side, stainless steel piping and calcium silicate insulation were used.

The actual layout of the piping was done using the ETRANS computer code. Because of differences in design and operating conditions, the layouts and performance of the Case III energy transport subsystems are somewhat different than for Case I. These layouts are fully explained in Appendix E.

\subsubsection{Energy Storage Subsystem}

There was no storage considered with Case III.

\subsubsection{Energy Conversion Subsystem}

The energy conversion subsystem for this case is identical to that described in Section 4.1.5. 


\subsection{CASE IV: 30-DEGREE BOWL WITH A MOLTEN SALT RECEIVER AND STORAGE}

This case consists of a field of 30-degree bowls which use molten salt as both the heat transport fluid and the thermal energy storage medium. The molten salt is used to raise steam for a Rankine cycle heat engine to produce electricity.

\subsubsection{Concentrator Subsystem}

The concentrator for this case is identical to that described in Section 4.3.1.

\subsubsection{Receiver Subsystem}

The Case IV receiver is a cylinder with a length approximately equal to $60 \%$ of one-half of the radius of curvature of the concentrator. It consists of a Schedule 40, 316 stainless steel support tube. $60.9 \mathrm{ft}$ in length with a 31-inch diameter. This support tube is spirally wrapped with sixteen parallel $1.25-i n c h \quad 0 D, 0.75-$ inch ID, tubes. The tube material used was Incoloy $800 \mathrm{H}$. The receiver tubes are painted with black Pyromark (TM) paint to reduce reflection and aid in the absorption of the concentrated solar flux.

The receiver is attached to a cantilevered boom which pivots about the center of curvature of the concentrator. Therefore, the receiver is able to track the focal line in two axes and to intercept much of the specularly reflected solar flux. However, because the receiver is only $60 \%$ of full length, some of the reflected flux will miss the receiver. This effect will vary with solar position.

\subsubsection{Energy Transport Subsystem}

The energy transport subsystem includes the collector field supply and return piping and the field supply pump. The transport system supplies the receivers with $550^{\circ} \mathrm{F}$ molten salt at $200 \mathrm{psi}$. The heated salt exits the receiver at $1050^{\circ} \mathrm{F}$ and $140 \mathrm{psi}$, and is returned to the storage subsystem. The receiver supply pumps and piping were carbon steel; the return side piping was stainless steel. Fiberglass insulation was used on the supply side and calcium silicate insulation was used on the return side. 
Layouts for the field piping were done by using ETRANS and are explained in Appendix E.

The storage discharge section of the transport system sends hot salt to the steam generator and returns the cooled salt to the storage subsystem.

\subsubsection{Energy Storage Subsystem}

The energy storage subsystem for this case is identical to that described in Section 4.2.4

\subsubsection{Energy Conversion Subsystem}

The energy conversion subsystem for this case is identical to that described in Section 4.2.5.

\subsection{CASE V: 30-DEGREE BOWL WITH AN IRIS, HEAT PIPE RECEIVER, STIRLING ENGINE} AND NO STORAGE

This case consists of a field of 30-degree bow1s with a sun-tracking mirror unit (called an iris). In the PERICLES project in Marseille, France, the iris has been experimentally demonstrated using a steam receiver. The receiver for Case $V$ is an isothermal heat pipe with a potassium working fluid. Electricity is generated by five Stirling engines attached to each receiver. The electricity generated by each bowl is moved to the grid by an electric transport system. This case has no energy storage.

\subsubsection{Concentrator Subsystem}

The iris concentrator is composed of a fixed 30-degree concentrator with a sun-tracking mirror unit called an iris. The fixed portion of the concentrator has surface dimensions identical to the dimensions of the concentrator used in Cases III and IV. The moveable portion of the concentrator (iris) has a width of 90 degrees of the aperture circumference of the concentrator, and a height of 15 degrees of the curvature of the concentrator. The iris is able to circumscribe 270 degrees of the concentrator; therefore, the center of the iris is able to move from due west to due east in a day. 
The addition of the iris increases the gross aperture area of the concentrator by $25 \%$ to $40,459 \mathrm{ft}^{2}\left(3758.6 \mathrm{~m}^{2}\right)$. This increased gross aperture area has an accompanying increase in theoretical surface area. The arc length of the bottom of the iris is 159.4 feet (48.6 m) and the arc length of the top of the iris is 225.5 feet $(68.7 \mathrm{~m})$. The arc length of the height of the iris is 53.1 feet $(16.2 \mathrm{~m})$. This results in a theoretical surface area of $10,287 \mathrm{ft}^{2}\left(955.7 \mathbb{m}^{2}\right)$ for the iris and a total concentrator theoretical surface area of $44,976 \mathrm{ft}^{2}\left(4178 \mathbb{m}^{2}\right)$. Thus, the theoretical surface area of the iris concentrator is $11.2 \%$ larger than its gross aperture area. The difference between surface and aperture area is larger than for the 30-degree concentrator but much less than that of the 60-degree concentrator.

\subsubsection{Receiver Subsystem}

The receiver for Case $V$ does not have a detailed design, but is assumed to be an isothermal heat pipe using potassium as the working fluid. It is a cylinder, with an evaporator length approximately equal to $20 \%$ of one-half of the radius of curvature of the concentrator. The receiver evaporator section is 20-ft-long and 32 inches in diameter; the condenser section is 5 feet long. The receiver material was assumed to be Incoloy $800 \mathrm{H}$. The exterior of the receiver was assumed to be painted with black Pyromark paint to reduce reflection and aid in the absorption of the concentrated solar flux.

The receiver is attached to a cantilevered boom which pivots about the center of curvature of the concentrator. Therefore, the receiver is able to track the focal line in two axes and to intercept some of the specularly reflected solar flux. However, because the evaporator section of the receiver is only $20 \%$ of full length, much of the reflected flux will miss the receiver. This effect will vary with solar position.

\subsubsection{Energy Transport Subsystem}

The transport subsystem is an ac power transmission network, and consists of the cables, transformers, circuit breakers, and miscellaneous equipment necessary for transmitting power from numerous large Stirling engines to the central distribution facility. 


\subsubsection{Energy Storage Subsystem}

There was no storage considered with Case $V$.

\subsubsection{Energy Conversion Subsystem}

The energy conversion subsystem takes thermal energy supplied from the receiver and converts it to electrical energy. The energy conversion subsystem for each bowl consists of heater tubes, five Stirling engines, their generators, and heat rejection units.

The heat engines are assumed to be $100 \mathrm{~kW}$ kinematic Stirling engines. The engines are water-cooled with the cooling water rejecting waste heat to the atmosphere through a fan-equipped, air-cooled heat exchanger. The Stirling engines were assumed to be scaled-up versions of the Model 4-95 MK II, $25 \mathrm{~kW}$ engine developed by USAB and tested by Advanco (Washom 1984). 
,

, 


\subsection{COMPONENT PERFORMANCE ANALYSIS}

This section discusses the performance of the various components of the five bowl configurations analyzed in this study. Each subsystem is discussed separately in order to easily compare the design point and annual performance. The annual average performance of the components was determined using the SOLSTEP computer code.

SOLSTEP was developed at Pacific Northwest Laboratory (PNL) and designed as a general solar thermal systems analysis tool (Bird 1980). It has been used in the past to analyze a wide range of solar thermal technologies for both electricity and industrial process heat applications. Key features of SOLSTEP are its ability to quickly analyze plants over a wide range of size and capacity factors, to provide an annual simulation of the system performance using actual weather data, and to calculate capital, operation and maintenance (O\&M), and levelized energy costs (LEC) for the plants.

System performance is modeled in SOLSTEP by evaluating the performance of each component using a number of steady-state calculations over small time steps. One-hour time steps are typically used in the performance analysis for a one-year period. The plant energy output is calculated by SOLSTEP for each time step based on the insolation avallable, component performance characteristics during the time step, plant parasitics, and the plant operating mode. In this manner SOLSTEP approximates the transient performance of the components, and therefore the transient performance of the entire plant.

Following the performance analysis of the plant, SOLSTEP performs an economic analysis. The economic portion of the code estimates the capital and operating costs of the solar thermal plant based upon user-supplied cost models. The code then uses the cost and performance assessments to calculate a levelized busbar energy cost.

In the performance and cost analyses, SOLSTEP investigates a number of combinations of collector field and energy storage combinations. These plant design points are then used by the code to determine the optimum plant configuration for any specific capacity factor. In addition to selecting 
optimal plant designs for specific plant capacity factors, SOLSTEP also reports two special case design points. One of these cases is the "no-storage" plant design. This is the plant design without energy storage, which resulted in the lowest LEC during the analyses. The no-storage design is not based on a specific solar multiple, but is selected on the basis of overall plant economics. The capacity factor which corresponds to no-storage designs varies among concepts because the economic and performance characteristics of each concept are different. For the same reasons, the capacity factor for no-storage designs can also vary for a single concept at different plant power ratings. because the performance and cost characteristics being optimized for the smali plants can vary significantly from the characteristics for large plants.

The second special design-point case reported by SOLSTEP is the optimaI LEC case. This is the plant design that had the lowest LEC, regardless of the plant capacity factor. As with the no-storage design points, the capacity factor corresponding to the optimal LEC case varies significantly among the concepts and can also vary somewhat with power level for an individual concept. It should be pointed out that the optimal LEC case is not necessarily a global optimum, but only the lowest energy cost located for plant sizes between 0.5 Mwe and 100 MWe and for no-storage to roughly 0.6 capacity factor (the scope of this study).

The analysis procedure for each of the bowl systems consisted of:

- characterization of design-point performance-The design-point performance of each component was investigated and characterized in a form that could be used as an input to SOLSTEP. The design-point performance is the performance of a component when it is operating at design-point conditions. Design-point conditions are defined as a solar insolation of $950 \mathrm{~W} / \mathrm{m}^{2}$, with typical ambient conditions, steady-state operation, and an angle of incidence equal to zero.

- characterization of off-design operation-After design-point performance was characterized, the influence of off-design operation was evaluated and characterized in a form that could be used as input to SOLSTEP. Typically, off-design operation, such as part-load operation or operation 
with reduced insolation, will result in a degradation in performance when compared to the design point.

- annual average performance-As each of the five bowl configurations was simulated, the annual performance of the various components was calculated in addition to overall plant performance. During a complete year, the plant is rarely operating at the design point. Consequently, annual component performance will always be less than design-point performance. The annual average performance is a better estimate of component performance than design-point performance, but its calculation requires a meteorological data base and simulation code like SOLSTEP.

The following section will report both design-point performance (SOLSTEP inputs) and annual average performance (SOLSTEP output) for each component. The impact of off-design-point operation is included in the calculation of annual average performance. The results are presented by configuration and component. Each configuration is discussed separately, and the component performance results are presented for five components: the concentrator subsystem, the receiver subsystem, the transport subsystem, the storage subsystem, and the energy conversion subsystem. The performance of each component is described in two ways: 1) the design-point performance is presented, followed by the annual average performance of the component, and 2) for each configuration, parasitic losses are discussed.

\subsection{CASE I: 60-DEGREE CONCENTRATOR WITH A WATER/STEAM RECEIVER AND NO STORAGE}

This case consists of a field of 60-degree bowls which use water/steam as the heat transport fluid. The steam is used in a Rankine cycle heat engine to produce electricity; this case has no energy storage.

\subsubsection{Concentrator Subsystem}

The concentrator subsystem consists of a field of 60-degree rim angle concentrators with an aperture diameter of $203 \mathrm{ft}(61.9 \mathrm{~m})$ and a gross aperture area of $32,365 \mathrm{ft}^{2}\left(3007 \mathrm{~m}^{2}\right)$. The concentrator uses glass/metal mirror panels. Gaps between these mirror panels result in the actual surface and aperture 
areas being $2.8 \%$ less than the gross areas; therefore, the net aperture area is $31,459 \mathrm{ft}^{2}\left(2922.7 \mathrm{~m}^{2}\right)$.

\subsubsection{Design-Point Performance}

The primary figure of merit for characterizing concentrator performance is concentrator efficiency. Concentrator efficiency includes the impact of cosine losses, shadowing, blocking, reflectivity losses, atmospheric attenuation, and spillage. Since the bowl system is a modular concept, the design-point performance will be the same for all concentrators of the same kind. Following is a discussion of how each of the losses listed above contributes to the design point performance of the 60-degree concentrator.

- cosine losses-Because the angle of incidence is equal to zero at the design point, there are no cosine losses at the design point.

- shadowing-The shadowing from the receiver support structure/legs, piping, and "cleaning snake" is calculated to be approximately 0.99 using projected areas. (a) on an annual basis, the losses are roughly estimated to be double its value, or about 0.98 . This value is considerably less than the 0.912 associated with the 65 -foot diameter test bowl at Texas Tech University (TTU), and is in good agreement with the 0.976 calculated by TTU for a 200-foot concentrator (Simpson, O'Hair and Reichert 1981). Since TTU was unable to supply PNL with shadowing as a function of solar position, the 0.98 value was used for both the design-point and annual performance estimates. It should be noted that the shadowing of the reflector caused by its own "lip" is a loss accounted for by the cosine loss, and the shadowing of one concentrator by the adjacent concentrator's receiver support structure is not considered.

- blocking-The blocking of the reflected flux by the receiver support structure/legs and piping is of the same order of magnitude as shadowing, but does not increase appreciably with lower sun elevations. It is assumed to remain at 0.99 for all sun positions.

(a) O'Hair, E. 1986. TTU. Personal communication during the project review meeting held at PNL, on June 26 and 27. 
- reflectivity losses-A clean, new reflectance of 0.94 was assumed for the concentrator mirror paneis. A concentrator cleaning system is incorporated into the concentrator. Weekly cleaning will maintain a high reflectance. It is assumed that the average reflectance is 0.93 ; hence the reflectivity degradation factor is $0.93 / 0.94=0.9894$. The average reflectance $(0.93)$ was used for both the design point and annual performance estimates.

- atmospheric attenuation-A very small fraction of the reflected solar flux is absorbed by the atmosphere before it reaches the receiver. This value was not measured or calculated by TTU. The atmospheric transmission loss for the bowl collector is estimated to be much less than for the central receiver, and was assumed to be 0.995 .

- spillage-The spillage is determined by reflector quality, tracking accuracy, receiver size and geometry, and receiver structural integrity. The total error budget for the concentrator reflector has been either measured or calculated to be about 0.08 degrees (1.4 mrad) (Simpson, 0 'Hair and Reichert 1981). Additionally, the receiver tracking accuracy is claimed to be either 0.02 degrees (Simpson, O'Hair and Reichert 1981) or 0.03 degrees (walters 1983). Combining these factors, and sizing the receiver accordingly, TTU estimates an intercept factor of 0.98 (Simpson, 0'Hair and Reichert 1981). Structurally, the receiver represents a long, cantilevered cylinder, exposed to high temperatures. Hence, some droop/bowing of the receiver will occur during operation; inevitably this will result in a permanent deformation of the receiver. It appears that a boom structure, plus passive cables, would limit light loss to $2 \%$, for a loss factor of 0.98 (Vann, Seth and Gudivada 1986). (The additional shadowing which may by caused be such a receiver support structure has not been accounted for.) Since the receiver for this case is of full length (one-half the radius of curvature), no end losses occur. The overall design-point spillage loss factor is thus estimated to be:

0.98 (optical loss) $\times 0.98$ (deflection loss) $=0.9604$. 
The design-point concentrator efficiency is the product of the various efficiency factors listed above. This is the percentage of the available flux that impinges on the receiver surface, where the available flux is defined as the product of the design-point direct normal insolation $\left(950 \mathrm{~W} / \mathrm{m}^{2}\right)$ and the gross aperture area $\left(3007 \mathrm{~m}^{2}\right)$. Therefore, the design-point efficiency for the 60-degree concentrator is:

$$
(0.98)(0.99)(0.93)(0.995)(0.98)(0.98)=.862
$$

And the amount of flux impinging on the receiver at the design point is:

$$
\left(950 \mathrm{~W} / \mathrm{m}^{2}\right)\left(2923 \mathrm{~m}^{2}\right)(.862)=2394 \mathrm{~kW}
$$

\subsubsection{Annual Average Concentrator Performance}

The annual average concentrator efficiency is a product of the constant concentrator losses (design-point losses), the cosine losses, and the multiple bounce losses due to reflectivity losses. The cosine losses at each solar position are calculated by:

$$
\cos (i n c)=\cos (a l t) * \cos (a z) * \sin (t i l t)+\sin (a l t) * \cos (t i l t)
$$

where:

inc = incident angle between the bow1 normal and earth sun line

alt = altitude, the angle above the horizon

az = azimuth, the angle between due south and the sun

tilt = tilt angle of the collector (pointing due south).

The cosine of the incident angle is the effective aperture for the bowl.

Energy lost due to reflectivity losses in multiple bounces are calculated according to: ${ }^{(a)}$

$$
\text { bounce modifier }=\left\{1-\left[0.0263^{*}(\text { inc }) / 75\right] /\left[1+0.972^{*} \text { (inc) } / 75^{\wedge} 5\right]\right\}
$$

The product of the $\cos (i n c)$ and the bounce modifier is the geometric optical efficiency of the bowl which varies with the solar position.

(a) This equation was calculated from information presented in The Crosbyton Solar Power Project, Vol. VII: Performance and Cost of Solar Gridiron Electric Power plants (Refchert et al. 1982). The data were modified to account for the higher reflectivity assumed in this study. 
The annual average concentrator efficiency is $56.0 \%$. The efficiency is constant with collector field size, because of the concept's modular nature. This efficiency is the highest of the bowl concentrator configurations analyzed, but it is low compared with sun-tracking concentrators. (See Appendix C for a more detailed discussion.)

\subsubsection{Receiver Subsystem}

The receiver/boiler is a cylinder with a length approximately equal to one-half the radius of the concentrator. It consists of a stainless steel support tube which is spirally wrapped with twenty paraliel tubes. The bottom $60 \%$ of the receiver (low flux area) uses 316 stainless steel tubes, and the top $40 \%$ of the receiver uses Inconel 617 tubes of the same size. The receiver tubes are painted with black Pyromark paint to reduce reflection and aid in the absorption of the concentrated solar flux.

\subsubsection{Design-Point Performance}

The receiver performance was determined using the method described in Appendix $D$. The results of this analysis show receiver optical and thermal losses. The receiver absorption and emittance are determined by the receiver geometry, angle of incident flux, and receiver tube material and coating. Since the receiver is a cylinder and the tubes are painted with black Pyromark paint, the absorptivity and emissivity were assumed to be 0.96 , the same as that of a central receiver (Williams et al. 1987). The much greater average incident angle of the flux (which would lower the absorptivity) was not considered because of the lack of experimental data. The total receiver thermal loss was estimated to be $0.071 \mathrm{~kW} / \mathbb{m}^{2}$ of concentrator aperture area. Receiver thermal losses were corrected in the annual simulation for ambient temperature variations and wind speed.

\subsubsection{Annual Average Receiver Efficiency}

The annual average receiver efficiency was determined by SOLSTEP to be 78.4\%. Because of the modular nature of the concept, receiver efficiency is constant with collector field size. The field efficiency (combined concentrator/receiver efficiency) was $43.9 \%$, which is also constant with collector field size. 


\subsubsection{Transport Subsystem}

The transport subsystem includes the collector field supply and return piping and the field supply pump. The transport system supplies the receivers with $100^{\circ} \mathrm{F}$ water at $1200 \mathrm{psi}$. Steam exits the receiver at $1000^{\circ} \mathrm{F}$ and $1000 \mathrm{psi}$ when it is returned to the turbine. The receiver supply piping and pumps were carbon steel and the insulation was fiberglass. On the return side, stainless steel piping and calcium silicate insulation were used.

\subsubsection{Design Point Performance}

The transport system performance was characterized using the ETRANS computer code (Barnhart 1980) and the methods described in Appendix E. This resulted in transport system design-point performance being determined for many different field sizes (number of bowls). The transport system thermal efficiencies and pumping power requirements are given in Appendix $E$ for each transport design. The thermal efficiency indicates the impact of heat losses from the piping, and the pumping power indicates the mechanical energy required to overcome viscous drag.

Thermal efficiency of the transport piping decreases with plant size because larger plants have larger collector fields involving more piping per square meter of collector area than small fields. Similarly, field pumping power increases with increasing plant size.

\subsubsection{Annual Average Transport Performance}

The annual average transport figure of merit includes the impact of both thermal losses and pumping power for the transport system. The transport figure of merit is given by the following equation.

Transport figure of merit $=\frac{Q_{I N}\left(\eta_{T S}\right)-W_{P T} / \eta_{E P G S}}{Q_{I N}}$

where $Q_{I N}=$ thermal energy entering transport subsystem

$\eta_{T S}=$ transport system thermal efficiency (from ETRANS)

$W_{P T}=$ transport system pump work (kwhe)

$\eta_{E P G S}=$ net thermal to electric conversion efficiency. 
For each time step, SOLSTEP calculates the amount of electricity required by the pumps to move the fluid through the transport system. To be used in the figure of merit, the total annual electric energy used by the pumps is transformed into thermal energy units. This transformation is done by calculating the thermal energy needed to generate the electricity used by the pump motor, and by using the annual average gross energy conversion efficiency.

Although this value is not used in the calculation of the annual system performance (because parasitics are accounted for separately in the code), it is reported to show the total penalty on the annual system performance represented by the transport system.

The figures of merit are reported in Table 5.1. The figures of merit steadily decline with increasing plant size as both thermal losses and pumping power increase.

\section{TABLE 5.1. Case I Transport System Annual Average Figure of Merit}

\begin{tabular}{rc} 
Plant Size, MWe & Figure of Merit (\%) \\
\cline { 1 - 2 } 0.5 & 95.5 \\
2.0 & 94.2 \\
10.0 & 93.3 \\
30.0 & 91.8 \\
100.0 & 90.0
\end{tabular}

\subsubsection{Storage Subsystem}

There was no storage considered with this case.

\subsubsection{Energy Conversion Subsystem}

The energy conversion subsystem converts thermal energy in the heat transfer fluid to electrical energy using a heat engine. In this case the conversion subsystem is coupled directly with the water/steam transport subsystem and uses a Rankine cycle heat engine. 


\subsubsection{Design-Point Performance}

The conditions of the steam entering the steam turbine depend on the transport subsystem. Conditions of the steam exiting the receiver are fixed at $1000^{\circ} \mathrm{F}$ and $1000 \mathrm{psia}$. Losses in the transport system result in a reduction in steam pressure and temperature. Table 5.2 presents typical turbine inlet steam conditions for each plant size.

\begin{tabular}{|c|c|c|}
\hline $\begin{array}{c}\text { Plant } \\
\text { Size (MW) }\end{array}$ & $\begin{array}{c}\text { Steam } \\
\text { Temperature }\left({ }^{\circ} \mathrm{F}\right)\end{array}$ & $\begin{array}{c}\text { Steam } \\
\text { Pressure (psia) }\end{array}$ \\
\hline .5 & 985 & 999 \\
\hline 2.0 & 978 & 995 \\
\hline 10.0 & 967 & 989 \\
\hline 30.0 & 956 & 977 \\
\hline 100.0 & 943 & 966 \\
\hline
\end{tabular}

The design of the steam power cycle is the result of a complicated performance and cost optimization procedure which was beyond the scope of this study. The approach was to review appropriate solar design studies and to select the most reasonable steam cycle for each combination of power level and steam conditions. The performance of the steam cycle was then taken from the design study. The steam conditions reported in Table 5.2 deviate substantially from those used in other studies. This is particularly true of turbine inlet pressure. Therefore, the gross efficiency was adjusted to reflect the impact of lower turbine inlet pressure using cycle efficiency corrections presented in Copeland (1980).

The SOLSTEP computer code models the steam cycle performance as consisting of a design-point gross efficiency which is adjusted by a part-load correction factor and an ambient temperature correction factor. The initial design-point efficiency was taken from previous studies and modified to account for turbine inlet condition variations. Table 5.3 reports the initial design-point efficiency, the source of this information, and the design-point efficiency after turbine inlet condition corrections. 
The gross efficiencies were calculated for design-point conditions consisting of a turbine backpressure of $2.5 \mathrm{"} \mathrm{Hg}$ and a full load. As the ambient temperature changes, the turbine backpressure will change, which in turn will cause the steam cycle gross efficiency to vary. Most performance information is based on wet bulb temperature assuming $35 \%$ humidity. The efficiency corrections were taken from published information (Bechtel Topical Report in Laity et al. (1980) (8echtel 1985).

TABLE 5.3. Water/Steam Energy Conversion Subsystem Design Point

\begin{tabular}{|c|c|c|c|}
\hline $\begin{array}{c}\text { Plant } \\
\text { Size (MW) }\end{array}$ & $\begin{array}{l}\text { Initial } \\
\text { Gross } \\
\text { Efficiency } \\
\end{array}$ & Source & $\begin{array}{c}\text { Design-Point } \\
\text { Efficiency (After } \\
\text { Steam Condition Correction) } \\
\end{array}$ \\
\hline 100.0 & .407 & Bechtel (1985) & .377 \\
\hline 30.0 & .385 & $\begin{array}{l}\text { Carrissa Plains } \\
\text { (Rockwe11 et al 1983) }\end{array}$ & .366 \\
\hline 10.0 & .354 & $\begin{array}{l}\text { Bechtel Topical Report } \\
\text { (Laity et al. 1980) }\end{array}$ & .338 \\
\hline 2.0 & .327 & $\begin{array}{l}\text { Bechtel Topical Report } \\
\text { (Laity et al. 1980) }\end{array}$ & .313 \\
\hline 0.5 & .314 & $\begin{array}{l}\text { Bechtel Topical Report } \\
\text { (Laity et al. 1980) }\end{array}$ & .313 \\
\hline
\end{tabular}

The part-load efficiency corrections were also taken from published information. The Bechtel data in Laity et al. (1980) provided part-load corrections for small turbines (0.5 MW, 2.0 MW, 10.0 MW). The part-load correction for the 100-MW turbine was taken from part-load heat balances for a water/steam system presented in Darnell et al. (1985). The part-load correction for the 30-MW case was calculated by taking a weighted average between the 10-MW and 100-MW corrections.

\subsubsection{Annual Average Energy Conversion Efficiency}

The annual average gross energy conversion efficiency including part load and ambient temperature correction is shown for a range of plant sizes in Table 5.4. As with the design-point gross efficiency, the annual average efficiency generally increases with plant size. 
TABLE 5.4. Case I Annual Average Energy Conversion Efficiency

\begin{tabular}{rc} 
Plant Size, Mwe & Annual Average Conversion Efficiency $(\alpha)$ \\
\cline { 2 - 2 } 0.5 & 30.4 \\
2.0 & 29.8 \\
10.0 & 31.9 \\
30.0 & 34.4 \\
100.0 & 35.4
\end{tabular}

\subsubsection{Parasitic Losses}

The operating parasitic losses consist of energy conversion parasitics (which are a function of thermal input to the turbine), field parasitics (which are a function of field size), pumping power, and fixed operating power. When the plant is not in operation, parasitic loads are modeled as consisting solely of standby loads.

\subsubsection{Design-Point Performance}

The design-point parasitics are presented in Table 5.5 as a function of plant size. The first two columns present the energy conversion parasitics as the sum of a constant and a fraction of the input from the heat engine. The third column presents field-related parasitic loads which are dominated by receiver tracking power requirements and consequently are constant when calculated on an area-normalized basis. Fixed operating power requirements are presented in the fourth column and standby power requirements are listed in column five. A detailed discussion of the definitions and calculation of parasitic losses is presented in Appendix $G$.

\subsubsection{Annual Average Parasitic Losses}

The annual average electrical parasitic losses as determined by SOLSTEP for Case I are presented in Table 5.6 for the system designs at each plant size. The parasitics are given as a fraction of the plant's gross output. The parasitic loss fraction is fairly constant across plant size and averages $11 \%$ to $12 \%$. 
TABLE 5.5. Design-Point Parasitic Losses for Case I

\begin{tabular}{|c|c|c|c|c|c|}
\hline $\begin{array}{c}\text { Plant } \\
\text { Size, MWe }\end{array}$ & $\begin{array}{l}\begin{array}{l}\text { Energy } \\
\quad \text { Para }\end{array} \\
\mathrm{a}, \mathrm{kWe} \\
\end{array}$ & $\begin{array}{l}\text { Conversion } \\
\text { itic(a) } \\
\text { b, kWe/kwt }\end{array}$ & $\begin{array}{c}\text { Field } \\
\text { Parasitic } \\
\mathrm{kWe} / \mathrm{m}^{2} \\
\end{array}$ & $\begin{array}{c}\text { Fixed } \\
\text { Parasitic } \\
\text { kWe } \\
\end{array}$ & $\begin{array}{c}\text { Standby } \\
\text { Parasitic } \\
\text { kwe } \\
\end{array}$ \\
\hline 0.5 & 2.5 & 0.0047 & 0.000011 & 4.7 & 10.5 \\
\hline 2.0 & 10.0 & 0.0048 & 0.000011 & 18.4 & 38.3 \\
\hline 10.0 & 47.0 & 0.0047 & 0.000011 & 88.6 & 173.2 \\
\hline 30.0 & 130.0 & 0.0047 & 0.000011 & 257.0 & 481.0 \\
\hline 100.0 & 420.0 & 0.0047 & 0.000011 & 823.0 & 1484.0 \\
\hline
\end{tabular}

(a) Parasitic power $=a+b$ (thermal input to heat engine).

TABLE 5.6. Case I Annual Average Parasitics As a Fraction of Gross Output

\begin{tabular}{rc} 
Plant Size, Mwe & Parasitic Fraction \\
\hline 0.5 & .119 \\
2.0 & .122 \\
10.0 & .117 \\
30.0 & .112 \\
100.0 & .115
\end{tabular}

\subsection{CASE II: 60-DEGREE CONCENTRATOR WITH A MOLTEN SALT RECEIVER AND STORAGE}

This case consists of a field of 60-degree bowls which use molten salt as both the heat transport fluid and the thermal energy storage medium. The molten salt is used to raise steam for a Rankine cycle heat engine to produce electricity.

\subsubsection{Concentrator Subsystem}

The concentrator subsystem is identical to the Case I concentrator, and consists of a field of 60-degree rim angle concentrators with an aperture diameter of $203 \mathrm{ft}(61.9 \mathrm{~m})$ and a gross aperture area of $32,365 \mathrm{ft}^{2}\left(3007 \mathrm{~m}^{2}\right)$. Gaps between the mirror panels result in the actual surface and aperture areas being $2.8 \%$ less than the gross areas; therefore, the net aperture area is 
$31,459 \mathrm{ft}^{2}\left(2922.7 \mathrm{~m}^{2}\right)$. The design-point and annual average performance is identical to that of the Case I concentrator discussed in Section 5.1.

\subsubsection{Receiver Subsystem}

The Case II receiver is a cylinder with a length approximately equal to one-half of the radius of curvature of the concentrator. It consists of a stainless steel support tube which is spirally wrapped with ten parallel Incoloy $800 \mathrm{H}$ tubes. The receiver tubes are painted with black Pyromark paint to reduce reflection and to ald in the absorption of the concentrated solar flux.

\subsubsection{Design-Point Performance}

The receiver performance was determined by using the method described in Appendix D. The results of this analysis consist of receiver optical and thermal losses. The receiver absorption and emittance are determined by the receiver geometry, angle of incident flux, and receiver tube material and coating. Because the receiver is a cylinder and the tubes are painted with black Pyromark paint, the absorptivity and emissivity are assumed to be 0.96 , the same as that of a central receiver (williams et al. 1987). The much greater average incident angle of the flux (which would lower the absorptivity) was not considered because of the lack of experimental data. The total receiver thermal loss was estimated to be $0.162 \mathrm{~kW} / \mathrm{m}^{2}$ of concentrator aperture area. Receiver thermal losses were corrected in the annul simulation for ambient temperature variations and wind speed.

\subsubsection{Annual Average Receiver Efficiency}

The annual average receiver efficiency was determined by SOLSTEP to be 61.4\%. Because of the modular nature of the concept, receiver efficiency is constant with collector field size. The field efficiency (combined concentrator/receiver efficiency) was $34.4 \%$, which is also constant with field size.

\subsubsection{Transport Subsystem}

The transport subsystem includes the collector field supply and return piping and the field supply pump. The transport system supplies the receivers with $550^{\circ} \mathrm{F}$ molten salt at $300 \mathrm{psi}$. The heated salt exits the receiver at 
$1050^{\circ} \mathrm{F}$ and $235 \mathrm{psi}$ and is returned to the storage subsystem. The receiver supply pumps and piping were carbon steel; the return side piping was stainless steel. Fiberglass insulation was used on the supply side and calcium silicate insulation was used on the return side.

\subsubsection{Design-Point Performance}

The transport system performance was characterized using the ETRANS computer code (Barnhart 1980) and by using the methods described in Appendix E. This resulted in the transport system performance being determined for many different field sizes (number of bowls). The transport system thermal efficiencies and pumping power requirements are given in Appendix $E$ for each transport design. The thermal efficiency indicates the impact of heat losses from the piping and pumping power indicates the mechanical energy required to overcome viscous drag.

Thermal efficiency of the transport piping decreases with plant size because larger plants have larger collector fields, which involve more piping per square meter of collector area than small fields. Similarly, field pumping power increases with increasing plant size.

\subsubsection{Annua] Average Transport Performance}

The annual average transport figure of merit is described in Section 5.1.3.2 and includes the impact of both thermal losses and pumping power for the transport system. The figures of merit are reported in Table 5.7 for nostorage designs and for plants with a capacity factor of 0.4 . The figure of merit steadily declines with increasing plant size as both thermal losses and pumping power increase.

\subsubsection{Storage Subsystem}

The storage subsystem consists of the molten salt storage tanks, molten salt, and the charge and discharge piping and equipment. The main loss mechanism for the storage subsystem is thermal losses from the storage tank. 
TABLE 5.7. Case II Transport System Annual Average Figure of Merit

\begin{tabular}{rcc} 
Plant Size, MWe & No-Storage (z) & 0.4 Capacity Factor (z) \\
\cline { 1 - 2 } 0.5 & 96.3 & 96.3 \\
2.0 & 95.6 & 95.3 \\
10.0 & 92.8 & 91.8 \\
30.0 & 91.1 & 89.2 \\
100.0 & 87.9 & 86.7
\end{tabular}

\subsubsection{Design-Point Performance}

The volume of the storage media was determined by the storage requirements and power rating of the design. The tank dimensions and insulation thickness were cost optimized to identify the least cost design. As part of the optimization procedure, the thermal losses from the tanks were determined. Each tank (the "hot" and "cold") was assumed to be isothermal. Obviously, tank dimensions increase with plant size and storage capacity. Larger tanks have less surface area for the contained volumes than small tanks, resulting in lower thermal losses for the larger tanks on a percentage basis. Tank sizes and performance data for the storage designs are shown in Table 5.8.

\subsubsection{Annual Average Storage Performance}

The annual average figure of merit for storage performance includes the impact of tank and storage media thermal losses, and discharge piping pumping power. The storage figure of merit is given by the following equation.

$$
\frac{Q_{\text {INS }} \times \eta_{\text {out }}-Q_{\text {SL }}-\frac{w_{\text {PS }}}{\eta_{\text {EPGS }}}}{Q_{\text {INS }}}
$$

where:

$$
\begin{aligned}
Q_{I N S} & =\text { energy entering the storage subsystem } \\
\eta_{\text {Out }} & =\text { storage output efficiency } \\
Q_{\text {SL }} & =\text { energy lost from storage } \\
W_{P S} & =\text { storage discharge pump work } \\
\eta_{E P G S} & =\text { net thermal to electric conversion efficiency. }
\end{aligned}
$$


The storage figure of merit is reported in Table 5.9 for 0.4 capacity factor plants at all plant sizes.

TABLE 5.8. Molten Salt Storage Design-Point Performance

\begin{tabular}{|c|c|c|c|c|}
\hline $\begin{array}{c}\text { Plant } \\
\text { Size, Mwe }\end{array}$ & $\begin{array}{c}\text { Storage } \\
\text { Hours }\end{array}$ & Height, m & Diameter, m & $\begin{array}{c}\text { Percent } \\
\text { Thermal Loss } \\
\text { Per Hour } \\
\end{array}$ \\
\hline 0.5 & $\begin{array}{r}3 \\
6 \\
9 \\
12\end{array}$ & $\begin{array}{l}5.0 \\
7.0 \\
8.0 \\
9.0\end{array}$ & $\begin{array}{l}2.5 \\
3.5 \\
4.0 \\
4.5\end{array}$ & $\begin{array}{l}0.324 \\
0.116 \\
0.0672 \\
0.045\end{array}$ \\
\hline 2.0 & $\begin{array}{r}3 \\
6 \\
9 \\
12\end{array}$ & $\begin{array}{r}9.0 \\
9.0 \\
10.0 \\
10.5\end{array}$ & $\begin{array}{l}4.5 \\
6.0 \\
6.5 \\
7.0\end{array}$ & $\begin{array}{l}0.18 \\
0.067 \\
0.045 \\
0.029\end{array}$ \\
\hline 10.0 & $\begin{array}{r}3 \\
6 \\
9 \\
12\end{array}$ & $\begin{array}{l}12.0 \\
11.0 \\
12.5 \\
14.0\end{array}$ & $\begin{array}{r}8.0 \\
11.0 \\
12.5 \\
14.0\end{array}$ & $\begin{array}{l}0.10 \\
0.037 \\
0.021 \\
0.014\end{array}$ \\
\hline 30.0 & $\begin{array}{r}3 \\
6 \\
9 \\
12\end{array}$ & $\begin{array}{l}12.5 \\
16.0 \\
18.0 \\
20.0\end{array}$ & $\begin{array}{l}12.5 \\
16.0 \\
18.0 \\
20.0\end{array}$ & $\begin{array}{l}0.065 \\
0.025 \\
0.015 \\
0.010\end{array}$ \\
\hline 100.0 & $\begin{array}{r}3 \\
6 \\
9 \\
12\end{array}$ & $\begin{array}{l}19.0 \\
15.0 \\
17.0 \\
19.0\end{array}$ & $\begin{array}{l}19.0 \\
30.0 \\
34.0 \\
38.0\end{array}$ & $\begin{array}{l}0.0425 \\
0.0130 \\
0.0079 \\
0.0053\end{array}$ \\
\hline
\end{tabular}

The storage figure of merit is quite high for all sizes but does increase with plant size. This is because larger plants have larger storage tanks which in turn have reduced thermal losses on a percentage basis. 


\section{TABLE 5.9. Case II Annual Average Storage Figure of Merit}

For 0.4 Capacity Factor Plants

\begin{tabular}{cc} 
Plant Size, Mwe & Annual Figure of Merit (\%) \\
\cline { 2 - 2 } 0.5 & 97.0 \\
2.0 & 98.1 \\
10.0 & 99.0 \\
30.0 & 99.0 \\
100.0 & 99.4
\end{tabular}

\subsubsection{Energy Conversion Subsystem}

The energy conversion subsystem converts thermal energy in the heat transfer fluid to electrical energy using a heat engine. In this case the conversion subsystem uses molten salt from storage as a heat source for a steam generator. The steam is then used in a Rankine cycle heat engine.

\subsubsection{Design-Point Performance}

The conditions of the steam entering the steam turbine depend on the temperature of the molten salt that is taken from storage and the heat exchanger design.

The heat exchangers in the steam generator were sized by examining previous designs to determine a reasonable heat transfer coefficient. The heat transfer coefficient, inlet and outlet temperatures, and required energy transfer data were known, and the log-mean method was used to select the heat exchanger area. The log-mean method was initially used to develop a design comparable to an existing design. Normally, the log-mean method would underestimate the area of the heat exchanger; therefore, a design margin was included to increase the calculated area. Table 5.10 sumnarizes the information used in the steam generator design.

The design of a steam power cycle is the result of a complicated performance and cost optimization procedure which was beyond the scope of this study. Our approach was to review appropriate solar design studies and to select the most reasonable steam cycle for each power level. The performance 
of the steam cycle was then taken from the design study. Occasionally, the performance would be adjusted for small variations in steam conditions.

\section{TABLE 5.10. Steam Generator Design Information}

\begin{tabular}{c} 
Heat Transfer Coefficient (Btu/ft2 $\left.{ }^{\circ} h^{\circ}{ }^{\circ} \mathrm{F}\right)$ \\
\hline$\frac{\text { Preheater }}{273} \quad \frac{\text { Evaporator }}{292} \quad \frac{\text { Superheater }}{385} \quad \frac{\text { Reheater }}{200} \quad \frac{\begin{array}{c}\text { Design } \\
25 \%\end{array}}{}$
\end{tabular}

The SOLSTEP computer code models the steam cycle performance as consisting of a design-point gross efficiency which is adjusted by a part-load correction factor and an ambient temperature correction factor. The design-point efficiency was taken from previous studies. Table 5.11 summarizes the turbine inlet conditions, gross efficiency and the sources used in selecting inlet conditions and gross efficiency.

\section{TABLE 5.11. Case II Design-Point Energy Conversion Efficiency}

\begin{tabular}{|c|c|c|c|c|c|c|c|}
\hline $\begin{array}{l}\text { Plant } \\
\text { Size (W) }\end{array}$ & Roheat & $\begin{array}{l}\text { Turbine Inlot } \\
\text { Stane Teaporature } \\
\propto(9)\end{array}$ & $\begin{array}{l}\text { Reheat Steal } \\
\text { Tenperature } \\
\propto \text { ( } 9 \text { ( })\end{array}$ & $\begin{array}{l}\text { Turb } \\
\text { Inlet } F \\
\text { we }\end{array}$ & $\begin{array}{l}\text { bine } \\
\text { Presaure } \\
\text { (psia) }\end{array}$ & $\begin{array}{l}\text { Gross } \\
\text { Efficiency }\end{array}$ & Sourco \\
\hline .5 & No & 538 (1600) & - & 8. 89 & (1909) & .316 & Bechtel Topical Roport (Laity ot al. 1986) \\
\hline 2.0 & No & $539(1000)$ & - & 18.9 & (1451) & .328 & Bechtel Topical Plains Roport (Laity et al. 1980) \\
\hline 10.0 & No & $538(1608)$ & - & 18.0 & (1460) & .357 & Bechtel Topical Repert (Laity et al, 1980) \\
\hline 30.6 & No & $538(1696)$ & - & 10.8 & (1460) & .358 & Carrisse Plains (Rockwoll ot al. 1983) \\
\hline 100.0 & Yes & $539(1608)$ & $538(1006)$ & 12.4 & (1890) & .423 & $\begin{array}{l}\text { Solar } 104 \text { (Southern California } \\
\text { Editon et al. 1982) }\end{array}$ \\
\hline
\end{tabular}

The gross efficiencies were calculated for design-point conditions consisting of a turbine backpressure of $2.5^{\prime \prime} \mathrm{Hg}$ and a full load. As ambient temperature changes, the turbine backpressure will change, which in turn will cause the stean cycle gross efficiency to vary. Most performance information is based on wet bulb temperature so a wet bulb temperature was calculated from a dry bulb temperature assuming a $35 \%$ relative humidity. The efficiency 
corrections were taken from published information (Bechtel Topical Report in Laity et al. 1980, and Bechtel 1985).

Part load efficiency corrections were also taken from published information. The Bechtel data in Laity et a1. (1980) provided part-load corrections for small turbines (0.5 MW, 2.0 MW, 10.0 MW). The part-load correction for the 100-MW turbine was taken from part-load heat balances for a water/steam system presented in Darnell et al. (1985). The part-load correction for the 30-MW case was calculated by taking a weighted average between the 10-MW and 100-MW corrections.

\subsubsection{Annual Average Energy Conversion Efficiency}

The annual average gross energy conversion efficiency including part-load and ambient temperature correction, is shown in Table 5.12 for a range of plant sizes with both no storage and a capacity factor of 0.4 . As with the design-point gross efficiency, the annual average efficiency increases with plant size. In addition, the plants with capacity factors of 0.4 consistently have higher efficlencies than the no-storage designs. This was caused by the no-storage plants being at part-load conditions more often than plants with storage.

TABLE 5.12. Case II Annual Average Energy Conversion Efficiency Plant Size, MWe No-Storage (\%) 0.4 Capacity Factor (\%)

$\begin{array}{rrr}0.5 & 29.2 & 32.0 \\ 2.0 & 30.3 & 33.1 \\ 10.0 & 33.2 & 36.1 \\ 30.0 & 35.3 & 38.7 \\ 100.0 & 39.1 & 42.4\end{array}$

\subsubsection{Parasitic Losses}

The operating parasitic losses consist of energy conversion parasitics (which are a function of thermal input to the turbine), field parasitics (which are a function of field size), pumping power, and fixed operating power. When 
the plant is not in operation, parasitic loads are modeled as consisting of standby loads and trace heating.

\subsubsection{Design-Point Performance}

The design-point parasitics are presented in Table 5.13 as a function of plant size. The first two columns present the energy conversion parasitics as the sum of a constant and a fraction of the input from the heat engine. The third column presents field-related parasitic loads, which are dominated by receiver tracking power requirements and consequently are constant when calculated on an area-normalized basis. Fixed operating power requirements are presented in the fourth column and standby power requirements are listed in column five. The final column lists the average trace heating power requirements when the plant is not operating. A detailed discussion of the definitions and caiculations of parasitic losses is presented in Appendix $G$.

\section{TABLE 5.13. Design-Point Parasitic Losses for Case II (No-Storage Design)}

\begin{tabular}{|c|c|c|c|c|c|c|}
\hline $\begin{array}{c}\text { Plant } \\
\text { Size, MWe }\end{array}$ & $\begin{array}{l}\text { Energy } \\
\text { Para } \\
a_{1} \text { kwe }\end{array}$ & $\begin{array}{l}\text { Conversion } \\
\text { sitic(a) } \\
\frac{b_{1} \mathrm{kWe} / \mathrm{kWt}}{}\end{array}$ & $\begin{array}{c}\text { Field } \\
\text { Parasitic } \\
\mathbf{k W e} / \mathrm{m}^{2} \\
\end{array}$ & $\begin{array}{c}\text { Fixed } \\
\text { Parasitic } \\
\text { kWe }\end{array}$ & $\begin{array}{r}\text { Standby } \\
\text { Parasitic } \\
\text { kwe }\end{array}$ & $\begin{array}{c}\text { Heat } \\
\text { Tracing } \\
\text { kwe }\end{array}$ \\
\hline 0.5 & 6.4 & 0.0122 & 0.000011 & 4.7 & 10.5 & 4.3 \\
\hline 2.0 & 27.0 & 0.0122 & 0.000011 & 18.4 & 39.6 & 17.2 \\
\hline 10.0 & 114.0 & 0.0122 & 0.000011 & 88.6 & 184.4 & 67.6 \\
\hline 30.0 & 316.0 & 0.0122 & 0.000011 & 257.0 & 485.8 & 131.4 \\
\hline 100.0 & 959.0 & 0.0122 & 0.000011 & 823.0 & 1504.0 & 679.4 \\
\hline
\end{tabular}

(a) Parasitic power $=a+b$ (thermal input to heat engine).

\subsubsection{Annual Average Parasitic Losses}

The annual average electrical parasitic losses as determined by SOLSTEP for Case II are presented in Table 5.14 at each plant size for both no storage and a capacity factor of 0.4 . The parasitics are given as a fraction of the plant's gross output. The parasitic loss fraction is fairly constant across plant size and averages $17 \%$ to $19 \%$ for the no-storage capacity and $12 \%$ to $14 \%$ for the 0.4 capacity factor. The 0.4 capacity factor case has a lower 
parasitic loss fraction because some parasitic loads vary only with plant size and not with plant output. Therefore, increasing the capacity factor for a given plant size increases the output at a faster rate than the parasitic increase.

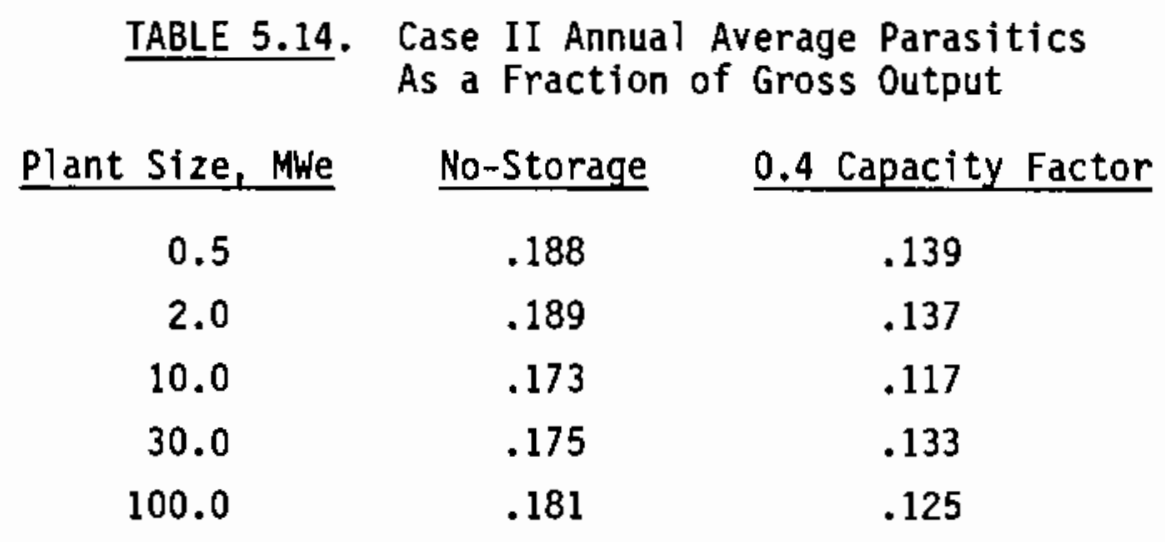

\subsection{CASE III: 30-DEGREE CONCENTRATOR WITH A WATER/STEAM RECEIVER AND NO STORAGE}

This case consists of a field of 30-degree bowls which use water/steam as the heat transport fluid. The steam is used in a Rankine cycle heat engine to produce electricity; this case has no energy storage.

\subsubsection{Concentrator Subsystem}

The concentrator subsystem consists of a field of 30-degree rim angle concentrators with an aperture diameter of $203 \mathrm{ft}(61.9 \mathrm{~m})$ and a gross aperture area of $32,365 \mathrm{ft}^{2}\left(3007 \mathrm{~m}^{2}\right)$. The concentrator uses glass/metal mirror panels. Gaps between these mirror panels result in the actual surface and aperture areas being $1.7 \%$ less than the gross areas; therefore, the net aperture area is $31,815 \mathrm{ft}^{2}\left(2955.7 \mathrm{~m}^{2}\right)$.

\subsubsection{Design-Point Performance}

The primary figure of merit for characterizing concentrator performance is concentrator efficiency. Concentrator efficiency includes the impact of cosine losses, shadowing, blocking, reflectivity losses, atmospheric attenuation, and spillage. Since the bowl system is a modular concept, the design-point performance will be the same for all concentrators of the same 
kind. The following is a discussion of how each of the losses listed above contributes to the design-point performance of the 30-degree concentrator.

- cosine losses-Since the angle of incidence is equal to zero at the design point, there are no cosine losses at design point.

- shadowing-The shadowing from the receiver support structure/legs, piping, and "cleaning snake" was estimated by TTU to be approximately 0.9946 . (a) Without knowing the basis of this estimate it was assumed to be the same on an annual basis. This value is considerably less than the 0.912 associated with the 65-foot diameter test bowl at TTU; but, the receiver support structure has a radically different design. It should be noted that the shadowing of the reflector caused by its own "lip" is a loss accounted for by the cosine loss. The shadowing of one concentrator by the adjacent concentrator's receiver support structure is not considered, even though it could be significant with this design.

- blocking-This design has no blocking of the reflected flux since the receiver support structure/legs and piping are all located outside of the concentrator.

- reflectivity losses-As with the 60-degree concentrator, a clean, new reflectance of 0.94 was assumed for the concentrator mirror panels. A concentrator cleaning system is incorporated into the concentrator. Weekly cleaning will maintain the high reflectance. It is assumed that the average reflectance is 0.93 ; hence the reflectivity degradation factor is $0.93 / 0.94=0.9894$. The average reflectance $(0.93)$ was used for both the design-point and annual performance estimates.

- atmospheric attenuation-A very small fraction of the reflected solar flux is absorbed by the atmosphere before it reaches the receiver. This value was not measured or calculated by TTU. It is estimated that the atmospheric transmission loss for the bowl collector is much less than for the central receiver; although this value would actually be larger for

(a) TTU correspondence on optical efficiency of a 30-degree concentrator, to T. Witliams, PNL, dated September 19, 1986. 
a 30-degree concentrator than for the 60-degree concentrator, the same value was assumed (0.995).

- spillage-The spillage is determined by reflector quality, tracking accuracy, receiver size and geometry, and recejver structural integrity. For the 30-degree concentrator, the same values for the optical loss (0.98) and deflection loss (0.98) were assumed as were used for the 60-degree concentrator. Since the receiver for this case is only $60 \%$ of full length (one-half the radius of curvature) some end losses occur. At the design point, an end loss of $0.8 \%$ was calculated using the ROSA computer code (Anderson R.M. and W.T. Ford 1984). The overall design-point spillage loss factor is therefore estimated to be:

0.98 (optical loss) $\times 0.98$ (deflection loss) $\times 0.992$ (end loss) $=0.9527$.

The design-point concentrator efficiency is the product of the various efficiency factors listed above. This is the percentage of the avallable flux that impinges on the receiver surface; where the available flux is defined as the product of the design-point, direct-normal insolation $\left(950 \mathrm{~W} / \mathrm{m}^{2}\right)$ and the gross aperture area $\left(3007 \mathrm{~m}^{2}\right)$. Therefore the design-point efficiency for the 30-degree concentrator is:

$$
(0.9946)(0.93)(0.995)(0.98)(0.98)(0.992)=.877
$$

And the amount of flux impinging on the receiver at the design point is:

$$
\left(950 \mathrm{~W} / \pi^{2}\right)\left(2956 \pi^{2}\right)(.877)=2462 \mathrm{~kW}
$$

\subsubsection{Annual Average Concentrator Performance}

The annual average concentrator efficiency is $43.8 \%$. The efficiency is constant with power level, because of the modular nature of the concept. This efficiency ranks in the middle among the concentrator configurations analyzed, but is low compared to sun-tracking concentrators. (See Appendix $\mathrm{C}$ for a more detailed discussion.)

\subsubsection{Receiver Subsystem}

The receiver/boiler is a cylinder with a length approximately equal to $60 \%$ of one-half the radius of curvature of the concentrator. It consists of 
a stainless steel support tube which is spirally wrapped with twenty parallel tubes. The bottom $60 \%$ of the receiver (low flux area) uses 316 stainless stee 1 tubes and the top $40 \%$ of the receiver uses Inconel 617 tubes of the same size. The receiver tubes are painted with black Pyromark paint to reduce reflection and aid in the absorption of the concentrated solar flux.

\subsubsection{Design-point Performance}

The receiver performance was determined by using the method described in Appendix D. The results of this analysis consist of receiver optical and thermal losses. The receiver absorption and emittance are determined by the receiver geometry, angle of incident flux, and receiver tube material and coating. Because the receiver is a cylinder and the tubes are painted with black Pyromark paint, the absorptivity and emissivity were assumed to be 0.96 , the same as that of a central receiver (Williams et al. 1987). The much greater average incident angle of the flux (whtch would lower the absorptivity) was not considered because of the lack of experimental data. The total receiver thermal loss was estimated to be $0.063 \mathrm{~kW} / \mathrm{m}^{2}$ of concentrator aperture area. Receiver thermal losses were corrected in the annual simulation for ambient temperature variations and wind speed.

\subsubsection{Annual Average Receiver Efficiency}

The annual average receiver efficiency was determined by SOLSTEP to be 78.8\%. Because of the modular nature of the concept, receiver efficiency was constant with collector field size. The field efficiency (combined concentrator/receiver efficiency) was $34.5 \%$, which was also constant with field size.

\subsubsection{Transport Subsystem}

The transport subsystem includes the collector field supply and return piping and the field supply pump. The transport system supplies the receivers with $100^{\circ} \mathrm{F}$ water at $1031 \mathrm{psi}$. Steam exits the receiver at $1000^{\circ} \mathrm{F}$ and $1000 \mathrm{psi}$, and is returned to the turbine. The receiver supply piping and pumps were carbon steel and the insulation was fiberglass. On the return side, stainless steel piping and calcium silicate insulation were used. 


\subsubsection{Design-Point Performance}

The transport system performance was characterized by using the methods described in Appendix E. This resulted in transport system design-point performance being determined for many different field sizes (number of bowls). The transport system design-point efficiencies and pumping power requirements are given in Appendix $E$ for each transport design. The thermal efficiency indicates the impact of heat losses from the piping and pumping power indicates the mechanical energy required to overcome viscous drag.

Thermal efficiency of the transport piping decreases with plant size because larger plants have larger collector fields involving more piping per square meter of collector area than small fields. Similarly, field pumping power increases with increasing plant size.

\subsubsection{Annual Average Transport Performance}

The annual average transport figure of merit is described in Section 5.1.3.2 and includes the impact of both thermal losses and pumping power for the transport system. The figures of merit are reported in Table 5.15. The figure of merit steadily declines with increasing plant size as both thermal losses and pumping power increase.

$\begin{gathered}\text { TABLE 5.15. } \\
\text { Case II I Transport System Annual } \\
\text { Average Figure of Merit }\end{gathered}$
\begin{tabular}{cc} 
Plant Size, MWe & Figure of Merit (\%) \\
\hline 0.5 & 92.9 \\
2.0 & 92.4 \\
10.0 & 90.0 \\
30.0 & 87.9 \\
100.0 & 85.8
\end{tabular}

\subsubsection{Storage Subsystem}

There was no storage considered with this case. 


\subsubsection{Energy Conversion Subsystem}

The energy conversion subsystem converts thermal energy in the heat transfer fluid to electrical energy by using a heat engine. In this case the conversion subsystem is coupled directly with the water/steam transport subsystem and uses a Rankine cycle heat engine.

\subsubsection{Design-Point Performance}

The design-point conditions and efficiencies were assumed to be identical to those of Case I described in Section 5.1.5.1.

\subsubsection{Annual Average Energy Conversion Efficiency}

The annual average gross energy conversion efficiency including part-load and ambient temperature correction is shown in Table 5.16 for a range of plant sizes. As with the design-point gross efficiency the annual average efficiency increases with plant size.

IABLE 5.16. Case III Annual Average Energy Conversion
Efficiency

\subsubsection{Parasitic Losses}

The operating parasitic losses consist of energy conversion parasitics (which are a function of thermal input to the turbine), field parasitics (which are a function of field size), pumping power, and fixed operating power. When the plant is not in operation, parasitic loads are modeled as consisting solely of standby loads. 


\subsubsection{Design-Point Performance}

The design-point parasitics are presented in Table 5.17 as a function of plant size. The first two columns present the energy conversion parasitics as the sum of a constant and a fraction of the input of the heat engine. The third column presents field-related parasitic loads which are dominated by receiver tracking power requirements and consequently are constant when calculated on an area-normalized basis. Fixed operating power requirements are presented in the fourth column and standby power requirements are listed in column five. A detailed discussion of the definitions and calculation of parasitic losses is presented in Appendix G.

TABLE 5.17. Design-Point Parasitic Losses for Case III

\begin{tabular}{|c|c|c|c|c|c|}
\hline $\begin{array}{c}\text { Plant } \\
\text { Size, MWe }\end{array}$ & $\begin{array}{l}\text { Energy } \\
\quad \text { Para } \\
a, \text { kwe }\end{array}$ & $\begin{array}{l}\text { Conversion } \\
\text { sitic(a) } \\
\underline{b}, \mathrm{kWe}^{2} / \mathrm{kWt}\end{array}$ & $\begin{array}{c}\text { Field } \\
\text { Parasitic } \\
\mathrm{kWe} / \mathbf{m}^{2} \\
\end{array}$ & $\begin{array}{c}\text { Fixed } \\
\text { Parasitic } \\
\text { kWe } \\
\end{array}$ & $\begin{array}{c}\text { Standby } \\
\text { Parasitic } \\
\quad \text { kWe } \\
\end{array}$ \\
\hline 0.5 & 2.5 & 0.0047 & 0.000011 & 4.7 & 11.3 \\
\hline 2.0 & 10.0 & $0.004 \mathrm{~B}$ & 0.000011 & 18.4 & 38.3 \\
\hline 10.0 & 47.0 & 0.0047 & 0.000011 & 88.6 & 177.8 \\
\hline 30.0 & 130.0 & 0.0047 & 0.000011 & 257.0 & 473.3 \\
\hline 100.0 & 420.0 & 0.0047 & 0.000011 & 823.0 & 1467.0 \\
\hline
\end{tabular}

(a) Parasitic power $=a+b$ (thermal input to heat engine).

\subsubsection{Annual Average Parasitic Losses}

The annual average electrical parasitic losses as determined by SOLSTEP for Case III are presented in Table 5.18 for the system designs at each plant size. The parasitics are given as a fraction of the plant's gross output. The parasitic loss fraction is fairly constant across plant size and averages about $14 \%$. 


\section{TABLE 5.18. Case III Annual Average Parasitics \\ As a Fraction of Gross Output}

\begin{tabular}{cc} 
Plant Size, MWe & Parasitic F \\
\cline { 1 - 1 } 0.5 & .144 \\
2.0 & .146 \\
10.0 & .137 \\
30.0 & .145 \\
100.0 & .144
\end{tabular}

5.4 CASE IV: 30-DEGREE CONCENTRATOR WITH A MDLTEN SALT RECEIVER AND STORAGE

This case consists of a field of 30-degree bowls which use molten salt as both the heat transport fluid and the thermal energy storage medium. The molten salt is used to raise steam for a Rankine cycle heat engine to produce electricity.

\subsubsection{Concentrator Subsystem}

The concentrator subsystem is identical to the Case III concentrator, and consists of a field of 30-degree rim angle concentrators with an aperture diameter of $203 \mathrm{ft}(61.9 \mathrm{~m})$ and a gross aperture area of $32,365 \mathrm{ft}^{2}\left(3007 \mathrm{~m}^{2}\right)$. Gaps between the mirror panels result in the actual surface and aperture areas being $1.7 \%$ less than the gross areas; therefore, the net aperture area is $31,815 \mathrm{ft}^{2}\left(2955.7 \mathrm{~m}^{2}\right)$. The design-point and annual average performance is identical to that of the Case III concentrator discussed in Section 5.3.

\subsubsection{Receiver Subsystem}

The Case IV receiver is a cylinder with a length approximately equal to $60 \%$ of one-half of the radius of curvature of the concentrator. It consists of a stainless steel support tube which is spirally wrapped with ten parallel Incoloy $800 \mathrm{H}$ tubes. The receiver tubes are painted with black Pyromark paint to reduce reflection and aid in the absorption of the concentrated solar flux.

\subsubsection{Design-Point Performance}

The receiver performance was determined by using the method described in Appendix $D$. The results of this analysis consist of receiver optical and 
thermal losses. The receiver absorption and emittance are determined by the receiver geometry, angle of incident flux, and receiver tube material and coating. Because the receiver is a cylinder and the tubes are painted with black Pyromark paint, the absorptivity and emissivity were assumed to be 0.96 , the same as that of a central receiver (Williams et a1. 1987). The much greater average incident angle of the flux (which would lower the absorptivity) was not considered because of the lack of experimental data. The total receiver thermal loss was estimated to be $0.292 \mathrm{~kW} / \mathrm{m}^{2}$ of the aperture area of the concentrator. Receiver thermal losses were corrected in the annual simulation for ambient temperature variations and wind speed.

\subsubsection{Annual Average Receiver Efficiency}

The annual average receiver efficiency was determined by SOLSTEP to be 39.3\%. Because of the modular nature of the concept, receiver efficiency was constant with plant size. The field efficiency (combined concentrator/receiver efficiency) was $17.2 \%$ which was also constant with field size.

\subsubsection{Transport Subsystem}

The transport subsystem includes the collector field supply and return piping and the field supply pump. The transport system supplies the receivers with $550^{\circ} \mathrm{F}$ molten salt at $200 \mathrm{psi}$. The heated sait exits the receiver at $1050^{\circ} \mathrm{F}$ and $140 \mathrm{psi}$ and is returned to the storage subsystem. The receiver supply pumps and piping were carbon steel; the return side piping was stainless steel. Fiberglass insulation was used on the supply side and calcium silicate insulation was used on the return side.

\subsubsection{Design-Point Performance}

The transport system performance was characterized by using the methods described in Appendix E. This resulted in transport system design-point performance being determined for many different field sizes (number of bowls). The transport system design-point efficiencies and pumping power requirements are given in Appendix $E$ for each transport design. The thermal efficiency indicates the impact of heat losses from the piping and pumping power indicates the mechanical energy required to overcome viscous drag. 
Thermal efficiency of the transport piping decreases with plant size because larger plants have larger collector fields involving more piping per square meter of collector area than small fields. Similarly, field pumping power increases with increasing plant size.

\subsubsection{Annual Average Transport Performance}

The annual average transport figure of merit is described in Section 5.1.3.2 and includes the impact of both thermal losses and pumping power for the transport system. The figures of merit are reported in Table 5.19 for plants with no storage and plants with a capacity factor of 0.4 . The figure of merit steadily declines with increasing plant size as both therma losses and pumping power increase.

IABLE 5.19. Case IV Transport System Annual Average Figure of Merit Plant Size, Mwe No-Storage (\%) 0.4 Capacity Factor (\%)

$\begin{array}{rrr}0.5 & 93.1 & 92.7 \\ 2.0 & 92.0 & 89.6 \\ 10.0 & 88.4 & 83.7 \\ 30.0 & 84.7 & 81.0 \\ 100.0 & 81.5 & 76.5\end{array}$

\subsubsection{Storage Subsystem}

The storage subsystem consists solely of the molten salt storage tanks and molten salt. The charge and discharge piping and equipment are included in the transport subsystem. The main loss mechanism for the storage subsystem is thermal losses from the storage tank.

\subsubsection{Design-Point Performance}

The design-point performance for this storage system is identical to that described in Section 5.2.4.1. 


\subsubsection{Annual Average Storage Performance}

The annual average figure of merit for storage performance is described in Section 5.2.4.2 and includes the impact of tank and storage media thermal losses, and discharge piping pumping power. The figure of merit for storage is reported in Table 5.20 for 0.4 capacity factor plants at all plant sizes.

The figure of merit for storage is quite high for all sizes but does increase with plant size. This is because larger plants have larger storage tanks, which in turn have reduced thermal losses on a percentage basis.

IABLE 5.20. Case IV Annual Average Storage Figure of Merit
for 0.4 Capacity Factor Plants
\begin{tabular}{cc} 
Plant Size, MWe & Annual Figure of Merit (\%) \\
\hline 0.5 & 97.2 \\
2.0 & 98.6 \\
10.0 & 99.1 \\
30.0 & 99.3 \\
100.0 & 99.5
\end{tabular}

\subsubsection{Energy Conversion Subsystem}

The energy conversion subsystem converts thermal energy in the heat transfer fluid to electrical energy by using a heat engine. In this case the conversion subsystem uses molten salt from storage as a heat source for a steam generator. The steam is then used in a Rankine cycle heat engine.

\subsubsection{Design-Point Performance}

The design-point conditions and efficiencies were assumed to be identical to those of Case II described in Section 5.2.5.1.

\subsubsection{Annual Average Energy Conversion Efficiency}

The annual average gross energy conversion efficiency including part-load and ambient temperature correction is shown in Table 5.21 for a range of plant sizes for both no-storage designs and plants with a capacity factor of 0.4 . 
As with the design-point gross efficiency the annual average efficiency increases with plant size. In addition, the plants with a capacity factor of 0.4 consistently have a higher efficiency than the no-storage designs. This was caused by the no-storage plants being at part-load conditions more often than would a plant with storage.

TABLE 5.21. Case IV Annual Average Energy Conversion Effictency Plant Size, Me $\quad$ No-Storage (\%) 0.4 Capacity Factor (\%)

$\begin{array}{rrr}0.5 & 29.2 & 31.9 \\ 2.0 & 29.6 & 33.2 \\ 10.0 & 31.8 & 36.1 \\ 30.0 & 34.1 & 38.9 \\ 100.0 & 38.2 & 42.6\end{array}$

\subsubsection{Parasitic Losses}

The operating parasitic losses consist of energy conversion parasitics (which are a function of thermal input to the turbine), field parasitics (which are a function of field size), pumping power, and fixed operating power. When the plant is not in operation, parasitic loads are modeled as consisting of standby loads and trace heating.

\subsubsection{Design-Point Performance}

The design-point parasitics are presented in Table 5.22 as a function of plant size. The first two columns present the energy conversion parasitics as the sum of a constant and a fraction of the input of the heat engine. The third column presents field-related parasitic loads which are dominated by receiver tracking power requirements and consequently are constant when calculated on an area-nomalized basis. Fixed operating power requirements are presented in the fourth column and standby power requirements are listed in column five. The final column lists the average trace heating power requirements when the plant is not operating. A detailed discussion of the definitions and calculation of parasitic losses is presented in Appendix $G$. 
TABLE 5.22. Design-Point Parasitic Losses for Case IV (No-Storage Designs)

\begin{tabular}{|c|c|c|c|c|c|c|}
\hline $\begin{array}{c}\text { Plant } \\
\text { Size, MWe }\end{array}$ & $\begin{array}{l}\begin{array}{l}\text { Energy } \\
\text { Para }\end{array} \\
a_{\text {r kWe }}\end{array}$ & $\begin{array}{l}\text { Conversion } \\
\text { sitic(a) } \\
\mathrm{b}, \mathrm{kWe} / \mathrm{kWt}\end{array}$ & $\begin{array}{c}\text { Field } \\
\text { Parasitic } \\
\mathrm{kWe} / \mathrm{m}^{2}\end{array}$ & $\begin{array}{c}\text { Fjxed } \\
\text { Parasitic } \\
\text { kwe }\end{array}$ & $\begin{array}{c}\text { Standby } \\
\text { Parasitic } \\
\text { kwe }\end{array}$ & $\begin{array}{l}\text { Heat } \\
\text { Tracing } \\
\text { kwe }\end{array}$ \\
\hline 0.5 & 6.4 & 0.0122 & 0.000011 & 4.7 & 9.9 & 12.0 \\
\hline 2.0 & 27.0 & 0.0122 & 0.000011 & 18.4 & 34.2 & 33.0 \\
\hline 10.0 & 114.0 & 0.0122 & 0.000011 & 88.6 & 153.6 & 129.2 \\
\hline 30.0 & 316.0 & 0.0122 & 0.000011 & 257.0 & 424.0 & 349.1 \\
\hline 100.0 & 959.0 & 0.0122 & 0.000011 & 823.0 & 1325.5 & 1497.3 \\
\hline
\end{tabular}

(a) Parasitic power $=a+b$ (thermal input to heat engine).

\subsubsection{Annual Average Parasitic Losses}

The annual average electrical parasitic losses as determined by SOLSTEP for Case IV are presented in Table 5.23 at each plant size for both no storage and a capacity factor of 0.4 . The parasitics are given as a fraction of the plant's gross output. The parasitic loss fraction is fairly constant across plant size and averages $38 \%$ to $43 \%$ for the no-storage capacity and $19 \%$ to $23 \%$ for the 0.4 capacity factor. The reason for the considerably higher Toss fraction, compared with the previous cases, is not an increase in the absolute parasitics but a significantly lower gross plant output. The 0.4 capacity factor case has a lower parasitic loss fraction because some parasitic loads vary only with plant size and not with plant output. Therefore, increasing the capacity factor for a given plant size, increases the output at a faster rate than the parasitic increase.

\begin{tabular}{|c|c|c|}
\hline Plant Size, MWe & No-Storage & $\underline{0.4 \text { Capacity Factor }}$ \\
\hline 0.5 & .427 & .226 \\
\hline 2.0 & .403 & .221 \\
\hline 10.0 & .382 & .196 \\
\hline 30.0 & .390 & .219 \\
\hline 100.0 & .415 & .190 \\
\hline
\end{tabular}




\subsection{CASE V: IRIS CONCENTRATOR, HEAT PIPE RECEIVER, STIRLING ENGINE, AND NO STORAGE}

This case consists of a field of 30-degree bowls with a sun-tracking mirror unit. The receiver is an isothermal heat pipe with a potassium working fluid. Electricity is generated by five stirling engines attached to each receiver. The electricity generated by each bowl is moved to the grid by an electric transport system. This case has no energy storage.

\subsubsection{Concentrator Subsystem}

The iris concentrator subsystem consists of a field of fixed 30-degree concentrators with sun-tracking mirror units called irises. The fixed portion of the concentrator is assumed, for performance modeling, to be identical to the concentrator used in Cases III and IV. This is an optimistic assumption, because the cost of the concentrator (as discussed in the next chapter) is based on a Mylar concentrator design for the fixed portion, and it is unlikely that the Mylar concentrator could actually achieve the performance levels of the glass/metal concentrator designs. The moveable portion of the concentrator (iris) has a width of 90 degrees of the concentrator aperture circumference and a height of 15 degrees of the concentrator curvature. The iris is able to circumscribe 270 degrees of the concentrator; therefore, the center of the iris is able to move from due west to due east in a day. The addition of the iris increases the gross aperture area of the concentrator by $25 \%$, to 40,459 $\mathrm{ft}^{2}\left(3758.6 \mathrm{~m}^{2}\right)$. The non-tracking portion of the $1 \mathrm{ris}$ concentrator is assumed to make up a contiguous surface; therefore there are no gaps in this portion. Gaps between the mirror panels of the tracking iris do exist. TTU estimates that the gaps will account for $0.9 \%$ of the entire theoretical surface area of the concentrator. (a) This results in a net aperture area of 40,093 $\mathrm{ft}^{2}$ $\left(3724.7 \mathrm{~m}^{2}\right)$.

(a) TTU correspondence to T. Williams, PNL, on optical efficiency of an iris concentrator, dated October 14, 1986. 


\subsubsection{Design-Point Performance}

The primary figure of merit for characterizing concentrator performance is concentrator efficiency. Concentrator efficiency includes the impact of cosine losses, shadowing, blocking, reflectivity losses, atmospheric attenuation, and spillage. Because the bowl system is a modular concept, the design-point performance will be the same for all concentrators of the same kind. The following is a discussion of how each of the losses listed above contributes to the design-point performance of the iris concentrator.

- cosine losses-Since the angle of incidence is equal to zero at the designpoint, there are no cosine losses at design-point.

- shadowing-The shadowing from the receiver support structure/legs, piping, and "cleaning snake" was estimated by TTU to be approximately 0.9946 (a) for the iris concentrator. Without knowing the basis of this estimate it was assumed to be the same on an annual basis. This value is considerably less than the 0.912 associated with the 65 -foot-diameter test bowl at TTU: but, the receiver support structure has a radically different design. It should be noted that the shadowing of the reflector caused by its own "lip" is a loss accounted for by the cosine loss. The shadowing of one concentrator by the adjacent concentrator's receiver support structure is not considered, even though it could be significant with this design. One should also note that the iris portion of the concentrator will not shadow the fixed portion of the concentrator, since the iris is always on the side of the concentrator away from the sun.

- blocking-This design has no blocking of the reflected flux because the receiver support structure is located outside of the concentrator. Additionally, the iris does not block any reflected flux.

- reflectivity losses-As with the 60-degree and 30-degree concentrators a clean, new reflectance of 0.94 was assumed for the concentrator reflectors. As noted previously, this is perceived to be an optimistic assumption

(a) TTU correspondence to T. Williams, PNL, on optical efficiency of an iris concentrator, dated October 14, 1986. 
because the cost of this concentrator was based on a Mylar design, which is not expected to achieve the performance levels of the glass/metal concentrators. A concentrator cleaning system is incorporated into the concentrator. Weekly cleaning will maintain a high reflectance. It is assumed that the average reflectance is 0.93 ; therefore, the reflectivity degradation factor is $0.93 / 0.94=0.9894$. The average reflectance $(0.93)$ was used for both the design-point and annual performance estimates.

- atmospheric attenuation-A very small fraction of the reflected solar flux is absorbed by the atmosphere before it reaches the receiver. This value was not measured or calculated by TTU. It is estimated that the atmospheric transmission loss for the bowl collector is much less than for the central receiver, although this value would actually be larger for the iris concentrator than for the 60-degree concentrator, the same value was assumed (0.995).

- spillage-The spillage is determined by reflector quality, tracking accuracy, receiver size and geometry, and receiver structural integrity. For the iris concentrator, the same values for the optical loss (0.98) and deflection loss (0.98) were assumed as were used for the 60-degree concentrator. Because the receiver for this case is only $20 \%$ of full length (one-half the radius of curvature) some end losses do occur. At the design-point, an end loss of $9.9 \%$ was calculated using the ROSA computer code. The overall design-point spillage loss factor is therefore estimated to be:

0.98 (optical loss) $\times 0.98$ (deflection loss) $\times 0.901$ (end loss) $=0.8653$. The design-point concentrator efficiency is the product of the various efficiency factors listed above. This is the percentage of the avallable flux that impinges on the receiver surface; where the available flux is defined as the product of the design-point, direct normal insolation (950 $\left.\mathrm{W} / \mathrm{m}^{2}\right)$ and the gross aperture area $\left(3007 \mathbb{m}^{2}\right)$. Therefore, the design-point efficiency for the iris concentrator is:

$$
(0.9946)(0.93)(0.995)(0.98)(0.98)(0.901)=.796
$$


And the amount of flux impinging on the receiver at the design point is:

$$
\left(950 \mathrm{~W} / \pi^{2}\right)\left(3725 \pi^{2}\right)(.796)=2818 \mathrm{~kW}
$$

\subsubsection{Annual Average Concentrator Performance}

The annual average concentrator efficiency is $38.5 \%$. The efficiency is constant with collector field size, because of the modular nature of the concept. This efficiency is the lowest among the concentrator configurations analyzed because the receiver is only $20 \%$ of full length. (See Appendix $C$ for a more detailed discussion.)

\subsubsection{Receiver Subsystem}

The receiver for Case $V$ does not have a detalled design, but it is assumed to be an isothermal heat pipe using potassium as the working fluid. It is a cylinder, with an evaporator length approximately equal to $20 \%$ of one-half the radius of curvature of the concentrator. The exterior of the receiver was assumed to be painted with black Pyromark paint to reduce reflection and aid in the absorption of the concentrated solar flux.

\subsubsection{Design-Point Performance}

The receiver performance was determined by using the method described in Appendix $D$. The results of this analysis consist of receiver optical and thermal losses. The receiver absorption and emittance are determined by the receiver geometry, angle of incident flux, and receiver tube materiat and coating. Because the receiver is a cylinder and the tubes are painted with black Pyromark paint, the absorptivity and emissivity were assumed to be 0.96 , the same as that of a central receiver (willfams et al. 1987). The much greater average incident angle of the flux (which would lower the absorptivity) was not considered because of the lack of experimental data. The total receiver thermal loss was estimated to be $0.2382 \mathrm{~kW} / \mathrm{m}^{\mathrm{F}}$ of the aperture area of the concentrator. Receiver thermal losses were corrected in the annual simulation for ambient temperature variations and wind speed.

\subsubsection{Annual Average Receiver Efficiency}

The annual average receiver efficiency was determined by SOLSTEP to be 39.5\%. Because of the modular nature of the concept, receiver efficiency was 
constant with collector size. The field efficiency (combined concentrator/ receiver efficiency) was $15.2 \%$ which was also constant with field size.

\subsubsection{Transport Subsystem}

The transport subsystem is an ac power transmission network, and consists of the cables, transformers, circuit breakers, and miscellaneous equipment necessary for transmitting power from numerous large Stirling engines to the central distribution facility. Performance estimates were based on the scaling of transport subsystem performance estimates for dish-Stirling systems (Williams et a1. 1987).

\subsubsection{Design-Point Performance}

Losses in the transport system for Case $V$ represent losses in transmission lines and electrical components. Table 5.24 reports the design-point transport efficiency for several field sizes. Transport efficiency decreases with plant size because larger fields have longer transmission lines with higher losses.

\section{TABLE 5.24. Case $V$ Transport System Design-} Point Efficiency

$\begin{array}{rcc}\begin{array}{r}\text { Fieid Size } \\ \left(1000 \mathrm{~m}^{2}\right)\end{array} & & \begin{array}{c}\text { Transport } \\ \text { Efficiency }(\%)\end{array} \\ 3.8 & & 97.4 \\ 15.0 & 97.3 \\ 78.9 & 97.1 \\ 229.3 & 96.4 \\ 774.3 & 95.9\end{array}$

\subsubsection{Annual Average Transport Performance}

The annual average transport performance is reported in Table 5.25. These results show they are the same as for the design-point results because losses are a percentage of output. Transport efficiency steadily declines with increasing plant size. This is caused by larger plants having larger fields with longer transmission lines, which in turn have higher losses. 
TABLE 5.25. Case V Transport System Annual

Average Efficlency

\begin{tabular}{|c|c|}
\hline Plant Size, Mwe & $\begin{array}{r}\text { Transpo } \\
\text { Efficienc } \\
\end{array}$ \\
\hline 0.5 & 97. \\
\hline 2.0 & 97 . \\
\hline 10.0 & 97. \\
\hline 30.0 & 96 \\
\hline 100.0 & 95 \\
\hline
\end{tabular}

\subsubsection{Storage Subsystem}

There was no storage considered with this case.

\subsubsection{Energy Conversion Subsystem}

The energy conversion subsystem takes thermal energy supplied from the receiver and converts it to electrical energy. The energy conversion subsystem for each bowl consists of the heater tubes, five Stirling engines, their generators, and heat rejection units.

The heat engines are assumed to be $100 \mathrm{~kW}$ kinematic Stirling engines. The engines are water-cooled with the cooling water rejecting waste heat to the atmosphere through a fan-equipped, air-cooled, heat exchanger. The Stirling engines were assumed to be scaled-up versions of the Model 4-95 MK II, $25 \mathrm{~kW}$ engine developed by USAB and tested by Advanco (Washom 1984).

\subsubsection{Design-Point Performance}

The gross energy conversion efficiency of the Stirling engines was specified by TTU to be $34.3 \%$ at $1200^{\circ} \mathrm{F}$. (a) The part-load correction curve shown in Figure 5.1 is for five Stirling engines run in series. (For example, if the available energy is only $50 \%$ of the energy required to run all five engines at full load, all five engines are not run at part load. Instead, 3 engines are run at $83 \%$ load.) There are two curves shown on the plot.

(a) TTU correspondence to T. Williams, PNL, on Case $V$ configuration and performance, dated October 14, 1986. 


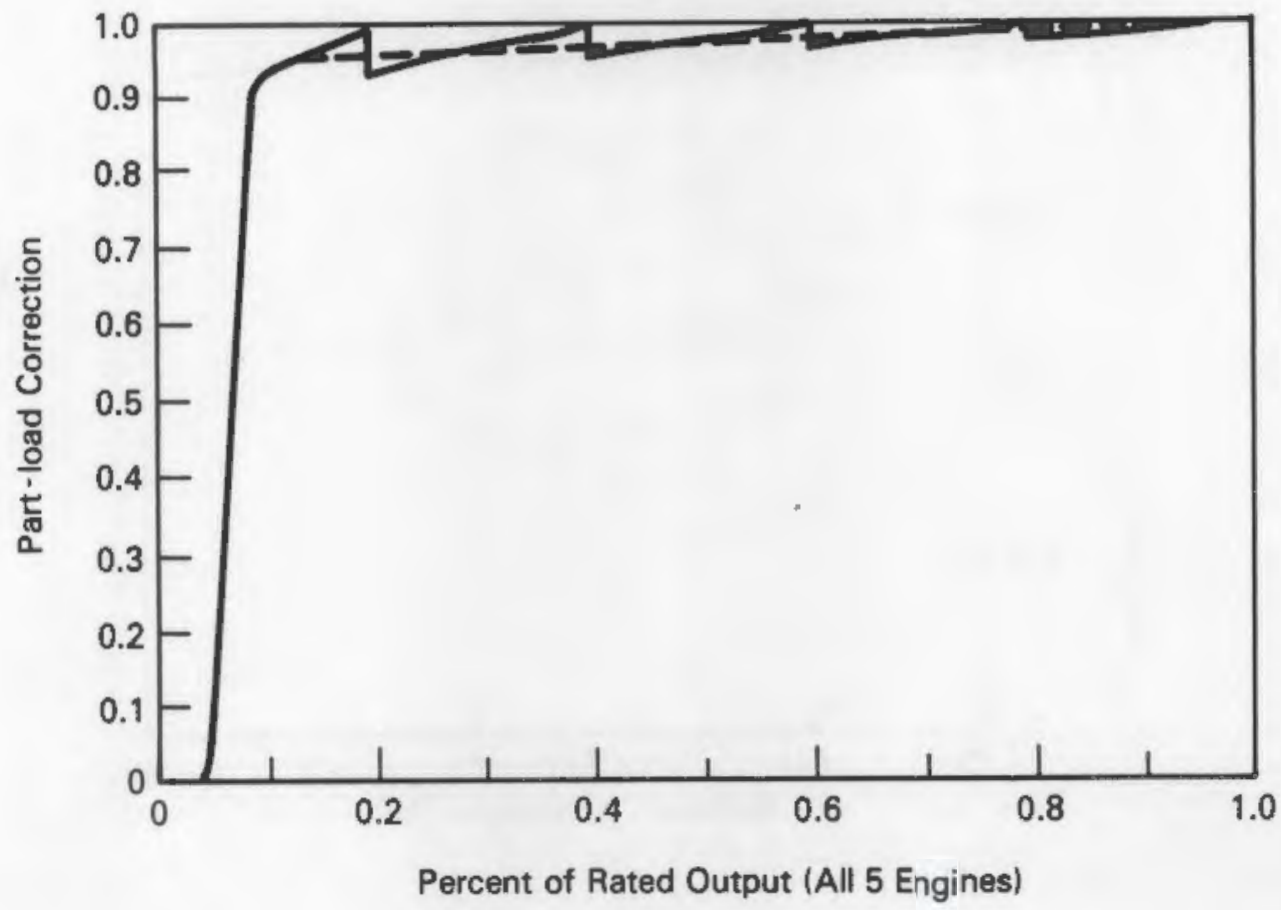

FIGURE 5.1. Part-Load Efficiency for Five Stirling Engines in Series

The jagged one is what the actual part-load curve would look like and the smooth curve is the one used in the SOLSTEP analysis. (The spline fit in SOLSTEP cannot handle the discontinuities.)

The ambient air temperature correction is a function of both the air temperature and the cooling fan set point of $16^{\circ} \mathrm{C}$, as shown in Figure 5.2. When the ambient temperature is below $16^{\circ} \mathrm{C}$, the fan parasitic energy requirement is greater than the increase in engine output because of the lower heat sink temperature, so the fan is not used. Conversely, above $16^{\circ} \mathrm{C}$, the fan parasitic energy requirement is lower than the increase in engine output, so the fan is used.

\subsubsection{Annual Average Energy Conversion Efficiency}

The annual average gross energy conversion efficiency for the Stirling heat engine including part-load and ambient temperature correction was determined by SOLSTEP to be $31.5 \%$. Because of the modular nature of the design, energy conversion efficiency is constant with plant size. 


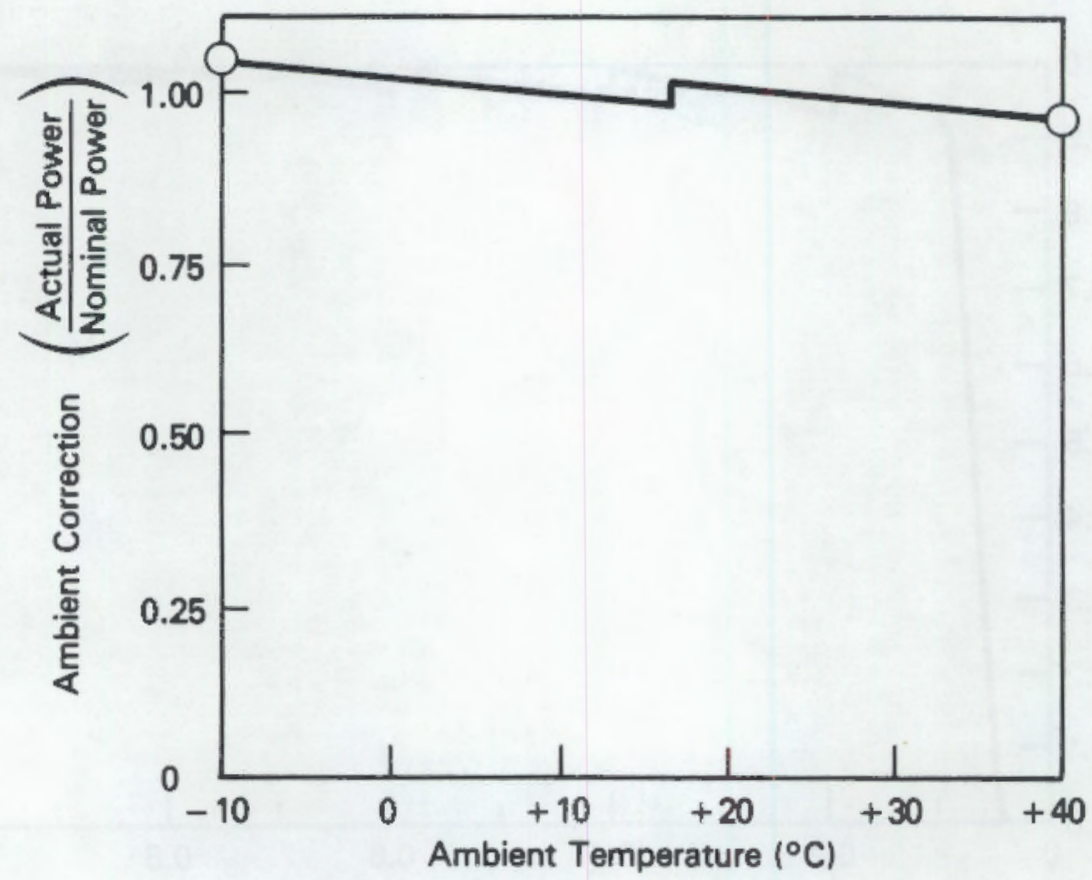

FIGURE 5.2. Ambient Temperature Correction for the Energy Conversion Subsystem in an Iris-Stirling System

\subsubsection{Parasitic Losses}

The operating parasitic losses consist of energy conversion parasitics (cooling fan power), field parasitics (which are a function of field size), and fixed operating power. When the plant is not in operation, parasitic loads are modeled as consisting of standby loads.

\subsubsection{Design-Point Performance}

The design-point parasitics are presented in Table 5.26 as a function of plant size. The first two columns present the energy conversion parasitics. The only electric energy conversion parasitic of a Stirling engine is the cooling fan; therefore, there is no parasitic when it is not operating and when it is operating ( $>16^{\circ} \mathrm{C}$ ambient) the load is shown in column two. The third column presents field-related parasitic loads which are dominated by receiver tracking power requirements and consequently are constant when calculated on an area-normalized basis. Fixed operating power requirements 
are presented in the fourth column and standby power requirements are listed in column five. A detailed discussion of the definitions and calculation of parasitic losses is presented in Appendix $G$.

TABLE 5.26. Design-Point Parasitic Losses for Case $V$

\begin{tabular}{|c|c|c|c|c|c|}
\hline $\begin{array}{c}\text { Plant } \\
\text { Size. MWe }\end{array}$ & $\begin{array}{c}\text { Energy } \\
\text { Para } \\
\end{array}$ & $\begin{array}{l}\text { onversion } \\
\text { itic(a) }\end{array}$ & $\begin{array}{c}\text { Field } \\
\text { Parasitic }\end{array}$ & $\begin{array}{c}\text { Fixed } \\
\text { Parasitic }\end{array}$ & $\begin{array}{c}\text { Standby } \\
\text { Parasitic } \\
\text { kWe }\end{array}$ \\
\hline 0.5 & 0.0 & 16.6 & 0.000011 & 2.5 & 15.2 \\
\hline 2.0 & 0.0 & 66.4 & 0.000011 & 9.9 & 60.7 \\
\hline 10.0 & 0.0 & 348.6 & 0.000011 & 49.5 & 317.0 \\
\hline 30.0 & 0.0 & 1012.6 & 0.000011 & 148.5 & 924.0 \\
\hline 100.0 & 0.0 & 3419.6 & 0.000011 & 495.0 & 3116.0 \\
\hline
\end{tabular}

(a) Parasitic power $=a+b$ (thermal input to heat engine).

\subsubsection{Annual Average Parasitic Losses}

The annual average electrical parasitic losses as determined by SOLSTEP for Case $V$ are presented in Table 5.27 for the system designs at each plant size. The parasitics are given as a fraction of the plant's gross output. The parasitic loss fraction does not vary with changes in plant size, and averages $37 \%$. The parasitics represent a larger fraction of the plant's gross output than Cases I through III because of the much lower gross annual output.

TABLE 5.27. Case V Annual Average Parasitics As a Fraction of Gross Output

\begin{tabular}{rr} 
Plant Size, MWe & Parasitic Fro \\
\hline 0.5 & .368 \\
2.0 & .368 \\
10.0 & .368 \\
30.0 & .371 \\
100.0 & .372
\end{tabular}




\subsection{COST ANALYSIS}

This section of the report presents and discusses the cost-estimating approach, results for Cases I through IV, and the iris system. The section begins by presenting the capital cost estimates prepared for concentrators, and then proceeds with capital cost estimates for receivers, transport, storage, energy conversion, and balance-of-plant components. Operation and Maintenance (08M) cost estimates are presented in the final subsection of this chapter. System levelized energy cost (LEC) and total plant cost results can be found in Chapter 7.0. Cost estimates for alternative concentrators and key cost uncertainties for all components are presented and discussed in Chapter 8.0.

\subsection{CONCENTRATOR COSTS}

The collectors for the fixed mirror distributed focus (FMDF) bowl systems have hemispherically-shaped concentrators which linearly focus the sun's rays upon the receiver. Concentrator designs were discussed in Chapter 4 . Three different concentrator designs were evaluated in this study: a fixed 60-degree concentrator, a fixed 30-degree concentrator, and a fixed 30-degree concentrator with a tracking 15-degree section called an iris. The estimates for each of these concepts are detailed in Sections 6.1.1, 6.1.2, and 6.1.3, respectively. In Table 6.1 the initial capital costs of each of the three concentrators are compared. The 30-degree concentrator with no iris ts the least expensive to build, however, to select the best concentrator, each concentrator's performance (as characterized in Chapter 5) and overall impact on system LEC must also be considered.

\section{1 .1 Baseline (Case I \& II) Concentrator}

The concentrator for cases I and II, commonly referred to as the baseline concentrator, is a 60-degree fixed concentrator which measures $203 \mathrm{ft}$ from rim to rim. The concentrator can be broken into three major structural components (civil works, superpanel/mirror units, and miscellaneous structural steel) including a cleaning system. Table 6.2 summarizes the total cost estimated per concentrator for each of the four components. 
TABLE 6.1. Concentrator Cost Summary

$(1984 \$)$

\begin{tabular}{|c|c|c|c|}
\hline Concentrator & $\$ 1000 / 80 w 1$ & $\$ / \mathbb{m}^{2}$ Aper. & $\$ / \pi^{2}$ Surf. \\
\hline 60-degree bow 1 & 406 & 139 & 104 \\
\hline 30-degree bow 1 & 286 & 97 & 90 \\
\hline $\begin{array}{l}\text { 30-degree bow1 } \\
\text { with iris }\end{array}$ & 332 & 89 & 80 \\
\hline
\end{tabular}

(a) The iris system concentrator couples the least costly alternative 30-degree concentrator (the Mylar concentrator; see Section 8.3) with a glass/metal tracking iris. Total aperture and surface area is greater for this combination than for either the 60-degree or 30-degree bowls.

TABLE 6.2. Main Concentrator Cost Components (Thousands of 1984\$)

Civil Works

Superpane1/Mirror Units

Structural Steel

Cleaning System

Total cost
79

259

44

$\underline{24}$

$\$ 406$

Civil works include site excavation, grading, compaction, and concrete work. Site excavation, grading, and compaction were consolidated into a single charge for earthwork. These charges include costs incurred to rough-form the ground into a bowl shape by using heavy construction equipment and compacting the excavated soil to an $85 \%$ proctor berm at the north (high) end of the concentrator. The cost to perform this work was estimated to be $\$ 3.40 / \mathrm{yd}^{3}$, which is based on estimating the standards derived from construction industry estimating data (Richardson 1983). The total concrete placement construction cost is calculated by estimating the cost incurred by each of eight subcomponents of the pier construction process. Table 6.3 presents each of the eight subcomponents and their associated costs. Combining costs for the eight concrete subcomponents with the excavation work $\left(12,000 \mathrm{yd}^{3}\left[03.40 / \mathrm{yd}^{3}\right)\right.$ yields a total civil works estimate of $\$ 79,120$. 
TABLE 6.3. Pier Construction Component costs $(1984 \$)$

\begin{tabular}{|c|c|c|}
\hline Component & Unit Cost & Total Cost \\
\hline Auguring & $2.20 / 1$ in $\mathrm{ft}$ & 2,070 \\
\hline Column Forms & $9.00 / 1 \mathrm{in} \mathrm{ft}$ & 4,370 \\
\hline Beam Forms & $3.50 / \mathrm{sq} \mathrm{ft}$ & 5,570 \\
\hline Rebar & $0.50 / 1 \mathrm{~b}$ & 11,450 \\
\hline Bells & $100.00 /$ ea & 3,800 \\
\hline Concrete Material & $50.00 / y d^{3}$ & 6,650 \\
\hline \multicolumn{3}{|l|}{ Concrete Labor } \\
\hline Columns & $37.00 / y d^{3}$ & 4,220 \\
\hline Beams & $10.00 / y^{3}$ & 190 \\
\hline Total Pier Cost & & $\$ 38,320$ \\
\hline
\end{tabular}

The cost estimate for structural steel was derived from four subcomponents (the pier caps, pier bracing, rim truss, and rim platform). Each subcomponent's cost was estimated by applying a standard unit cost (\$0.70/1b) for "highvolume," mass-produced fabricated steel products. The total miscellaneous steel weight for the baseline bowl design is $63,000 \mathrm{lb}$, and was estimated (by this approach) to cost $\$ 44,000$.

The superpanel/mirror panel units are one of the more complex parts of the concentrator. The estimate for this unit was prepared by breaking down the construction and installation processes into individual steps and then by estimating the labor and material cost for each step.

The superpanel/mirror panel unit was broken down into the following operations: manufacturing the mirror panels and superpanels, transporting the mirror panels and superpanels to the construction site, attaching the mirror panels to the superpanels, and placing the superpanels onto the bowl support structure. The unit $\left(\$ / \mathrm{m}^{2}, \$ / 1 \mathrm{~b}\right)$ manufactured costs of mirror panels and superpanels were established by standardizing each with the unit costs that were estimated in a previous Pacific Northwest Laboratory (PNL) study (Williams et a1. 1987) for similar components of dish, trough, and heliostat concentrators. The mirror panel cost estimate ( $\$ 39 / \mathrm{m}^{2}$ of surface area) is 
identical to the unit cost for the mirror panels used by the parabolic dish concentrator. Both the dish and the bowl have similarly sized mirror panels and both requite curvature in two directions. In a similar fashion, the unit cost for manufacturing structural steel support elements for the dish and heliostat $(\$ 0.55 / 1 \mathrm{~b})$ was used as the basis for estimating the manufactured cost of the superpanel pieces.

Transportation costs were estimated for factory-manufactured components (mirror panels, superpanels, and miscellaneous structural steel). The number of shipments required per bowl was determined by considering the weight and volume of the units to be shipped and the capacity of the trucks used. Mirror panels and miscellaneous steel are weight-limited, and superpanel pieces are volume-limited. A unit transportation cost of $\$ 1.45 / \mathrm{mile}$ and roundtrip transportation distance of $600 \mathrm{miles}$ per load (identical to assumptions used in a previous PNL study (Williams et a1. 1987)) yielded a total transportation cost of approximately $\$ 8,000$ per bowl for the estimated 9.5 truck loads per bowl.

Site assembly and installation costs for the mirror panels and superpanels were estimated by modifying costs that were estimated for similar site assembly and installation activities required for a heliostat (Northrup 1981). Each of the assembly and installation steps for a heliostat was compared with the required assembly and installation steps for mirror panels and superpanels. An installation manhour estimate was developed by eliminating some activities required by the heliostat and by modifying others. The total site assembly and installation charges were estimated to be approximately $\$ 55,000$ per bowl.

Each of the bowl systems includes a built-in cleaning system which negates the need for a separate cleaning vehicle in balance-of-plant. A mature "snakelike" cleaning system was assumed to cost one-half of the cost estimated in an earlier Texas Tech report (O'Hair 1982). The cost of the PVC water supply piping was estimated by comparing it to unit costs $\left(\$ / \pi^{2}\right.$ covered) for large underground sprinkler systems.

Unit costs for each component of the baseline concentrator are shown in Table 6.4, based on the net aperture area of $2923 \mathrm{~m}^{2}$ for the baseline bowl. 
The net aperture area excludes the area taken up by the cracks between mirror paneis. The gross aperture, based on full coverage from rim to rim is $3007 \mathrm{~m}^{2}$.

\section{TABLE 6.4. Baseline Concentrator Component cost Estimates \\ (1984\$/square meter of net aperture area)}

$\begin{array}{lc}\text { Civil Works } & 27 \\ \text { Misc. Structural Steel } & 16 \\ \text { Mirror Panel Manufacturing } & 52 \\ \text { Superpanel Manufacturing } & 15 \\ \text { Transportation of Factory Components } & 3 \\ \text { Mirror Panel/Superpanel Installation } & 19 \\ \text { Water Supply and Cleaning System } & \frac{8}{2}\end{array}$

\subsubsection{Case III \& IV Concentrators}

The gross aperture area for the Case III and IV concentrators is identical to the baseline concentrator, but its rim angle is only half as large. This results in a bowl that is much "flatter." Costs for the 30-degree bowl (Cases III and IV) were estimated by using unit costs identical to the baseline bowl, where appropriate, and by adjusting for quantitative differences established by the design requirements. The cost relationship relative to the baseline concentrator is identified in Table 6.5 for each component.

TABLE 6.5. Component Cost Relationships Relative to the Baseline Bowl

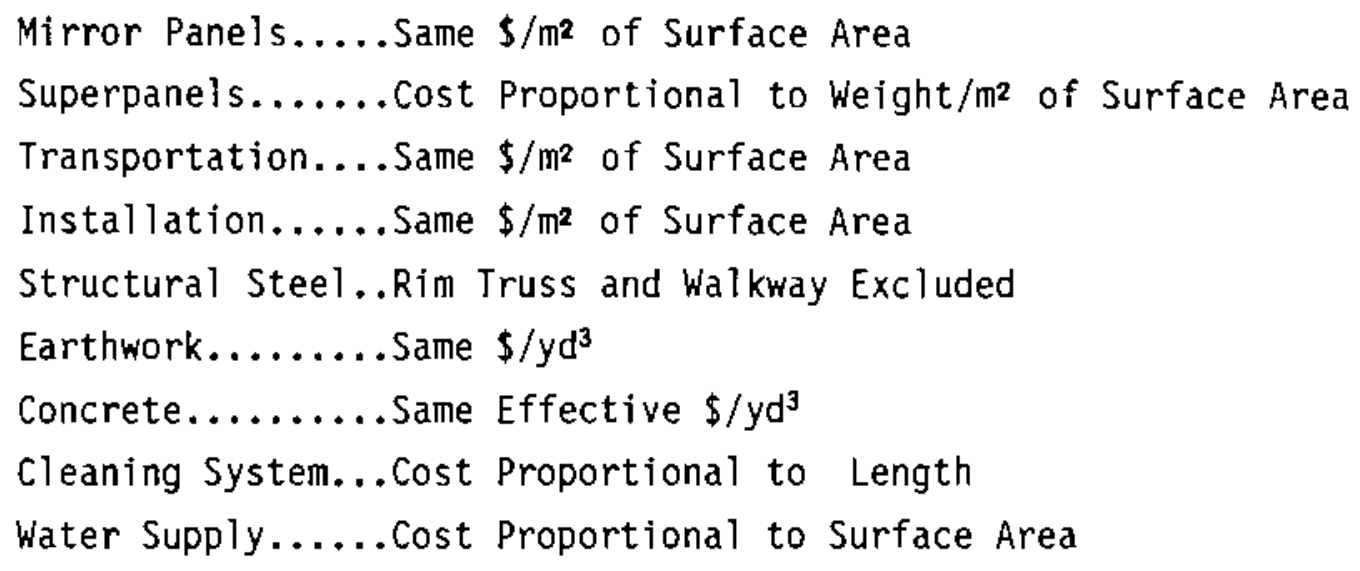


Table 6.6 shows the resulting component and total unit costs for the $30-$ degree concentrator. In general, the unit cost of the 30-degree concentrator is less than that for the 60-degree concentrator because its surface area is smaller, even though both have the same gross aperture area. Design changes also contribute to the lower cost per square meter. Civil works charges for the 30-degree bowl were reduced by not "burying" the bowl so deeply into the ground. This cost reduction was somewhat offset by a requirement for heavier superpanels. Another major factor was the reduction in miscellaneous steel costs, which was because of the elimination of the rim truss and walkway specified for the 60-degree design.

TABLE 6.6. 30-Degree Concentrator Component Cost Estimate (1984\$/square meter of net aperture area)

Civil Works

Misc. Structural Steel

Mirror Panel Manufacturing

Superpanel Manufacturing

Transportation of Factory Components

Mirror Panel/Superpanel Installation

Water Supply and Cleaning System

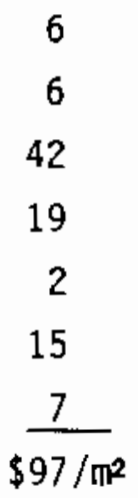

\subsubsection{Iris Concentrator}

The iris system concentrator is composed of a fixed 30-degree concentrator and a tracking 15-degree mirror unit (hereafter, the tracking mirror unit is referred to as the iris). The iris travels along the rim of the fixed bowl as it tracks the sun during the day. The iris consists of mirror panels supported by a superpanel structure which is mounted on a "grandstand" framework constructed of pipes. The grandstand is mounted on steel wheels, which allow it to be pulled by a cable system along a set of tracks that circumscribe 270 degrees of the bowl.

Because the iris system concentrator is basically an extension of a standard 30-degree concentrator, the cost to add the iris to any one of the 
alternative concentrators (e.g., glass on cast-in-place concrete concentrator, glass on precast concrete concentrator, membrane concentrator, or Mylar stabilized-soil concentrator) was estimated separately. In this study, the a) ternative concentrator that had the lowest cost was combined with the iris to form the complete iris system concentrator. The main cost components associated with adding an iris to a fixed 30-degree bowl are additional earthwork, the track and drive system, the grandstand, superpanels, mirror panels, and an additional cleaning system. Table 6.7 summarizes the estimated costs of the iris system components.

IABLE 6.7. Iris Concentrator Component Costs $(1984 \$)$

Earthwork and Piers 16,400

Track and Drive System 28,500

Misc. Structural Steel

18,200

Mirror Panel Manufacturing

37,300

Superpanel Manufacturing 17,300

Mirror Panel/Superpanel Installation 13,600

Cleaning System Total 4,900 $\$ 136,200$

The iris track system consists of a pair of concrete footers 2-feet-wide by 6 -inches-thick with steel rails $(13.3 \mathrm{lb} / \mathrm{ft})$ mounted upon them. The rails are positioned to parallel the rim of the concentrator at distances of 15.6 $\mathrm{ft}$ and $30.6 \mathrm{ft}$, and to run the entire length of the 270-degree track bed. The drive system is presumed to be a simple motor/cable/pulley system. Concrete support piers, similar to those specified for Cases I through IV, were also included. Incremental earth moving costs were estimated first by calculating the requirements for forming the iris track and second by applying the same unit cost $\left(\$ 3.40 / \mathrm{yd}^{3}\right)$ for cut, fill, and compaction as was used for the other concentrator earthwork estimates. Concrete footer and pier costs were estimated by applying identical unit costs (see Table 6.3) for components similar to the other cases. Additional cost data were acquired from Richardson (1983). The cost of steel rails was estimated by applying the standard rate of $\$ 0.70 / 1 \mathrm{~b}$ 
for mass-produced fabricated steel products. Motor, cable, and pulley costs were added to complete the estimate.

The main structure of the iris consists of three parts: the grandstand support structure, the superpanels, and the mirror panels. The grandstand structure is built from pipes which are shop- and field-welded into a framework. The cost of the grandstand structure was estimated by applying the unit cost of $\$ 0.70 / 1 \mathrm{~b}$ to the total weight of the piping framework. The costs of the mirror panels $\left(\$ 39 / \mathbb{m}^{2}\right.$ of surface area), superpanels ( $\$ 18 / \mathbb{m}^{2}$ of surface area), and mirror panel/superpanel assembly and installation ( $\$ 14 / \mathbb{m}^{2}$ of surface area) were based on their respective unit costs for the Cases III and IV concentrator because of the almost identical design requirements for the iris.

The iris unit requires its own cleaning equipment, separate from the cleaning system required for the fixed portion of the iris system concentrator. The cost for the iris cleaning system was estimated by prorating the cost of the cleaning system for the fixed portion of the concentrator according to their respective arc lengths. The PVC water supply piping installed for the fixed concentrator cleaning system was presumed to also supply water to the iris cleaning unit.

Throughout this chapter, and in other cost-oriented sections of this report, the cost estimating approaches and results developed in a previous PNL study (Williams et al. 1987) are referenced. Whenever possible, identical cost estimating approaches and cost assumptions have been used in the analyses of bowl system components. In some cases (e.g., molten salt storage) the total component cost used for evaluating the bowl systems is identical to the cost that was developed in the study for other solar thermal power systems. In other cases (e.g., unit costs for pipe, pumps, insulation, valves, fittings, etc.) identical unit costs were employed in developing the cost estimate when subcomponents were the same as in other solar thermal power systems. Specific similarities and differences in the design and cost estimating approaches are discussed in more detail in each of the individual component sections. 


\subsection{RECEIVER COSTS}

The receiver system is composed of two major units, the absorber and the support structure, each of which was described in chapter 4 . Table 6.8 summarizes the estimated cost of each of these two components for Cases I through IV and Table 6.9 lists the key material unit costs used for estimating all of the cases.

$\begin{array}{rlr}\text { TABLE 6.8. } & \text { Cases I Through IV Receiver Cost Estimates } \\ \text { Case I } & \begin{array}{l}\text { Absorber } \\ \text { Support Structure }\end{array} & \frac{\$ 114,500}{\$ 67,100} \\ & \$ 181,600 \\ \text { Case 2 } & \begin{array}{l}\text { Absorber } \\ \text { Support Structure }\end{array} & \begin{array}{r}\$ 155,400 \\ \$ 67,100\end{array} \\ & \$ 222,500 \\ \text { Case 3 } & \begin{array}{l}\text { Absorber } \\ \text { Support Structure }\end{array} & \$ 256,600 \\ & \frac{\$ 134,200}{\$ 390,800} \\ \text { Case } 4 & \begin{array}{l}\text { Absorber } \\ \text { Support Structure }\end{array} & \$ 375,800 \\ & & \$ 134,200 \\ & & \$ 510,000\end{array}$

TABLE 6.9. Receiver Material Unit Costs

$\begin{array}{lr}\text { Stainless Steel } 316 \text { Pipe } & \$ 4 / 1 \mathrm{~b} \\ \text { Stainless Steel } 316 \text { Tubing } & \$ 5 / 1 \mathrm{~b} \\ \text { Incoloy } 800 \mathrm{H} \text { Pipe } & \$ 9 / 1 \mathrm{~b} \\ \text { Incoloy } 800 \mathrm{H} \text { Tubing } & \$ 12 / 1 \mathrm{~b} \\ \text { Inconel } 617 \text { Tubing } & \$ 25 / 1 \mathrm{~b} \\ \text { Structural Steel } & \$ 0.85 / 1 \mathrm{~b}\end{array}$

The Case I water/steam absorber proved to be the least expensive of the Case I through IV systems. Case II, which employs molten salt as its working fluid, uses larger tubes (compared to Case I) made of Incoloy $800 \mathrm{H}$ over its entire length rather than a combination of stainless steel 316 and Inconel 617. The combined effects of the change in design resulted in the case II 
absorber being more expensive than the Case I absorber. The small increase in Case II absorber weight (relative to Case I) was presumed to have no impact on the requirements or cost for the support structure.

Case III and IV receivers are both significantly more costly than their Case I and II counterparts. The 30-degree (Case III and IV) systems have support structure tower heights and absorber diameters that are roughly twice that for the Case I and II (60-degree) systems. The relative costs of cases III and IV compared with Cases I and II directly reflect these two fundamental design differences. The relative cost of Cases III and IV parallel that for Cases I and II for the same reasons as cited in the above paragraph. Additional receiver cost estimating details are presented in the following paragraphs.

The manufacturing cost of each of the absorbers was estimated by the following procedure: 1) identify the material type and dimensional specifications for each component of the absorber, 2) identify fabrication and assembly operations required to manufacture the absorber, 3) estimate the total material costs by applying the unit costs specified in Table 6.9, 4) estimate total direct manufacturing labor hours by consulting industry estimating manuals (Page 1976, Winslow 1980, Wood 1980), and 5) apply manufacturing cost factors to the direct material and labor estimates to derive a total manufactured cost estimate. Transportation costs (estimated by using the same approach and assumptions as for manufactured concentrator components) and field assembly costs (aligning and bolting up) were added to complete the estimate. The principal assumptions used to develop the manufacturing cost factors are given in Table 6.10 .

The support structure includes the foundation, tower, drive and controls, pedestal, boom, manlift, and heat shield. Although the absorber was presumed to have been manufactured at a central facility and shipped to the site location, the support structure was presumed to have been field-constructed. The tower and boom cost for Cases I and II was estimated based on the typicaI installed cost of "light production" structural steel components $(\$ .85 / \mathrm{lb})$. The cost of the drive, controls, and pedestal unit was estimated by applying a manufacturing cost reduction factor to costs estimated by Texas Tech University (TTU) (1982) for building 10 units. The actual cost percentage 


\section{TABLE 6.10. Manufacturing Cost Assumptions}

Material-Related Overheads

Labor-Related Overheads

General \& Administrative costs

Working Capital

Direct Labor Rate

Facility cost

Land Cost

Plant Economic Life

Real cost of Capital

Effective Income Tax Rate

Property and Other Tax Rate

Equipment Depreciation

Building Depreciation

Land and Working Capital

Investment Tax Credit
10\% of Direct Materials

150\% of Direct Labor

$20 \%$ of Burdened Labor \& Material

$30 \%$ of G\&A and Burdened Labor \& Material

$\$ 9.00 / \mathrm{hr}$.

$\$ 50 / \mathrm{ft}^{2}$

$\$ 25,000$ /acre

20 years

$10 \%$

$50 \%$

$1 \%$

5 year ACRS

18 year ACRS

Non-depreciable

$10 \%$ (equipment only)

reduction estimated for manufactured absorbers [ $57 \%$ less than estimated by TTU (1982) for 10 units] was also applied to the drive, control, and pedestal units. Foundation costs were estimated by applying the same concrete-related unit costs described in Section 6.1 to the design specifications. Costs for the manlift and heat shield were derived from data in Richardson (1983) and Means (1983).

Limited design information was avatlable for the Cases III and IV support structures. The nature of the 30-degree bowl (Cases III and IV) requires a tower that is roughly twice as high as for the 60-degree bowls (Cases I and II). In addition, the bulkier Case III and IV absorbers greatly increase the load on these taller towers. Absorber weights for Cases I through IV are shown in Table 6.11 .

Relative central receiver tower costs that were previously estimated by PNL and by Stearns-Roger were consulted to estimate the impact on tower cost of doubling the tower height and load (Williams et al. 1987, Stearns-Roger 1979). Data from these sources indicated that support structure costs would 
probably increase by a factor of two to three. Support structure costs for Cases III and IV were optimistically estimated to be only double that for the Case I and II systems.

TABLE 6.11. Receiver Absorber Weights

$\begin{array}{lr}\text { Case I } & 9,100 \mathrm{lb} \\ \text { Case II } & 12,100 \mathrm{lb} \\ \text { Case III } & 22,100 \mathrm{lb} \\ \text { Case IV } & 30,300 \mathrm{lb}\end{array}$

The iris system receiver is fundamentally different from the Case I through IV receiver units. It consists of a 33-inch diameter potassium heat pipe with a twenty-foot-long evaporator section and a five-foot-long condenser section. The heat pipe estimate was developed in a manner similar to that described for the other absorbers, but with less detailed design specifications.

Materials and fabrication of the heat pipe shell make up the majority of its cost. The material cost of the heat pipe shell was estimated based on using Incoloy $800 \mathrm{H}$ at a cost of $\$ 9 / 1 \mathrm{~b}$. The cost of the wicking elements was scaled up from designs and costs developed by Dynatherm (1979).

The iris receiver support structure was judged to have similar design requirements and costs as the Case III and IV receiver support structures. All three of these systems are based on 30-degree fixed bowls with approximately 200-ft-tall towers. Although the iris absorber itself was estimated to weigh only $6100 \mathrm{lb}$, the tower and boom must also support five Stirling engines, which were estimated to weigh approximately $3000 \mathrm{lb}$ each. The total absorber and engine weight that must be supported $(21,000 \mathrm{lb})$ is nearly identical to the absorber weight for the Case III receiver. Table 6.12 summarizes the absorber and support structure costs for the iris receiver.

TABLE 6.12. Iris Receiver Cost Estimate

$\begin{array}{ll}\text { Absorber } & \$ 110,900 \\ \text { Support Structure } & \$ 134,200 \\ & \$ 245,100\end{array}$




\subsection{TRANSPORT COSTS}

Transport system designs were developed with the assistance of ETRANS (Barnhart 1980), a PNL computer model that optimizes the design of thermal energy transport systems for distributed solar thermal collectors (see Appendix E). ETRANS designs specify the requirements for pumps, pump motors, pipes, valves, fittings, insulation, and heat tracing. Approximately a dozen designpoint field sizes were modeled for each case to characterize the range of field sizes corresponding to plant power ratings of 0.5 to 100 MWe. Unit costs for transport system subcomponents (pipe, valves, pumps, insulation, etc.) identical to those used in a previous PNL study (Williams et al. 1987) were applied to the design-point specifications to yield design-point estimates. SOLSTEP cost estimating models were developed from the design-point estimates by regressing cost against concentrator aperture area.

Four thermal transport systems were characterized in this study. The combination of two working fluids and two concentrator designs yielded the four cases identified below:

- Case I: 60-degree bowl with steam transport

- Case II: 60-degree bowl with molten salt transport

- Case III: 30-degree bowl with steam transport

- Case IV: 30-degree bow1 with molten salt transport.

In general, the steam systems are more costly than molten salt. Three critical design factors affect the relative costs of steam and molten salt transport: design velocity, system pressure, and the volumetric heat capacity. The lower energy density $\left(\mathrm{Btu} / \mathrm{ft}^{3}\right)$ of steam will increase the required pipe diameter, and higher operating pressure associated with steam transport requires thicker pipe walls (relative to molten salt transport). On the other hand, the higher design velocity for steam transport systems works to decrease the required pipe diameter and mitigates the majority of the above two disadvantages.

Two other cost differentiating design factors are related to the concentrator design. The 30-degree bowl concentrators require longer risers and downcomers, which tends to increase piping costs. However, the 30 -degree 
bowl designs also have a lower thermal input than the 60-degree bowl systems. This lowers the volumetric flow rate, which decreases the required pipe diameter, and tends to decrease piping costs. The dominant effect changes with field size, as is explained in more detail below.

Transport cost results are presented in Table 6.13 and in Figure 6.1. As previously discussed, steam transport (Cases I and III) is generally more expensive than molten salt transport (Cases II and IV). Unit costs increase substantially with field size (number of bowls) for all four cases as would be expected for a distributed thermal energy collection system. The Case III (30-degree bowl with steam transport) design flow is so much lower than Case I (60-degree bowl with steam transport) that this cost advantage overcomes the added cost of a ionger riser and downcomer at all field sizes except for systems of one or two bowls. For molten salt systems, the advantage of a lower flow rate for the 30-degree bowl (Case IV) is not so great, and the crossover point occurs near a field size of approximately 80 bowis. The crossover occurs because the advantage of a lower flow rate per bowl compounds in the inter-bowl collection piping as the number of bowls increases, but the disadvantage of a longer riser and downcomer remains constant, regardless of the number of bowls. The crossover point is different for molten salt and steam systems because of the unique nature of the thermal loads and design flow rates for each case.

\begin{tabular}{|c|c|c|c|c|}
\hline \multirow[b]{2}{*}{ No. Bowls } & \multicolumn{4}{|c|}{ Case Number } \\
\hline & $\underline{I}$ & II & III & IV \\
\hline 1 & 23 & 17 & 24 & 22 \\
\hline 5 & 30 & 20 & 26 & 25 \\
\hline 25 & 42 & 31 & 36 & 35 \\
\hline 100 & 66 & 55 & 62 & 53 \\
\hline 250 & 78 & 65 & 68 & 63 \\
\hline
\end{tabular}




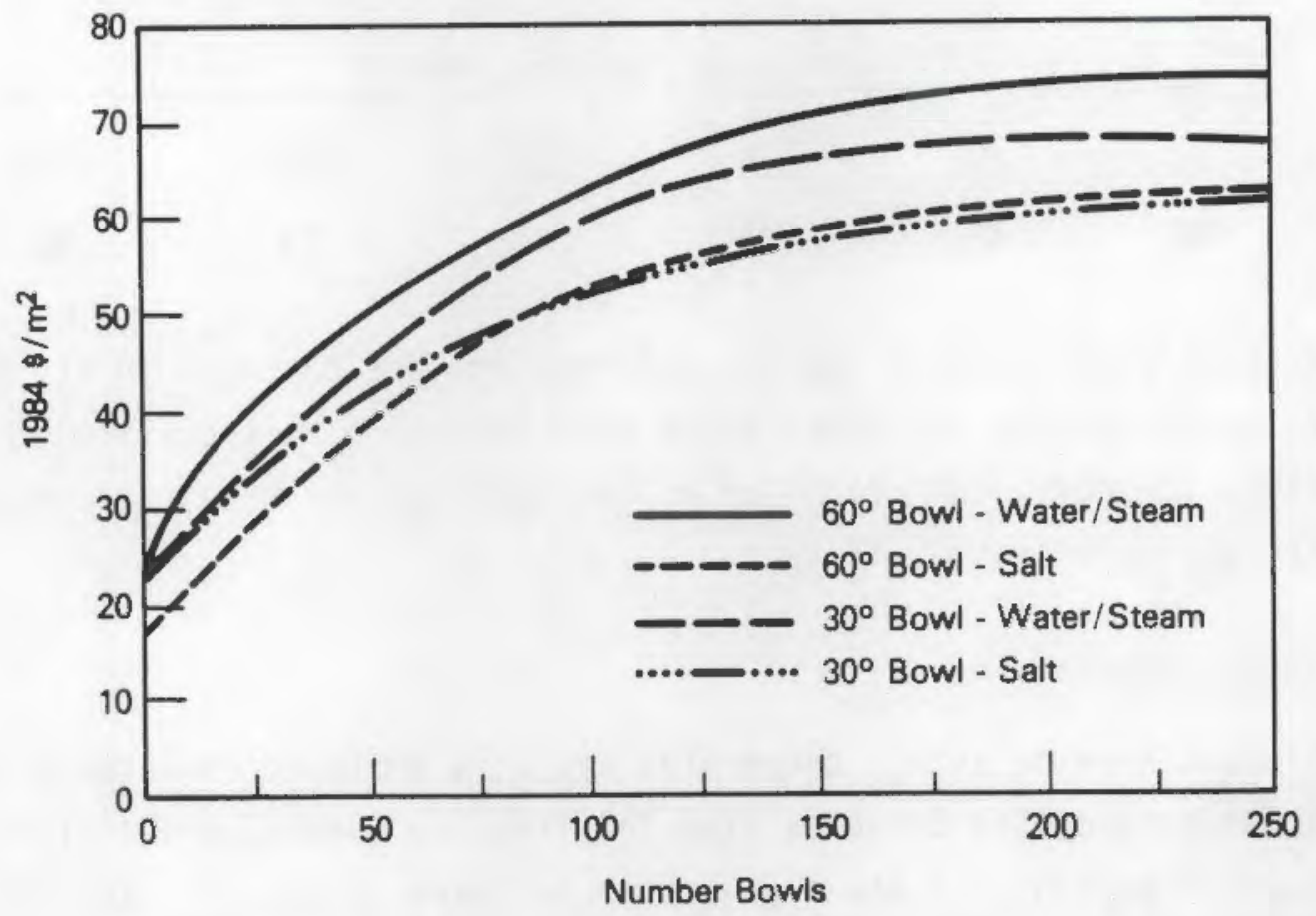

FIGURE 6.1. Transport Cost Results: Cases I-IV

Transport costs were also estimated for the iris/Stirling system. This distributed engine concept requires electric transport, rather than thermal transport, and has requirements similar to those of a dish/Stirling system. The cost approach taken was to modify the dish electric transport design from a previous PNL study (Williams et al. 1987) to reflect the less distributed nature of the bowl (iris) system. A unit cost of approximately $\$ 8 / \mathrm{m}^{2}$ was estimated for all field sizes corresponding to the range ( 0.5 to $100 \mathrm{MWe})$ of plant sizes investigated.

\subsection{STORAGE COSTS}

Molten salt thermal storage was included for Cases II and IV. Storage was not included for Cases I and III, or for the iris system. Molten salt storage costs used in the analysis of bowl systems are identical to the costs developed in a previous PNL study (Williams et al. 1987) for central receiver systems. Unit storage costs are shown in Table 6.14 as a function of storage capacity. 
TABLE 6.14. Molten Salt Storage Costs

(1984\$/kWht of Storage Capacity)

Storage Capacity, MWht

\begin{tabular}{llllll}
\hline 10 & $\frac{30}{88}$ & $\frac{100}{25}$ & $\frac{300}{18}$ & $\frac{1000}{13}$ & $\frac{3000}{12}$
\end{tabular}

Economies-of-scale for molten salt storage are captured in the containment and media maintenance equipment which have declining unit costs with increasing capacity. The media unit cost for molten salt storage remains constant with capacity at approximately $\$ 4 / \mathrm{kWht}$.

\subsection{ENERGY CONVERSION COSTS}

A steam Rankine energy conversion cycle is employed in Cases I through IV. Steam is supplied directly from the field in Cases I and III; steam is created in a molten salt steam generator in Cases II and IV. In addition to the molten salt steam generator, energy conversion components include the turbine-generator, condenser, cooling tower, and other ancillary equipment required to complete the cycle. System designs at 100 MWe also include a reheater for all water/steam and molten salt cases. As a rule of thumb, the turbine-generator cost is about equal to the sum of the costs of the condenser, cooling tower, and ancillary equipment. Molten salt steam generators add approximately $15 \%$ to $20 \%$ to the total cost of the turbine-generator, condenser, cooling tower, and ancillaries; reheaters add another $5 \%$.

The primary source of energy conversion component cost data was a previous PNL study (Williams et al. 1987). Energy conversion costs for the molten salt bowl systems are exactly as they were estimated in the study for the molten salt central receiver systems. Energy conversion costs for water/steam bowl systems were adjusted upward from costs estimated in the prior study for the water/steam central receiver system, reflecting the slight difference in steam conditions between the two systems. The difference in steam conditions resulted in a cost increase relative to the central receiver water/steam system of about $3 \%$. 
Energy conversion costs (in $1984 \$ /$ kWe of gross generating capacity) for the water/steam and molten salt bowl systems are shown in Table 6.15 as a function of power level. Energy conversion costs for the water/steam systems are lower than the molten salt systems at each power level because they have no steam generator. Both systems show strong economies-of-scale, especially for power levels less than 30 Mwe.

\section{TABLE 6.15. Rankine Energy Conversion Costs}

(1984\$/kWe Gross)

\begin{tabular}{|c|c|c|c|c|c|}
\hline \multirow[b]{2}{*}{ System } & \multicolumn{5}{|c|}{ Power Level (MWe) } \\
\hline & 0.5 & 2 & 10 & 30 & 100 \\
\hline te & 1400 & 1100 & 620 & 410 & 320 \\
\hline Molten Salt & 1600 & 1200 & 700 & 480 & 380 \\
\hline
\end{tabular}

Energy conversion for the iris system consists of five 100 kWe Stirling engines mounted on the condenser section of a potassium heat pipe receiver. Components of the Stirling conversion system include the heater tubes, the Stirling engine, a generator, and a heat rejection system.

The starting point for developing the $100 \mathrm{kWe}$ Stirling engine estimate was the design and cost estimated for the $25 \mathrm{kWe}$ dish-Stirling engine in a previous PNL study (Williams et al. 1987). The $25 \mathrm{kWe}$ engine cost was adjusted to account for differences in the presumed annual manufacturing production volume, economies-of-scale related to unit size, and the boundary between receiver and energy conversion equipment. These differences are summarized in Table 6.16.

TABLE 6.16. Stirling Engine Cost Adjustment Factors

Cost Factor
Annual Production Rate
Unit Size
System Boundary

\begin{tabular}{|c|c|}
\hline 25 kWe Engine & $100 \mathrm{kWe}$ Engine \\
\hline 28,782 & 3325 \\
\hline $25 \mathrm{kWe}$ & $100 \mathrm{kWe}$ \\
\hline $\begin{array}{l}\text { heater tubes in } \\
\text { receiver }\end{array}$ & $\begin{array}{l}\text { heater tubes in } \\
\text { energy conversion }\end{array}$ \\
\hline
\end{tabular}


The annual production rates assumed for the two engines were derived from the ground rule specifying that annual production rates for distributed components be equivalent to an annual concentrator aperture production rate of 2.5 million square meters. Dish and iris systems concentrator apertures of $86.86 \mathrm{~m}^{2}$ and $3758 \mathrm{~m}^{2}$, respectively, yield annual concentrator production rates of 28,782 and 665 , respectively. The equivalent annual production rate of 100-kwe Stirling engines (with five engines per bowl) is 3325. The cost impact of production level economies-of-scale was evaluated by comparing massproduction cost reduction factors implied in Stirling engine manufactured cost studies. These studies were prepared by the Jet Propulsion Laboratory (Fortgang and Mayers 1980), Advanco (Washom 1984) and Pioneer Engineering and Manufacturing (1984).

A comparison of unit costs for Stirling engines of different sizes at different production rates (Percival 1982) indicates that unit size economiesof-scale exist, but the extent was difficult to assess. A rule of thumb for unit size economies-of-scale is that costs are proportional to unit sizes raised to the 0.6 power (i.e., cost ratio $=\left[(\right.$ size 1$\left.) /(\text { size } 2)^{0.6}\right]$.

The net effects of the production level disadvantage and the unit size advantage of the 100-kWe engine, relative to the 25-kWe engine, were estimated to be of no consequence. Data in Percival (1982) indicate that either production level or unit size economies-of-scale may dominate, depending on the specific production levels and unit sizes contemplated. The unit cost of the 100-kwe bow1, Stirling engine energy conversion system was estimated to be $\$ 200 / \mathrm{kWe}$ of gross generating capacity. This is $\$ 30 / \mathrm{kWe}$ higher than the dish Stirling engine energy conversion system cost, because the heater tubes (and the receiver cost account for the dish system) were included in the cost of the bowl stirling engine system.

\subsection{ALANCE-OF-PLANT COSTS}

Balance-of-plant is a direct capital cost account which includes support equipment that is necessary for plant operation, but that is not directly related to the concentrator, receiver, transport, storage, or energy conversion components. Balance-of-plant was broken into the following six subcomponents: 
land and site preparation, structures, power conditioning, master control, spare parts, and service facilities. Costs for four of these subcomponents (all, but master control and power conditioning) were aggregated from individual pieces of equipment or site requirements.

Balance-of-plant requirements and costs for the bowl systems were developed from specifications for dish, trough, and central receiver systems characterized in a previous PNL study (Williams et al. 1987). Specific changes to the requirements of the above systems were identified from an $i$ tem by $i$ tem consideration of each subcomponent and from an assessment of the unique requirements (if any) dictated by the bowl systems. Each of the four Rankine bowl systems have identical balance-of-plant requirements and costs; the Stirling bowl system has unique requirements and costs for three of its subcomponents. The modifications to dish, trough, and central receiver balanceof-plant specifications that were required by the bowl systems are described in the following paragraphs.

Land and site preparation charges for the bowl systems (Rankine and Stirling) are assumed to be the same as for central receiver and dish systems. Bowl system (Rankine and Stirling) structure and power conditioning costs are assumed to be the same as estimated for central receiver, dish, and trough systems.

Master control costs for Rankine bowl systems were set equal to previously estimated costs for central receiver and trough Rankine systems. Master control costs for the Stirling bowl system were estimated by modifying the dish system estimate. The cost to control each 100-kWe bowl engine was assumed to be no greater than the cost to control each $25-k$ we dish engine.

The costs for spare parts for central receiver, dish, and trough systems were estimated by allowing $3 \%$ of the initial capital cost of centralized components (such as central receivers and Rankine heat engines) and $0.3 \%$ for distributed components (such as concentrators and trough receivers). Application of this general principal to the Rankine bowl systems yields the same spare parts fractions as for the corresponding components of the trough system. 
Except for the Stirling engine, Stirling bowl system spare parts fractions are the same for each of the Rankine bowl systems. The spare parts fraction for Stirling engines is less than for Rankine energy conversion, but higher than the typical distributed component due to its frequent maintenance requirements. The spare parts fraction for the bowl Stirling engines $(0.6 \%)$ is identical to the fraction assumed for the dish Stirling engines.

Service facilities include vehicles, communications, protection (security), feedwater maintenance (for Rankine systems), and domestic water supply. Rankine bowl system costs and requirements for four of the five subcomponents (all, but vehicles) are the same as previously estimated for other solar thermal Rankine systems (central receivers and trough). Bowl systen vehicular requirements are less because their concentrators have a buflt-in cleaning system. Therefore, bowl systems do not require any concentrator cleaning vehicles.

Communications, protection (security), and domestic water supply requirements for the Stirling bowl systems are identical to the Rankine systems. Vehicular requirements are identical to the dish systems, except that the concentrator washing vehicle is, again, not necessary. No feedwater maintenance is required for Stirling systems.

Balance-of-plant cost results for the four Rankine bowl systems are presented in Table 6.17 for a range of power levels and field sizes (number of bowls). Stirling bowl system balance-of-plant cost results are presented in Table 6.18 for the same power levels and 1dentical number of bowls. Stirling bowl system unit balance-of-plant costs are lower than for Rankine bowl systems with the same number of bowls and at the same power level. This is because of lower charges for spare parts and the master control, and also because there is no need for feedwater maintenance. The difference in unit costs for this comparison can also be attributed to the greater aperture area per bowl for the Stirling bowl system compared with the Rankine bowl systems. Balanceof-plant component costs fixed for a given power level (e.g., power conditioning) are spread over a larger total aperture area, therefore reducing the reported unit cost. 
TABLE 6.17. Balance-of-Plant Cost Results: Rankine Bowl Systems (a) (No Storage Systems)

\begin{tabular}{rrr} 
Power Leve1, MWe & Number of Bowls & $\frac{1984 \$ / \mathrm{m}^{2}}{}$ \\
\cline { 2 - 3 } 2 & 1 & 140 \\
10 & 4 & 72 \\
30 & 20 & 46 \\
100 & 60 & 32
\end{tabular}

(a) Minor differences in spare parts costs among each of the four Rankine bowl systems results in balance-of-plant costs that vary by less than $2 \%$ among the four systems.

TABLE 6.18. Balance-of-Plant Cost Results: Stirling Bowl System

\begin{tabular}{rrr} 
Power Level, MWe & Number of Bowls & 1984 $\$ / \mathrm{m}^{2}$ \\
\cline { 2 - 3 } 0.5 & 1 & 87 \\
2 & 4 & 42 \\
10 & 20 & 25 \\
30 & 60 & 18 \\
100 & 200 & 15
\end{tabular}

\subsection{OPERATIONS AND MAINTENANCE COSTS}

Operations and maintenance costs were aggregated from operating labor, maintenance labor and materials, and overhead labor subcomponents, O\&M costs estimated for a previous PNL study (Williams et al. 1987) served as the basis for bowl system 0\&M estimates, with modifications as dictated by the nature of the bowl system designs.

Operating labor requirements were set equal to the assumptions specified for the trough and dish systems for (Cases I through IV) and the iris system, respectively (Williams et al. 1987). Cases I through IV and trough solar thermal systems all have distributed energy collection and central energy conversion. The iris system, like the dish system evaluated in a previous PNL study (Williams et al. 1987), is based on distributed energy conversion 
and electric transport. Operating costs for the Stirling engines are much lower than for Cases I through IV because there is no central boiler or energy conversion unit. Operating labor assumptions are presented in Table 6.19 as a function of system power rating for Cases I through IV and the iris system.

TABLE 6.19. BowT System Operating Labor Requirements (Full Time Equivalents)

Bowl System

\begin{tabular}{|c|c|c|c|c|}
\hline \multicolumn{5}{|c|}{ Power Level, MWe } \\
\hline 0.5 & 2.0 & 10.0 & 30.0 & 100.0 \\
\hline
\end{tabular}

Cases I-IV

Iris

\section{5}

1.5
7.5

1.5
7.5

1.5
7.5

1.5
10.5

1.5

Maintenance labor and material costs were estimated as fractions of the initial capital cost for SOLSTEP modeling purposes. Except for concentrator and receiver maintenance fractions, the maintenance fractions that were estimated in a previous PNL study (Williams et al. 1987) were used again for similar components of dish, trough, and central receiver systems. The bowl concentrator maintenance fraction was reduced to reflect weekly automatic cleaning and the lack of maintenance-intensive drive and control components for the Cases I through IV concentrators. The iris system also employs an automatic cleaning system, but requires maintenance of the iris drive and tracking unit. Drive and control systems are required for bowl receivers, which increase their maintenance costs relative to non-tracking receivers. However, bowl systems do have an overall drive and control costs advantage by spreading the costs for these items (whether included in the concentrator or receiver account) over a larger mirror area. Finally, while periodic receiver tube repairs for cases I through IV were estimated to be similar (as a fraction of initial cost) to central receivers, maintenance of the iris heat pipe receiver was estimated to be two-thirds less because of the lack of multiple tubes exposed to the fluctuating solar thermal environment.

Bow] system 0\&M costs are summarized in Table 6.20 as a function of the number of bowls. The economy-of-scale shown for Cases I through IV can be attributed to the relatively fixed operating labor costs. Operating labor 
dominates the total 0\&M charge for small systems, but rapidly becomes less important for larger systems as its cost is spread over a larger field size. In contrast, operating labor is not nearly as important for the iris system. Iris system 0\&M is dominated by maintenance costs for the Stirling engine. The frequency and extent of repair required for the Stirling engine results in a maintenance cost fraction for this component that is roughly higher than for any other component.

TABLE 6.20. Bowl System 08M Costs

(1984\$; No-Storage Systems)

\begin{tabular}{|c|c|c|c|c|c|}
\hline $\begin{array}{c}\text { Power Level } \\
\text { MWe }\end{array}$ & $\begin{array}{l}\text { Number }(a) \\
\text { of Bowls }\end{array}$ & $\frac{\text { Cases }}{\$ 1000 \mathrm{~s} / \mathrm{yr}}$ & $\frac{-I V^{(b)}}{\$ / m^{2} / y r}$ & Iris & $\frac{\text { stem }}{\$ / \pi^{2} / y r}$ \\
\hline 0.5 & 1 & 419 & 139 & 106 & 28 \\
\hline 2 & 4 & 483 & 40 & 215 & 14 \\
\hline 10 & 20 & 791 & 13 & 789 & 10 \\
\hline 30 & 60 & 1557 & 9 & 2215 & 10 \\
\hline 100 & 200 & 4389 & 7 & 7196 & 10 \\
\hline
\end{tabular}

(a) Iris concentrator aperture $=3725 \mathrm{~m}^{2}$; Cases I and II concentrator apertures $=2923 \mathrm{~m}^{2} ;$ Cases III and IV concentrator aperture areas $=2956 \mathrm{~m}^{2}$.

(b) Costs presented are for Case II; costs for Cases I, III, and IV are similar. 


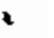

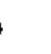




\subsection{SYSTEM RESULTS}

This chapter presents overall system results for each concept at various plant sizes and capacity factors. Definitions of plant design points and the way design points were selected are discussed in Section 7.1. Section 7.2 describes annual system efficiencies; plant capital, and operation and maintenance (O\&M) costs are examined in Section 7.3. Levelized energy costs (LEC) are presented and discussed in Section 7.4. System LEC results for the bowl concepts are compared with long-term goals established for solar thermal technology and with other solar thermal technologies in Section 7.5 .

\subsection{PLANT DESIGN POINTS}

Design-point information for a solar thermal plant specifies the physical features of the plant (such as concentrator field size), the output characteristics of the plant (such as the plant capacity), and the output characteristics based on meteorological assumptions. Many studies have applied different definitions to plant design-point specifications. The purpose of this section is to explain the plant design-point definitions used in this report so that the system results can be properly interpreted.

The plant power rating is defined as the maximum electrical output the plant will supply to the utility grid. The plant power rating is therefore not the same as the nominal capacity of the heat engine. For central engine plants (all cases except the iris-stirling concept) the heat engine capacity is greater than the plant power rating, so that the plant can supply full-rated power to the grid and also can supply the parasitic power requirements for the plant. For the iris-Stirling concept, which uses distributed engines, the installed heat engine capacity varies proportionally with collector field size. As the collector field size is varied by SOLSTEP during the plant optimization, the heat engine capacity is also varied. The results of the optimization for the iris-Stirling case were similar to the results for central heat engines in that the total installed capacity of the heat engines was higher than the plant power rating. 
The plant capacity factor is a dimensionless variable, which provides a representation of the total energy produced by the solar plant during the year. The definition of capacity factor used in this study is:

$$
\text { Capacity Factor }=\frac{\text { Annual Plant Electric Output }(\mathrm{kWh})}{\text { Plant Rating }(\mathrm{kW}) \star \text { Hours in Analysis Period (hr) }}
$$

Capacity factors reported include allowances for scheduled and unscheduled maintenance, both of which reduce the capacity factor which would be predicted based on $100 \%$ availability.

The optimal balance between the collector field size and storage capacity for a given plant rating and plant capacity factor is determined by the analysis code SOLSTEP. Rather than designing the plant based on an arbitrary design point (such as producing rated power at a specific insolation level), SOLSTEP is used for analyzing a number of alternative field sizes to determine the minimum LEC design for a given plant rating. For concepts which use energy storage (Cases II and IV) the code also analyzes different energy storage capacities, and then selects the plant designs which result in the minimum LEC for each plant capacity factor specified by the user.

In addition to selecting optimal plant designs for specific plant capacity factors, SOLSTEP also reports two special case design points. One of these cases is the "no-storage" plant design, which is the plant design that resulted in the lowest LEC. The no-storage design is not based on a specific solar multiple, but is selected on the basis of overall plant economics. The capacity factor which corresponds to no-storage designs varies among concepts because the economic and performance characteristics of each concept are different. For the same reasons, the capacity factor for no-storage designs can also vary for a single concept at different plant power ratings, because the performance and cost characteristics being optimized for the small plants can vary significantly from the characteristics for large plants.

The second special case design point reported by SOLSTEP is the optimal (or minimum) LEC case. This is the plant design that had the lowest LEC, regardless of the plant capacity factor. As with the no-storage design points, the capacity factor corresponding to the optimal LEC case varies significantly 
among the concepts and can also vary somewhat with power level for an individual concept. In comparing the minimum LEC results, it should be remembered that the systems may be at different capacity factors. Neither the no-storage nor the minimum LEC values in themselves provide a complete picture for comparing one solar concept with another, but together they provide a simple economic screening tool. In cases where the LECS of two concepts are close, the concepts should be compared for specific applications (specifying capacity factor, or energy load profile) to determine which is most economical.

All of the component and system performance results in this report are based on annual simulations (i.e., performance simulated over an entire year) unless stated otherwise. Weather data for Barstow, California in 1976 was used in the simulation.

\subsection{SYSTEM PERFORMANCE}

This section discusses overall system performance results. Section 7.2.1 presents an overview of system performance for the five concepts. Section 7.2.2 includes a more detailed description of system performance presented as efficiency "waterfall" bar charts.

\subsubsection{Overall Plant Efficiency}

This section presents plant annual efficiency results. The plant annual efficiency calculated by SOLSTEP is an operating efficiency, and assumes that the plant is available for operation during every time step in the analysis period. Allowances for plant down-time because of scheduled or unscheduled maintenance are accounted for in the LEC, but are not included in the calculation of annual efficiency. The annual efficiency is defined as:

$$
\text { Annual System Efficiency }=\frac{A E O}{A I * C A}
$$

where: $A I=$ annual direct normal insolation, $\mathrm{kWh} / \mathrm{m}^{2}$

$\mathrm{CA}=$ concentrator net aperture area, $\mathrm{m}^{2}$

AEO = plant annual energy output assuming $100 \%$ availability, kWh. 
Annual system efficiencies for no-storage cases for all five bowl concepts are summarized in Figure 7.1. All of the concepts using a central Rankine cycle heat engine (Cases I through IV) show decreases in overall system efficiency as plant sizes decrease. This trend is caused primarily by decreasing component efficiency in the heat engine for smaller turbine sizes. The efficiency of the iris-Stirling concept is constant over the range of plant sizes because of the modular heat engine design. Comparing the cases over the entire range of plant sizes, both systems using 60-degree concentrators had higher efficiencies that the cases using 30-degree concentrators because of the large difference in the concentrator efficiency. The water/steam (w/s) cases proved to have higher annual efficiencies than the salt cases because of the significant receiver thermal loss penalty for the salt receiver. The iris-stirling concept's system efficiency was poor over the entire range of plant sizes because of the low concentrator and receiver performance.

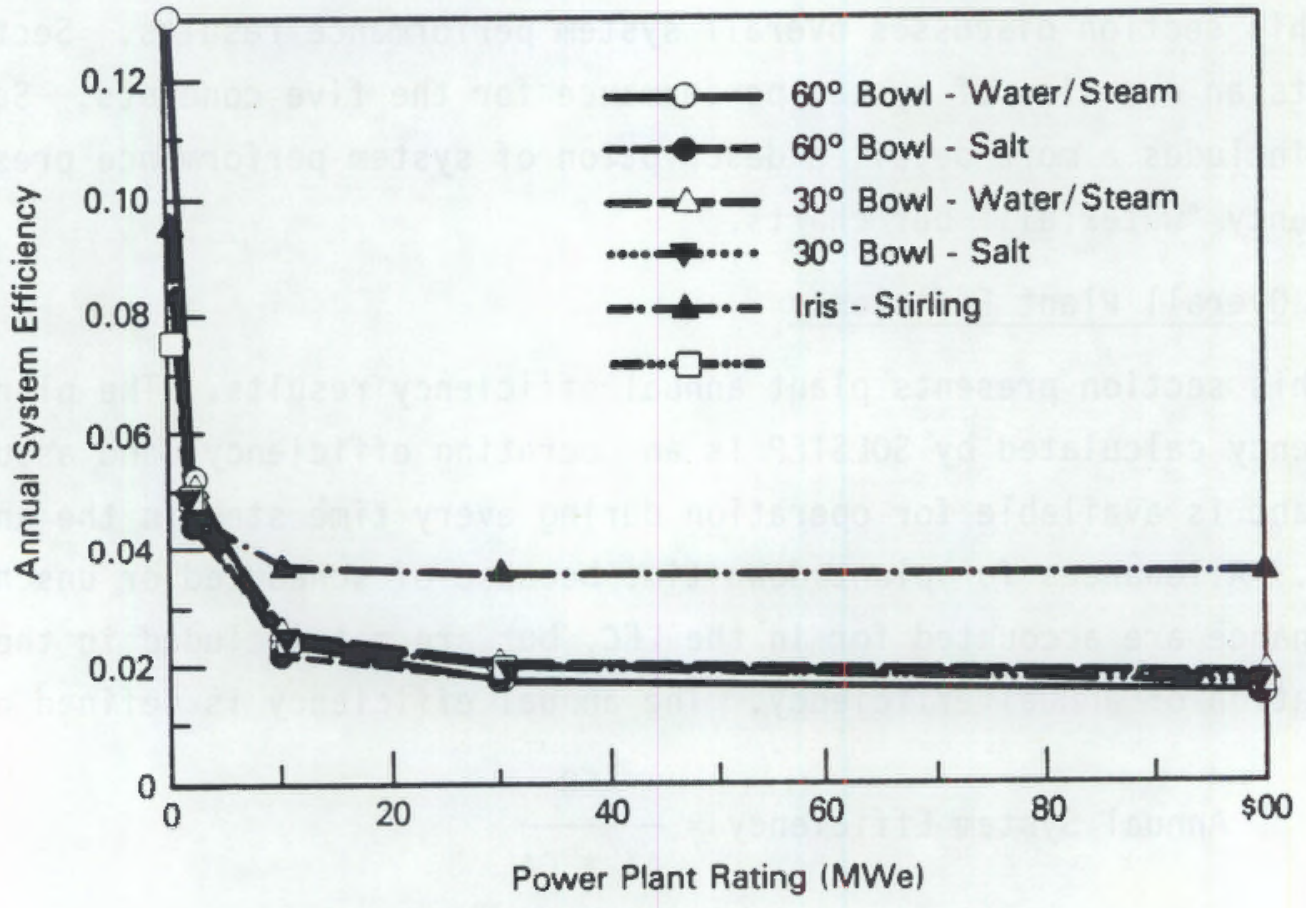

FIGURE 7.1. Annual System Efficiency for No-Storage Designs 
For the concepts that use energy storage, adding storage slightly increased the system annual efficiency through improvements in the turbine efficiency (reduced part load operation), reductions in turbine startup energy (fewer turbine shutdowns due to short cloud transients), and reduced conversion mismatch losses (discussed in the next section). For example, for the 60degree-salt system, including energy storage for the 100-MWe plant increased the annual system efficiency from $8.9 \%$ for the no-storage case to $10.3 \%$ for systems with several hours of energy storage.

\subsubsection{System Energy Losses}

The total energy that is produced by the plant and reaches the grid is the result of individual component efficiencies (annual component efficiencies are discussed in Chapter 5), general plant energy losses, and losses due to plant availability. These losses can be summarized in an energy loss "waterfall" diagram. Before discussing the waterfall diagrams for individual concepts, each of the major energy loss mechanisms associated with a solar powe plant will be defined.

Concentrator. Energy loss mechanisms included in the concentrator efficiency include cosine losses, blocking, shadowing, atmospheric attenuation, glass reflectivity, reflectivity degradation (due to dirt and long term permanent losses), solar tracking errors, and receiver spillage. The energy potentially available to the concentrator system is calculated as the product of the annual direct normal insolation times the concentrator net aperture area. By this definition, any insolation occurring at sun angles which cannot be used by the concentrator (low sun angles) is considered a concentrator loss. When comparing concentrator (or receiver) efficiency calculations from different sources, it should be remembered that many estimates define concentrator efficiency based on the insolation that can actually be used by the concentrator; this type of definition can result in misleading concentrator efficiencies, which are unrealistically high.

Receiver. Losses included in the receiver annual efficiency consist of all losses which occur from the time the flux impinges on the receiver 
surface until the thermal energy is transferred away from the receiver in a working fluid. The total energy potentially available to the receiver is the annual flux delivered from the concentrator (incident insolation less all concentrator losses). Receiver losses include reflective losses and thermal losses due to radiation, convection, and conduction. An important aspect from the standpoint of characterizing annual performance is that receiver thermal losses continue even in no-insolation periods until the receiver reaches ambient temperature; an example is nighttime cool-down. Receiver thermal losses during periods with no insolation result in potentially useful energy being used to warm the receiver to operating temperature when the plant begins operation.

Transport. Thermal transport subsystems include losses from the time the working fluid leaves the receiver to the time the thermal energy is delivered to either the storage subsystem or the energy conversion subsystem. The total input energy to the thermal transport system is the annual energy absorbed by the working fluid in the receiver. For thermal transport systems, losses include only the heat losses from the piping: parasitic losses due to pumping power requirements and any heat tracing requirements are accounted for in plant parasitics. For the electric energy transport system used with the iris-Stirling concept, the efficiency includes the effect of losses between the distributed generators and the point where the plant exports power to the grid. The total energy input used in the transport efficiency calculation for the iris-Stirling concept is the annual energy output from all the distributed generators.

Conversion Mismatch. Conversion mismatch losses account for any thermal energy which exceeds the maximum input rate to the heat engine and therefore cannot be used to produce energy. For systems without thermal energy storage, conversion mismatch losses occur any time collected energy from the field would exceed the current (based on ambient conditions) full load input requirements of the heat engine. Systems with thermal energy storage can dispatch energy to storage when power from the field exceeds the maximum heat engine input, and therefore have more flexibility 
in reducing conversion mismatch losses. For systems with thermal energy storage, conversion mismatch losses would occur only after storage had been fully charged and the thermal input requirements of the heat engine were exceeded. Conversion mismatch losses could be avoided entirely by selecting a heat engine with a maximum thermal input equal to the maximum thermal output from the collector field; however, such an approach does not represent a cost effective plant design strategy.

Storage. Performance of thermal storage subsystems includes thermal losses from the time thermal energy is delivered to the input heat exchanger (or storage tank itself if an input heat exchanger is not required) to the time energy is removed through the output heat exchanger. This section provides a discussion of the no-storage cases only, therefore, storage losses are not shown on the waterfall energy loss charts.

Heat Engine Start Up. This category of losses includes all of the thermal energy used to initially warm the heat engine, ramp it to full speed, and bring it into synchronization with the grid.

Conversion. Energy conversion efficiency includes all losses related to the thermodynamic performance of the heat engine, heat rejection equipment, and the generator. The heat engine efficiency reported in this report is an operating efficiency, which is calculated based on the actual energy delivered to the heat engine during operating periods; losses because of conversion mismatch during start up are accounted for in the above categories. Conversion losses do not include parasitic power requirements for the heat engine, which are included with plant parasitics.

Plant Parasitics. These losses include the electric power requirements for the solar plant during operational periods and periods when the plant is shut down. These parasitics include:

- heat engine - Rankine cycle heat engine parasitics include the feed pump, condensate pump, circulation water pump, condenser vacuum pump, turbine controls, bearing cooling water, gland seal condenser, and cooling tower fans. For the Stirling engines the parasitics account for cooling fan power requirements. 
- energy storage - Parasitics include storage input and output pumps for thermal storage systems, and any heat tracing requirements.

- energy transport - Parasitics for thermal transport systems include power required for the main field circulation pump (and any booster pumps) and for field recirculation pumps (used in water-steam systems to recirculate condensate). Where required, parasitic loads for transport heat tracing are also included. Electric energy losses for electric transport systems are accounted for in the transport efficiency and not as parasitics.

- miscellaneous operating parasitics - These parasitics include concentrator tracking power requirements, water treatment system, service water system, and heating, ventilation, and air conditioning (HVAC) and master control system.

- standby parasitics - Standby power requirements are incurred while the plant is not operating. They include any concentrator standby power and receiver circulation power requirements, receiver heat tracing, turbine bearing cooling water, service water, cooling tower fan (for seal steam), HVAC, lighting, plant control system, and any miscellaneous uses.

Turbine Standby. These are electrical parasitic power requirements associated with the Rankine cycle heat engine standby requirement including turbine turning power, circulation pumps for standby steam, and $\mathrm{gland}$ seal steam.

Availability. Availability losses represent the loss of output caused by scheduled and unscheduled plant outages.

The various loss mechanisms associated with each plant design are summarized on a plant energy loss "waterfall" chart. The "waterfall" charts show the impact of the significant losses on annual performance. For example, Figure 7.2 is an energy loss "waterfall" chart for a 100 -MWe, 60-degree-w/s concept with a concentrator net aperture area of $561,150 \mathrm{~m}^{2}$. The bar on the left shows the total annual energy available in the insolation, if they were always directly oriented toward the sun through the entire year. The bars to 
the right show the impact of various loss mechanisms on the useful energy. The waterfall charts shown in this section do not exactly match the system efficiency graphs for the no-storage cases for two reasons: 1) the waterfall charts are presented for slightly different field sizes than for the no-storage results; the number of bowls (192) was standardized for the waterfall charts to highlight differences between the concepts, 2) the waterfall charts include energy losses from plant availability but, as discussed in the previous section, availability is not included in the system efficiency results. Consequently, the factors given in Figures 7.2 through 7.6 do not match the overall efficiencies reported in Table 1.1 and Figure 7.1 .

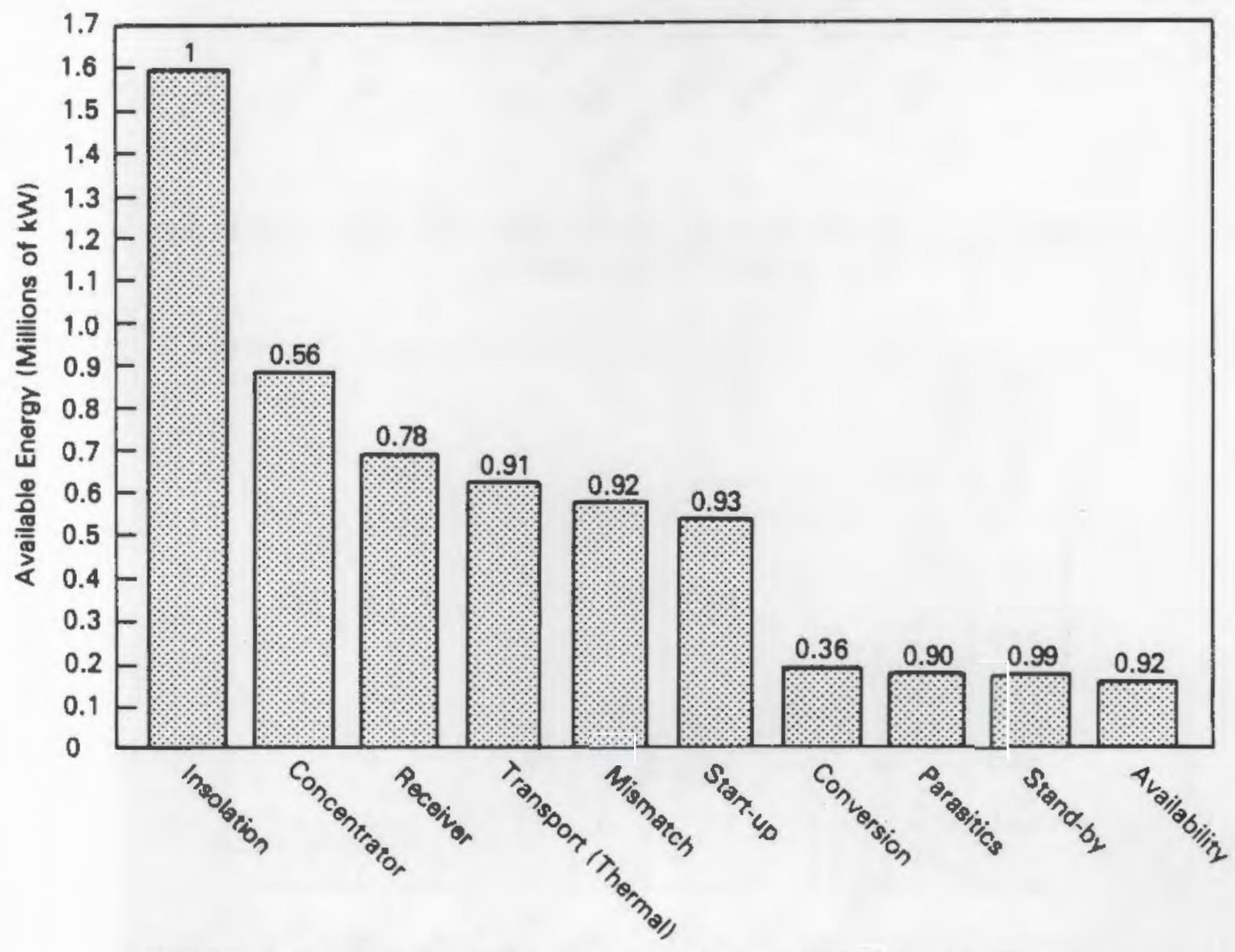

FIGURE 7.2. Annual Energy Losses for a 100-MWe, 60-DegreeWater/Steam Plant with 192 Bowls 


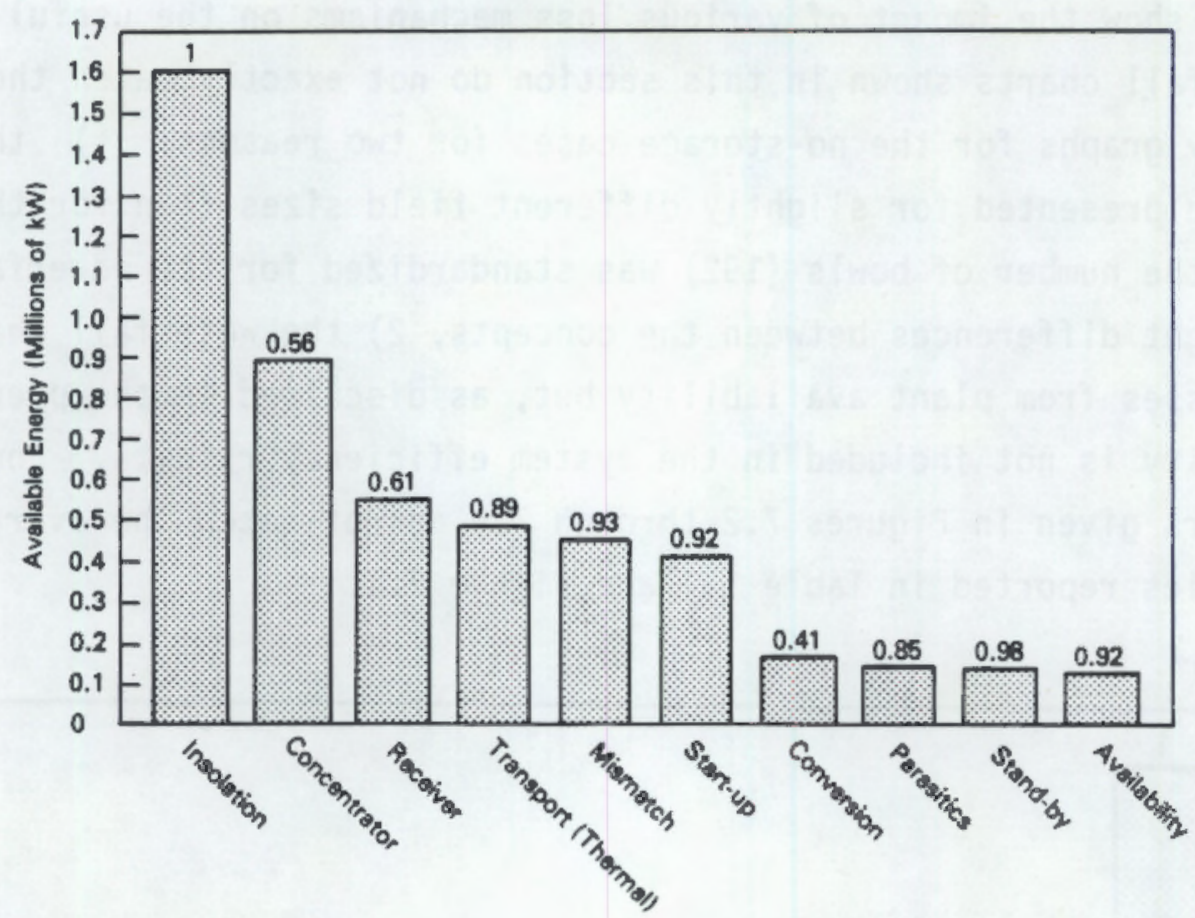

FIGURE 7.3. Annual Energy Losses for a 100-MWe, 60-DegreeSalt Plant with 192 Bowls

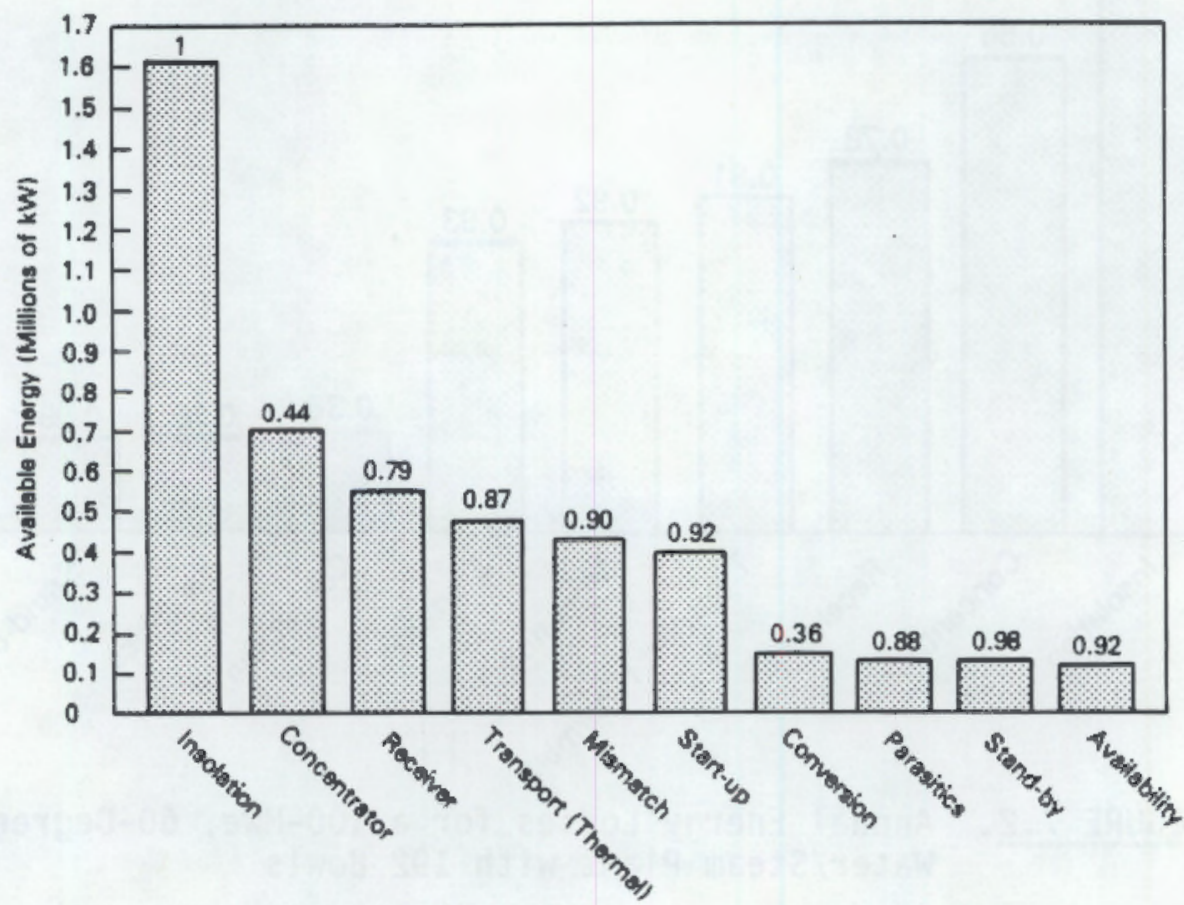

FIGURE 7.4. Annual Energy Losses for a 100-MWe, 30-DegreeWater/Steam Plant with 192 Bowls 


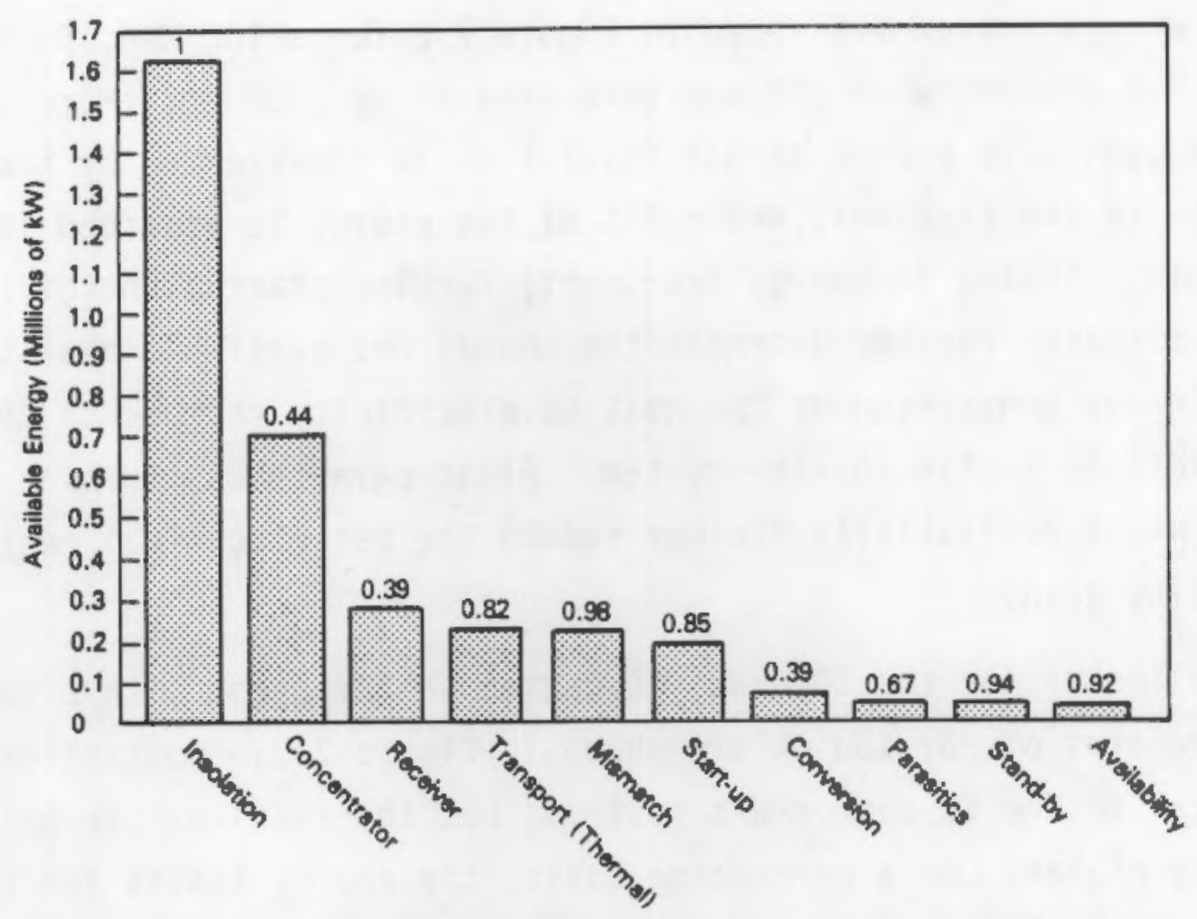

FIGURE 7.5. Annual Energy Losses for a 100-MWe, 30-DegreeSalt Plant with 192 Bowls

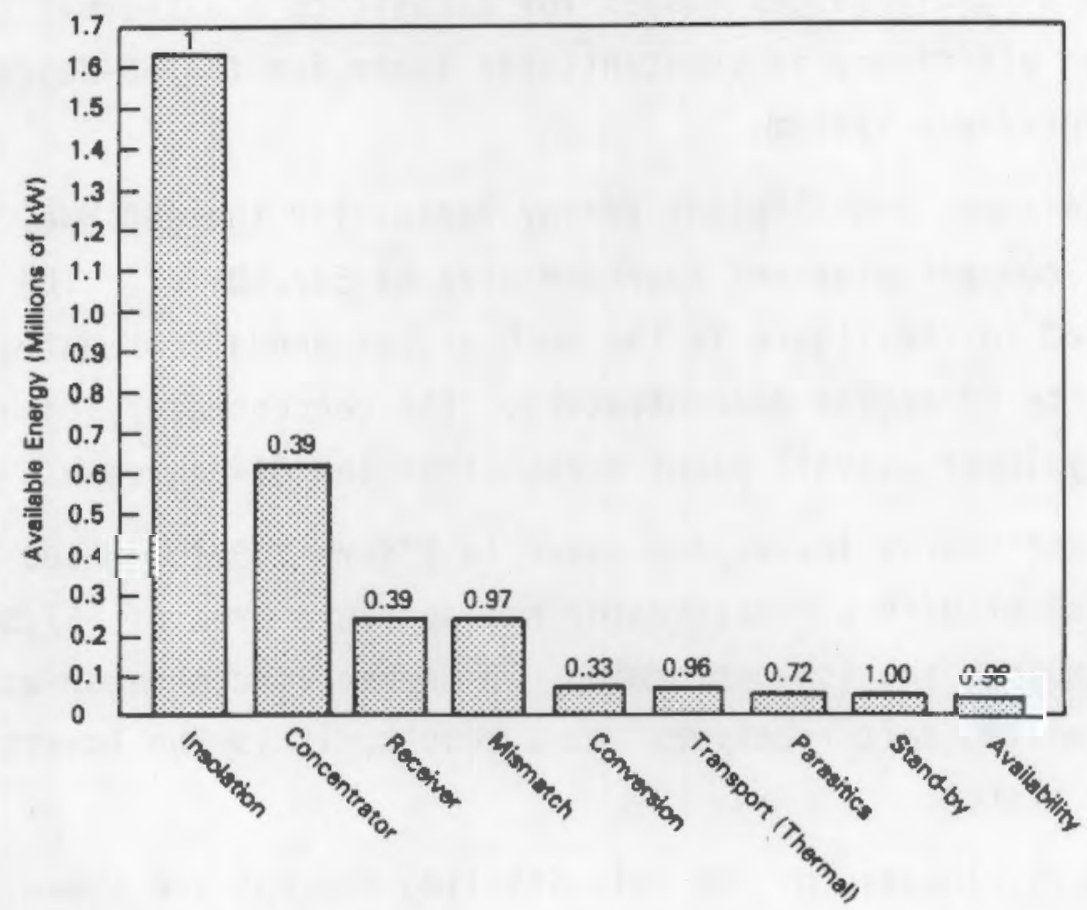

FIGURE 7.6. Annual Energy Losses for a 100-MWe, 30 iris-Stirling Plant with 192 Bowls 
Plant energy losses are shown in Figure 7.2 for a 100-MWe, 60-degree-w/s concept with a concentrator net aperture area of $561,150 \mathrm{~m}^{2}$. More than onehalf of the available direct normal insolation is transferred by the concentrator to the receiver, where $78 \%$ of the energy is absorbed into the working fluid. Losses in energy transport, turbine startup energy, and conversion mismatch further decrease the annual net available heat to the turbine. Energy conversion of the heat to electricity represents the biggest single efficiency factor for the system. Plant parasitics, turbine standby power, and plant availability further reduce the net electrical energy available to the utility grid.

Energy losses for the 100-MWe, 60-degree-salt concept with a concentrator net aperture area of $561,150 \mathrm{~m}^{2}$ are shown in Figure 7.3. Concentrator losses are identical to the 60 -degree-w/s systems, but the receiver thermal losses are dramatically higher. On a percentage basis, the energy losses for thermal transport and plant parasitics are slightly higher for the 60-degree-salt case than for the 60 -degree-w/s concept. The result of the much higher receiver losses and the slightly larger losses for parasitics and thermal transport is that the system efficiency is substantially lower for the 60-degree-salt system than the 60 -degree-w/s system.

Figure 7.4 shows annual plant energy losses for the 100-MWe, 30-degree-w/s concept with a concentrator net aperture area of $567,501 \mathrm{~m}^{2}$. The most striking feature revealed in the figure is the much higher annual concentrator losses compared with the 60-degree concentrators. The concentrator losses result in a significantly lower overall plant output than the 60 -degree-w/s concept.

Annual plant energy losses are shown in Figure 7.5 for a 100-MWe, 30degree-salt concept with a concentrator net aperture area of $567,501 \mathrm{~m}^{2}$. This system combines the low-performing, 30-degree concentrator with the high losses of the molten salt receiver. As a result, it is the lowest performing central engine system.

Annual energy losses for the iris-Stirling concept are shown in Figure 7.6 for a 100 -MWe system with a concentrator net aperture area of $572,119 \mathrm{~m}^{2}$. 
The large amount of concentrator energy losses are because of spillage associated with the short receiver used in this concept. Even with the short receiver length, receiver thermal losses are quite high for this concept because of the high-temperature isothermal receiver. The concentrator and receiver losses are dominant reasons for the poor annual system performance.

\subsection{SYSTEM CAPITAL AND O\&M COST RESULTS}

This section presents information on the initial capital costs and annual system 0\&M costs for the bowl systems. The total initial capital cost versus the system power rating is plotted in Figure 7.7 for the no-storage systems. The iris-Stirling system has the lowest initial capital cost of any of the concepts. All of the systems exhibit economies-of-scale, although in different magnitudes. The central engine concepts (Cases I through IV) exhibit the greatest reduction in unit costs $(\$ / \mathrm{kW})$ with plant size. This occurs because as these systems are increased in size their respective energy conversion systems and other centralized components benefit greatly from economies-ofscale in component cost, which reduces the power plant's unit cost. Conversely, the iris-stirling system is not affected as much by economies-of-scale, because most of its components are distributed, and therefore, the number of these components increases proportionally as the plant size increases. For example, the energy conversion system of the iris-stirling scales linearly with the collector field size because the engines are built into the receiver.

It is important to realize that the system which is least expensive initially is not necessarily the most cost effective alternative. As an example, the initial capital cost of the iris-Stirling system is the least expensive of the bowl concepts, but has significantly higher costs for annual 0\&M. The Mylar liner (see concentrator descriptions in Chapter 6) must be replaced periodically and the cost of this replacement is not represented in these initial capital cost comparisons. The annual maintenance/replacement cost of the Stirling engines is also quite high. The best indicator of economic viability is the LEC, which is presented in Section 7.4. 


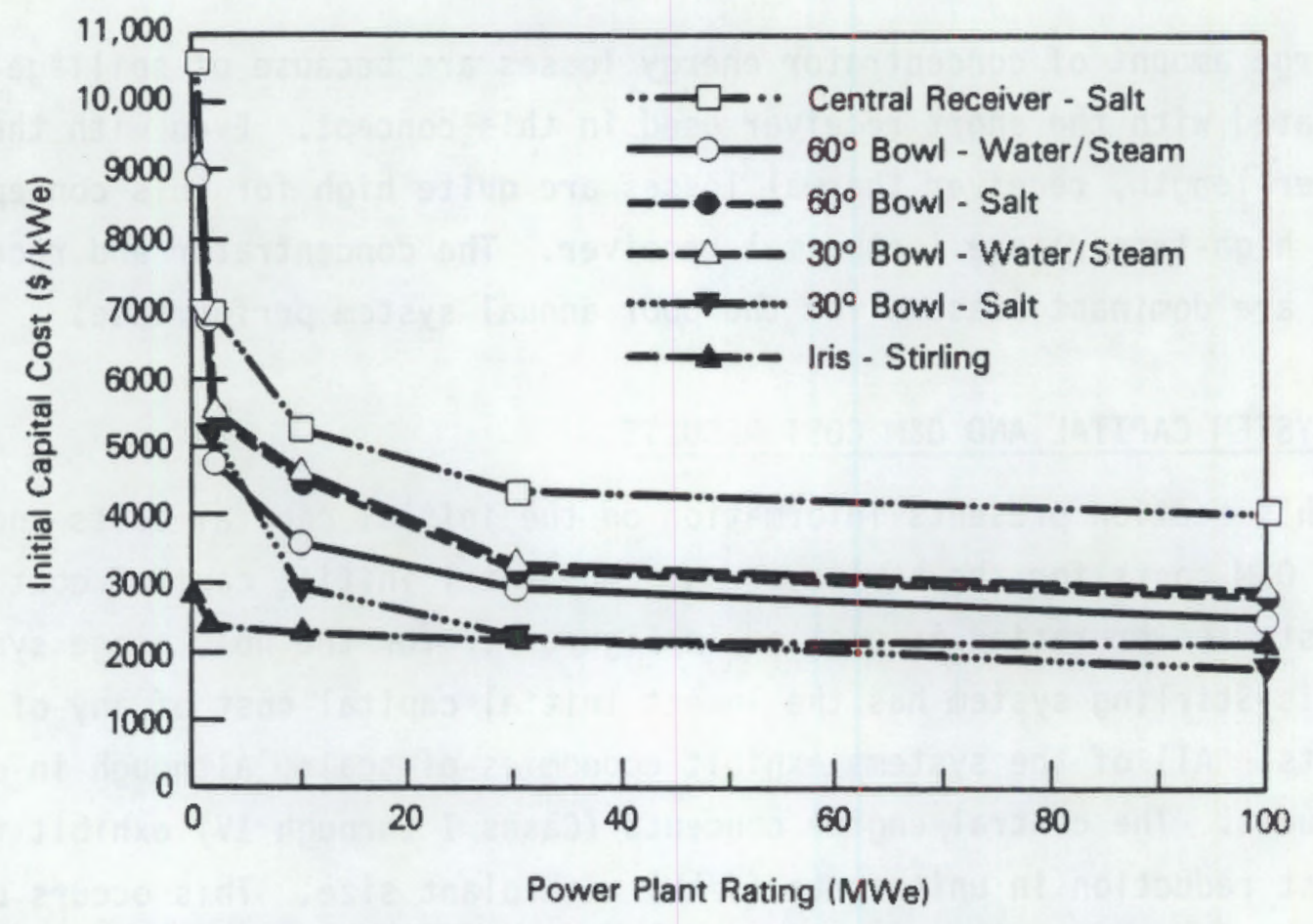

FIGURE 7.7. Initial Capital Cost of No-Storage Designs

Figure 7.8 shows how $0 \& M$ costs, expressed as a fraction of the initial capital cost, change for the no-storage systems as plant size increases. In relative terms, all of the concepts have significantly higher charges for 0\&M at smaller plant sizes. The 08M costs of the four central engine concepts (Cases I through IV) are all similar. Because of charges for Stirling engine maintenance, the annual O\&M costs for the iris-Stirling case are higher than for the other concepts.

\subsection{SYSTEM LEC RESULTS}

System LEC as a function of power level is shown in Figure 7.9 for each of the technologies at no-storage conditions. An additional detail in the LEC of the concepts is shown in Figure 7.10, which uses an expanded scale. The LEC, like plant capital cost, shows strong economies-of-scale, with the energy cost for the very small plants substantially higher than for the larger plants. The smaller plants have higher energy costs because of the higher unit costs and lower system efficiencies that occur at the small plant sizes. 


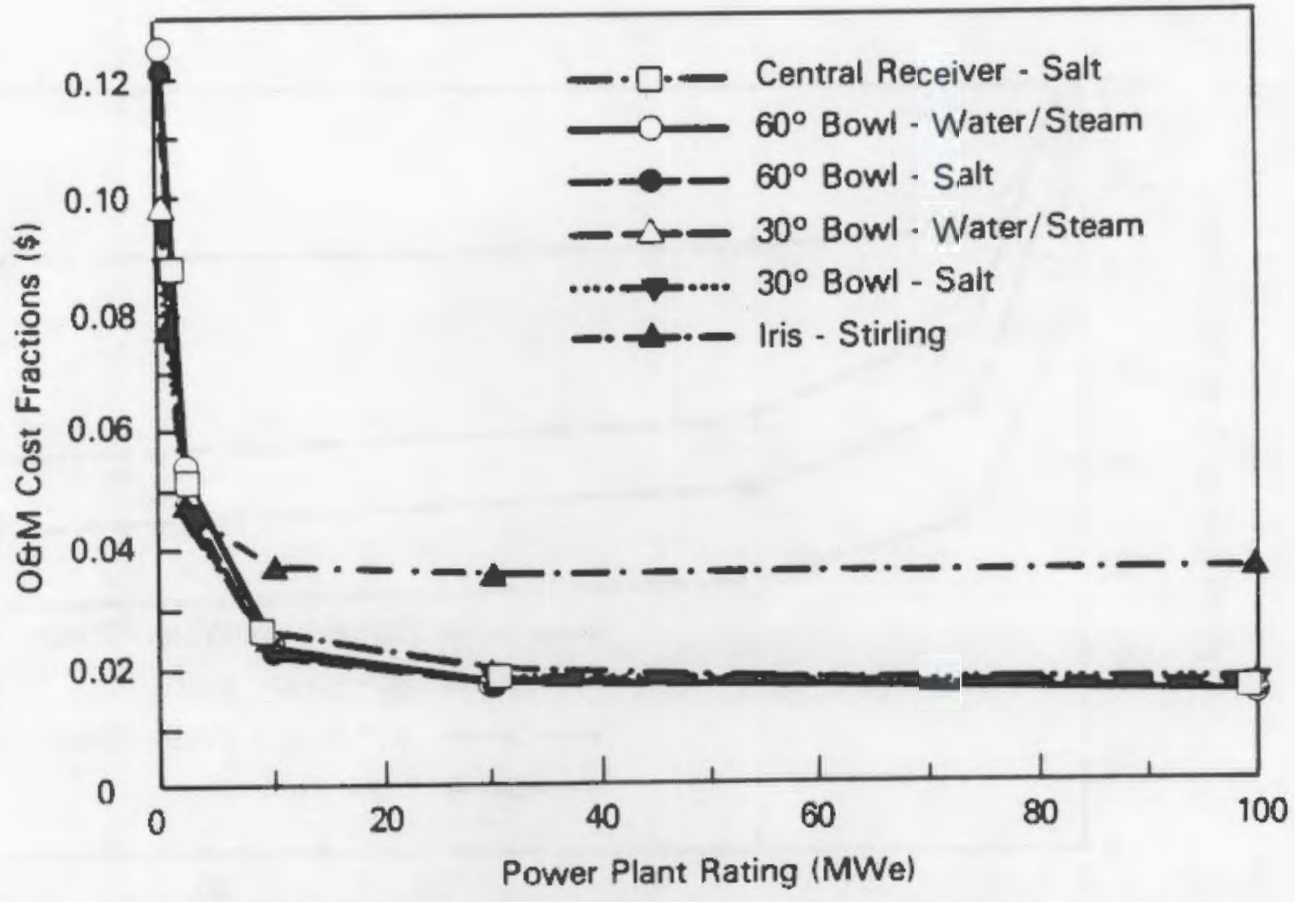

FIGURE 7.8. O\&M Cost Fractions of No-Storage Designs

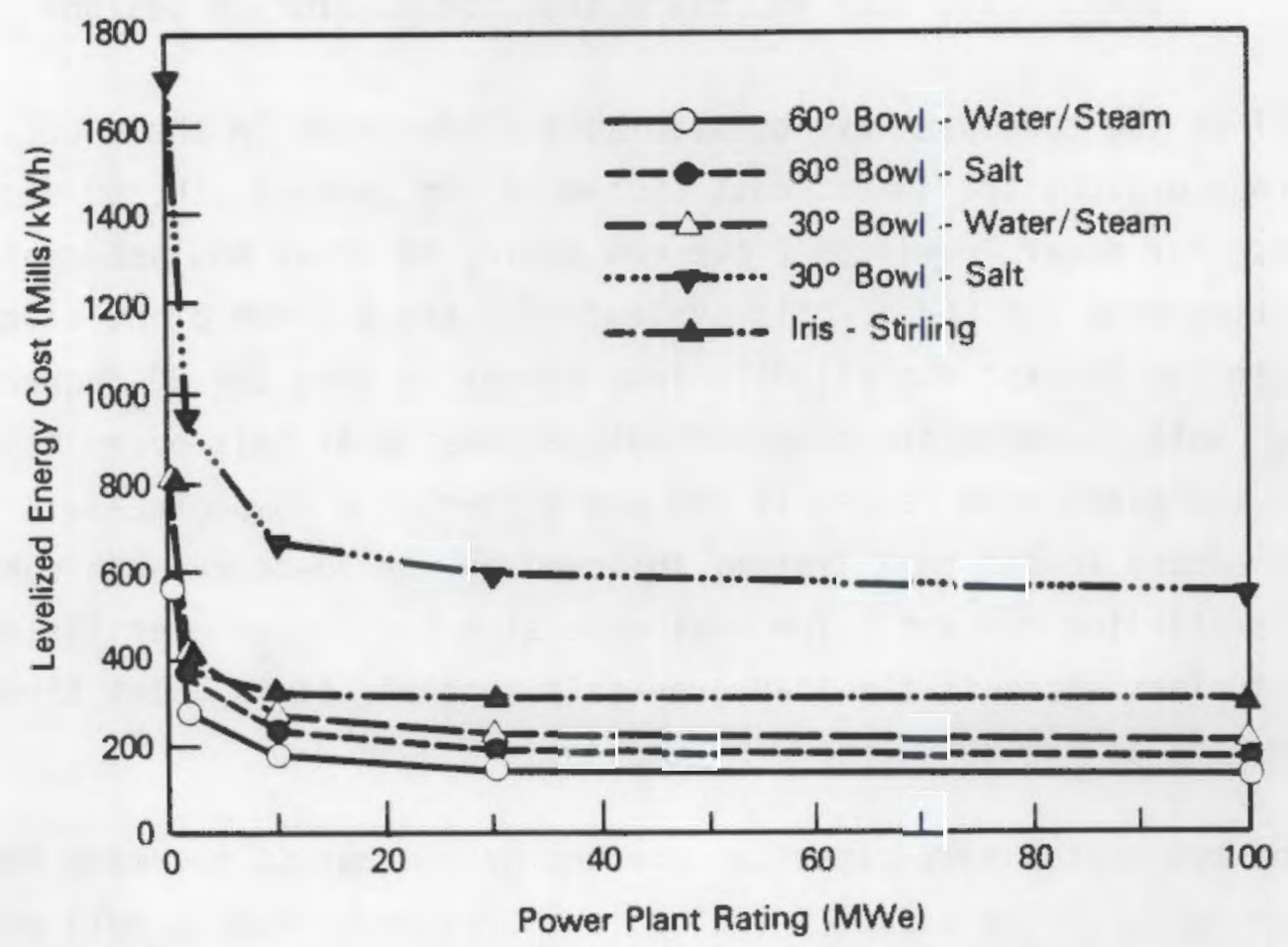

FIGURE 7.9. LEC vs. Plant Size for No-Storage Designs 


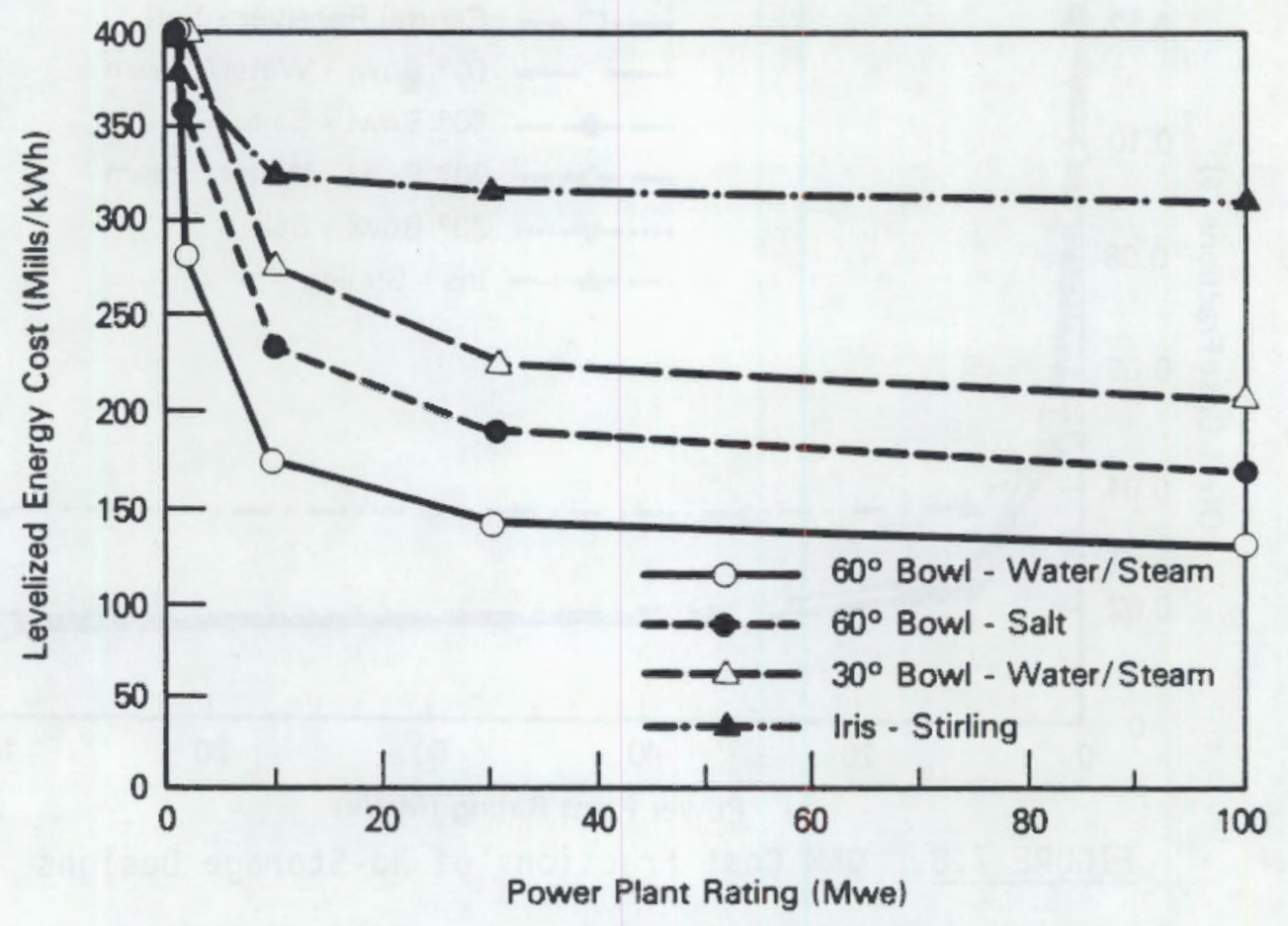

FIGURE 7.10. LEC vs. Plant Size for No-Storage Designs

All of the concepts have considerable differences in their LEC. For the no-storage designs the lowest cost system is, in general, the 60-degree-w/s concept. For power levels of 2 MWe and above, no other bowl concept is competitive with the LEC of this system. For the 0.5-MWe plant size, the iris-Stirling concept was slightly less expensive than the 60 -degree-w/s, although both concepts are prohibitively expensive at this power level. Over most of the plant size ranges (2 MWe and higher) the 60-degree-salt concept was the second lowest cost system, followed by the 30-degree-w/s concept and the iris-stirling concept. The most expensive LEC system over the entire range of plant sizes is the 30-degree-salt concept; it is about three times as expensive as the 60 -degree-w/s concept.

The two molten salt cases can use energy storage to increase the plant capacity factor. The capacity factor is increased by adding both collection and energy storage capacity. Increasing the capacity factor reduces the LEC of both salt systems by capturing economies-of-scale in some of the collection 
components, and by spreading fixed energy conversion costs and fixed plant parasitics over a larger annual power output. Figure 7.11 shows the energy cost of the minimum LEC systems, and Figure 7.12 shows the same results on an expanded scale. The LEC results shown for the water/steam and irisStirling cases are the same as for the no-storage cases, while the LEC of the molten salt cases is significantly lower. At the 100-MWe plant size, the 60 -degree-w/s system remains the lowest LEC case, although the difference between it and the 60-degree-salt case is not extreme. At power levels below $10 \mathrm{MWe}$, the 60-degree-salt system is slightly less expensive than the 60-degree$\mathrm{w} / \mathrm{s}$ system. The 30 -degree-salt system is still the most expensive concept over the entire range of power plant sizes that were analyzed.

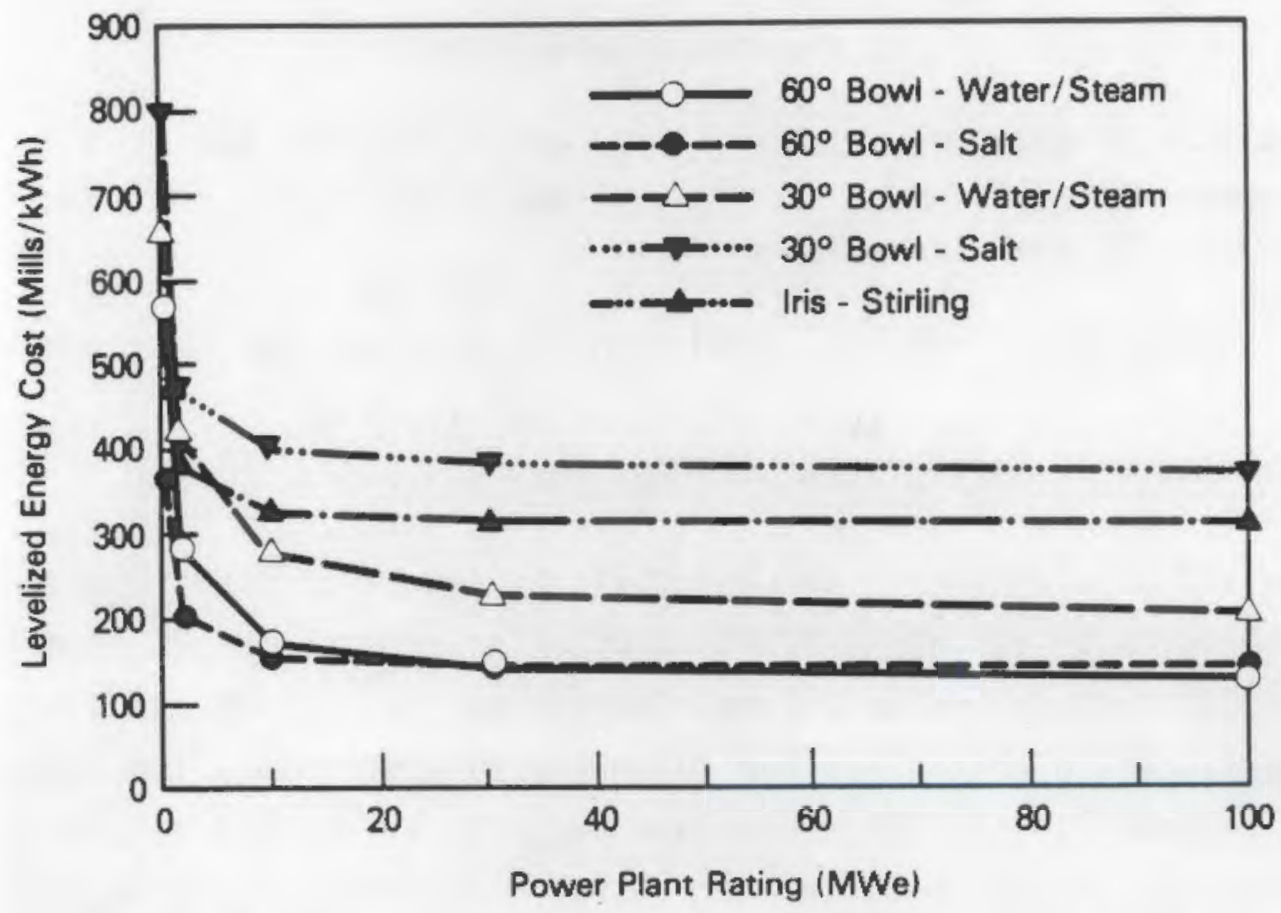

FIGURE 7.11. LEC vs. Plant Size for Minimum LEC Designs 

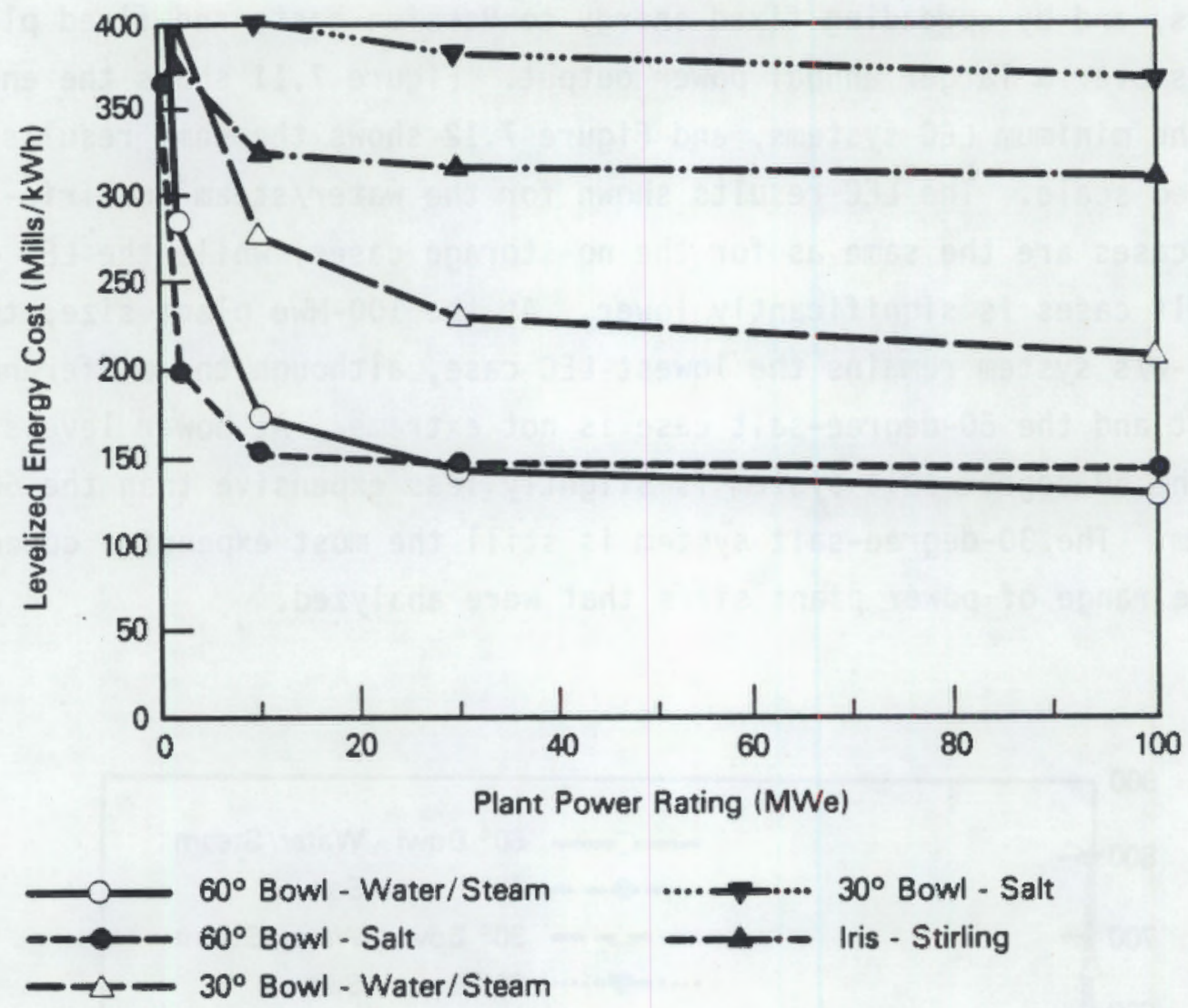

FIGURE 7.12. LEC vs. Plant Size for Minimum LEC Designs

\subsection{COMPARISON WITH SOLAR THERMAL ENERGY COST GOALS}

As an aid to planning research activities needed to make solar thermal energy a technically and economically attractive option, the US Department of Energy's (DOE) National Solar Thermal Technology Program has established longterm performance and cost goals for solar thermal technology (DOE 1986). The goals are intended to provide achievable targets, which when met, would result in the widespread usage of solar thermal technologies in the marketplace. This section compares the LEC results for the bowl concepts analyzed in this study with the long-term DOE system LEC goals for electricity applications.

The DOE long-term LEC for solar thermal electricity applications has been established at 50 mills/kWh (DOE 1986). This goal, which is felt to be achievable by the use of central receiver and dish technologies, would result 
in solar thermal electricity being economically competitive with a wide range of conventional energy sources.

The economic approach used to calculate system LECs in this study is in agreement with the approach used in calculating the DOE long-term energy cost goal. There are several areas however where the assumptions/results of this study are fundamentally different from those used for the DOE goals. These differences are:

insolation. The DOE long-term goals are based on an annual insolation assumption of $2690 \mathrm{kWh} / \mathrm{m}^{2}$. The results of this study are based on 1976 Barstow, California insolation, which recorded direct normal insolation of $2848 \mathrm{kWh} / \mathrm{m}^{2}$.

availability. The DOE long-term goals assume $100 \%$ plant availability in the calculation of LECS. The results of this study assume varying degrees of plant availability for each concept in calculating the LEC; a typical availability factor is 0.92 .

indirect and contingency costs. The DOE long-term goals assume a $20 \%$ rate for indirect and contingency costs in calculating system installed costs. The estimate of indirect and contingency costs developed for this study was $35 \%$.

The lowest LEC achieved by any of the bowl concepts was $130 \mathrm{mill} / \mathrm{s} / \mathrm{kWh}$ for the 60 -degree-w/s case at 100 -MWe plant size; this is more than twice the level of the DOE long-term LEC goal. For a sensitivity analysis, the LEC for the 60 -degree-w/s case was recalculated after adjusting insolation, availability, and indirect and contingency costs to mirror the assumptions in the DOE long-term goals. The result of this analysis was an LEC of roughly $120 \mathrm{mills} / \mathrm{kWh}$, still more than twice the value of the goal.

\subsection{COMPARISON WITH OTHER SOLAR THERMAL CONCEPTS}

The no-storage LECS of the five bowl concepts are compared with the nostorage LEC for a molten salt cavity central receiver with salt storage (CRsalt) and a parabolic dish with stirling engine (dish) in Figure 7.13. 

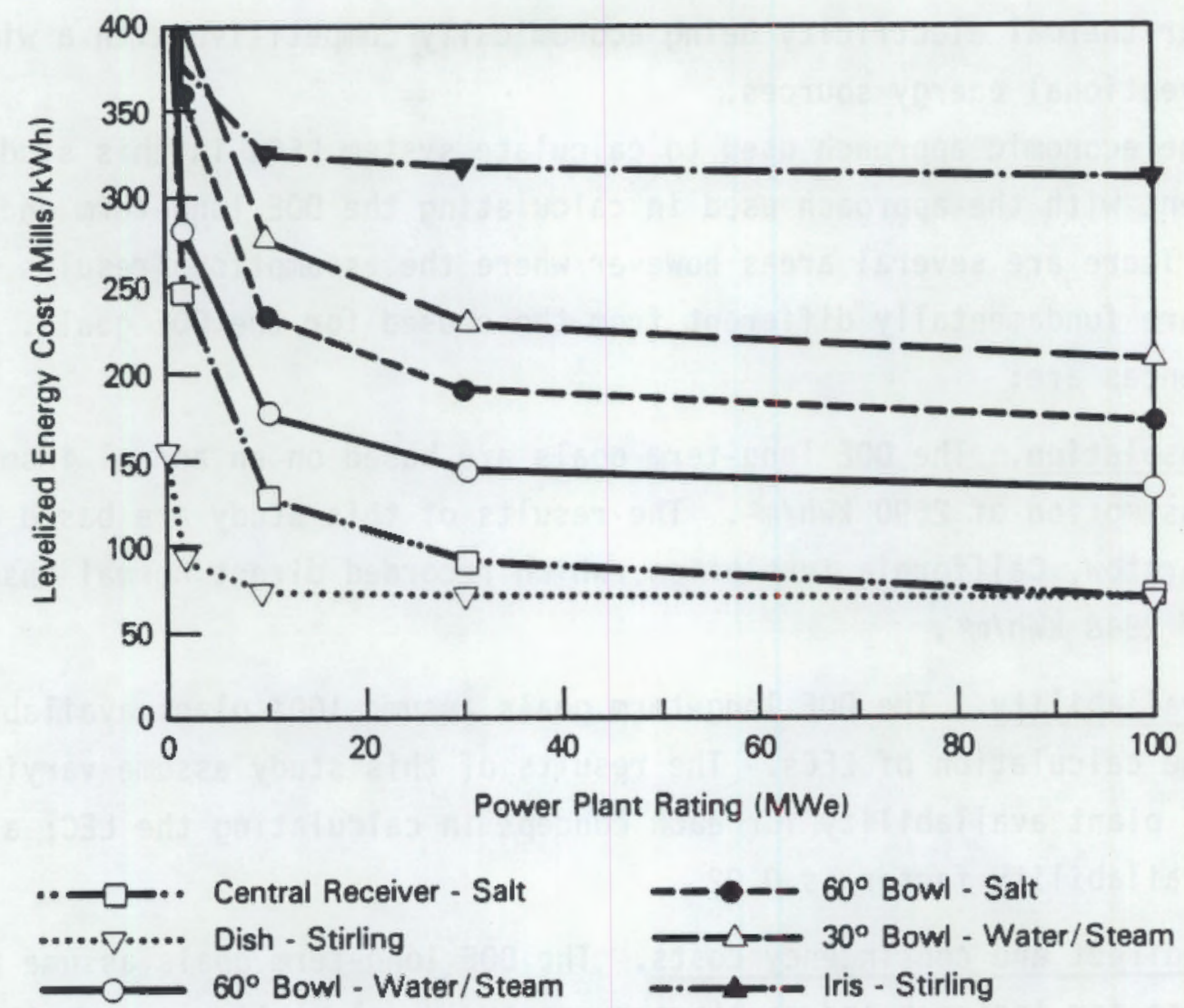

FIGURE 7.13. LEC for Bowls, Central Receiver-Salt and Dish-Stirling No-Storage Designs

The projections for the other solar technologies are taken from data developed in a companion document which analyzed the concepts using identical approaches, assumptions, and ground rules to those used in this evaluation (Williams et al. 1987). Over nearly all the range of plant sizes considered (2 MWe and above), both the dish and CR-salt systems are much less expensive than any of the bowl technologies considered. At the 0.5-MWe size, the dish system has a large LEC advantage over any of the other solar technologies. At the 100-MWe plant size, the LEC of the CR-salt system and the dish system are comparable.

The minimum LEC of the five bowl concepts is compared with the minimum LEC for the CR-salt and dish concepts in Figure 7.14. The minimum LEC of the CRsalt system is reduced significantly from the LEC of the no-storage case, so that the CR-salt concept has a slightly lower LEC than the dish at 100 MWe. The dish still shows advantages over the CR-salt system at plant sizes of 
10 MWe and below. Once again, over plant sizes of 2 MWe and above, both the dish and CR-salt system are much less expensive than any of the bowl technologies considered. At the 0.5-MWe plant size the dish system exhibits extremely large LEC advantages over the other technologies.

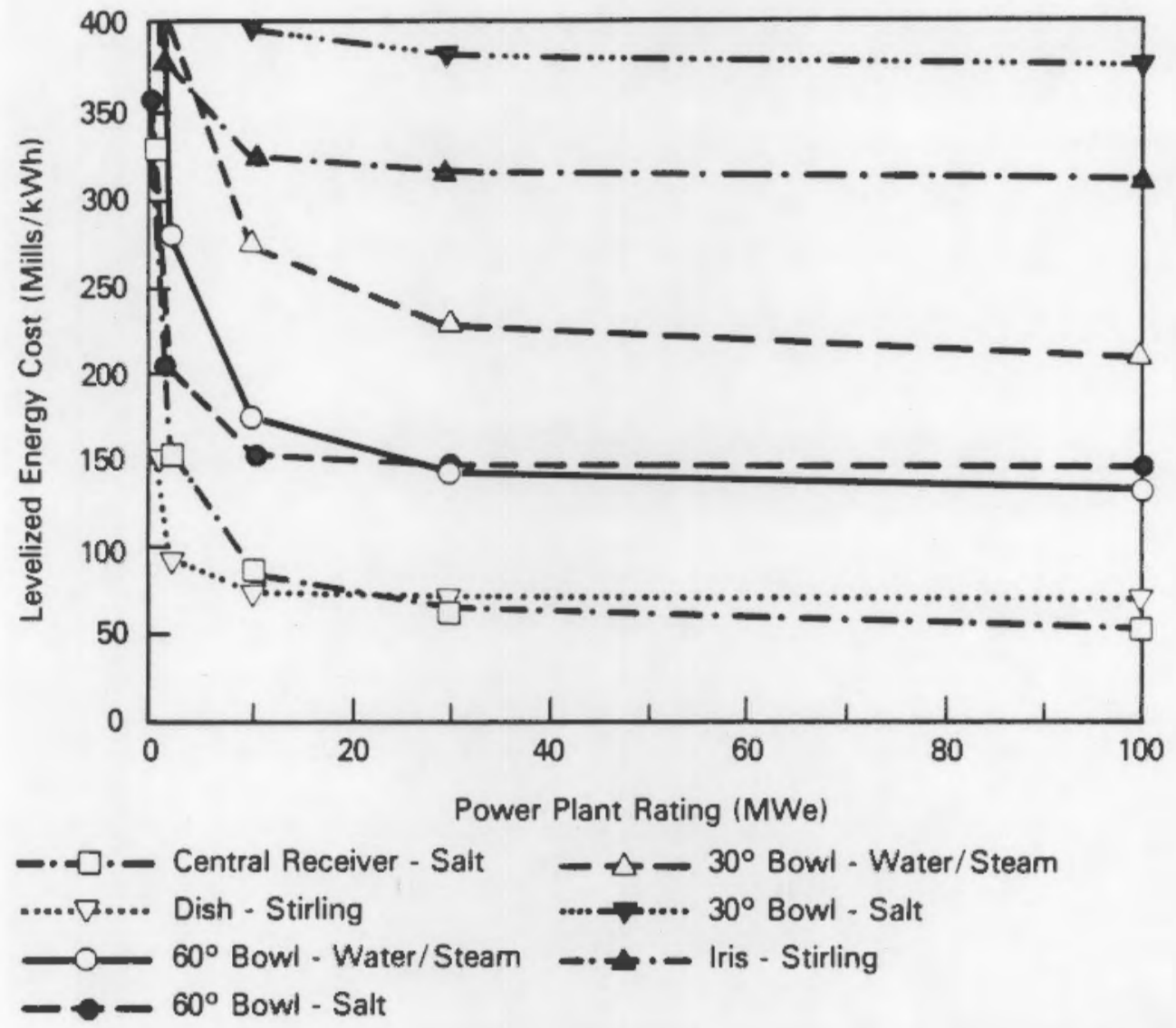

FIGURE 7.14. Minimum LEC for Bowls, Central Receiver-Salt, and Dish-Stirling 



\subsection{SENSITIVITY ANALYSES}

This chapter presents various sensitivity analyses for key uncertainty factors of the bowl concepts that could affect the levelized energy cost (LEC) results. The primary focus of the chapter is on the elements of uncertainty that could potentially reduce the LECs of the bowl concepts, because the results of the study indicated they would not be competitive with the best solar thermal electric technologies. Areas of uncertainty which might increase the bow 1 concepts' LECs are not specifically addressed. Specific performance analysis sensitivities are discussed in Section 8.1 and cost analysis uncertainties are addressed in more general terms in Section 8.2. The impact on system LEC of four specific alternative concentrator designs is discussed in Section 8.3, along with the general sensitivity of solar thermal system LEC to concentrator and receiver cost reductions.

\subsection{KEY PERFORMANCE ANALYSIS UNCERTAINTIES}

The area with the highest uncertainty in the performance analysis is the receiver thermal loss analysis which is discussed in Section 8.1.1. The remainder of the performance analysis also has some uncertainty associated with it, but these areas do not require special consideration because one of the following conditions exist:

- the uncertainty is small

- the uncertainty is large but the parameter is relatively unimportant (i.e., even a large change in the parameter would not effect the overall system performance)

- the uncertainty is large but one sided (could only decrease the system performance).

For the concentrator system the major uncertainty is associated with the spillage estimate. No adjustment was made for wind effects. At even moderate winds, the receiver would have difficulty maintaining the position that minimizes spillage. For the other parameters that make up the concentrator 
performance, the uncertainties are either very small or the parameters are relatively unimportant.

The receiver optical performance is highly uncertain. The maximum absorptivity that could be expected is about 0.96 (the value that was used). However, the majority of the flux on the receiver occurs at incident angles different than zero. In fact, in the area of highest flux concentration the reflected energy is striking the receiver at low angles which would increase the reflectivity of the receiver. Texas Tech University (TTU) claims that their test receiver at the ADVS has an absorptivity of 0.90 , irrespective of the flux angle of incidence (Simpson, O'Hair and Reichert 1981). It is almost certain that the actual absorptivity would be lower than the value used in this analysis; this would tend to decrease the system performance and increase the LEC.

The remaining subsystems (transport, storage, and energy conversion) have well-defined loss mechanisms that determine their performance. Therefore, the uncertainty of their performance characterization is low, and any error is likely to be small and should have only minimal effect on the overall plant performance.

\subsubsection{Receiver Thermal Losses}

The computer code developed (during this study) to calculate heat losses by convection and radiation for Case III was able to predict a temperature profile similar to the input received from TTU for the Case I receiver. To check the method, the profile for Case III was used to calculate a THRLSS (a) value by using the piecewise method of Case I. This calculation gave a THRLSS of $0.07 \mathrm{~kW} / \mathrm{m}^{2}$, a value that is within $10 \%$ of the $0.063 \mathrm{~kW} / \mathrm{m}^{2}$ value obtained from the code. This tends to verify the method used in Case I, but does not prove that the code did indeed generate the correct thermal profile. The profile is, however, similar to that generated by a totally independent code used by TTU for case I. Therefore, the THRLSS value from the computer code can be used

(a) THRLSS is a SOLSTEP input variable, and is defined as the design-point receiver thermal losses $(\mathrm{kW})$ divided by the concentrator aperture area $\left(m^{2}\right)$. 
with a degree of confidence. Sensitivity studies of the THRLSS effect in SOLSTEP cover the range of uncertainty of the loss values. Heat transfer calculations can have an error of up to $20 \%$ when compared with data. This is because the correlations include a range of micro-processes that make up the physics of heat transfer. The data from which correlations are derived, also have an uncertainty which contributes to the uncertainty of the correlation.

\subsubsection{Wind Speed Impact}

The wind speed is assumed to affect only the rate of convective heat transfer from the receiver. Other losses because of radiation, conduction, and cool-down are assumed to be the same because the control system keeps the outlet conditions the same, which means that the temperature profile remains constant.

The wind speed is a variable factor and there is some evidence that the meterological tower wind speed is reduced (a factor of three) in the vicinity of the receiver because of blocking and boundary layer drag of the concentrator field itself. The amount of sensitivity (of the LEC results) to this possible variation was studied by running SOLSTEP with different wind speed assumptions. Table 8.1 shows an example of this calculation for Case I. A change in wind speed from $10 \mathrm{mph}$ to $3 \mathrm{mph}$ changes the LEC by about $4 \%$.

TABLE 8.1. SOLSTEP LEC Sensitivity to Assumed Wind Speed

\begin{tabular}{|c|c|c|}
\hline THRLSS & $\begin{array}{l}\text { Annual Receiver } \\
\text { Efficiency }\end{array}$ & Relative LEC \\
\hline .071 & .78 & 1.0 \\
\hline .071 & .79 & 0.99 \\
\hline .058 & .82 & 0.96 \\
\hline .052 & .83 & 0.94 \\
\hline
\end{tabular}

Case I

Actual Wind Speeds

Sensitivity Case A -

Constant $10-m p h$ wind

Sensitivity Case B -

$\therefore \quad$ Constant 3-mph wind

Sensitivity Case C -

Natural Convection Only

.83

0.94 


\subsubsection{Total Loss Uncertainties}

Several methods for calculating thermal losses were used, and each of these generally agreed with each other when cross-check calculations were done. This agreement among different methods, codes, and analysts indicates that the results are within the bounds of normal engineering accuracy.

Heat transfer calculations were done using correlations of heat transfer that have been developed using laboratory measurements. The scatter of the original data, as well as the applications of these correlations to specific cases, which don't mirror the ideal conditions for which the correlations apply, give an uncertainty to general industrial heat transfer calculations. The order of uncertainty in heat losses for the receivers can be accounted for by using a range of THRLSS values in the SOLSTEP code to uncover any sensitivity (of the LECs) to the accuracy of the thermal losses; shown in Table 8.1. Had a strong relationship occurred, this relationship would have indicated that a non-optimized design had been used, or that more detailed loss calculations/ experiments would have to be done to more accurately predict the thermal losses.

The larger uncertainties in these calculations stem from: averaging the losses that vary with inclination angle and receiver slope, averaging the assumptions for the temperature profile around the receiver, assuming a single emissivity of the receiver surface, assuming the view factor, and lacking details on wind flow and convective flow patterns of the ambient air. The combined uncertainties contribute to and should fall within the range of typical $20 \%$ industrial uncertainty for heat transfer.

To quantify the effect of the errors in the receiver loss estimates, a sensitivity analysis was done. Table 8.2 shows the results of this analysis. The baseline results columns are identical to those reported earlier and the sensitivity results columns have different assumptions for the receiver losses. In Cases I and II the receiver losses used in the sensitivity analysis were estimates made by $\operatorname{TTU}^{(a)}$. For the remaining cases, the receiver losses used

(a) Personal communications from TTU to T. Williams on May 8, 1986 and November 8, 1986. 
in the sensitivity analysis were one-half the amount estimated in the baseline case.

TABLE 8.2. Receiver Losses Sensitivity Analysis Results (Annual Operating Efficiencies--100 MWe No Storage)

\begin{tabular}{|c|c|c|c|c|}
\hline & & & Sens & \\
\hline & Receiver & System & Receiver & System \\
\hline $\begin{array}{l}\text { Case I, } \\
60 \text {-degree-w/s }\end{array}$ & .784 & .110 & .814 & .114 \\
\hline $\begin{array}{l}\text { Case II, } \\
60 \text {-degree-salt }\end{array}$ & .614 & .087 & .748 & .105 \\
\hline $\begin{array}{l}\text { Case III, } \\
30 \text {-degree-w/s }\end{array}$ & .788 & .075 & .869 & .083 \\
\hline $\begin{array}{l}\text { Case IV, } \\
30 \text {-degree-salt }\end{array}$ & .393 & .031 & .636 & .058 \\
\hline $\begin{array}{l}\text { Case } V \\
\text { iris-Stirling }\end{array}$ & .395 & .034 & .637 & .058 \\
\hline
\end{tabular}

\subsection{KEY COST UNCERTAINTIES}

In general, uncertainty in cost analysis is caused by two factors: 1) uncertainty in the design, and 2) uncertainty in the cost, given the design. The former refers to the level of design detail available, while the latter refers to the cost estimating approach. These two factors are linked because the level of accuracy associated with a cost estimate is limited by the level of detail in the design description. For example, given complete blueprints for a building, its cost could be estimated by itemizing material and labor for each individual component or by multiplying total floor area by a ruleof-thumb cost per square foot. 8y using a rudimentary sketch of the building, only the latter approach would be possible.

The impact of cost uncertainties can be minimized by focusing on the relative costs of components and systems rather than their individual absolute costs. Consistent estimating approaches were employed for plant components 
of the same kind and with a similar level of detail, to minimize the uncertainty for differential or relative cost comparisons.

The accuracy of cost estimating approaches used for evaluating the bow systems generally paralleled the level of design detail available. Therefore, differences in uncertainty among the many systems and components is roughly proportional to the level of design detail. The cost uncertainty of bowl system components is discussed in these terms in the following sections.

\subsubsection{Concentrator Cost Uncertainties}

The cost of the 60-degree (Cases I and II) concentrator was estimated from a design, which identified the type and quantity of construction materials and described how the individual elements fit together. Design information for the 30-degree (Case III and IV) concentrator was limited to external dimensional data. Although both of these concentrators are based on the same general design concept, the estimate for the 30-degree version must be considered to have a higher level of uncertainty because of less detail in its design specification.

\subsubsection{Receiver Cost Uncertainties}

Similar to the design data for 60-degree (Cases I and II) concentrator, the design data for the Case I receiver included detailed identification of construction materials and physical descriptions of each of its principal elements. Receiver design information for cases II through IV was 1 imited to the absorber tubing and tubing support pipe. Although these two elements make up the majority of the costs of the absorber, lack of specific information on the costs of the absorber or on the costs of the support structure elements increases the uncertainty of these estimates. The uncertainty of the support structure estimate for Cases III and IV is especially great because its design requirements (height, loading) varied considerably from the Case I system.

\subsection{3 other Component Uncertainties}

Little or no relative cost uncertainty exists among the remaining system components because the same level of design detail and estimating approach was used for Cases I through IV. 


\subsection{ALTERNATIVE CONCENTRATOR DESIGNS}

Even when detailed design specifications are available and detailed cost and performance evaluations are conducted, some uncertainty remains as to whether the designs represent the optimal configuration of the general concept. Two types of sensitivity analyses were conducted which addressed the possibility of alternative costs for bowl concentrators and receivers, which are the most unique components of the bowl concept relative to other solar thermal concepts. Costs were estimated for four alternative designs of a 200-ft-diameter, 30degree concentrator. The alternative concentrator costs were each substituted for the Case III concentrator cost, and new system LECs were calculated. The second type of sensitivity analysis was conducted for Case I concentrators and receivers. The cost of each of these components was varied over ranges of $\$ 0-280 / m^{2}$ and $\$ 0-120 / m^{2}$, respectively.

Details of the estimating procedure for the alternatives are presented in Appendix I. A summary of their estimated unit costs is shown in Table 8.3. The impact on system LEC of substituting each of these alternative concentrator costs for the Case III concentrator cost is shown in Figure 8.1. The data shown in Figure 8.1 are for minimum LEC designs of 100-MWe systems.

TABLE 8.3. Alternative Concentrator Unit Costs

$\begin{array}{lc}\text { Concentrator Type } & \frac{\text { Unit Cost }}{\left(\$ / \mathrm{m}^{2}\right)} \\ \text { Case III (glass/metal) } & 95 \\ \text { Cast in Place Concrete } & 105 \\ \text { Pre-Cast Concrete } & 114 \\ \text { Mylar } & 65^{\star} \\ \text { Membrane } & 79^{\star \star} \\ & \\ \star 18 \% \text { of initial } \$ 65 / \mathrm{m}^{2} & \text { must be replaced every five years. } \\ \star * 46 \% \text { of initial } \$ 79 / m^{2} & \text { must be replaced every ten years. }\end{array}$

None of the alternative concentrator designs significantly improved the economic performance of the Case III system over the glass/metal design, even though their performance was assumed to be identical to the glass/metal design. Actual concentrator performance for the alternative concentrators would probably 
be much lower, which would raise the LEC of the alternative concentrator systems relative to that shown in Figure 8.1 .

The general sensitivity of system LEC to concentrator cost is shown in Figure $\mathbf{8 . 2}$ for the Case I bowl system, dish/Stirling system, and molten salt central receiver system. The Case I system was selected for this comparison because it had the lowest LEC of the bowl systems analyzed. The nominal concentrator estimate for each system is identified in Figure 8.2, which also shows that the bowl system would not be competitive with the dish or central receiver system even if the concentrator were free.

Finally, the general sensitivity of system LEC to receiver cost is shown in Figure $\mathbf{8 . 3}$ for the Case I bowl system, dish/Stirling system, and molten salt central receiver system. As was the case for the general sensitivity to concentrator cost, the bowl system would not be competitive with the dish or central receiver system even if the receiver was free.

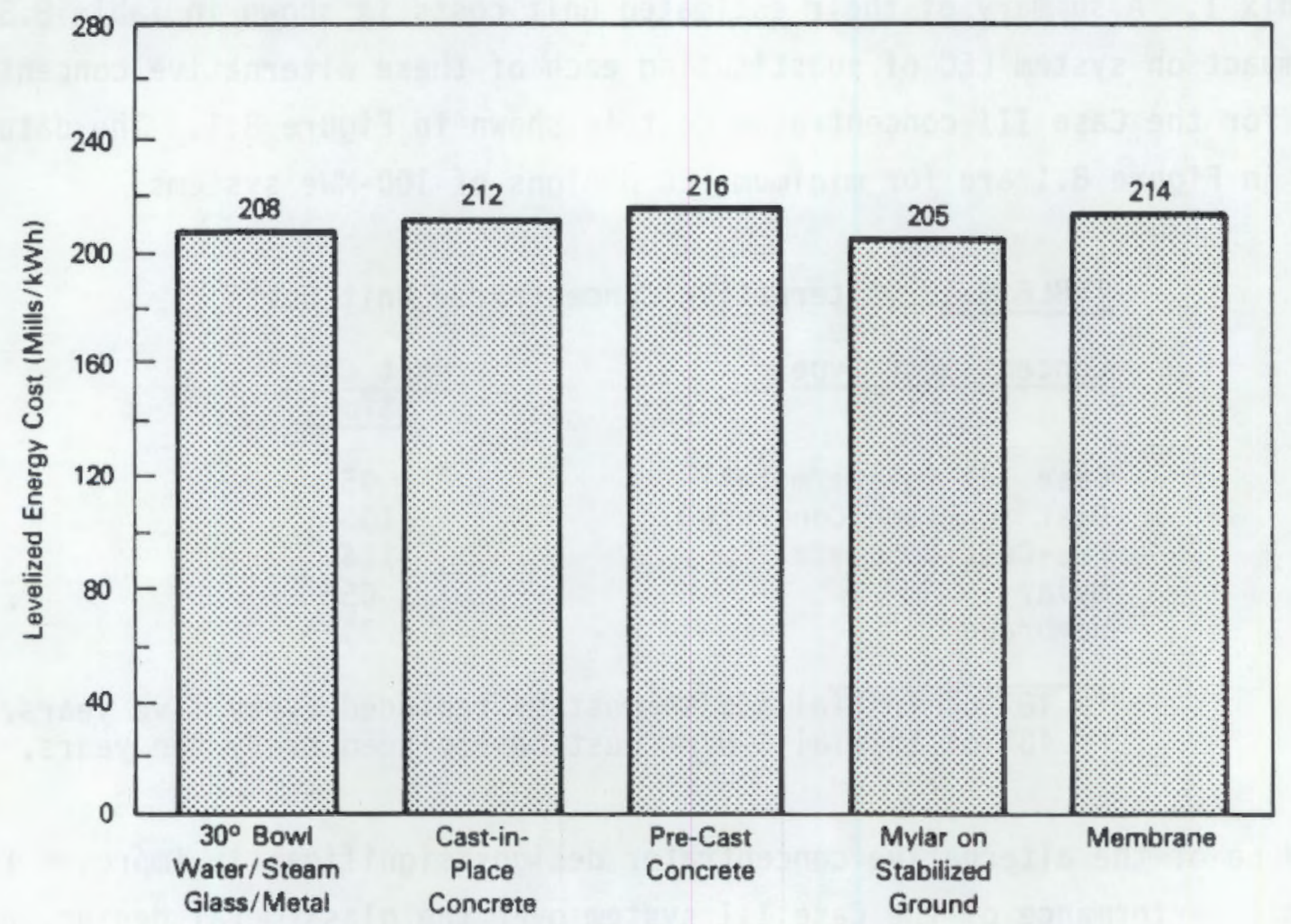

FIGURE 8.1. LEC for Alternative Concentrators 


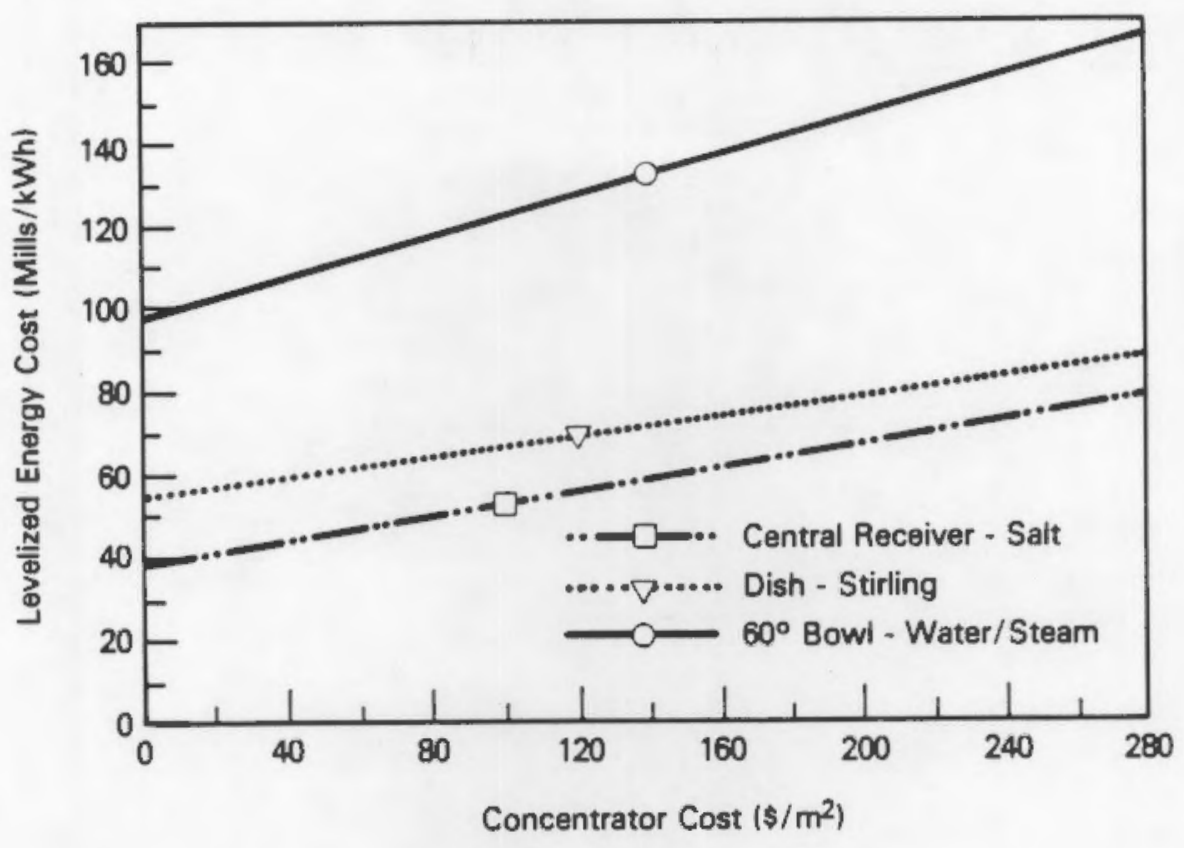

FIGURE 8.2. Concentrator Cost Sensitivity for 100-MWe Minimum LEC Designs

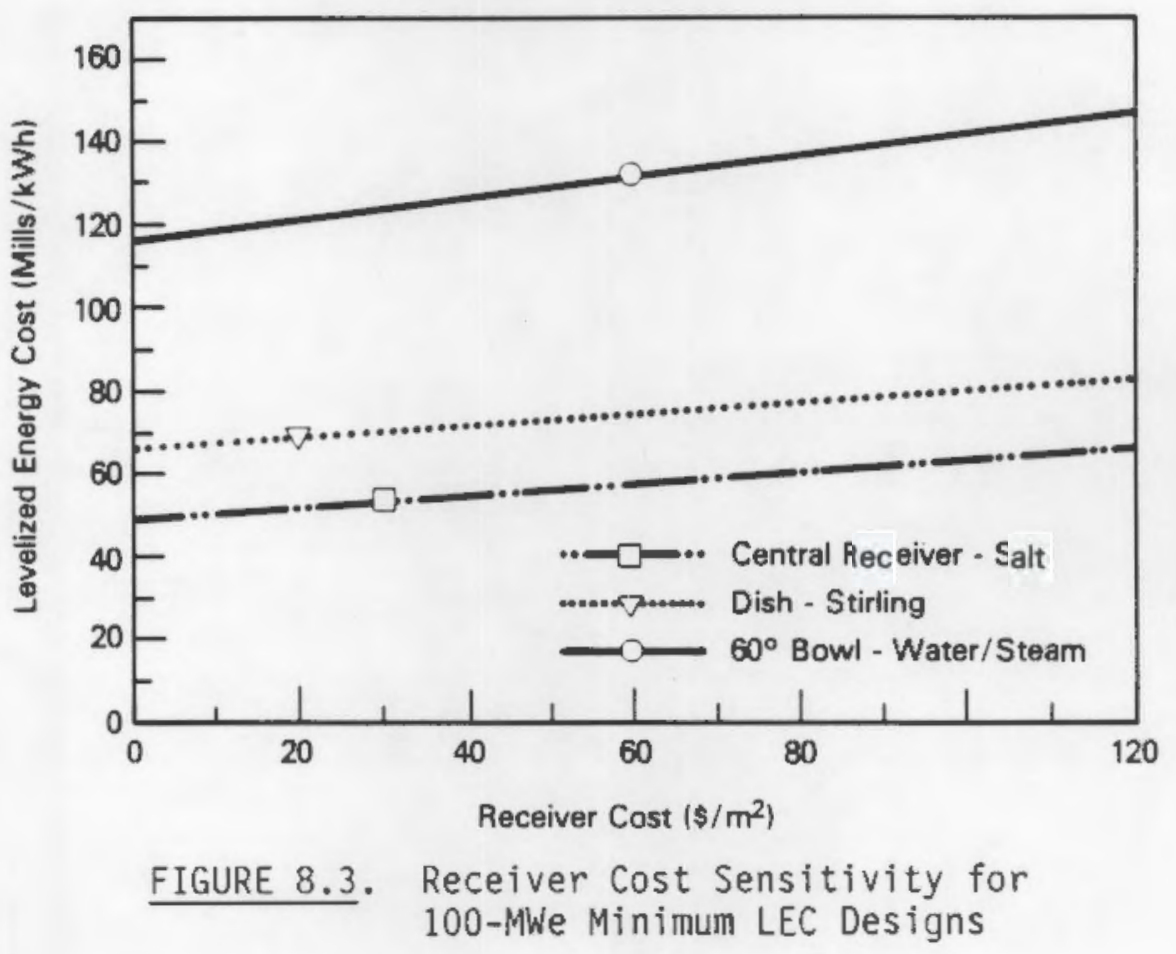


? 
APPENDIX A

STUDY PROCESS AND GROUND RULES 


\section{STUDY PROCESS AND GROUND RULES}

This appendix provides background information on the parties involved in the study, and elaborates on the ground rules used in the study. As part of the study process, an Analytical Coordination Committee (ACC) was formed to provide a critical review of the study as it progressed. The ACC consisted of members from Pacific Northwest Laboratory (PNL), Solar Energy Research Institute (SERI), and Texas Tech University (TTU).

One of the products of the ACC was a criteria and assumptions document, which provided a summary of agreements by the ACC on the study approach, ground rules, assumptions, and methods of evaluating the fixed mirror distributed focus (FMDF) bowl technology. Key information from the criteria and assumptions document is summarized below.

\section{A.1 STUDY APPROACH}

The analysis will be performed consistent with the economic methodology specified by the Solar Thermal Five-Year Program Plan. All of the solar thermal technologies will be analyzed on a consistent basis including, analytical methods, critical assumptions on performance, and cost definitions. The analysis will sufficiently detail all components to adequately evaluate the cost/performance.

The analysis will develop projections of the potential performance and cost of the FMDF bowl technology. These projections will be compared to the solar thermal multi-year program cost goal for electricity generation.

A previous PNL study (Williams et al. 1987) has addressed the potential of several other solar thermal technologies to meet the multi-year program plant cost goal for electricity generation. To maximize the comparability of the FMDF analysis with the analysis of the prior concepts, the ground rules and analytical approaches from the previous study will be used wherever applicable. The implications of this approach are: 
- Consistent assumptions will be used regarding performance capabilities for components applicable to all technologies (such as the site insolation characteristics, the reflectivity of glass, etc.).

- A mass production scenario is assumed for cost projections. This will reflect the ultimate costs which could be achieved when large scale production is reached. The probability of attaining this production level is not addressed by the study; it will be assumed that a large scale bowl industry exists.

- Differences in the current technology statuses of the concepts are eliminated as much as possible. The results of the study are projections of what could be achieved by the FMDF technology, assuming development support by public and private sources.

- The FMDF bowl will be analyzed over a range of sizes and capacity factors. The ACC will be the interface to provide test data, simulations analyses, systems design information, and other data available from the Crosbyton Solar Power Project, and to provide clarification of that data.

Sensitivity analyses will be used to address the impact of component costs.

\section{A.2 STUDY GROUND RULES AND ASSUMPTIONS}

For this study, all concepts will be evaluated using the SOLSTEP analysis code and 1976 weather data for Barstow, California.

The assumptions for the cost analyses are the following:

- Cost estimates will be based on the construction of a production plant.

- The annual installation rate of solar thermal capacity will be assumed to be equivalent to 2.5 million square meters of reflective aperture area per year.

- Standard construction techniques are assumed to be developed which preclude extraordinary indirect and contingency costs. 
- Developmental costs required to achieve a "commercial" industry will be excluded.

Economic assumptions used in the calculations are summarized in Table A.1. These assumptions are based on recommendations for calculations to be compared with the long-term technology goals for solar thermal systems. These economic data have been used in the analyses of all solar thermal systems.

Results will be analyzed for a solar only, non-hybrid system, to aljow direct comparison with the U.S. Department of Energy (DOE) electricity system goal.

For all cases using a central steam Rankine heat engine, the same heat engine previously used for the solar characterization study will be employed. PNL may supplement these data as appropriate to adjust for different inlet conditions.

Sensitivity studies will be performed in all cases on receiver and concentrator costs. A range shall be large enough to evaluate the effect of each on LEC.

The baseline reflector material shall be silvered glass with the same optical properties used for the previous solar characterization study (Williams et a?. 1987).

\section{A.3 EVALUATION CRITERIA}

The evaluation criteria for assessing the potential of solar bowls is LECs $(\$ / k$ Whe) for electric power generation. This factor includes annual efficiency as well as the cost of the collector, engine, transport, etc. The same criteria will be employed in comparing solar bowls to other solar thermal technologies. Central receivers, parabolic dishes and parabolic troughs will be compared to solar bowls. 
TABLE A.1. Economic Assumptions

Manufactured Component Ground Rules

- Annual production rate equivalent to $2.5 \mathrm{E} 6 \mathrm{~m}^{2}$ of reflective aperture area per year

- Real cost of capital $=10 \%$

- Plant economic 1 ife $=20$ years

- Investment tax credit $=10 \%$

- Effective income tax rate $=50 \%$

- Property and other taxes $=1 \%$

Power Plant Economic Ground Rules

- Price year = 1984

- Real after tax cost of capital $=3.15 \%$

- Investment tax credit $=10 \%$

- Construction period:

- 0.5 and 2 MWe - 1 year

- 10 Mwe - 2 years

- 30 and 100 Mwe - 3 years

- Plant economic life $=30$ years

- Depreciation life $=10$ years

- Property and other taxes = 1\%

- General inflation $=4 \%$ 


\section{APPENDIX B}

LEVELIZED ENERGY COST CALCULATIONS 


\section{APPENDIX B}

\section{LEVELIZED ENERGY COST CALCULATIONS}

This appendix provides a description of the levelized energy cost (LEC) approach to economic evaluation of solar thermal power plants. LECs are 1 ife cycle costs that include a plant's capital cost, operation and maintenance cost, taxes, interest, and return on investment. An LEC approach provides an economically correct treatment of these costs and allows an equitable comparison of alternative solar thermal power systems.

In the following section, general economic principles relating to LEC calculations, such as the time value of money, discount rate, and net present value are defined and explained. The appropriate use of LEC analyses for choosing among alternatives is discussed in Section B.2. Section B. 3 provides an overview of the general approach to LEC calculations, and the final section presents key economic assumptions used in this study.

\section{B.1 GENERAL ECONOMIC PRINCIPLES}

The purpose of an economic evaluation is to select the best investment, i.e., the investment that maximizes the wealth of the investor. An economically correct methodology for comparing alternatives must consider (at a minimum) the time value of money and inflation. These concepts are discussed below.

The time value of money results from the fact that people prefer to consume goods immediately rather than at a later date. A lender forgoes the use of loaned money until it is later repaid. Lenders require compensation (in the form of interest) for postponing their consumption.

As a result of the time value of money, expenses or revenues (cash flows) which occur at different times cannot be directly compared on a face value basis. The most common way to correctly interpret cash flows occurring at different times is through a present value calculation. In a present value calculation, a discount rate compensates for the time value of money. The discount rate is the minimum rate of return that an investor is willing to 
accept from the investment. In the case of a lender, the discount rate is equivalent to the interest rate charged on the loan. Interest (discount) rates are a function of the intrinsic productivity of capital (or to what extent additional capital can increase output of goods and services), the expected inflation rate, and a risk premium having to do with the variability of the cash flows. The rate of constant dollar interest is the compensation for postponing consumption when there is no inflation. The greater the uncertainty in the timing or magnitude of a cash flow (risk), the higher the real interest (or discount) rate will be.

Inflation is another fundamental concept that has a significant impact on economic evaluations. Inflation is a decrease in the purchasing power of currency over time, and affects all the expenses and revenues associated with an investment. In periods of inflation, investors demand higher returns (higher discount rates) as compensation for postponing consumption, because money received later will buy fewer goods and services than it will today.

Economic evaluations can handle inflation in one of two ways. The first approach is to include the effects of the expected inflation rate into all revenue and expense streams. This approach is called a nominal (or current) dollar method and results in estimates of the actual face-value cash flows to occur in each year. The second method of accounting for inflation is to exclude the effects of inflation from all cash flows. This approach is called a real (or constant) dollar method, because it expresses all cash flows in dollars of constant purchasing power. Either approach to inflation will yield a correct evaluation of energy alternatives. However, it is important that all the economic calculations be expressed consistently, i.e., either in nominal or real terms.

All possible investments of the same risk will not necessarily earn the same rate of return. Deciding which investment to select can be done by calculating the net present value. The net present value is the difference between the present value of the investment and the present value of the cash flows to be received. For an investment to be attractive, the net present value must be greater than zero. Selecting investments with negative net present values (NPV) decreases wealth; conversely, selecting investments with 
positive NPVs increases wealth. Businesses and individual investors attempt to maximize their wealth and to select investments on this basis. Wealth maximization occurs when all positive NPV investments are chosen. When choosing between mutually exclusive investments (e.g., the energy source for a particular power plant) the alternative with the largest NPV will be the one that maximizes the wealth of the investor.

\section{B.2 USING LEVELIZED ENERGY COST ANALYSIS}

Deciding between alternatives on the basis of capital cost, system efficiency, or any other single parameter will not necessarily yield the most economically efficient method or maximize the wealth of investors. The LEC approach is one economically correct method which can be used to appropriately choose among alternatives.

There are two important constraints in LEC calculations. The first is that a selection among alternatives using the LEC approach is only reasonabie when the alternatives are providing equivalent service. If the characteristics or use of the energy systems are dramatically different (for instance, a peaking plant being compared with a base load plant), the LEC cannot be used by itself in deciding which alternative is better, because the value of the energy produced by each plant may be dramatically different. The second constraint is that LEC comparisons are only appropriate when the economic assumptions used in the calculations are consistent. This constraint is especially important when comparing LEC calculations from different sources. The economic assumptions will substantially affect the magnitude of the LEC calculated, even though they may not alter a relative comparison of concepts. Using the LEC to compare technologies must be restricted to cases where the economic assumptions are equivalent.

\section{B.3 LEVELIZED ENERGY COST APPROACH}

LEC analysis employs the concepts discussed above. But, since the result is given in terms of an energy cost, an LEC approach makes the results easier to understand when comparing energy alternatives. The economic result is the same, however. Selecting the lowest LEC from the possible alternatives which 
provide equivalent service maximizes the wealth of the investors. Therefore, when making energy investments, businesses and individual investors will generally select the option with the lowest LEC, even though it may not be the option with the highest thermodynamic efficiency. There is a trade-off between cost and process or system efficiency. LEC calculations are able to correctly evaluate this trade off and to determine the most economically efficient method.

An LEC is an annual cost (AC) divided by an annual energy output. The $A C$ is defined as a hypothetical uniform cost stream, which over the plant's $1 \mathrm{ife}$, has the same present value as all of the actual plant costs. The general steps involved in calculating an LEC (assuming that the annual energy output and all plant costs are known) are: 1) calculate the capital recovery factor and fixed charge rate(s), 2) calculate present values for all cost streams, and 3) calculate ACs and LECs. These steps are discussed in more detail beiow.

The $A C$ is made up of capital costs and recurring costs. Because the tax laws treat these costs differently, they must be considered separately in the LEC analysis. The present value of all recurring costs must be multiplied by a capital recovery factor (CRF) to yield a single annual cost that represents all recurring costs over the life of the plant. This single annual cost is equivalent to the payment on a loan with the principle amount equal to the present value of all the recurring costs. The CRF is calculated as:

$$
\mathrm{CFR}=\frac{\mathrm{k}}{1-(1+k)^{-\mathrm{N}}}
$$

where: $k$ = discount rate

$$
N=\text { plant lifetime. }
$$

The contribution of the capital costs to the $A C$ is the product of the present value of the capital construction costs and the fixed charge rate (FCR). The FCR accounts for income taxes (including depreciation and investment tax credit effects), return on equity, interest on debt, insurance, property taxes, and other taxes. The FCR is calculated as:

$$
F C R=C R F *\left[\frac{1-t *(D P F)-i t C}{1-t}\right]+p
$$


where: $C R F=$ capital recovery factor

$\mathrm{t}=$ effective income tax rate

$\mathrm{DPF}=$ depreciation factor (defined below)

$i t c=i n v e s t m e n t$ tax credit

$p=$ insurance and effective property and other tax rate.

The depreciation factor is calculated from the formula:

$\mathrm{DPF}=\sum_{i=1}^{N} \frac{d p_{i} \star\left(1-\frac{i t c}{2}\right)}{(1+k)^{i-1}}$

where: $d p_{j}=$ depreciation fraction allowed in year $i$

$i=$ year relative to year 0 (the last year of construction)

$i$ tc $=$ investment tax credit

$k=$ discount rate

$n=$ depreciation lifetime.

The reference time period for the present value calculation in the equation above and in the other present value calculations is year 0 , the last year of plant construction. The choice of the year to use as the basis for present value calculations is a matter of convention. The above depreciation factor equation assumes that the plant construction is completed at the end of a tax year, therefore the value of the first year's depreciation is not discounted. The values of dpi are determined from the Accelerated cost Recovery System (ACRS) depreciation schedules for the appropriate tax life of the investment. The tax life depends upon both the type of property and the ownership. ACRS depreciation schedules are summarized in Table B.1. 
TABLE B.1. ACRS Depreciation Schedules

(Percentage Depreciation in Each Year)

Depreciation Lifetime

\begin{tabular}{|c|c|c|c|}
\hline Year & 5 Year & 10 Year & 15 Year \\
\hline 1 & 15 & 8 & 5 \\
\hline 2 & 22 & 14 & 10 \\
\hline 3 & 21 & 12 & 9 \\
\hline 4 & 21 & 10 & 8 \\
\hline 5 & 21 & 10 & 7 \\
\hline 6 & & 10 & 7 \\
\hline 7 & & 9 & 6 \\
\hline 8 & & 9 & 6 \\
\hline 9 & & 9 & 6 \\
\hline 10 & & 9 & 6 \\
\hline 11 & & & 6 \\
\hline 12 & & & 6 \\
\hline 13 & & & 6 \\
\hline 14 & & & 6 \\
\hline 15 & & & 6 \\
\hline
\end{tabular}

A special FCR is used for land because land cannot be depreciated for tax purposes. The land FCR is calculated as:

$$
F C R L=\frac{C R F}{1-t}+p
$$

where: $\quad C R F=$ capital recovery factor

$$
\begin{aligned}
& t=\text { effective income tax rate } \\
& p=\text { effective property and other tax rate. }
\end{aligned}
$$

The next step in calculating the LEC is to determine the actual cash flows (nominal dollars) of all capital costs, including costs for indirect and contingency costs. Each year's construction cash flow can be calculated as:

$$
C_{i}=\mathrm{CAP}_{b} * F R_{i} *(1+\mathrm{gC})^{i-b}
$$


where: $c_{i}=$ capital cost expended in year $i$

$i=$ year relative to year 0 (the last year of construction)

$\mathrm{CAP}_{\mathrm{b}}=$ total plant capital cost estimate in year $b$

$b=$ base year for capital cost estimate relative to year 0

$F R_{i}=$ fraction of $\mathrm{CAPb}$ intended to be spent in year $i$

gc = capital cost escalation rate.

The present value of all capital construction costs can then be calculated as:

$$
\text { PVC }=\sum_{i=1}^{N} \frac{c_{i}}{(1+k)^{i}}
$$

where: $C_{i}=$ capital cost in year $i$

$i=$ year relative to year 0 (the last year of construction)

$k=$ discount rate.

The present value of land cost (assuming land is resold at the end of the plants life) can be calculated as:

$$
P V L=\frac{L C_{b} *(1+g 1)^{1-b}}{(1+k)^{i}}-\frac{L C_{b} *(1+g 1)^{N-b}}{(1+k)^{N}}
$$

where: $L C_{b}=$ land cost estimate in year $b$

$$
\begin{aligned}
\mathrm{gl} & =\text { land escalation rate } \\
\mathrm{i} & =\text { year land purchased relative to year } 0 \\
\mathrm{~b} & =\text { year of } 1 \text { and cost estimate relative to year } 0 \\
\mathrm{k} & =\text { discount rate } \\
\mathrm{N} & =\text { plant lifetime. }
\end{aligned}
$$

The next step is to calculate the present value of all operations and maintenance (08M) costs; (PVO):

$$
P V O=\left(1+g_{0}\right)^{-b} * O M_{b} *\left(\frac{1+g_{0}}{k-g_{0}}\right) *\left[1-\left(\frac{1+g_{0}}{1+k}\right)^{N}\right]
$$


where: $g_{0}=0 \& M$ escalation rate

$b=$ base year for 0\&M cost estimate relative to year 0

$O M_{b}=0 \& M$ annual estimate in year $b$ without allowing for escalation

$k=$ discount rate

$N=$ plant lifetime.

None of the solar thermal plants in this study required fuels. For plants that require fuel (such as hybrid plants), the present value of fuel (PVF) costs would be calculated as:

$$
P V F=\left(1+g_{f}\right)^{-b} * F_{b} *\left(\frac{1+g_{f}}{k-g_{f}}\right) \star\left[1-\left(\frac{1+g_{f}}{1+k}\right)^{N}\right]
$$

where: $g_{f}=$ fuel escalation rate

$b=$ base year for fuel cost estimate relative to year 0

$F_{b}=$ fuel annual estimate in year $b$ without allowing for escalation

$k=$ discount rate

$N=$ plant lifetime.

The annualized cost (AC) of the plant (expressed in year $b$ dollars) can then be calculated as:

$$
A C=\left(1+g_{j}\right) \star^{b}[F C R L * P V L+F C R * P V C+C R F *(P V O+P V F)]
$$

where: $A C=$ annualized cost in year $b$ dollars

$$
\begin{aligned}
b & =\text { base year for costs relative to year } 0 \\
g_{j} & =\text { general inflation rate. }
\end{aligned}
$$

The LEC is then calculated as:

$$
L E C=\frac{A C}{A_{\text {out }}}
$$

where: $L E C=$ levelized energy cost

$$
A C=\text { annualized cost }
$$

$A_{\text {out }}=$ annual energy output in appropriate units.

The LEC calculations in this study were carried out on a real dollar basis. LEC comparisons can be made on the basis of either real or nominal 
dollars. A real dollar LEC is an energy cost which is level over time in dollars of constant purchasing power; a nominal dollar LEC is level over time in the actual dollars of each year. Nominal dollar LEC calculations are always numerically higher (for any positive inflation rate) than are real dollar LEC calculations because general inflation over the plant's lifetime is included in the energy cost.

The real dollar LEC is obtained first by calculating the nominal dollar LEC as shown above and then converting for inflation. This conversion is done by the formula:

$$
\operatorname{LEC}_{r}=\frac{\operatorname{LEC}_{n}}{\operatorname{CRF}} * \frac{\left(k-g_{i}\right)}{\left(1+g_{j}\right) *\left(1-\frac{\left(1+g_{j}\right)}{(1+k)}\right)^{N}}
$$

where: $L_{E C}=$ real dollar $L E C$

$$
\begin{aligned}
\mathrm{LEC}_{n} & =\text { nominal dollar } \mathrm{LEC} \\
\mathrm{CRF} & =\text { capital Recovery factor } \\
\mathrm{k} & =\text { discount rate } \\
\mathrm{g}_{i} & =\text { general inflation rate } \\
\mathrm{N} & =\text { plant lifetime. }
\end{aligned}
$$

An alternative approach to calculating the real dollar LEC would be to express all of the economic inputs in real terms. This approach is less desirable because it will not account for inflation lessening the value of depreciation (which reduces tax payments) in future years.

\section{B.4 ECONOMIC ASSUMPTIONS}

The Solar Thermal Five Year Plan (DOE 1984) provides standard economic assumptions which were employed for the LEC calculations in this study. These assumptions are presented in Table B.2. 
TABLE B.2. Power Plant Economic Ground Rules

Parameter
Price year
Real after tax cost of capital
General Inflation Rate
Investment tax credit
Effective income tax rate
Plant economic life
Depreciation life
Property and other taxes
Construction period

Assigned Value
1984
$3.15 \%$
$4 \%$
$10 \%$
$50 \%$
30 years
10 years (ACRS)
$1 \%$
0.5 and 2 Mwe - 1 year
10 Mwe -2 years
30 and 100 Mwe - 3 years


APPENDIX $C$

CONCENTRATOR PERFORMANCE DATA 
APPENDIX C

\section{CONCENTRATOR PERFORMANCE DATA}

As Chapter 5 explains, the primary figure of merit for characterizing concentrator performance is concentrator efficiency. Concentrator efficiency includes the impact of cosine losses, coverage, shadowing, blocking, reflectivity losses, atmospheric attenuation, and spillage. Because the bowl system is a modular concept, the design-point and annual performance will be the same for all concentrators of the same kind (60-degree, 30-degree, and iris). For the concentrator analysis done in this study the coverage, shadowing, blocking, reflectivity losses, atmospheric attenuation, and the optical and deflection portions of the spillage loss are assumed to be constant. Therefore, the only portions of the concentrator efficiency that vary with solar position are the cosine loss and the end loss portion of the spillage.

In this appendix, the cosine loss and end loss for the various concentrators are discussed. The concentrator performance matrices that were input to SOLSTEP, and the hourly concentrator perfornance are discussed in the following sections.

\section{C.1 COSINE LOSS}

The cosine loss reduces the amount of energy that can be collected because it reduces the effective aperture for the bowl. The cosine loss for a bowl concentrator without an iris is the same as that for a flat plate with the same orientation as the aperture of the bowl. Therefore, the cosine losses at each solar position are calculated by:

$$
\cos (i n c)=\cos (a l t){ }^{\star} \cos (a z){ }^{\star} \sin (t i l t)+\sin (a l t) * \cos (t i l t)
$$

where: inc = incident angle between the bowl normal and earth sun line alt = altitude, the angle above the horizon

$a z=a z i m u t h$, the angle between due south and the sun tilt = tilt angle of the collector $\left(15^{\circ}\right.$ pointing due south $)$. 
When a tracking iris is used on the concentrator the cosine loss is reduced for most solar positions because the iris is always on the side of the bowl away from the sun. The following equation was provided by Texas Tech University $(T T U)^{(a)}$ and it gives the cosine loss for the iris concentrator as a function of solar position.

$$
\begin{aligned}
& \text { cosine loss }=\pi / 180^{\star}\left\{(i r w) \sin ^{2}\left(r a_{j}\right)+[180-(i r w)]^{\star} \sin ^{2}\left(r a_{f}\right)\right\}^{\star} \cos (i n c) \\
& +\sin (i r w) \star\left\{\left[\pi / 180^{\star}\left(r a_{j}-r a_{f}\right)\right]-.5^{\star}\left[\sin \left(2^{\star} r a_{i}\right)-\sin \left(2^{\star} r a_{f}\right)\right]\right\} \sin ^{\star}(i n c)
\end{aligned}
$$

where: inc = incident angle between the bowl normal and earth sun line

$$
\begin{aligned}
& r a_{f}=\text { rim angle of the fixed portion of the concentrator }\left(30^{\circ}\right) \\
& r a_{j}=\text { rim angle of the iris portion of the concentrator--from the top }
\end{aligned}
$$
to the iris to the center of the fixed portion of the concentrator $\left(45^{\circ}\right)$

irw = one half the angular width of the iris along the circumference of the fixed aperture $\left(90^{\circ} / 2=45^{\circ}\right)$.

\section{C.2 END LOSS}

For the 60-degree rim angle concentrator (Cases I and II) there were no end losses because the receivers were of full length.

The 30-degree rim angle concentrators (Cases III and IV) had receivers that were $60 \%$ of full length. Therefore, the flux that would impinge on the portion of the receiver that is missing must be calculated. Since the flux distribution of the fixed mirror distributed focus (FMDF) receiver varies with solar position this factor is not constant and is included with the cosine loss in the geometric optical efficiency (GEO) input matrix to SOLSTEP. The ROSA ${ }^{(b)}$ computer code was used to determine the percentage of the full-length receiver flux that would impinge on a receiver that was $60 \%$ of full length. The calculation was made at approximately 10 different incident angles. From these calculations it was possible to interpolate a value of the end loss for each entry in the GEO matrix.

(a) Personal communication from TTU to J. Dirks, PNL, on November 11, 1986.

(b) Anderson, R. M., and W. T. Ford. 1984. ROSA: A Computer Model for Optical Power Ratio Calculations. Texas Tech University, Lubbock, Texas. 
The iris concentrator (Case $V$ ) data that was received from $\operatorname{TTU}^{(a)}$ shows that an end loss exists even for full-length receivers. However, this did not effect the method of calculation, since the ROSA code results only report the flux striking the receiver. Therefore, the calculation was made in the same manner as for the 30-degree concentrator. Because this iris receiver was only 20-feet-long, only that portion of the flux that impinged on the top $20 \%$ of the receiver was considered. Figure $C .1$ shows the iris receiver capture ( 1 - end loss) as a function of incident angle. The end-loss effect on hourly concentrator performance is discussed in Section C.4.

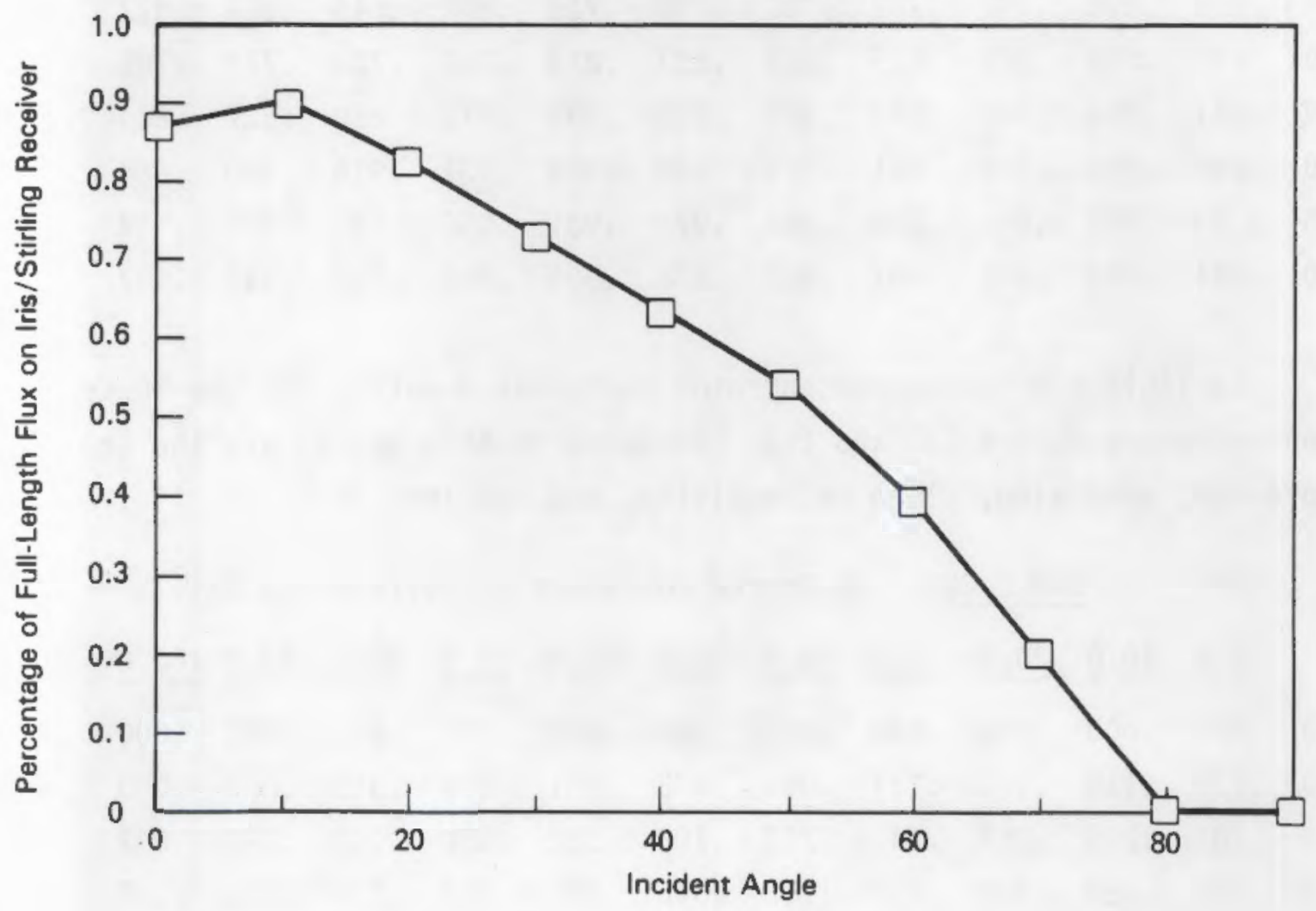

FIGURE C.1. Capture as a Function of Incident Angle for Iris Collector

(a) Personal communication to T. Williams, PNL, on October 14, 1986. 


\section{3 CONCENTRATOR PERFORMANCE MATRICES}

In Table C.1 is the concentrator performance matrix for the 60-degree concentrators (Cases I and II). Included in this matrix are the cosine loss and multiple bounce losses.

TABLE C.1. 60-Degree Concentrator Performance Matrix

$\underline{0.0} \underline{10.0} \underline{20.0} \quad \underline{30.0} \quad \underline{40.0} \quad \underline{50.0} \quad \underline{60.0} \underline{70.0} \underline{80.0} \underline{90.0} \underline{100.0} \underline{110.0} \underline{120.0}$

$\begin{array}{llllllllllllll}0 & .000 & .000 & .000 & .000 & .000 & .000 & .000 & .000 & .000 & .000 & .000 & .000 & .000\end{array}$

$\begin{array}{llllllllllllll}10 & .416 & .412 & .401 & .383 & .358 & .327 & .291 & .252 & .209 & .166 & .122 & .080 & .040\end{array}$

$\begin{array}{llllllllllllll}20 & .564 & .561 & .550 & .532 & .508 & .479 & .445 & .407 & .367 & .326 & .284 & .244 & .206\end{array}$

$\begin{array}{llllllllllllll}30 & .697 & .693 & .683 & .667 & .645 & .617 & .586 & .551 & .514 & .475 & .437 & .400 & .365\end{array}$

$\begin{array}{llllllllllllll}40 & .809 & .806 & .797 & .782 & .762 & .738 & .710 & .678 & .645 & .611 & .577 & .544 & .513\end{array}$

$\begin{array}{lllllllllllllll}50 & .898 & .896 & .888 & .875 & .858 & .837 & .813 & .787 & .759 & .730 & .701 & .673 & .647\end{array}$

$\begin{array}{lllllllllllllll}60 & .961 & .959 & .953 & .942 & .929 & .912 & .893 & .872 & .850 & .827 & .804 & .782 & .762\end{array}$

$\begin{array}{llllllllllllll}70 & .994 & .993 & .988 & .981 & .971 & .959 & .946 & .931 & .916 & .900 & .884 & .969 & .954\end{array}$

$\begin{array}{llllllllllllll}75 & 1.00 & .998 & .994 & .988 & .981 & .972 & .961 & .950 & .938 & .926 & .914 & .902 & .991\end{array}$

$\begin{array}{llllllllllllll}80 & .994 & .994 & .991 & .987 & .982 & .976 & .969 & .962 & .954 & .945 & .937 & .929 & .922\end{array}$

In Table C.2 is the concentrator performance matrix for the 30-degree concentrators (Cases III and IV). Included in this matrix are the cosine loss, coverage, shadowing, clean reflectivity, and end loss.

\section{TABLE C.2. 30-Degree Concentrator Performance Matrix}

$\begin{array}{rrrrrrrrrrrrrr} & \underline{0.0} & \underline{10.0} & \underline{20.0} & \underline{30.0} & \underline{40.0} & \underline{50.0} & \underline{60.0} & \underline{70.0} & \underline{80.0} & \underline{90.0} & \underline{100.0} & \underline{110.0} & 120.0 \\ 0 & .000 & .000 & .000 & .000 & .000 & .000 & .000 & .000 & .000 & .000 & .000 & .000 & .000 \\ 10 & .138 & .135 & .125 & .111 & .093 & .073 & .051 & .031 & .013 & .000 & .000 & .000 & .000 \\ 20 & .283 & .279 & .267 & .247 & .222 & .193 & .162 & .130 & .100 & .072 & .047 & .028 & .012 \\ 30 & .455 & .450 & .435 & .412 & .382 & .346 & .308 & .257 & .228 & .190 & .155 & .125 & .099 \\ 40 & .638 & .632 & .616 & .591 & .557 & .518 & .474 & .428 & .383 & .339 & .298 & .260 & .228 \\ 50 & .808 & .803 & .787 & .762 & .729 & .689 & .645 & .596 & .551 & .504 & .461 & .420 & .385 \\ 60 & .881 & .878 & .870 & .858 & .842 & .823 & .797 & .756 & .713 & .670 & .629 & .590 & .556 \\ 70 & .908 & .907 & .903 & .897 & .889 & .879 & .862 & .845 & .827 & .809 & .779 & .749 & .721 \\ 80 & .908 & .908 & .906 & .903 & .899 & .894 & .888 & .881 & .872 & .862 & .852 & .843 & .834\end{array}$




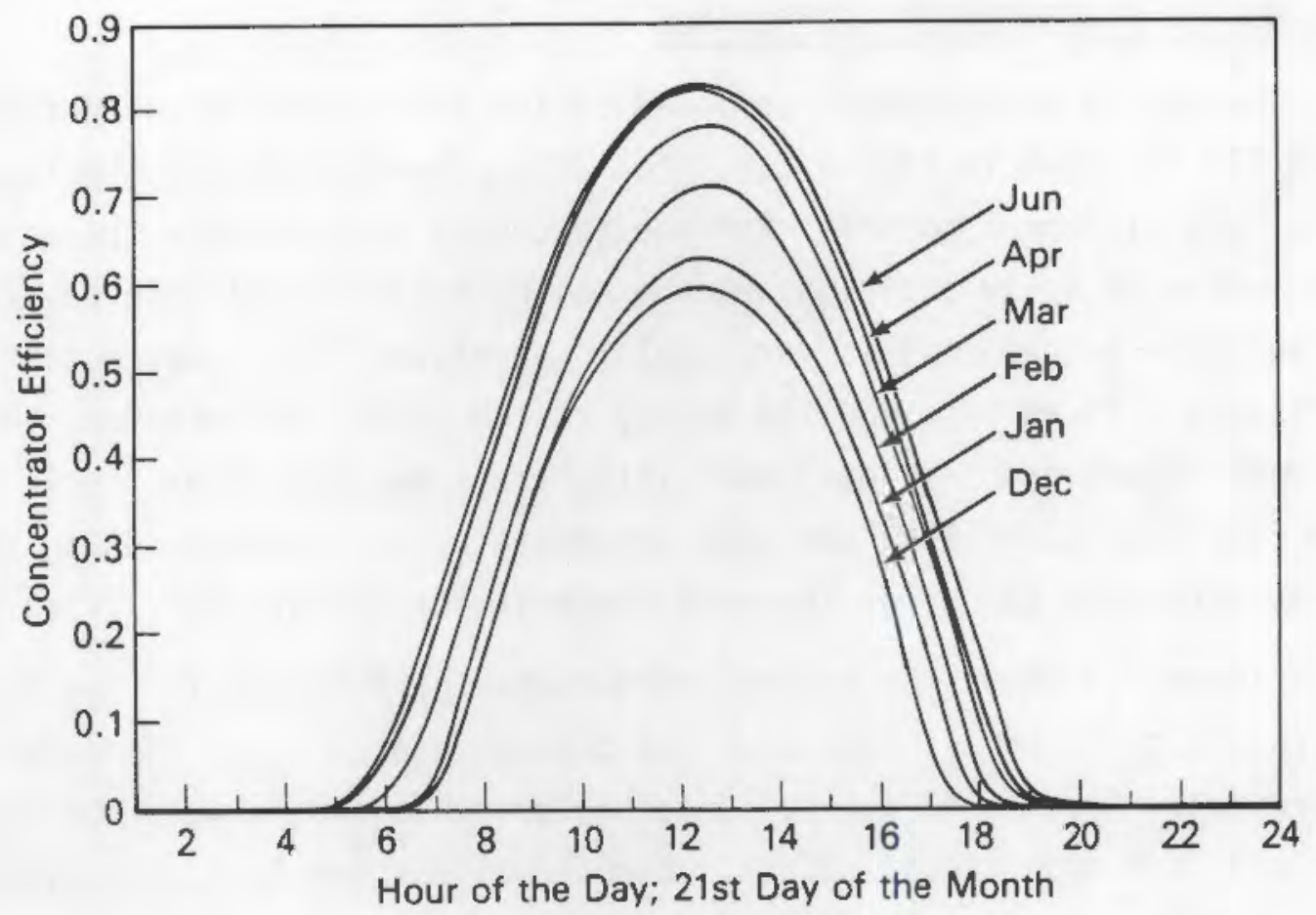

FIGURE C.2. 60-Degree Concentrator Hourly Efficiency

In Table C.3 is the concentrator performance matrix for the iris concentrator (Cases V). Included in this matrix are the cosine loss, coverage, shadowing, clean reflectivity, and end loss.

\section{IABLE C.3. Iris Concentrator Performance Matrix}

\begin{tabular}{|c|c|c|c|c|c|c|c|c|c|c|c|c|c|}
\hline & & & & & & & & & & & & & \\
\hline 0 & & & & & & 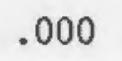 & & & 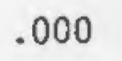 & 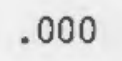 & & & \\
\hline & & & & & & 056 & & & 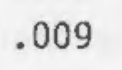 & 00 & 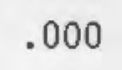 & & \\
\hline & & & 43 & 24 & 200 & 71 & & & 080 & 055 & 35 & & \\
\hline & & 14 & 03 & 83 & 35 & 32. & & .2 & 205 & 167 & 132 & 10 & 07 \\
\hline & & 50 & & 22 & & 468 & & & 35 & 316 & & & \\
\hline & .681 & 17 & 664 & & & S & & 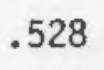 & .493 & . 458 & & & \\
\hline & & 82 & 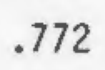 & .755 & 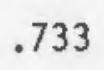 & .70 & .672 & .64 & .608 & .577 & .548 & 5 & .49 \\
\hline & 01 & 314 & 0 & 25 & .805 & .783 & & 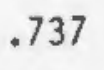 & .709 & 3 & 8 & 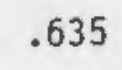 & 61 \\
\hline & 11 & 312 & 316 & 21 & .826 & .815 & 802 & .787 & .773 & .760 & .746 & .733 & 72 \\
\hline
\end{tabular}




\section{C.4 HOURLY CONCENTRATOR PERFORMANCE}

The hourly concentrator performance for the 60-degree concentrator (Cases I and II) is shown in Figure C.2. The data presented is for the twenty-first day of six different months. For the 60-degree concentrator the only losses that vary with solar position are the cosine loss and multiple bounce loss. The multiple bounce loss is very small; therefore, the figure essentially represents a fixed loss and the hourly cosine loss. As expected, the curves are bell shaped and peak near noon (standard time, not solar time). It can be seen from the figure that the peak concentrator performance during the winter can be more than $25 \%$ below the peak concentrator performance during the summer.

Figure C.3 shows the hourly concentrator performance for the 30-degree concentrator (Cases III and IV). The data presented is in the same form as for Figure C.2. For the 30-degree concentrator there are no multiple bounces but end loss is a significant effect. Because of the end loss, the figure shows a much sharper peak for the 30-degree concentrator performance than for the 60degree concentrator. Without the end loss the figure would be almost identical to Figure C.2. The end-loss effect is most pronounced at large incident angles. Therefore, the morning and evening hours have severely degraded performance. In addition, because of a larger incident angle and therefore, high end loss, the winter solstice peak concentrator performance is only about one-half that of the summer solstice performance.

For the iris concentrator (Case V) the hourly performance is shown in Figure C.4. For this concentrator there are minimal multiple bounce losses and, compared with the other concentrators, reduced cosine losses. However, the end loss is so severe (see Figure C.1) that for all hours of the year the concentrator performance is below that of either of the other two concepts. As with the 30degree concentrator, the end loss of the iris concentrator degrades the morning and evening performance as well as the performance during the winter. Although the spillage caused by the end loss is a concentrator loss, it is because of the receiver design. If a full-length receiver had been used, instead of one that was $20 \%$ of full length, the annual concentrator performance of the iris (60.9\%--with a full length receiver) would have been vastly superior to that of the 60-degree concentrator $(56.0 \%)$. 


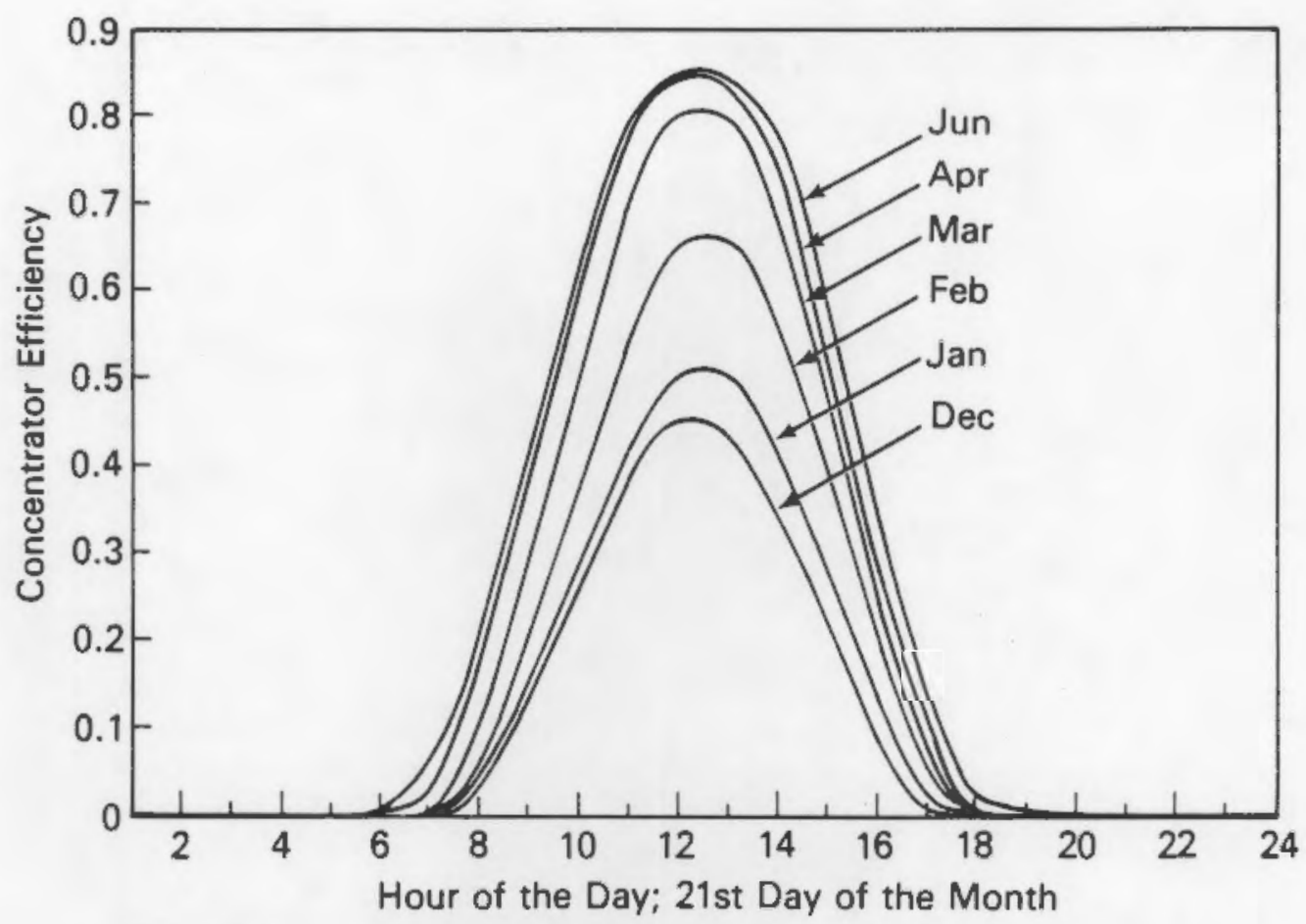

FIGURE C.3. 30-Degree Concentrator Hourly Efficiency

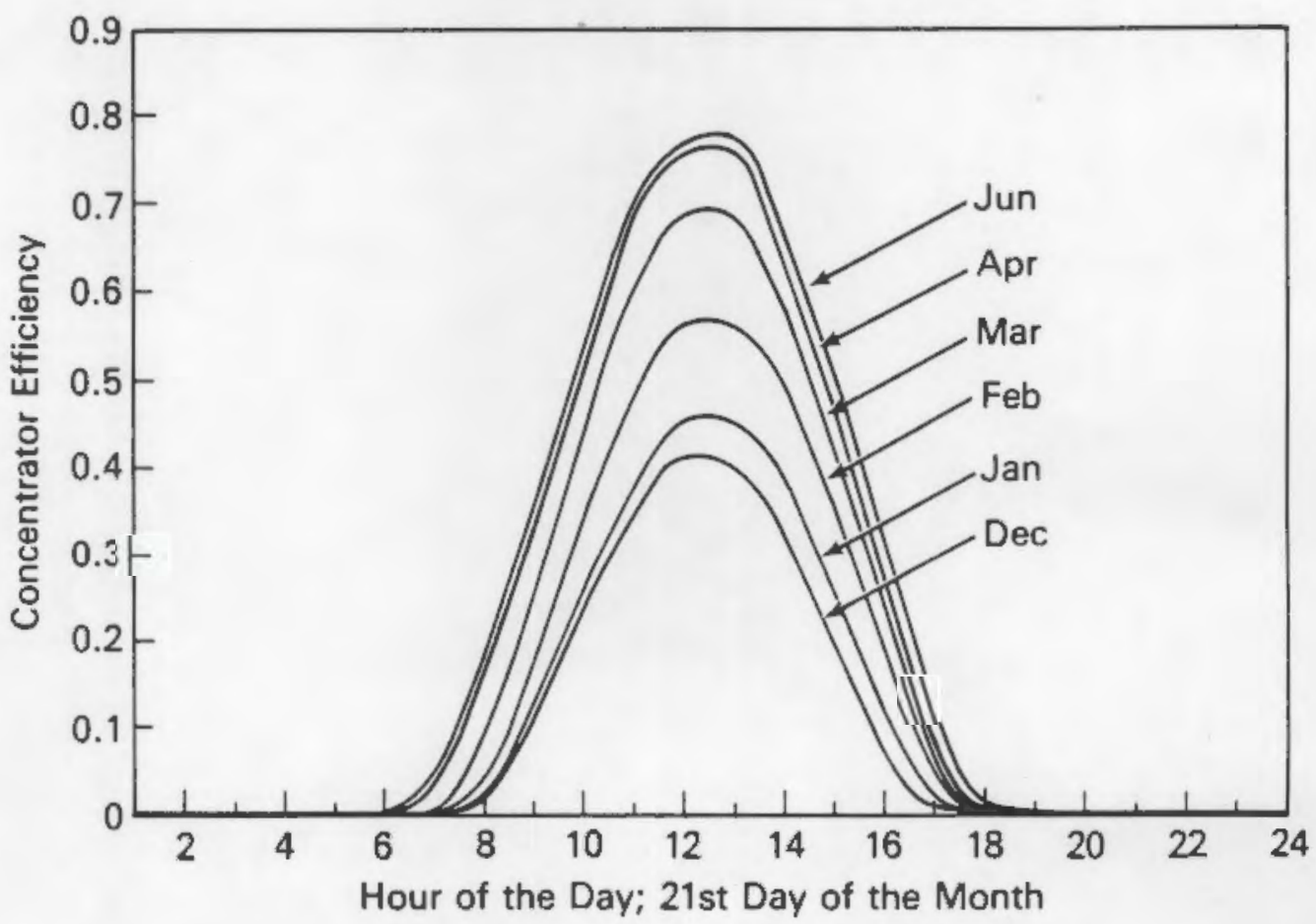

FIGURE C.4. Iris Concentrator Hourly Efficiency 

APPENDIX D

RECEIVER THERMAL LOSS CALCULATIONS 


\section{APPENDIX D}

\section{RECEIVER THERMAL LOSS CALCULATIONS}

This appendix provides additional detail on the approach used to calculate receiver thermal losses for the five receivers considered in the analysis. The techniques varied considerably among the receivers because of the dramatic differences in design detail and available data. With the exception of the Case I actual receiver, no test data and very little simulation data are available for the receivers, so the estimates of thermal losses are subject to uncertainty. Given that the uncertainty is high, and that optimistic assumptions were used in developing estimates of receiver thermal losses, it likely that measured thermal losses for the Cases II through $V$ receivers would be higher than predicted in this study.

The thermal losses from the receivers were calculated for each case by using standard engineering procedures and correlations of heat transfer. The receivers considered for this calculation consisted of the tubing being wrapped around the support pipe and being subjected to the concentrated insolation from the collectors. The working fluid is passed through this tubing. The calculation is done as a heat balance among the incoming concentrated heat, the heat to the working fluid, and the losses by convection, radiation, conduction, and nighttime cool-down. The calculated losses for each receiver case were converted to a loss factor (THRLSS) that is an input to the SOLSTEP code. Correction factors for wind, ambient temperature, and power input rate were calculated for a range of these variables and were normalized to give correction tables for each factor as inputs to SOLSTEP.

The amount of heat losses and the method of calculating them depends on the surface temperature of the receiver. The temperature varies along the receiver because of the varying input concentration and the changing temperature and condition of the working fluid as it moves along the inside of the the receiver tubing. For those cases where part of the circumference of a tubing wrap was in shadow, the temperature was taken as an average of the heated and unheated parts of the wrap. The difference in temperature between the receiver 
and the surroundings provides the driving force for heat transfer by convection and radiation, and by conduction to the support structure of the receiver. At night the receiver cools down, so heat is lost that must be replaced at startup the next day. The nighttime cool-down losses were taken as a time distributed loss over a typical operating day to allow them to be easily added to the other losses on a time basis.

\section{D.1 CASE I: 60-DEGREE CONCENTRATOR WATER/STEAM RECEIVER}

Case I had quite a bit of background information. It had been extensively studied by Texas Tech University (TTU) and had detailed results for several cases from different computer codes they had used. The objective of this task was to determine whether TTU estimates of receiver losses appeared reasonable. Tables of data provided for this basic case were verified by some check calculations, and were then used to build a table of correction factors for SOLSTEP. The temperature profile was assumed to stay the same at any power level; the difference in power to be taken up by an adjustment in operating flow rate.

The temperature profile of the receiver is shown in Figure 2-21 of Simpson, O'Hair and Reichert (1981). This temperature profile is assumed to remain the same throughout the day. The receiver heat input and loss results for the base case at 10 mph wind are given in Table D-2 of Simpson, O'Hair and Reichert (1981).

A calculation check of the TTU calculated heat losses was made by the sectional averaging of temperatures for the outside of the cylindrical receiver. The receiver is considered as several constant temperature lengths for which the losses are calculated and summed. The sum of the convection and radiation losses in the check calculation are $621 \mathrm{kBtu} / \mathrm{hr}$, versus $642 \mathrm{kBtu} / \mathrm{hr}$ given by the computer program result of the Texas Tech fixed mirror distributed focus (FMDF) Thermo-fluid Analysis code. Based on these calculations, the overall losses predicted by TTU for this receiver were felt to be reasonable. Estimated design-point receiver heat losses are shown in Table D.1; the total heat loss does not equal the individual components because of roundoff. 
IABLE D.1. Case I Receiver Design-Point Heat Losses

\begin{tabular}{lr} 
Radiation & $89 \mathrm{~kW}$ \\
Convection & $103 \mathrm{~kW}$ \\
Conduction & $2 \mathrm{~kW}$ \\
\cline { 2 - 2 } Total & $195 \mathrm{~kW}$
\end{tabular}

\section{D.2 CASE II: 60-DEGREE CONCENTRATOR SALT RECEIVER}

The Case II receiver did not have as extensive a background as the Case I receiver. Receiver design assumptions provided by TTU are shown in Table D.2. The calculations provided by TTU during the course of the study gave temperature profiles (fluid temperature versus distance along the receiver) and receiver efficiencies.

For this receiver Pacific Northwest Laboratory (PNL) developed an independent estimate of the receiver efficiencies (or losses) to use in the study. As with Case I, a piecewise calculation of the receiver thermal losses was performed. The fluid temperature profile and salt flow rate provided by TTU were used to derive a surface temperature, and the receiver radiative and convective losses were calculated from the surface temperature. In modeling the annual receiver performance in SOLSTEP, correction factors were derived for the receiver input power levels, because the temperature difference across the wall (from the fluid salt to the surface) was significant. The estimated design-point receiver heat losses are shown in Table D.3.

\section{D.3 CASE III: 30-DEGREE CDNCENTRATOR WATER/STEAM RECEIVER}

Case 3 had no input from TTU on receiver temperature profile or power input. A list of receiver design assumptions used in developing thermal loss estimates is shown in Table D.4. The design assumptions were based on relevant characteristics of the other salt and water/steam receivers characterized by TTU. 
TABLE D.2. Case II Receiver Design Assumptions

Receiver Design Operating Conditions

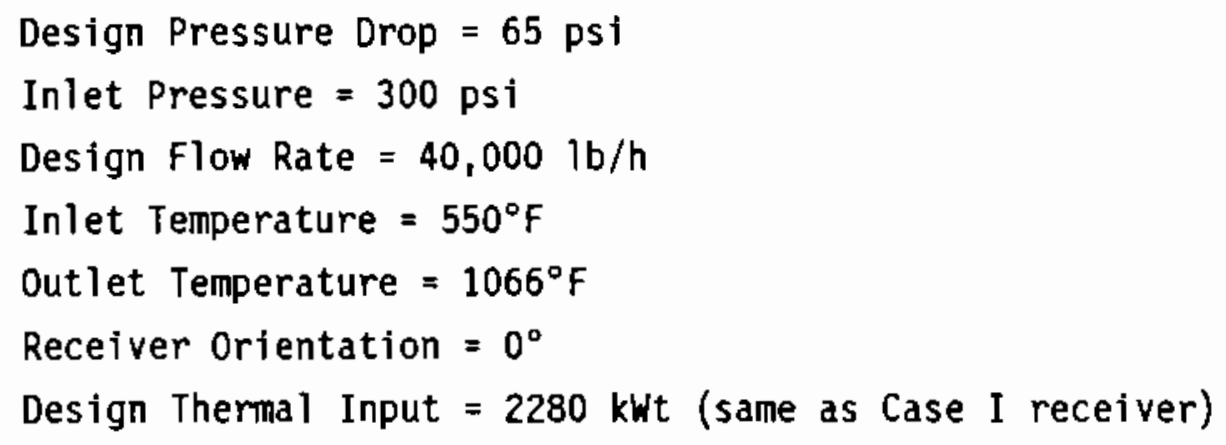

Receiver overall dimension is 18.75 -inches outside diameter (OD) Receiver length $=58 \mathrm{ft}$

Tube inside diameter (ID) $=.04167 \mathrm{ft}(0.5$ inch)

Tube $O D=.072929 \mathrm{ft}(0.87515 \mathrm{inch})$

TABLE D.3. Case II Receiver Design-Point Heat Losses

$\begin{array}{lr}\text { Radiation } & 333 \mathrm{~kW} \\ \text { Convection } & 156 \mathrm{~kW} \\ \text { Conduction } & \frac{2 \mathrm{~kW}}{491 \mathrm{~kW}} \\ \text { Total } & 491 \mathrm{k}\end{array}$

Thermal loss calculations for this receiver presented a unique problem because no temperature profile was received from TTU for this case. This problem is similar to that in Case IV, for which a single phase salt heating code SOLAR was programmed. For this receiver, however, the working fluid is water that is heated from subcooled, through boiling, to the superheated outlet state. The problem is complicated by the fact that the properties and heat transfer coefficients have to be in keeping with the water conditions in the tubes. The pressure drop must also be calculated in order to determine the boiling temperatures. A simple analytical model was developed to perform the calculations. The basic approach used in the calculations is outlined in Table D.5. Because both temperature and pressure were known at the outlet, but 
only temperature at the inlet, the calculations were done from the outlet end and worked toward the inlet end.

TABLE D.4. Case III Receiver Design Assumptions

Receiver Design Operating Conditions

\begin{tabular}{ll} 
Estimated Peak Input Power & 2114 \\
Inlet Temperature $\left({ }^{\circ} \mathrm{F}\right)$ & 100 \\
Outlet Temperature $\left({ }^{\circ} \mathrm{F}\right)$ & 1000 \\
Receiver Design & \\
\hline $\begin{array}{l}\text { Number of Tubes } \\
\text { Tube ID (in.) }\end{array}$ & 32 \\
Tube OD (in.) & 0.3675 \\
Flow Area (sq. in.) & 0.535622 \\
Receiver OD (in.) & 3.39 \\
Receiver Length (ft) & 33.5 \\
Support Tube OD (in.) & 60.9 \\
ST Wall Thickness (in.) & 32.4 \\
\end{tabular}

0.5 
IABLE D.5. Calculational Procedure for Case III Receiver

- Start with mass flow rate assumption, $\dot{m}$

- Iterate to find $\dot{i}$ that will give the correct inlet temperature

- Step down through $j$ surface elements to find element temperature

- Perform heat balance on each element

- Return temperature when error criterion is met

- Calculate pressure increment and element pressure

- Check to see if saturation temperature has been reached

- Convert any heat below the saturation to a quality value

- Continue iterating down but finding quality by heat balances

- Calculate two-phase pressure increment and element pressure

- Switch to subcooled conditions when quality goes less than zero

- Convert any "negative" quality to subcooling

- Continue iterating down finding element temperature for liquid

- Calculate liquid increment of pressure and element pressure

- Check inlet element temperature criterion, try next im

- Store input heat, temperatures, losses, quality and pressures

- Print and graph results

The estimated design-point receiver heat losses are shown in Table D.6; the total heat loss does not equal the individual components because of roundoff.

TABLE D.6. Case III Receiver Design-Point Heat Losses

\begin{tabular}{lr} 
Radiation & $81 \mathrm{~kW}$ \\
Convection & $69 \mathrm{~kW}$ \\
Conduction & $5 \mathrm{~kW}$ \\
\cline { 2 - 3 } Total & $156 \mathrm{~kW}$
\end{tabular}

D.4 CASE IV: 30-DEGREE CONCENTRATOR SALT RECEIVER

Design assumptions received from TTU for this receiver are highlighted in Table D.7. 
TABLE D.7. Case IV Receiver Design Assumptions

Receiver Design Operating Conditions

Design Pressure Drop $=60 \mathrm{psi}$

Inlet Pressure $=200$ psi

Design Flow Rate $=28,000 \mathrm{lb} / \mathrm{h}$ (ETRANS)

Inlet Temperature $=550^{\circ} \mathrm{F}$

Outlet Temperature $=1050^{\circ} \mathrm{F}$

Receiver Orientation = zero degrees

Design Thermal Input $=1532 \mathrm{~kW}_{\mathrm{t}}$

Receiver Design

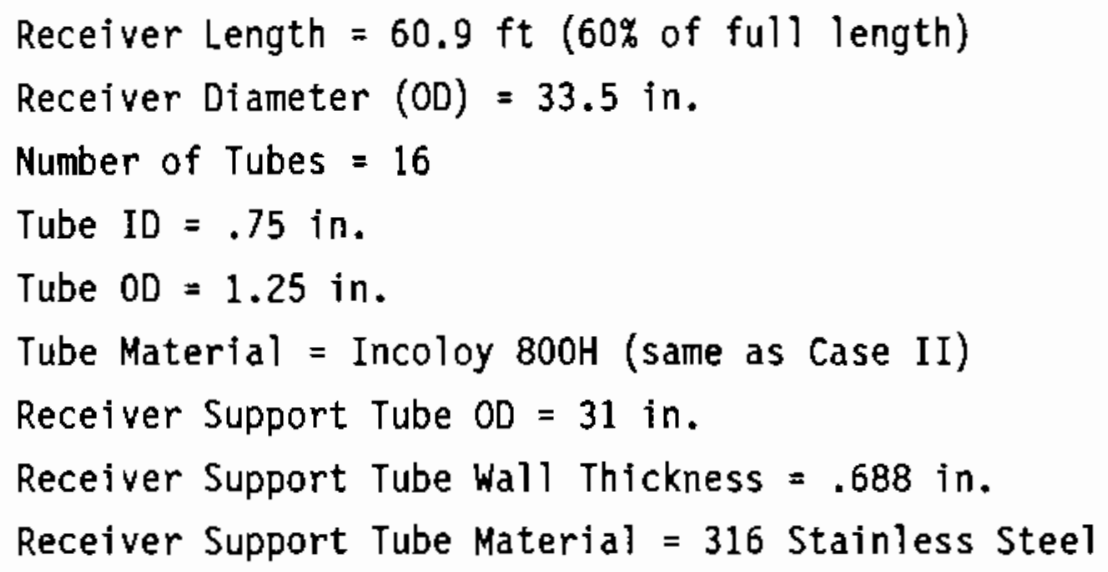

The performance estimates for this receiver provided by ITU included estimates of flux on the receiver as a function of receiver position. This information was used to calculate the receiver surface temperature profile, and then the radiative and convective losses. Table D. 8 highlights the basic approach used in the calculation. Receiver design-point thermal loss estimates are shown in Table D.9.

\section{D.5 CASE V: IRIS/STIRLING RECEIVER}

Very little design information was available for the Iris/Stirling receiver. Because the Stirling engine requires an isothermal heat input, a heat pipe receiver was specified. This simplifies the estimation of thermal losses, because an isothermal receiver surface temperature can be assumed. The 
basic design aspects of the receiver are shown in Table D.10. Table D.11 summarizes the receiver design-point thermal loss estimates.

IABLE D.8. Calculational Procedure for Case IV Receiver

- Start with mass flow, $\dot{m}$ assumption

- Iterate to find $\dot{m}$

- Step through $j$ surface elements to find element temperature

- Perform heat balance

- Return temperature when error criterion is met

- Store input, temperature losses

- Try next in

- Print results when error criterion is met

TABLE D.9. Case IV Receiver Design-Point Heat Losses

$\begin{array}{lr}\text { Radiation } & 500 \mathrm{~kW} \\ \text { Convection } & 314 \mathrm{~kW} \\ \text { Conduction } & 5 \mathrm{~kW} \\ \text { Totat } & 819 \mathrm{~kW}\end{array}$

TABLE D.10. Case V Receiver Design Assumptions

Receiver Design Operating Conditions

Delivery Temperature $=1200^{\circ} \mathrm{F}$

Surface Temperature $=1250^{\circ} \mathrm{F}$

Receiver Design

$$
\begin{aligned}
& \text { Receiver Length }=20 \mathrm{ft}(20 \% \text { of full length) } \\
& \text { Receiver Diameter }(00)=32 \mathrm{in} .
\end{aligned}
$$

TABLE D.11. Case V Receiver Design-Point Heat Losses

$\begin{array}{ll}\text { Radiation } & 697 \mathrm{~kW} \\ \text { Convection } & 19 \mathrm{~B} \mathrm{~kW} \\ \text { Total } & 895 \mathrm{~kW}\end{array}$

0.8 
APPENOIX E

TRANSPORT SYSTEM PERFORMANCE ANALYSIS 


\section{APPENDIX E}

\section{TRANSPORT SYSTEM PERFORMANCE ANALYSIS}

The transport subsystem consists of the field piping network and the collector risers and downcomers. The design and analysis of the system were carried out with the use of the ETRANS (Energy TRANsport System) computer code (Barnhart 1980). ETRANS was developed at Pacific Northwest Laboratory (PNL) to optimize the piping system associated with distributed networks of solar collectors.

The ETRANS code optimizes the flow field piping, section by section, using an iterative approach to find the combination of pipe diameter and insulation thickness that results in the lowest life cycle cost. Results of the analysis include the capital investment required, the total heat loss, the pumping power, the resulting operating expenses, and the specifications for the characterized piping system components.

Parameters characterizing the thermal performance, pumping power, and total capital investment of the transport system were modeled as a function of field size and were supplied as input to the SOLSTEP computer code. This appendix will describe the details of the overall analysis.

\section{E.1 SYSTEM DEFINITION}

Table E.1 provides a list of general parameters defining the transport system for each fixed mirror distributed focus (FMDF) bowl case studied. The developed system designs were based on peak operating conditions. Case III pressure drop data were not available from Texas Tech University (TTU); therefore, estimated values were used. Because of the limited information available on the riser and downcomer, specifications of pipe lengths and associated components were based on best engineering estimates.

The water/steam systems (Cases I and III) are direct Rankine cycle systems. Steam generated in the receiver flows through the return side of the transport system to the heat engine, is then condensed, and flows as liquid through the 
supply side back to the receiver. In a direct cycle, the boundary between the heat engine, or load, and the transport system is not clearly defined.

TABLE E.1. FMDF Bowl Field Specifications

Field Description

Bowl Design, deg

Working Fluid

Concentrator Dia., ft

Peak Input Power, kWe

Operating Hours

Capacity Factor

\section{Receiver Design}

Flow Rate, $1 \mathrm{bm} / \mathrm{hr}$

Pressure Drop, psi

Outlet Temperature, ${ }^{\circ} \mathrm{F}$

Outlet Pressure, psia

Transport System

Supply Temperature, ${ }^{\circ} \mathrm{F}$

Supply Side Piping

Supply Side Insulation

Return Side Piping

Return Side Insulation

Riser Pipe Length, ft

Downcomer Pipe Length, $\mathrm{ft}$

\& Flex Hoses in Riser and Downcomer

Load Pressure Drop, psi
Case I

60

steam

203

2280

8.7

0.36

5827

175

1000

1000

100

CS

fiber-

glass

SS

calcium

silicate

180

180

4.4

900
Case II

60

salt

203

2280

8.2

0.34

40116

65

1066

235

550

CS

fiber-

glass

SS

calcium

silicate

180

180

4.4

0
Case III

$\begin{array}{rr}30 & 30 \\ \text { steam } & \text { salt } \\ 203 & 203 \\ 2114 & 1828 \\ 7.0 & 6.0 \\ 0.29 & 0.25\end{array}$

$\begin{array}{rr}5403 & 33187 \\ 175 & 60 \\ 1000 & 1050 \\ 1000 & 140\end{array}$

100

550

CS

CS

fiber-

glass

glass

SS

SS

calcium

silicate silicate

318

318

318

318

2.5

2.5

900 
For this study, the return-side boundary was established at the inlet to the steam chest of the turbine. The supply-side boundary was established at the discharge of the low pressure condensate booster pumps. In this way, the transport system flow field circulating pumps also serve as the boiler main feed pumps. The field circulating pumps were sized to provide the required flow and pressure rise for the transport system. The feed pumps were selected to operate with a suction of $100 \mathrm{psi}$ and a discharge pressure of $1200 \mathrm{psi}$.

The molten salt systems (Cases II and IV) contain storage tanks. The return line feeds into a large hot tank and the supply line comes from a large cold tank. Because of this, the field transport load pressure drop for these cases is 0 psi.

\section{E.2 FIELD LAYOUT}

Design of a collector field layout involves a tradeoff between the cost of overly long pipe runs versus collector performance losses because of shading. The physical dimensions of the FMDF bowl design demands a significant amount of piping for fluid distribution. The collector field spacings used for the bowl systems were based on those specified by TTU: a north-south spacing of 322 feet (center-to-center) and an east-west spacing of 203 feet (center-tocenter). The basic arrangement is depicted in Figure E.1.

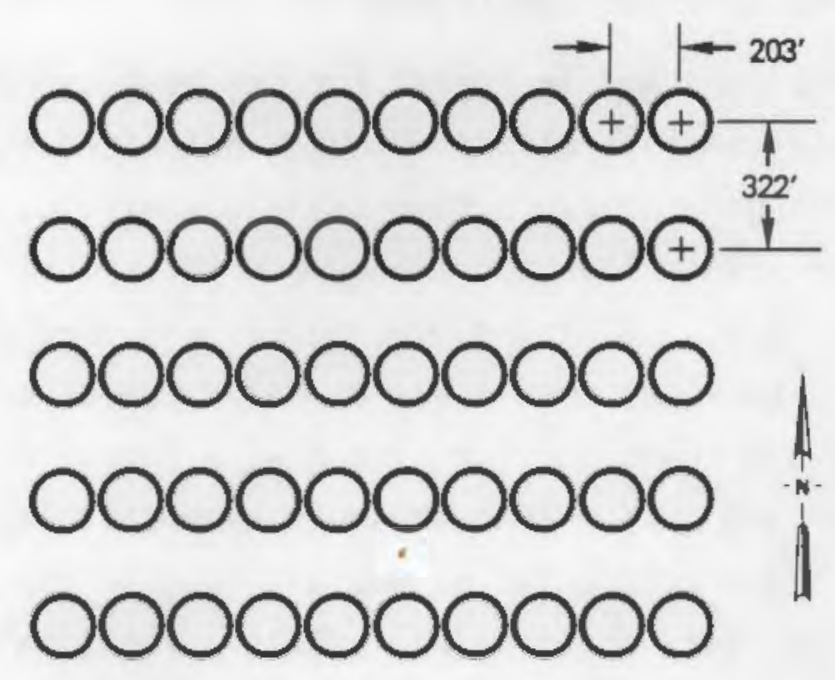

FIGURE E.1. General Bowl Field Arrangement 
The piping layouts used were selected from those available in the ETRANS code. A parabolic dish collector layout was used for field sizes greater than 100 bowls. The smaller field sizes were modeled using a module layout feature. Preliminary calculations showed that the module layouts provide lower capital costs for bowl fields sizes smaller than 100 bowls.

Figure E.2 shows the ETRANS parabolic dish layout. The basic arrangement is suitable for the larger bowl systems where the total number of collectors is on the order of those found in typical dish systems. Ideally the plant is located in the center of a square symmetrical field of collectors; the code is then able to use one-eighth symmetry in order to perform the analysis. To account for the asymmetry in the specified bowl layout, and the symmetry required by ETRANS, two sets of calculations were performed for each design. The first calculation was done by using the correct field spacing in the northsouth direction. The second calculation was done by using the east-west field spacing and the final results were obtained by taking the average of the two separate results.

The basic dish layout includes field supply and return lines which are collinear and supported above the ground. Each section in the main headers and branches are individually optimized. In addition to these sections, each collector has a riser and downcomer associated with it; these are optimized in groups using nominal fluid conditions.

A description of the module layout for the bowl system is given in Figure 3a. A module consists of a previously optimized sub-field of collectors. The modules are arranged in double rows along a manifold. Figure $3 \mathrm{~b}$ shows the ETRANS model of the system layout. Two symmetric layouts were used to obtain the actual system layout. A single bowl module was used for one set of calculations, and a two-bowl module was used for the other. The modules included the riser and downcomer for each bowl along with connecting pipe. These modules were laid out in a north-south symmetric layout and an east-west symmetric layout. Each configuration was analyzed so that the total input power, pumping power, etc. would be equivalent. The final system was characterized by the averaging of the two separate sets of results. 


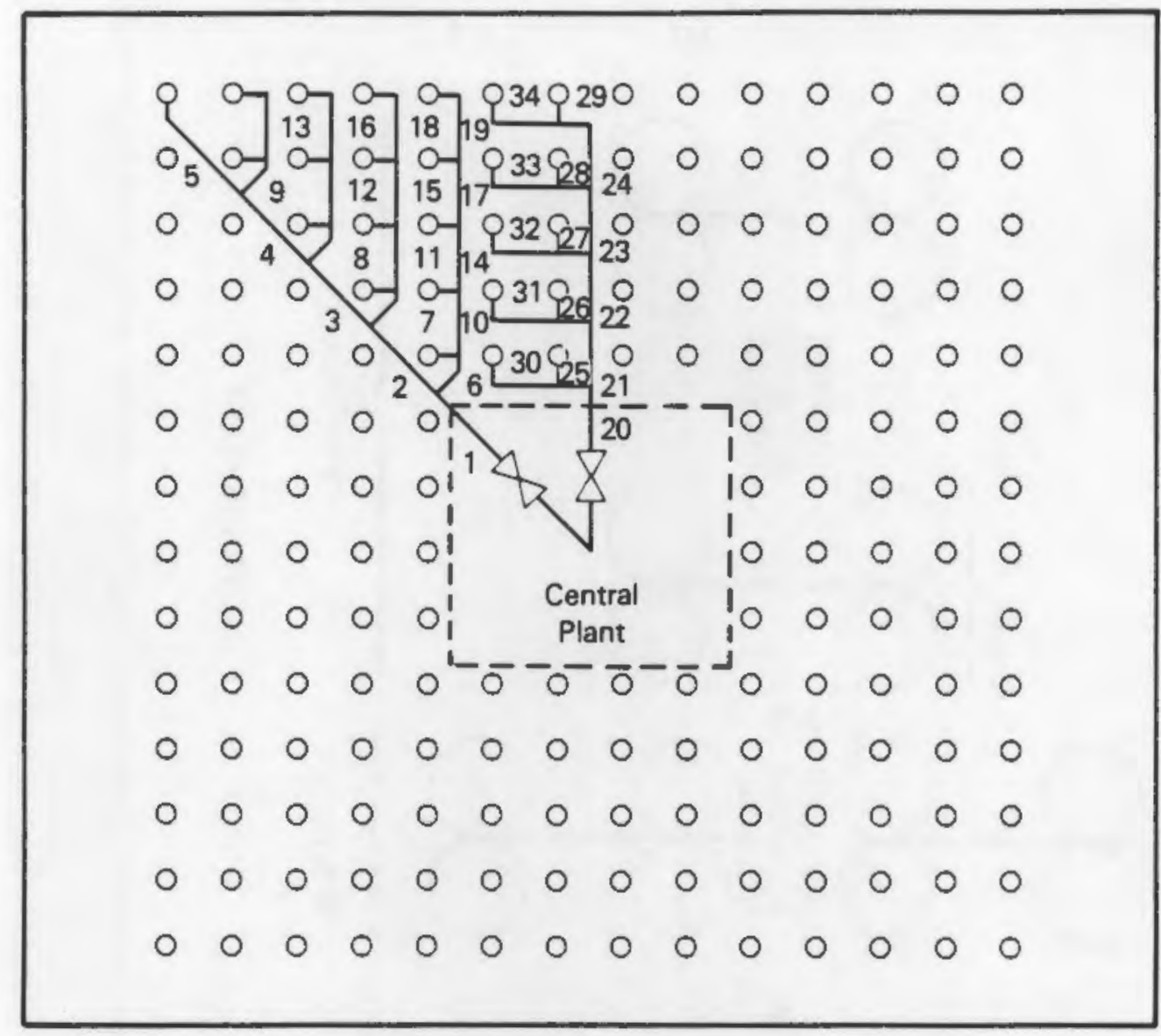

FIGURE E.2. Parabolic Dish Collector Field Layout

The field shown in Figure $3 a$ is the optimal design for minimum life cycle costs. A design with just two rows of concentrators is more costly and less efficient because of the larger main header pipes required.

The module field provides a more optimal layout than the parabolic dish field for the smaller system sizes (1-100 bowl range) because it minimizes the main header lengths. Though the total length of piping is longer with this layout, the size of the main header pipes is the smallest possible. This results in lower piping costs during installation and reduced thermal losses during operation, therefore providing the lower cost and higher efficiency transport systems. Beyond a certain field size, the dish piping layout provides the more efficient, less costly, layout. 
Example: 16 Bowis

m
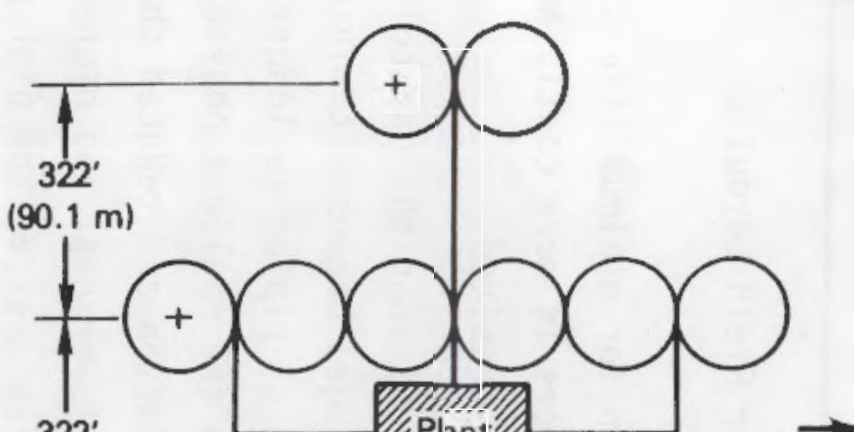

1

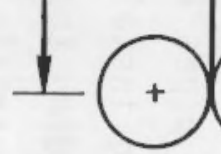

1

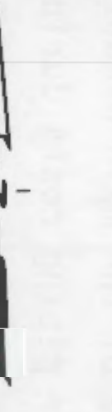

(a) System Layout

FIGURE E.3a. System Layout

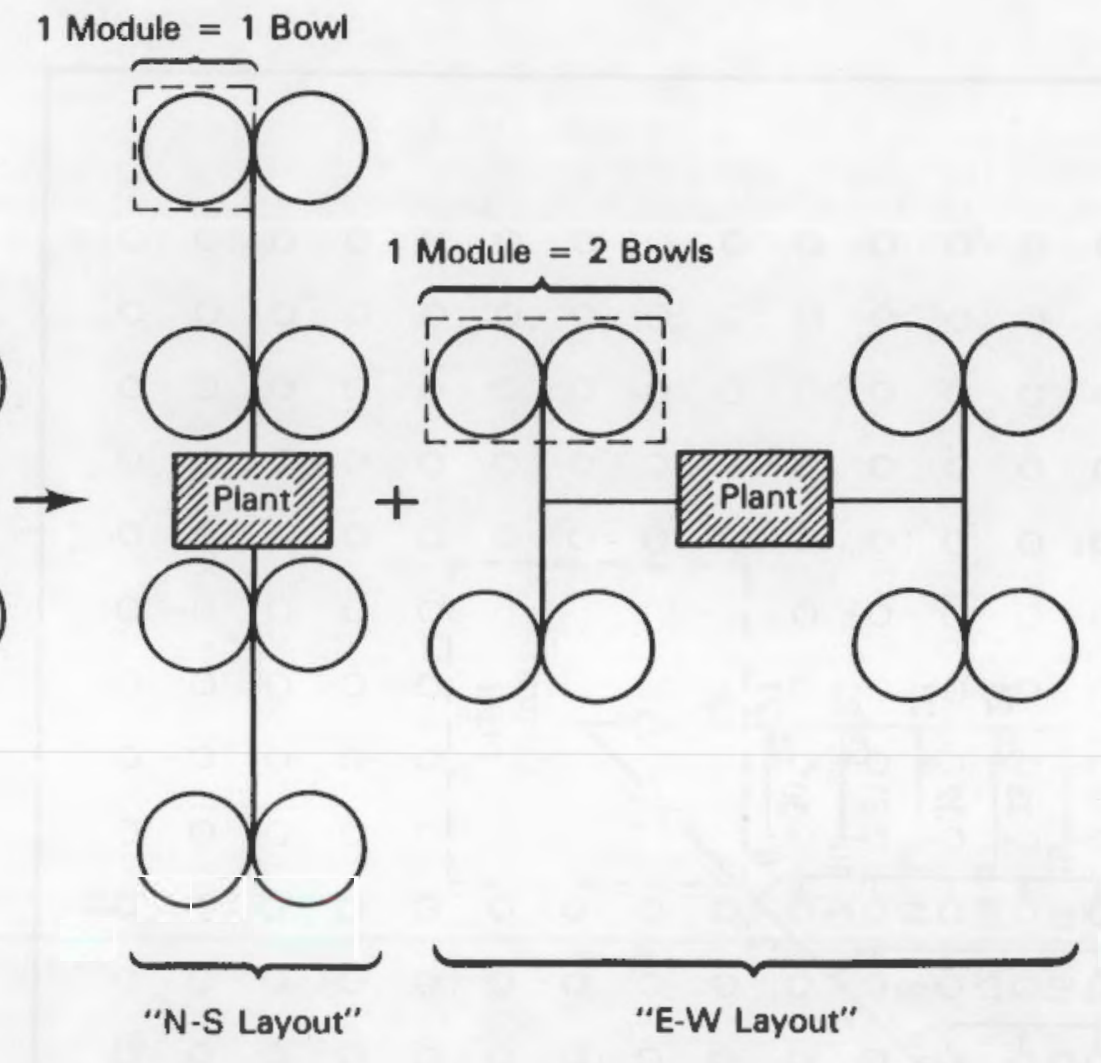

(b) ETRANS Model 


\section{E.3 PIPING SYSTEM DETAILS}

The piping system consists of schedule 40 and 80 carbon steel piping on the supply (cold) side and schedule 40 and 80 stainless steel piping on the return (hot) side. The transition for schedule change is based on the standard Code formulas for pipe wall (PW) thickness (Crocker 1973). Fiberglass insulation is used on the supply side. The return side insulation is calcium silicate.

Specifications of fittings and supports within the field are based on the standard piping systems defined in ETRANS. Fittings are welded into the lines. Valves and receivers are flanged. Support spacing and design are based on tabulated data from previous studies (Barnhart 1980). Thermal expansion loops are U-shaped and are spaced according to a convenient field dimension. The length of each expansion loop is based on tabulated data and is adjusted for operating temperature, interloop spacing, and material properties.

Flex hose is included in the riser and downcomer sections to provide rotational movement and compensation for thermal expansion. Estimated lengths are supplied in Table E.1. Costs are based on flex hose sized at the optimized riser and downcomer diameters, which ranged from 1 to 4 inches.

For the molten salt systems, the cost of the fluid was included to account for the initial cost of filling the field and for the cost of continuous replenishment. Heat tracing is required to prevent freezing during nighttime cooldown. Both capital and operating expenses for heat tracing were included in the analysis. The value used for the cost of the molten salt is $\$ 436.40$ per 1000 kilograms. The fluid makeup rate is assumed to be $1.5 \%$ per year.

\section{E.4 PUMP DETAILS}

Capital costs for the pump, motor, and associated piping system are included in the total capital investment of the transport system. The pump costs are based on multi-stage, high-pressure, carbon steel, centrifugal pumps for the steam systems and single-stage, low-pressure, carbon steel centrifugal pumps for the molten salt systems. 
For each transport system design, three pumps were used to provide system reliability. Each pump was rated at one half of maximum design flow. Inlet and outlet jolation valves, associated fittings and piping, insulation and installation costs were all included in the total cost of the pump system. The piping sizes along with the pump and motor component sizes were computed external to ETRANS. For small field sizes, the pump system cost is approximately $25 \%$ of the total transport system cost and for very large fields, the cost is approximately $1 \%$ of the total system cost.

\section{E.5 SYSTEM PERFORMANCE CALCULATIONS}

The performance of the energy transport system is characterized by the required pumping power and the corresponding thermal losses. A steady-state analysis is carried out by ETRANS to evaluate the pumping power and day and night heat losses. The results are based on section-by-section calculations using average values for the flow conditions and ambient temperatures. Specified operating conditions are given in Table E.1.

Local fluid properties were used in the calculations except at collector risers, downcomers, and connecting components, where the nominal fluid properties are used. Fluid properties for draw salt were taken from previous ETRANS studies and verified against data that are currently being used. Steam properties were obtained from the EPRI water properties functions (EPRI 1983).

The energy required to pump the working fluid through a section for a period of $t$ hours per day is calculated as :

$$
P w=\frac{f}{2 p_{s}}\left(\frac{L}{D}\right) e q \int_{0}^{t} \frac{m \rho v^{2}}{\eta_{p} \eta_{m}} d t
$$

where: $\quad P_{w}=$ pump work

$$
\begin{aligned}
f & =\text { fanning friction factor } \\
\rho & =\text { density of fluid } \\
\left(L_{D}\right)_{\text {eq }} & =\text { equivalent length over pipe diameter }
\end{aligned}
$$




$$
\begin{aligned}
& m=\text { mass flow rate } \\
& v=\text { velocity of fluid } \\
& \eta_{p}=\text { pump efficiency } \\
& \eta_{m}=\text { motor efficiency. }
\end{aligned}
$$

Key assumptions used in the above equation are:

1. fully turbulent flow through smooth pipes

2. resistance to flow of valves and fittings expressed in terms of (L/D)eq with values taken from Crane (1974)

3. steady-state flow at average conditions.

This equation is used with each candidate pipe size for a given section to determine the corresponding pumping costs. The pump and motor efficiencies are assumed to be 0.83 and 0.90 ; respectively.

In addition to the section-by-section optimization routine, a downsizing procedure was employed. Pipe sections of parallel flow paths located in the shorter loops can often be made smaller than the apparent optimum because of the requirement of equal loop pressure drops. This allows ETRANS to make a second pass through the field to downsize appropriate pipe sections. The result is a reduction in both capital costs and heat losses.

\section{E.6 HEAT LOSS CALCULATION}

For both the daytime and nighttime heat loss calculations, the pipe is assumed to be at fluid temperature and the outer surface of the insulation at ambient temperature. This implies that the insulation is the only significant resistance to heat flow. The daytime heat loss calculation therefore reduces to the steady-state analysis of fluid flow in a single-walled cylinder. The daytime ambient temperature used in the analysis is $77^{\circ} \mathrm{F}\left(25^{\circ} \mathrm{C}\right)$.

For nighttime heat loss calculations, the fluid is assumed to be stagnant and may initially be subcooled, two-phased, or superheated. Depending upon the fluid's initial state and the rate of heat loss, the fluid may remain in its initial state or drop to a lower one (e.g., from superheated to subcooled). other factors accounted for in the analysis are: 1) isothermal cooling of a 
two-phase mixture, 2) thermal capacitance of the pipe, and 3) temperature dependency of the thermal conductivity of insulation. The nighttime ambient temperature was assumed to be $59^{\circ} \mathrm{F}\left(15^{\circ} \mathrm{C}\right)$.

For the molten salt systems, heat tracing is included in the analysis. When the calculations show that the fluid will freeze before the night ends, heat trace power is turned on at the level required to maintain the fluid just above the freezing point. The cost of the heat trace energy is then added to the other operating expenses and therefore becomes another element in the life cycle cost. In this way ETRANS detemines directly whether it is more cost-effective to run the heat tracing or to install thicker insulation. The heat trace energy is not included as a thermal loss in the transport system but is included in the plant parasitics.

ETRANS calculates a daily average thermal efficiency (considering both daytime and nighttime losses) based on the parameters in Table E.1. The operating hours used in the analysis are taken from preliminary SOLSTEP runs used to determine the approximate number of hours per day the system is actually operated. The ETRANS calculations assume that the plant operates every day, and while the transport system is operating the fluid is at design conditions. Therefore, the daily average thermal efficiency and the annual average efficiencies are the same. If there are extended periods of non-operation, the actual losses will be less because the transport fluid will be at lower temperatures (so the losses will be lower), and/or the energy losses from the transport system will be supplied by the heat tracing (salt systems) or cold weather heater (water \steam systems).

\section{E.7 ETRANS RESULTS}

The minimum levelized energy cost (LEC) transport subsystem designs and performance for each of the four bowl cases with thermal transport were characterized. The results are tabulated in Tables E.2 through E.5. 
TABLE E.2. FMDF Bow1 Transport Systern Conditions

Case I: 60-Degree Bowl, Water/Steam System

\begin{tabular}{|c|c|c|c|c|c|}
\hline \multirow{2}{*}{$\begin{array}{c}\text { Gross } \\
\text { Concentrator } \\
\text { Area, } m^{2} \\
\end{array}$} & \multirow[b]{2}{*}{$\begin{array}{c}\text { Number } \\
\text { of Bowls } \\
\end{array}$} & \multirow[b]{2}{*}{$\begin{array}{c}\text { System } \\
\text { Efficiency } \\
\end{array}$} & \multirow[b]{2}{*}{$\begin{array}{l}\text { Pumping } \\
\text { Power, kWe }\end{array}$} & \multicolumn{2}{|c|}{$\begin{array}{c}\text { Turbine Inlet Fluid } \\
\text { Conditions }\end{array}$} \\
\hline & & & & Temp., ${ }^{\circ} \mathrm{F}$ & Pressure, psia \\
\hline 3007 . & 1 & 98.1 & 7.77 & 988.4 & 999.3 \\
\hline 6014 . & 2 & 97.2 & 15.56 & 982.8 & 998.0 \\
\hline 24055 . & 8 & 95.6 & 62.52 & 973.3 & 992.8 \\
\hline 48110 . & 16 & 95.5 & 127.3 & 970.1 & 992.8 \\
\hline 96219. & 32 & 94.3 & 253.8 & 963.1 & 986.1 \\
\hline 144329. & 48 & 93.5 & 382.3 & 958.1 & 981.6 \\
\hline 192440 & 64 & 93.0 & 507.4 & 956.7 & 977.2 \\
\hline 240548 . & 80 & 92.6 & 638.0 & 955.0 & 975.2 \\
\hline 577315. & 192 & 91.0 & 1536.4 & 943.6 & 966.8 \\
\hline 757726 . & 252 & 90.6 & 2019.2 & 942.1 & 965.3 \\
\hline
\end{tabular}

System Efficiency $=\frac{\text { Total Average Energy - Total Thermal Loss }}{\text { Total Average Energy }} * 100 \%$

where:

total average energy $=10121 \mathrm{kWh} /$ day per bowl (SOLSTEP preliminary result) total thermal loss includes daytime and nighttime losses. Nighttime loss is the heat lost at night up to the point where power is required to keep the fluid from freezing.

Fluid conditions are at the exit of the transport system. 
TABLE E.3. FMDF Bowl Transport System Conditions

Case II: 60-Degree Bowl, Molten Salt System

Gross

\begin{tabular}{c} 
Concentrator \\
Area, $\pi^{2}$ \\
\hline
\end{tabular}

3007 .

6014 .

12027.

24055.

48110 .

96219.

144329.

192440 .

240548 .

577315.

757726.

2345344 .
Number of Bowls Efficiency

97.9

96.8

96.8

96.0

95.1

93.4

92.4

91.7

91.1

88.5

88.1

85.9
Pumping Power, kwe

Storage Inlet Fluid Conditions

\begin{tabular}{cc}
\hline Temp. ${ }^{\circ} \mathrm{F}$ & Pressure, psia \\
1065. & 223.1 \\
1064. & 220.1 \\
1064. & 220.1 \\
1063. & 209.2 \\
1061. & 206.1 \\
1060. & 189.7 \\
1059. & 176.5 \\
1058. & 165.7 \\
1058. & 153.7 \\
1055. & 135.7 \\
1055. & 129.8 \\
1053. & 105.4
\end{tabular}

System Efficiency $=\frac{\text { Total Average Energy - Total Thermal Loss }}{\text { Total Average Energy }} * 100 \%$

where:

total average energy $=7558 \mathrm{kWh} /$ day per bowl (SOLSTEP preliminary result) total thermal loss includes daytime and nighttime losses. Nighttime loss is the heat lost at night up to the point where power is required to keep the fluid from freezing.

Fluid conditions are at the exit of the transport system. 
TABLE E.4. FMDF Bowl Transport System Conditions

Case III: 30-Degree Bow1, Water/Steam System

\begin{tabular}{|c|c|c|c|c|c|}
\hline \multirow{2}{*}{$\begin{array}{l}\text { Gross } \\
\text { Concentrator } \\
\text { Area, } \mathrm{m}^{2}\end{array}$} & \multirow[b]{2}{*}{$\begin{array}{c}\text { Number } \\
\text { of Bowls }\end{array}$} & \multirow[b]{2}{*}{$\begin{array}{c}\text { System } \\
\text { Efficiency }\end{array}$} & \multirow[b]{2}{*}{$\begin{array}{l}\text { Pumping } \\
\text { Power, kWe }\end{array}$} & \multicolumn{2}{|c|}{ Conditions } \\
\hline & & & & Temp., ${ }^{\circ} \mathrm{F}$ & Pressure, psia \\
\hline 3007 . & 1 & 96.3 & 7.23 & 978.4 & 995.3 \\
\hline 6014 . & 2 & 94.9 & 14.47 & 971.6 & 994.5 \\
\hline 24055 . & 8 & 93.9 & 58.14 & 966.5 & 989.8 \\
\hline 48110 . & 16 & 93.0 & 116.3 & 962.0 & 989.8 \\
\hline 96219. & 32 & 91.4 & 234.1 & 955.6 & 982.7 \\
\hline 144329. & 48 & 90.1 & 353.3 & 951.6 & 975.9 \\
\hline 192440. & 64 & 89.2 & 473.0 & 948.5 & 971.3 \\
\hline 240548 . & 80 & 88.4 & 592.9 & 946.1 & 968.2 \\
\hline 577315. & 192 & 87.0 & 1431.4 & 930.9 & 961.6 \\
\hline 757726 . & 252 & 86.5 & 1881.4 & 929.7 & 960.0 \\
\hline
\end{tabular}

System Efficiency $=\frac{\text { Total Average Energy - Total Thermal Loss }}{\text { Total Average Energy }} * 100 \%$

where:

total average energy $=6589 \mathrm{kWh} /$ day per bowl (SOLSTEP preliminary result) total thermal loss includes daytime and nighttime losses. Nighttime loss is the heat lost at night up to the point where power is required to keep the fluid from freezing.

Fluid conditions are at the exit of the transport system. 
TABLE E.5. FMDF Bowl Transport System Conditions

Case IV: 30-Degree Bowl, Water/Steam System

\begin{tabular}{|c|c|c|c|c|c|}
\hline \multirow{2}{*}{$\begin{array}{c}\text { Gross } \\
\text { Concentrator } \\
\text { Area, } \pi^{2} \\
\end{array}$} & \multirow{2}{*}{$\begin{array}{c}\text { Number } \\
\text { of Bowls }\end{array}$} & \multirow{2}{*}{$\begin{array}{c}\text { System } \\
\text { Efficiency }\end{array}$} & \multirow{2}{*}{$\begin{array}{l}\text { Pumping } \\
\text { Power, kwe }\end{array}$} & \multicolumn{2}{|c|}{$\begin{array}{c}\text { Storage Inlet Fluid } \\
\text { Conditions }\end{array}$} \\
\hline & & & & Temp., ${ }^{\circ} \mathrm{F}$ & Pressure, psia \\
\hline 3007 & 1 & 95.2 & 1.48 & 1044. & 126.5 \\
\hline 6014 & 2 & 93.6 & 3.05 & 1043. & 124.3 \\
\hline 24055 . & 8 & 92.5 & 13.47 & 1042 . & 116.5 \\
\hline 48110. & 16 & 91.1 & 27.65 & 1041. & 114.3 \\
\hline 96219. & 32 & 88.9 & 62.90 & 1039. & 102.5 \\
\hline 144329 . & 48 & 87.4 & 107.3 & 1038. & 89.2 \\
\hline 192440 . & 64 & 86.3 & 156.3 & 1037 & 78.9 \\
\hline 288658. & 96 & 84.7 & 281.7 & 1036 & 54.5 \\
\hline 577315. & 192 & 82.4 & 568.9 & 1033. & 53.1 \\
\hline 962192. & 320 & 81.5 & 1016.8 & 1032 . & 42.4 \\
\hline 2345344 & 780 & 78.0 & 2946.6 & 1031. & 12.7 \\
\hline
\end{tabular}

System Efficiency $=\frac{\text { Total Average Energy - Total Thermal Loss }}{\text { Total Average Energy }} * 100 \%$

where:

total average energy $=4515 \mathrm{kWh} /$ day per bowl (SOLSTEP preliminary result) total thermal loss includes daytime and nighttime losses. Nighttime loss is the heat lost at night up to the point where power is required to keep the fluid from freezing.

Fluid conditions are at the exit of the transport system. 
APPENDIX $F$

PLANT COST DATA 
This appendix lists summary SOLSTEP cost data for bowl Cases I through IV and the iris system. Cost data are presented for each of the five power levels examined in this study. For systems without storage, cost data are presented for the no-storage designs. For systems where storage was included, data are presented for the no-storage designs and for designs with a capacity factor of 0.4. (The designs for the 0.4 capacity factor plants represent interpolations by SOLSTEP; therefore, these designs may not have an integer number of bowls.)

Specificaliy, the cost data presented include the capital cost of each of the six solar thermal system components plus indirect and contingency costs, operating and maintenance costs (08M), and replacement capital in both absolute and unit cost forms. The contribution of each component toward the total levelized energy cost (LEC) is also included. 
TABLE F.1. Plant Cost Breakdown for 60-Degree-W/S System at 0.5 MWe COLLECTOR FIELD SIZE, $\mathrm{m}^{2}$ STORAGE SIZE, MWht 5,845

PLANT CAPACITY FACTOR:

SYSTEM COST SUMMARY

CAPITAL INVESTMENT COSTS

O\&M COSTS (ANNUAL)

REPLACEMENT CAPITAL

TOTAL LEVELIZED ENERGY COST

LEC MILLS/ kWh

195.9

385.4

$\$ 0 / \mathrm{kWe}$

581.3

CAPITAL COST BREAKDOWN

CONCENTRATOR COST
RECEIVER COST
ENERGY TRANSPORT COST
ENERGY CONVERSION COST
ENERGY STORAGE COST
OTHER PLANT COSTS
INDIRECTS AND CONTINGENCIES

811890
360840
147819
772085
0
445458
888332

$\$ 139 / \pi^{2}$

$\$ 62 / m^{2}$

$\$ 25 / \mathrm{m}^{2}$

46.3

20.6

$\$ 1,544 / \mathrm{kWe}$

8.4

44.0

$\$ 0 / \mathrm{kWht}$

$\$ 891 / \mathrm{kWe}$

26.0

$\$ 1,777 / \mathrm{kWe}$

50.6

TABLE F.2. Plant Cost Breakdown for 60-Degree-W/S System at 2 MWe

$\begin{array}{lr}\text { COLLECTOR FIELD SIZE, m² } & 17,536 \\ \text { STORAGE SIZE, MWht } & 0 \\ \text { PLANT CAPACITY FACTOR: } & 0.224\end{array}$

SYSTEM COST SUMMARY

CAPITAL INVESTMENT COSTS

O\&M COSTS (ANNUAL)

REPLACEMENT CAPITAL

$$
\begin{array}{r}
\text { COST, } \$ \\
9490638 \\
504131
\end{array}
$$

TOTAL LEVELIZED ENERGY COST

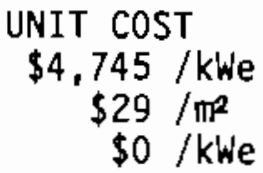

LEC

MILLS/kWh

153.9

128.2

$\$ 0 / \mathrm{kWe}$

282.1

CAPITAL COST BREAKDOWN

CONCENTRATOR COST

RECEIVER COST

ENERGY TRANSPORT COST

ENERGY CONVERSION COST

ENERGY STORAGE COST

OTHER PLANT COSTS

INDIRECTS AND CONTINGENCIES
2435535

1082460

571892

2028975

911240

2460536
$\$ 139 / \mathrm{m}^{2}$

$\$ 62 / m^{2}$

$\$ 33 / \mathrm{m}^{2}$

$\$ 1,014 / \mathrm{kWe}$

$\$ 0 / \mathrm{kWht}$

$\$ 456 / \mathrm{kWe}$

$\$ 1,230 / \mathrm{kwe}$
39.4

17.5

9.2

32.8

15.2

39.8 
TABLE F.3. Plant Cost Breakdown for 60-Degree-W/S System at 10 MWe

COLLECTOR FIELD SIZE, $\mathrm{m}^{2}$

STORAGE SIZE, MWht

PLANT CAPACITY FACTOR:

SYSTEM COST SUMMARY

CAPITAL INVESTMENT COSTS

O\&M COSTS (ANNUAL)

REPLACEMENT CAPITAL

TOTAL LEVELIZED ENERGY COST

CAPITAL COST BREAKDOWN

CONCENTRATOR COST

RECEIVER COST

ENERGY TRANSPORT COST

ENERGY CONVERSION COST

ENERGY STORAGE COST

OTHER PLANT COSTS

INDIRECTS AND CONTINGENCIES
70,144

0.202

0.202
LEC

MILLS/kWh

127.1

46.6

$\$ 0 / \mathrm{kWe}$

173.7

35.0

15.6

11.3

22.5

$\$ 625 / \mathrm{kWe}$

$\$ 0 / k W h t$

$\begin{array}{llr}2631210 & \$ 263 / \mathrm{kWe} & 9.9 \\ 9138176 & \$ 914 / \mathrm{kWe} & 32.8\end{array}$

$\begin{array}{llr}2631210 & \$ 263 / \mathrm{kWe} & 9.9 \\ 9138176 & \$ 914 / \mathrm{kWe} & 32.8\end{array}$

$\begin{array}{llr}2631210 & \$ 263 / \mathrm{kWe} & 9.9 \\ 9138176 & \$ 914 / \mathrm{kWe} & 32.8\end{array}$

TABLE F.4. Plant Cost Breakdown for 60-Degree-W/S System at 30 MWe

COLLECTOR FIELD SIZE, $\mathbb{m}^{2}$

STORAGE SIZE, MWht

PLANT CAPACITY FACTOR:

SYSTEM COST SUMMARY

CAPITAL INVESTMENT COSTS

O\&M COSTS (ANNUAL)

REPLACEMENT CAPITAL

TOTAL LEVELIZED ENERGY COST
175,359

0.186

$\operatorname{CosT}, \$$

86409191

1476673

0
LEC

MILLS/kWh

112.4

30.1

$\$ 0 / \mathrm{kWe}$

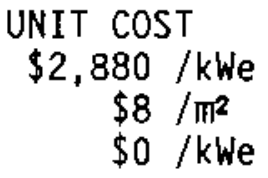

$\$ 139 / \mathrm{m}^{2}$

$\$ 62 / \mathrm{m}^{2}$

$\$ 56 / \mathrm{m}^{2}$

$\$ 449 / \mathrm{kWe}$

$\$ 0 / \mathrm{kWht}$

$\$ 187 / \mathrm{kWe}$

$\$ 747 / \mathrm{kWe}$
31.6

14.0

12.6

17.5

0

7.6

29.1 
IABLE F.5. Plant Cost Breakdown for 60-Degree-W/S System at 100 MWe

COLLECTOR FIELD SIZE, $m^{2}$

STORAGE SIZE, MWht

PLANT CAPACITY FACTOR:

SYSTEM COST SUMMARY

CAPITAL INYESTMENT COSTS

OBM COSTS (ANNUAL)

REPLACEMENT CAPITAL

TOTAL LEYELIZED ENERGY COST

CAPITAL COST BREAKDOWN

CONCENTRATOR COST

RECEIVER COST

ENERGY TRANSPORT COST

ENERGY CONVERSION COST

ENERGY STORAGE COST

OTHER PLANT COSTS

INDIRECTS AND CONTINGENCIES
514,388

0.172

COST, $\$$ UNIT COST

$249832538 \quad \$ 2,498 / \mathrm{kWe}$

3759861

0

$\$ 7 / \mathrm{m}^{2}$

$\$ 0 / \mathrm{kWe}$

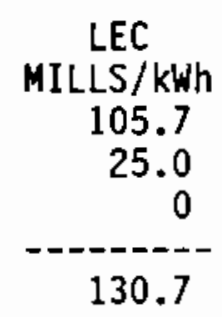

71442810

31752360

36685136

31310578

13870257

64771397

$\$ 139 / \pi^{2}$
$\$ 62 / \mathrm{m}^{2}$
$\$ 67 / \mathrm{m}^{2}$
$\$ 313 / \mathrm{kWe}$
$\$ 0 / \mathrm{kWht}$
$\$ 139 / \mathrm{kWe}$
$\$ 648 / \mathrm{kWe}$

30.2

13.4

15.5

13.2

0

6.1

27.3 
TABLE F.6. Plant Cost Breakdown for Two 60-Degree-Salt Systems at 0.5 MWe

COLLECTOR FIELD SIZE, $\mathbb{\pi}^{2}$

STORAGE SIZE, MWht

PLANT CAPACITY FACTOR:

SYSTEM COST SUMMARY

CAPITAL INVESTMENT COSTS

O\&M COSTS (ANNUAL)

REPLACEMENT CAPITAL

TOTAL LEVELIZED ENERGY COST

CAPITAL COST BREAKDOWN

CONCENTRATOR COST

RECEIVER COST

ENERGY TRANSPORT COST

ENERGY CONVERSION COST

ENERGY STORAGE COST

OTHER PLANT COSTS

INDIRECTS AND CONTINGENCIES
5,845

0.203
COST, $\$$ 3582016 432963

0

811890

445036

103352

846459

446608

928671

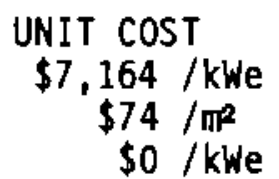

$\$ 139 / \mathbb{R}^{2}$ $\$ 76 / \mathbb{R}^{2}$ $\$ 18 / \pi^{2}$ $\$ 1,693 / \mathrm{kWe}$ $\$ 0 / \mathrm{kWht}$ $\$ 893 / \mathrm{kWe}$ $\$ 1,857 / \mathrm{kWe}$
LEC

MILLS/kWh

257.4

487.8

745.2

8,768

10.575

0.4

SYSTEM COST SUMMARY

CAPITAL INVESTMENT COSTS

O\&M CDSTS (ANNUAL)

REPLACEMENT CAPITAL

TOTAL LEVELIZED ENERGY COST
$\operatorname{cosT}, \$$ 5797454 463989

15006

1217835

667554

157345

848837

903567

499273

1503043
UNIT COST

$\$ 11,595 / \mathrm{kWe}$ $\$ 53 / \pi^{2}$ $\$ 30 / \mathrm{kWe}$
58.2

31.9

7.4

60.6

32.8

66.5
LEC

MILLS/ kWh

207.2

260.1

0.7

468

CAPITAL COST BREAKDOWN

CONCENTRATOR COST

ENERGY TRANSPORT COST

ENERGY CONVERSION COST

ENERGY STORAGE COST

OTHER PLANT COSTS

INDIRECTS AND CONTINGENCIES 
TABLE F.7. Plant cost 8reakdown for Two 60-Degree-Salt Systems at 2 MWe

COLLECTOR FIELD SIZE, $m^{2}$

STORAGE SIZE, MWht

PLANT CAPACITY FACTOR:

SYSTEM COST SUMMARY

CAPITAL INVESTMENT COSTS

OBM COSTS (ANNUAL)

REPLACEMENT CAPITAL

TOTAL LEVELIZED ENERGY COST

CAPITAL COST BREAKDOWN

CONCENTRATOR COST

RECEIVER COST

ENERGY TRANSPORT COST

ENERGY CONVERSION COST

ENERGY STORAGE COST

OTHER PLANT COSTS

INDIRECTS AND CONTINGENCIES

COLLECTOR FIELD SIZE, $\pi^{2}$

STORAGE SIZE, MWht

PLANT CAPACITY FACTOR:

SYSTEM COST SUMMARY

CAPITAL INVESTMENT COSTS

O\&M COSTS (ANNUAL)

REPLACEMENT CAPITAL

TOTAL LEVELIZED ENERGY COST

CAPITAL COST BREAKDOWN

CDNCENTRATOR COST

RECEIVER COST

ENERGY TRANSPORT COST

ENERGY CONVERSION COST

ENERGY STDRAGE COST

OTHER PLANT COSTS

INDIRECTS AND CONTINGENCIES
20,459

0.193

0.193

COST, \$ UNIT COST

10837897

525819

0

$\$ 5,419 / \mathrm{kWe}$

$\$ 26 / \pi^{2}$

$\$ 0 / \mathrm{kWe}$

$\$ 139 / \mathrm{m}^{2}$

$\$ 76 / m^{2}$

$\$ 20 / \pi^{2}$

$\$ 1,136 / \mathrm{kWe}$

$\$ 0 / k$ wht

$\$ 469 / \mathrm{kWe}$

$\$ 1,405 / \mathrm{kWe}$

29,057

55.136

0.4

COST, \$

16387088

603955

78241

UNIT COST
$\$ 8,194 / \mathrm{kWe}$
$\$ 21 / \pi^{2}$
$\$ 39 / \mathrm{kWe}$

LEC

MILLS/kWh

156.7

90.6

1.0

248.3

4035736

2212181

624891

2276589

1916593

1072594

4248504

$\begin{aligned} \$ 139 & / \pi^{2} \\ \$ 76 & / \pi^{2} \\ \$ 22 & / \pi^{2} \\ \$ 1,138 & / \mathrm{kWe} \\ \$ 35 & / \mathrm{kWht} \\ \$ 536 & / \mathrm{kWe} \\ \$ 2,124 & / \mathrm{kWe}\end{aligned}$

38.5

21.1

6.0

21.7

18.3

10.6

40.5 
TABLE F.8. Plant Cost Breakdown for Two 60-Degree-Salt Systems at 10 Mwe

COLLECTOR FIELD SIZE, $\pi^{2}$ STORAGE SIZE, MWht

PLANT CAPACITY FACTOR:

SYSTEM COST SUMMARY

CAPITAL INVESTMENT COSTS

OBM COSTS (ANNUAL)

REPLACEMENT CAPITAL

TOTAL LEVELIZED ENERGY COST

CAPITAL COST BREAKDOWN

CONCENTRATOR COST

RECEIVER COST

ENERGY TRANSPORT COST

ENERGY CONVERSION COST

ENERGY STORAGE COST

OTHER PLANT COSTS

INDIRECTS AND CONTINGENCIES

COLLECTOR FIELD SIZE, $\mathbf{m}^{2}$

STORAGE SIZE, WWht

PLANT CAPACITY FACTOR:

SYSTEM COST SUMMARY

CAPITAL INVESTMENT COSTS

OBM COSTS (ANNUAL)

REPLACEMENT CAPITAL

TOTAL LEVELIZED ENERGY COST

CAPITAL COST BREAKDOWN

CONCENTRATOR COST

RECEIVER COST

ENERGY TRANSPORT COST

ENERGY CONVERSION COST

ENERGY STORAGE COST

OTHER PLANT COSTS

INDIRECTS AND CONTINGENCIES
93,525

0.187

COST, \$ UNIT COST

44976681

975469

0

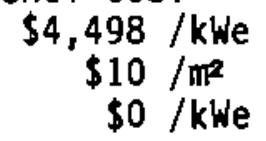

LEC

MILLS/kWh

174.9

59.5

$$
234.4
$$

12989565

7120206

3203598

7149121

2853570

11660621

138,302

269.548

0.4

COST, \$ 68829430

1313857

382503

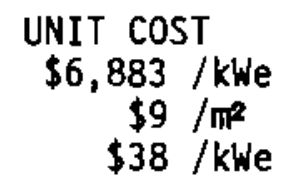

LEC

MILLS/kWh

135.8

40.6

1.0

177.4

19208724

10529226

5646484

7177021

4980558

3442751

17844666
$\$ 139 / \pi^{2}$

$\$ 76 / \pi^{2}$

$\$ 41 / \mathrm{m}^{2}$

$\$ 718$ /kWe

$\$ 18 / \mathrm{kWht}$

$\$ 344 / \mathrm{kWe}$

$\$ 1,784 / \mathrm{kWe}$
37.8

20.7

11.1

14.1

9.8

7.2

35.1

\section{F.7}


TABLE F.9. Plant Cost Breakdown for Two 60-Degree-Salt Systems at 30 MWe COLLECTOR FIELD SIZE， $\mathrm{m}^{2}$ STORAGE SIZE, MWht 187,050

PLANT CAPACITY FACTOR:

0.154

SYSTEM COST SUMMARY

CAPITAL INVESTMENT COSTS

O\&M COSTS (ANNUAL) 4929189

REPLACEMENT CAPITAL 1622518

TOTAL LEVELIZED ENERGY COST

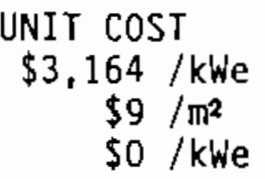

$\$ 139 / \mathrm{m}^{2}$

$\$ 76 / \mathrm{m}^{2}$

$\$ 47 / \mathrm{m}^{2}$

$\$ 521 / \mathrm{kWe}$

$\$ 0 / \mathrm{kWht}$

$\$ 191 / \mathrm{kWe}$

$\$ 820 / \mathrm{kWe}$
LEC

MILLS/ kWh

150.0

40.2

0

190.2

CAPITAL COST BREAKDOWN

RECEIVER COST

ENERGY TRANSPORT COST

ENERGY CONVERSION COST

ENERGY STORAGE COST

OTHER PLANT COSTS

INDIRECTS AND CONTINGENCIES
25979130

8744616

15615907

5737854

24611270

401,131

782.084

0.4
COLLECTOR FIELD SIZE, $\mathrm{m}^{2}$

STORAGE SIZE, MWht

PLANT CAPACITY FACTOR:

SYSTEM COST SUMMARY

CAPITAL INVESTMENT COSTS

O\&M COSTS (ANNUAL)

REPLACEMENT CAPITAL

TOTAL LEVELIZED ENERGY COST

CAPITAL COST BREAKDOWN

CONCENTRATOR COST

RECEIVER COST

ENERGY TRANSPORT COST

ENERGY CONVERSION COST

ENERGY STORAGE COST

OTHER PLANT COSTS

INDIRECTS AND CONTINGENCIES
$\operatorname{cosT}, \$$ 198799485

3102334

1109819

$$
\begin{aligned}
& \text { UNIT COST } \\
& \$ 6,627 / \mathrm{kWe} \\
& \$ 8 / \mathrm{m}^{2} \\
& \$ 37 / \mathrm{kWe}
\end{aligned}
$$

55712612 30538765

26408127

15736625

10527439

8335312

51540605

$\$ 139 / \mathrm{m}^{2}$
$\$ 76 / \mathrm{m}^{2}$
$\$ 66 / \mathrm{m}^{2}$
$\$ 525 / \mathrm{kWe}$
$\$ 13 / \mathrm{kWht}$
$\$ 278 / \mathrm{kWe}$
$1,718 / \mathrm{kWe}$

36.9

20.2

17.5

10.4

7.0

5.9

34.1 
TABLE F.10. Plant Cost Breakdown for Two 60-Degree-Salt Systems at 100 MWe

COLLECTOR FIELD SIZE, $\mathrm{m}^{2}$ STORAGE SIZE, MWht

PLANT CAPACITY FACTOR:

SYSTEM COST SUMMARY

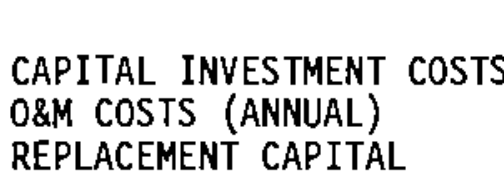

TOTAL LEVELIZED ENERGY COST

$$
\begin{array}{r}
561,150 \\
0 \\
0.148
\end{array}
$$


TABLE F.11. Plant Cost Breakdown for 30-Degree-W/S System at 0.5 MWe COLLECTOR FIELD SIZE, $\mathbb{m}^{2}$ STORAGE SIZE, MWht

PLANT CAPACITY FACTOR:

8,867

0.217

SYSTEM COST SUMMARY

CAPITAL INVESTMENT COSTS

OBN COSTS (ANNUAL)

REPLACEMENT CAPITAL

COST, \$

4734341

460658

TOTAL LEVELIZED ENERGY COST
LEC MILLS/kWh

317.5

484.4

$\$ 52 / \mathrm{m}^{2}$

$\$ 0 /$ kWe
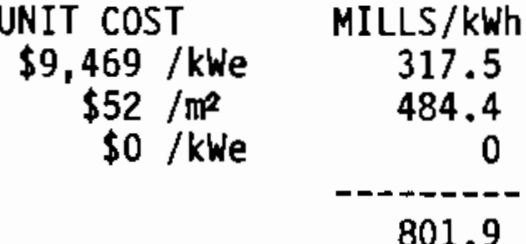

801.9

CAPITAL COST BREAKDOWN

$\begin{array}{lr}\text { CONCENTRATOR COST } & 856995 \\ \text { RECEIVER COST } & 1172730 \\ \text { ENERGY TRANSPORT COST } & 226273 \\ \text { ENERGY CONYERSION COST } & 778368 \\ \text { ENERGY STORAGE COST } & 0 \\ \text { OTHER PLANT COSTS } & 472553 \\ \text { INDIRECTS AND CONTINGENCIES } & 1227422\end{array}$

$\begin{array}{rlr}\$ 97 / \mathrm{m}^{2} & 57.3 \\ \$ 132 / \mathrm{m}^{2} & 78.4 \\ \$ 26 / \mathrm{m}^{2} & 15.1 \\ \$ 1,557 / \mathrm{kWe} & 52.0 \\ \$ 0 / \mathrm{kWht} & 0 \\ \$ 945 / \mathrm{kWe} & 32.6 \\ \$ 2,455 / \mathrm{kWe} & 82.1\end{array}$

TABLE F.12. Plant cost Breakdown for 30-Degree-W/S System at 2 MWe

COLLECTOR FIELD SIZE, $m^{2}$ STORAGE SIZE, MWht

PLANT CAPACITY FACTOR:

SYSTEM COST SUMMARY

CAPITAL INVESTMENT COSTS

O\&M COSTS (ANNUAL)

REPLACEMENT CAPITAL

TOTAL LEVELIZED ENERGY COST

CAPITAL COST BREAKDOWN

CONCENTRATOR COST

RECEIVER COST

ENERGY TRANSPORT COST

ENERGY CONVERSION COST

ENERGY STORAGE COST

OTHER PLANT COSTS

INDIRECTS AND CONTINGENCIES

$$
\begin{array}{r}
20,690 \\
0 \\
0.178
\end{array}
$$


TABLE F.13. Plant Cost Breakdown for 30-Degree-W/S System at 10 MWe

COLLECTOR FIELD SIZE, $\pi^{2}$

STORAGE SIZE, MWht

PLANT CAPACITY FACTOR:

SYSTEM COST SUMMARY

CAPITAL INVESTMENT COSTS

O\&M COSTS (ANNUAL)

REPLACEMENT CAPITAL

TOTAL LEVELIZED ENERGY COST
93,600

0.169

$\begin{array}{lrc} & \text { COST, } \$ & \text { UNIT COST } \\ \text { CAPITAL INVESTMENT COSTS } & 46257878 & \$ 4,626 / \mathrm{kWe} \\ \text { O\&M COSTS (ANNUAL) } & 1110706 & \$ 12 / \pi^{2} \\ \text { REPLACEMENT CAPITAL } & 0 & \$ 0 / \mathrm{kWe}\end{array}$

LEC MILLS/KWh 199.5 75.1 0

274.6

CAPITAL COST BREAKDOWN

$\begin{array}{lrcr}\text { CONCENTRATOR COST } & 9045805 & \$ 97 / \mathbb{m}^{2} & 38.9 \\ \text { RECEIVER COST } & 12378470 & \$ 132 / \mathbb{m}^{2} & 53.2 \\ \text { ENERGY TRANSPORT COST } & 3731195 & \$ 34 / \mathbf{m}^{2} & 16.0 \\ \text { ENERGY CONVERSION COST } & 6269968 & \$ 627 / \mathrm{kWe} & 27.0 \\ \text { ENERGY STORAGE COST } & 0 & \$ 0 / \mathrm{kWht} & 0 \\ \text { OTHER PLANT COST } & 2839657 & \$ 284 / \mathrm{kWe} & 12.8 \\ \text { INDIRECTS AND CONTINGENCIES } & 11992783 & \$ 1,199 / \mathrm{kWe} & 51.6\end{array}$

TA8LE F.14. Plant Cost Breakdown for 30-Degree-W/S System at 30 Mwe

COLLECTOR FIELD SIZE, $\mathbb{m}^{2}$

STORAGE SIZE, MWht

PLANT CAPACITY FACTOR:

SYSTEM COST SUMMARY

CAPITAL INVESTMENT COSTS

O\&M COSTS (ANNUAL)

REPLACEMENT CAPITAL

TOTAL LEVELIZED ENERGY COST
189,169

0.136

CAPITAL COST BREAKDOWN

CONCENTRATOR COST
RECEIVER COST
ENERGY TRANSPORT COST
ENERGY CONVERSION COST
ENERGY STORAGE COST
OTHER PLANT COSTS
INDIRECTS AND CONTINGENCIES
18281610

25016940

10256278

13476755

5728266

25465946

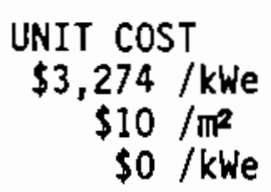

$\$ 97 / \pi^{2}$

$\$ 132 / \pi^{2}$

$\$ 54 / \mathrm{m}^{2}$

$\$ 449 / \mathrm{kWe}$

so / kWht

$\$ 191 / \mathrm{kWe}$

$\$ 849 / \mathrm{kWe}$
LEC

MILLS/kWh

174.8

53.3

228.1

32.5

44.4

18.2

23.9

10.6

45.2 
TABLE F.15. Plant Cost Breakdown for 30-Degree-W/S System at 100 MWe COLLECTOR FIELD SIZE, $\mathbb{R}^{2}$ STORAGE SIZE, MWht 567,501

PLANT CAPACITY FACTOR:

$$
0.128
$$

SYSTEM COST SUMMARY

$\begin{array}{lrr} & \text { COST, } \$ & \text { UNIT COST } \\ \text { CAPITAL INVESTMENT COSTS } & 286398451 & \$ 2,864 / \mathrm{kWe} \\ \text { O\&M COSTS (ANNUAL) } & 5071773 & \$ 9 / \mathrm{m}^{2} \\ \text { REPLACEMENT CAPITAL } & 0 & \$ 0 / \mathrm{kWe}\end{array}$

TOTAL LEVELIZED ENERGY COST

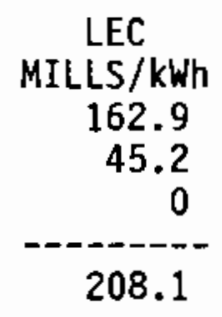

CAPITAL COST BREAKDOWN

$\begin{array}{lr}\text { CONCENTRATOR COST } & 54844925 \\ \text { RECEIVER COST } & 75050950 \\ \text { ENERGY TRANSPORT COST } & 36635543 \\ \text { ENERGY CONVERSION COST } & 31314907 \\ \text { ENERGY STORAGE COST } & 0 \\ \text { OTHER PLANT COSTS } & 14300678 \\ \text { INDIRECTS AND CONTINGENCIES } & 74251448\end{array}$

$\$ 97 / \pi^{2}$

$\$ 132 / \pi^{2}$

$\$ 65 / \pi^{2}$

$\$ 313 / \mathrm{kWe}$

$\$ 0 / \mathrm{kWht}$

$\$ 143 / \mathrm{kWe}$

$\$ 743 / \mathrm{kWe}$
31.1

42.6

20.8

17.8

0

8.5

42.1 
TABLE F.16. Plant Cost Breakdown for Two 30-Degree-Salt Systems at 0.5 Mwe

COLLECTOR FIELD SIZE, $\mathbb{m}^{2}$

STORAGE SIZE, MWht

PLANT CAPACITY FACTOR:

SYSTEM COST SUMMARY

CAPITAL INVESTMENT COSTS

O\&M COSTS (ANNUAL)

REPLACEMENT CAPITAL

TOTAL LEVELIZED ENERGY COST

CAPITAL COST BREAKDOWN

CONCENTRATOR COST

RECEIVER COST

ENERGY TRANSPORT COST

ENERGY CONVERSION COST

ENERGY STORAGE COST

OTHER PLANT COSTS

INDIRECTS AND CONTINGENCIES
8,867

0.107

COST, \$

5300447

47374B

0

856995

1533570

213925

846459

475308

1374190

17,505

26.205

0.4

COLLECTOR FIELD SIZE, $\mathbf{m}^{2}$

STORAGE SIZE, MWht

PLANT CAPACITY FACTOR:

UNIT COST

$\$ 10,601 / \mathrm{kWe}$

$\$ 53 / \pi^{2}$

$\$ 0 / k$ We

LEC

MILLS/kwh

720.5

1009.8

1730.3

116.2

207.9

$\$ 173 / \pi^{2}$

$\$ 24 / \pi^{2}$

$\$ 1,693 / \mathrm{kWe}$

$\$ 0 / k$ wht

$\$ 951 / \mathrm{kWe}$

$\$ 2,748 / \mathrm{kWe}$

29.0

114.7

66.4

186.3

SYSTEM COST SUMMARY

CAPITAL INVESTMENT COSTS

O\&M COSTS (ANNUAL)

REPLACEMENT CAPITAL

$\operatorname{cosT}, \$$ 10911863 568769

TOTAL LEVELIZED ENERGY COST

CAPITAL COST BREAKDOWN

CONCENTRATOR COST

RECEIVER COST

ENERGY TRANSPORT COST

ENERGY CONVERSION COST

ENERGY STORAGE COST

OTHER PLANT COSTS

INDIRECTS AND CONTINGENCIES
1691819

3027465

447307

852831

1465744

597696

2829001

$$
\begin{aligned}
& \text { UNIT COST } \\
& \$ 21,824 / \mathrm{kWe} \\
& \$ 32 / \pi^{2} \\
& \$ 0 / \mathrm{kWe}
\end{aligned}
$$

LEC

MILLS/kwh

411.3

336.4

747.7
63.6

113.9

16.8

32.1

55.1

23.4

106.4 
TABLE F.17. Plant Cost Breakdown for Two 30-Degree-Salt Systems at 2 MWe

COLLECTOR FIELD SIZE, $m^{2}$

STORAGE SIZE, MWht

PLANT CAPACITY FACTOR:

SYSTEM COST SUMMARY

CAPITAL INVESTMENT COSTS

O\&M COSTS (ANNUAL)

REPLACEMENT CAPITAL

TOTAL LEVELIZED ENERGY COST

CAPITAL COST BREAKDOWN

CONCENTRATOR COST

RECEIVER COST

ENERGY TRANSPORT COST

ENERGY CONVERSION COST

ENERGY STORAGE COST

OTHER PLANT COSTS

INDIRECTS AND CONTINGENCIES
23,646

0.09 $\begin{array}{rc}\text { COST, } \$ & \text { UNIT COST } \\ 13817857 & \$ 6,909 / \mathrm{kWe} \\ 611238 & \$ 26 / \mathrm{m}^{2} \\ 0 & \$ 0 / \mathrm{kWe}\end{array}$

2285225

4089350

619753

2268721

972401

3582407

$\begin{aligned} \$ 97 & / \pi^{2} \\ \$ 173 & / \pi^{2} \\ \$ 26 & / \pi^{2} \\ \$ 1,134 & / \mathbf{k W e} \\ \$ 0 & / \mathrm{kWht} \\ \$ 486 & / \mathrm{kWe} \\ \$ 1,791 & / \mathrm{kWWe}\end{aligned}$

91.8

164.2

24.9

91.1

40.4

143.9
COLLECTOR FIELD SIZE, $\mathrm{m}^{2}$

STORAGE SIZE, MWht

PLANT CAPACITY FACTOR:

SYSTEM COST SUMMARY

CAPITAL INVESTMENT COSTS

O\&M COSTS (ANNUAL)

REPLACEMENT CAPITAL

TOTAL LEVELIZED ENERGY COST
69,711

99.897

0.4
LEC

556.3

386.1

942.4

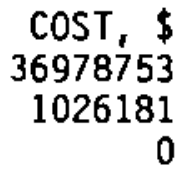

UNIT COST

$\$ 18,489 / \mathrm{kWe}$

$\$ 15 / \pi^{2}$

$\$ 0 /$ kWe
LEC

MILLS/kWh

353.6

153.9

CAPITAL COST BREAKDOWN

$\begin{array}{lr}\text { CONCENTRATOR COST } & 6737133 \\ \text { RECEIVER COST } & 12055922 \\ \text { ENERGY TRANSPORT COST } & 2001960 \\ \text { ENERGY CONVERSION CDST } & 2293111 \\ \text { ENERGY STORAGE COST } & 2824395 \\ \text { OTHER PLANT COSTS } & 1479148 \\ \text { INDIRECTS AND CONTINGENCIES } & 9587084\end{array}$

$\begin{array}{rlr}\$ 97 & / \pi^{2} & 64.3 \\ \$ 173 & / \pi^{2} & 115.0 \\ \$ 29 & / \pi^{2} & 19.1 \\ \$ 1,147 & / \mathrm{kWe} & 21.9 \\ \$ 28 & / \mathrm{kWht} & 26.9 \\ \$ 740 & / \mathrm{kWe} & 15.0 \\ \$ 4,794 & / \mathrm{kWe} & 91.4\end{array}$


IABLE F.18. Plant Cost Breakdown for Two 30-Degree-Salt Systems at 10 Whe

COLLECTOR FIELD SIZE, $\mathbf{m}^{2}$

STORAGE SIZE, MWht

PLANT CAPACITY FACTOR:

SYSTEM COST SUMMARY

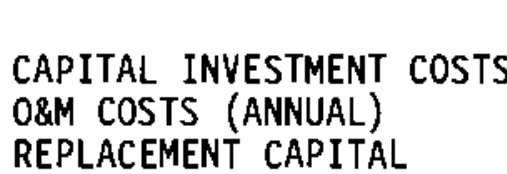

TOTAL LEVELIZED ENERGY COST

CAPITAL COST BREAKDOWN

CONCENTRATOR COST

RECEIVER COST

ENERGY TRANSPORT COST

ENERGY CONVERSION COST

ENERGY STORAGE COST

OTHER PLANT COSTS

INDIRECTS AND CONTINGENCIES
94,583

0.078

0.078

COST, $\$$

52762204

1257187

0
LEC

MILLS/kWh

489.7

183

$\$ 0 /$ kwe

672.7

9140805

16357230

3567732

7137051

288029

13679089
$\$ 97 / \pi^{2}$

$\$ 173 / \pi^{2}$

$\$ 38 / \pi^{2}$

$\$ 714$ /kWe

$\$ 0 /$ kWht

$\$ 288 / \mathrm{kWe}$

$\$ 1,368 / \mathrm{kWe}$
84.6

151.4

33.0

66.1

28.0

126.6
COLLECTOR FIELD SIZE, $\mathrm{m}^{2}$

STORAGE SIZE, MWht

PLANT CAPACITY FACTOR:

SYSTEM COST SUMMARY

CAPITAL INVESTMENT CDSTS

O\&M COSTS (ANNUAL)

REPLACEMENT CAPITAL

TOTAL LEVELIZED ENERGY COST
346,837

482.644

0.4
Cost, \$ 179393082 3526777

0
UNIT COST

$\$ 17,939 / \mathrm{kWe}$. $\$ 10 / \mathrm{m}^{2}$

$\$ 0 /$ kwe

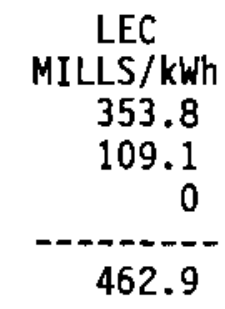

33519286

59981880

18969349

7262399

7499881

5650971

46509316

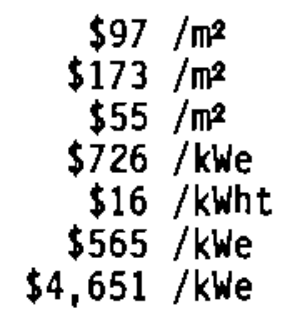

65.9

118.0

37.3

14.3

14.8

12.0

91.5 
TABLE F.19. Plant Cost Breakdown for Two 30-Degree-Salt Systems at 30 MWe

COLLECTOR FIELD SIZE, $m^{2}$

STORAGE SIZE, MWht

PLANT CAPACITY FACTOR:

SYSTEM COST SUMMARY

CAPITAL INVESTMENT COSTS

O\&M COSTS (ANNUAL)

REPLACEMENT CAPITAL

TOTAL LEVELIZED ENERGY COST

CAPITAL COST BREAKDOWN

CONCENTRATOR COST

RECEIVER COST

ENERGY TRANSPORT COST

ENERGY CONVERSION COST

ENERGY STDRAGE COST

OTHER PLANT COSTS

INDIRECTS AND CONTINGENCIES
236,459

0.069

LEC

$\cos T, \$$
131494782

UNIT COST

$\$ 4,383 / \mathrm{kWe}$

$\$ 11 / \pi^{2}$

$\$ 0 / \mathrm{kWe}$

MILLS/kWh

459.0

140.9

0

22852060

40893160

11797516

15609304

6251504

34091238

941,263

1535.07

0.4

PLANT CAPACITY FACTOR:

SYSTEM COST SUMMARY

CAPITAL INVESTMENT COSTS

OBM COSTS (ANNUAL)

REPLACEMENT CAPITAL
$\operatorname{COST}$, \$ 490228972
8982839
0

UNIT COST

$\$ 16,341 / \mathrm{kWe}$

$\$ 10 / \pi^{2}$

$\$ 97 / \pi^{2}$

$\$ 50 / \pi^{2}$

$\$ 520 / \mathrm{kWe}$

$\$ 0 /$ kWht $\$ 208 / \mathrm{kWe}$

$\$ 1,136 / \mathrm{kWe}$

79.6

142.4

41.1

54.3

22.9

118.7

TOTAL LEVELIZED ENERGY COST

$\$ 0 / k W e$

LEC

MILLS/KWh

325.2

93.4

418.6

CAPITAL COST BREAKDOWN

CONCENTRATOR COST

RECEIVER COST

ENERGY TRANSPORT COST

ENERGY CONVERSION COST

ENERGY STORAGE COST

OTHER PLANT COSTS

INDIRECTS AND CONTINGENCIES
90966408

162781992

61771176

15892134

17621786

14099081

127096395

$\$ 97 / \mathbb{m}^{2}$
$\$ 173 / \mathbb{m}^{2}$
$\$ 66 / \mathbb{R}^{2}$
$\$ 530 / \mathbf{k W e}$
$\$ 11 / \mathrm{kWht}$
$\$ 470 / \mathrm{kWe}$
$\$ 4,237 / \mathrm{kWe}$

60.2

107.7

40.9

10.5

11.7

10.1

84.1 
TABLE F.20. Plant Cost Breakdown for Two 30-Degree-Salt Systems at 100 MWe

COLLECTOR FIELD SIZE, $\mathbf{m}^{2}$

STORAGE SIZE, MWht

PLANT CAPACITY FACTOR:

SYSTEM COST SUMMARY

CAPITAL INVESTMENT COSTS 405800931

O\&M COSTS (ANNUAL)

REPLACEMENT CAPITAL

TOTAL LEVELIZED ENERGY COST

CAPITAL COST BREAKDOWN

CONCENTRATOR COST

RECEIVER COST

ENERGY TRANSPORT COST

ENERGY CONVERSION COST

ENERGY STORAGE COST

OTHER PLANT COSTS

INDIRECTS AND CONTINGENCIES
744,845

0.069
105207645

\section{0}

LEC

MILLS/kWh

430.5

123.5

$\$ 0 / \mathrm{kWe}$

$\$ 97 / \pi^{2}$

$\$ 173 / \pi^{2}$

$\$ 63 / \pi^{2}$

$\$ 368 / \mathrm{kWe}$

$\$ 0 / \mathrm{kWht}$

$\$ 163 / \mathrm{kWe}$

$\$ 1,052 / \mathrm{kWe}$
76.2

136.3

49.4

39.0

18.2

111.4
POWER LEVEL, MWe:

COLLECTOR FIELD SIZE, $\mathbf{m}^{2}$

STORAGE SIZE, MWht

PLANT CAPACITY FACTOR:
100

$2,955,734$

$4,675.40$

0.4

SYSTEM COST SUMMARY

CAPITAL INVESTMENT COSTS 1583373284

O\&M COSTS (ANNUAL)

REPLACEMENT CAPITAL

TOTAL LEVELIZED ENERGY COST

0

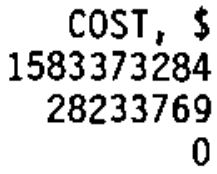

285650748

511164500

243412506

37342623

53255594

42043145

410504168
UNIT COST

$\$ 15,834$ /kWe

$\$ 10 / \mathbb{R}^{2}$

$\$ 0 / \mathrm{kWe}$

CAPITAL COST BREAKDOWN

CONCENTRATOR COST
RECEIVER COST
ENERGY TRANSPORT COST
ENERGY CONVERSION COST
ENERGY STORAGE COST
OTHER PLANT COSTS
INDIRECTS AND CONTINGENCIES

LEC MILLS/kWh 288.9

80.8

369.7

$\begin{array}{rr}\$ 97 / \mathbb{R}^{2} & 52.0 \\ \$ 173 / \pi^{2} & 93.1 \\ \$ 82 / \mathbb{m}^{2} & 44.3 \\ \$ 373 / k W e & 6.8 \\ \$ 11 / k W h t & 9.7 \\ \$ 420 / \text { kWe } & 8.3 \\ \$ 4,105 / \text { kWe } & 74.7\end{array}$


TABLE F.21. Plant Cost Breakdown for Iris/Stirling System at 0.5 MWe $\begin{array}{lr}\text { COLLECTOR FIELD SIZE, } \mathrm{m}^{2} & 3,725 \\ \text { STORAGE SIZE, MWht } & 0 \\ \text { PLANT CAPACITY FACTOR: } & 0.081\end{array}$

SYSTEM COST SUMMARY

$\begin{array}{lrrr} & \text { COST, } \$ & \text { UNIT COST } & \text { MILLS/kWh } \\ \text { CAPITAL INYESTMENT COSTS } & 1391125 & \$ 2,782 / \mathrm{kWe} & 246.4 \\ \text { O\&M COSTS (ANNUAL) } & 106057 & \$ 28 / \mathrm{m}^{2} & 298.7 \\ \text { REPLACEMENT CAPITAL } & 77723 & \$ 155 / \mathrm{kWe} & 19.3 \\ & & & -r \\ \text { TOTAL LEVELIZED ENERGY COST } & & & 564.4 \\ & & & \\ \text { ITAL COST BREAKDOWN } & & & \\ & & & \\ \text { CONCENTRATOR COST } & 330792 & \$ 89 / \mathrm{m}^{2} & 58.3 \\ \text { RECEIVER COST } & 244335 & \$ 66 / \mathrm{m}^{2} & 43.1 \\ \text { ENERGY TRANSPORT COST } & 27494 & \$ 7 / \mathrm{m}^{2} & 4.8 \\ \text { ENERGY CONVERSION COST } & 100000 & \$ 200 / \mathrm{kWe} & 17.6 \\ \text { ENERGY STORAGE COST } & 0 & \$ 0 / \mathrm{kWht} & 0 \\ \text { OTHER PLANT COSTS } & 327842 & \$ 656 / \mathrm{kWe} & 59.0 \\ \text { INDIRECTS AND CONTINGENCIES } & 360662 & \$ 721 / \mathrm{kWe} & 63.6\end{array}$

TABLE F.22. Plant Cost Breakdown for Iris/Stirling System at 2 MWe COLLECTOR FIELD SIZE, $\mathrm{m}^{2} \quad 14,899$ STORAGE SIZE, MWh 14,899
0
0.081 PLANT CAPACITY FACTOR:

1

SYSTEM COST SUMMARY

CAPITAL INVESTMENT COSTS

O\&M COSTS (ANNUAL)

REPLACEMENT CAPITAL

$\begin{array}{ccc} & & \text { LEC } \\ \text { COST, } \$ & \text { UNIT COST } & \text { MILLS/kWh } \\ 4650576 & \$ 2,325 / \text { WWe } & 205.7 \\ 215072 & \$ 14 / \mathrm{m}^{2} & 151.4 \\ 310852 & \$ 155 / \text { WWe } & 19.3 \\ & & ---19.4\end{array}$

CAPITAL COST BREAKDOWN

$\begin{array}{lr}\text { CONCENTRATOR COST } & 1322992 \\ \text { RECEIVER COST } & 977210 \\ \text { ENERGY TRANSPORT COST } & 113686 \\ \text { ENERGY CONVERSION COST } & 400000 \\ \text { ENERGY STORAGE COST } & 0 \\ \text { OTHER PLANT COSTS } & 630983 \\ \text { INDIRECTS AND CONTINGENCIES } & 1205705\end{array}$

$\begin{array}{rlr}\$ 89 / \mathrm{m}^{2} & 58.3 \\ \$ 66 / \mathrm{m}^{2} & 43.1 \\ \$ 8 / \mathrm{m}^{2} & 5.0 \\ \$ 200 & / \mathrm{kWe} & 17.6 \\ \$ 0 / \mathrm{kWht} & 0 \\ \$ 315 / \mathrm{kWe} & 28.6 \\ \$ 603 / \mathrm{kWe} & 53.1\end{array}$


TABLE F.23. Plant Cost Breakdown for Iris/Stirling System at 10 MWe COLLECTOR FIELD SIZE， $\mathrm{m}^{2} \quad 78,219$ STORAGE SIZE, MWht PLANT CAPACITY FACTOR: $\quad 0.085$

SYSTEM COST SUMMARY

\section{CAPITAL INVESTMENT COSTS \\ O\&M COSTS (ANNUAL) \\ REPLACEMENT CAPITAL}

TOTAL LEVELIZED ENERGY COST

$\begin{array}{rc}\text { COST, } \$ & \text { UNIT COST } \\ 22528130 & \$ 2,253 / \mathrm{kWe} \\ 824012 & \$ 11 / \mathrm{m}^{2} \\ 1632003 & \$ 163 / \mathrm{kWe}\end{array}$

6945840 5130450 621124 2100000

ENERGY TRANSPORT COST

ENERGY CONVERSION COST

ENERGY STORAGE COST

OTHER PLANT COSTS

INDIRECTS AND CONTINGENCIES

$\begin{array}{lr}\text { CONCENTRATOR COST } & 6945840 \\ \text { RECEIVER COST } & 5130450 \\ \text { ENERGY TRANSPORT COST } & 621124 \\ \text { ENERGY CONVERSION COST } & 2100000 \\ \text { ENERGY STORAGE COST } & 0 \\ \text { OTHER PLANT COSTS } & 1890090 \\ \text { INDIRECTS AND CONTINGENCIES } & 5840626\end{array}$

LEC

MILLS/ kwh

193.7

110.8

19.3

323.8

59.4

43.9

5.3

18.0

$\$ 210 / \mathrm{kWe}$

$\$ 0 / \mathrm{kwht}$

$\$ 189 / \mathrm{kWe}$

$\$ 584 / \mathrm{kWe}$
17.2

49.9

TABLE F.24. Plant Cost Breakdown for Iris/Stirling System at 30 MWe

COLLECTOR FIELD SIZE, $\pi^{2}$

STORAGE SIZE, MWht

PLANT CAPACITY FACTOR:

SYSTEM COST SUMMARY

CAPITAL INVESTMENT COSTS

O\&M COSTS (ANNUAL)

REPLACEMENT CAPITAL

TOTAL LEVELIZED ENERGY COST

CAPITAL COST BREAKDOWN

CONCENTRATOR CDST
RECEIVER COST
ENERGY TRANSPORT COST
ENERGY CONVERSION COST
ENERGY STORAGE COST
OTHER PLANT CDSTS
INDIRECTS AND CONTINGENCIES

$$
\begin{array}{r}
227,209 \\
0 \\
0.082
\end{array}
$$
COST, \$ UNIT COST
63640742
2250129
4740561
$\$ 2,121 / \mathrm{kWe}$
$\$ 10 / \pi^{2}$
$\$ 158 / \mathrm{kWe}$

20175936
14902680
1851037
6100000
0
4111638
16499451

$\$ 89 / \mathrm{m}^{2}$
$\$ 66 / \mathrm{m}^{2}$
$\$ 8 / \mathrm{m}^{2}$
$\$ 203 / \mathrm{kWe}$
$\$ 0 / \mathrm{kWht}$
$\$ 137 / \mathrm{kWe}$
$\$ 550 / \mathrm{kWe}$

60.5

44.7

5.5

18.3

0

13.5

49.4 
TABLE F.25. Plant cost Breakdown for Iris/Stirling System at 100 MWe

COLLECTOR FIELD SIZE, $m^{2}$ STORAGE SIZE, MWht

PLANT CAPACITY FACTOR:

SYSTEM COST SUMMARY

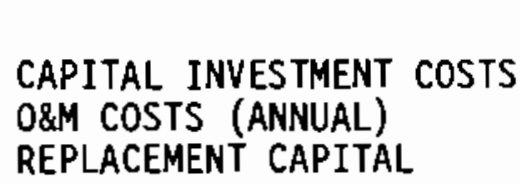

TOTAL LEVELIZED ENERGY COST

CAPITAL COST BREAKDOWN

CONCENTRATOR COST

RECEIVER COST

ENERGY TRANSPORT COST

ENERGY CONVERSION COST

ENERGY STORAGE COST

OTHER PLANT COSTS

INDIRECTS AND CONTINGENCIES
767,296

0.083

COST, \$ UNIT COST

211470456

7407468

16009133

$\$ 2,115 / \mathrm{kWe}$

$\$ 10 / \pi^{2}$

$\$ 160 / \mathrm{kWe}$

68135232

50327160

6436553

20600000

11145839

54825672

$\$ B 9 / \pi^{2}$

$\$ 66 / m^{2}$

$\$ 8 / \pi^{2}$

$\$ 206 / \mathrm{kWe}$

$\$ 0 / \mathrm{kWht}$

$\$ 111 / \mathrm{kWe}$

$\$ 548 / \mathrm{kWe}$
60.5

44.7

5.7

18.3

0

10.9

48.7 
APPENDIX G

PARASITIC POWER REQUIREMENTS 
APPENDIX G

PARASITIC POWER REQUIREMENTS

Parasitic losses were explicitly considered in this analysis. Each parasitic load was identified and appropriate scaling relationships were developed. The constants in the various scaling relationships were either calculated or taken from previous studies. Parasitic losses were assumed to have five components.

Energy Conversion Subsystem Parasitic Losses - These consist of parasitics that scale with turbine load and include feed pumps, condensate pumps circulating water pumps and cooling tower fans. The constants in the scaling relationships were calculated from data for the Solar 100 design (SCE 1982). Where appropriate, parasitics were adjusted for different flow rates and heat rejection requirements. Parasitic losses associated with the Stirling engine include the water pump and cooling fan. The cooling fan is assumed to operate when ambient temperature exceeds $16^{\circ} \mathrm{C}$.

Field and Storage Pumps - This parasitic load includes the power required to drive the field pumps and storage discharge pumps. These pumps were sized as part of this study and the part-load adjusted energy consumption was included as a parasitic load.

Concentrator Tracking Power - Concentrator tracking power is scaled with field size, but is constant per unit of concentrator area.

Fixed Operating Power Requirements - These parasitic loads occur during plant operation but do not vary with plant load. They include the condenser vacuum pump, turbine controls, bearing cooling water, gland seal condenser, water treatment system, service water system, heating, ventilation and air conditioning (HVAC), and master control system. These loads are estimated from the Solar-100 and Crosbyton designs and are scaled for a plant size.

Trace Heating Power Requirements - Trace heating power requirements are incurred when a plant using molten salt as the heat transfer fluid is not 
operating. The trace heating power requirements are derived directly from the ETRANS output (Appendix E).

Standby Power Requirements - Standby power requirements are incurred while the plant is not operating. Standby parasitics dependent on field size include transport heat tracing, concentrator standby power, and receiver pumping power. Parasitics, which are modeled as being independent of field size, include storage heat tracing, circulation pumps for standby steam, turbine turning gears, turbine bearing cooling water, gland seal steam, service water, cooling tower fans (for seal steam), HVAC, lighting, plant control systems and any miscellaneous uses. These loads are estimated from data for the Solar-100 design (SCE 1982).

\section{G.1 METHODOLOGY}

Inputs to the SOLSTEP parasitic model for concentrator tracking power (TR1, TR2), fixed operating power requirements (AUXOP), standby power requirements (SB1, SB2, SB3), and trace heat power requirements (SBHT1, SBHT2, SBHT3) for the solar bowl were derived from a differential analysis of the central receiver (water/steam) design (Williams et al. 1987). This method of analysis was used to maintain consistency among the various designs being studied by eliminating arbitrary design differences (i.e., those differences not resulting from function, but from personal preferences of the design engineers). Because SOLSTEP inputs for the central receiver (steam/water) design had been calculated prior to the analysis of the bowl design, the central receiver analysis was used as a starting point for the bowl analysis.

Justification for using a differential analysis was predicated on the similarities of the power generating facilities of both designs. Two of the three parasitic models (fixed operating requirements and standby power requirements) deal almost entirely with components in the power generating facility. This facility should be almost identical for the bowl and central receiver designs at a given level of gross power output. In Table G.1, each component of the parasitic model that applies to the bowl design is listed 
and compared with the equivalent value obtained for the central receiver design. The values are given in horsepower and are relative to a 5MWe plant.

Parasitic model inputs for the water/steam central receiver design were derived from the Solar-100 molten salt design (SCE 1982). Modifications were made to convert the original salt system to the water/steam system. The primary source of information regarding the design of the solar bowl is the preliminary design for a 5MWe solar/fossil plant prepared by Texas Tech University (TTU) (Simpson, O'Hair and Reichert 1982).

TABLE G.1. Differential Analysis

\begin{tabular}{|c|c|c|}
\hline $\begin{array}{l}\text { Parasitic Model } \\
\text { Component }\end{array}$ & $\begin{array}{l}\text { Differential } \\
\text { Between } \\
\text { Bowl and } \\
\text { Central Receiver } \\
\text { (hp, 5MWe plant) }\end{array}$ & Comments \\
\hline \multicolumn{3}{|l|}{ Concentrator Tracking Power } \\
\hline Tracking System & $\mathrm{N} / \mathrm{A}$ & $\begin{array}{l}\text { Tracking system is unique to } \\
\text { bowl system. Information was } \\
\text { extracted from TTU design. }\end{array}$ \\
\hline \multicolumn{3}{|l|}{ Fixed Operating Power } \\
\hline Condenser Vacuum Pump & -2.81 & $\begin{array}{l}\text { Used explicitly in Solar-100 } \\
\text { design, but accounted for in } \\
\text { compressed air load in bowl design. } \\
\text { On an overall basis, no difference } \\
\text { (see compressed air). }\end{array}$ \\
\hline Turbine Control/Lube Pump & & No difference. \\
\hline Bearing Cooling Water Pump & & No difference. \\
\hline Gland Seal Condenser Fan & & No difference. \\
\hline Water Treatment System & & No difference. \\
\hline HVAC & & No difference. \\
\hline Controls & +2.53 & $\begin{array}{l}\text { Approximately } 30 \% \text { was added to } \\
\text { the central receiver design to } \\
\text { account for the extra controls } \\
\text { necessary for the bowl field. }\end{array}$ \\
\hline
\end{tabular}

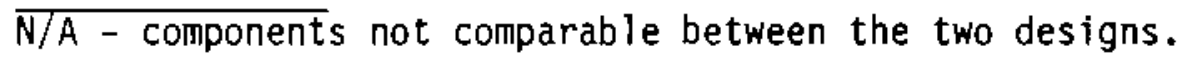


TABLE G.1. (contd)

Differential

Between

Bowl and

Parasitic Model

Central Receiver

Component

(hp, 5MWe plant)

Comments

Lighting

Compressed Air

Standby Power

Turbine Turning Gear

Bearing Cooling Water Pump

Gland Seal Condenser Fan

Water Treatment System

Service Water Pumps

Cooling Tower Fans

Cold Weather Heater

Bowl Cleaning System

HVAC
$\mathrm{N} / \mathrm{A}$

$+4.11$
Lighting requirements vary significantly between designs for the bowl and central receiver (primarily due to the intensity of use in the shop/rehab. facility). Lighting requirements were obtained from the TTU design.

Approximately $30 \%$ was added to the central receiver design to account for additional controls necessary for the bowl field. Also, 2.81 hp was added for the air ejector used instead of a condenser vacuum pump.

No difference.

No difference.

No difference.

No difference.

No difference.

No difference.

N/A Field heating system is not necessary for central receiver design.

N/A Bowl cleaning is unique to the bowl design.

No difference.

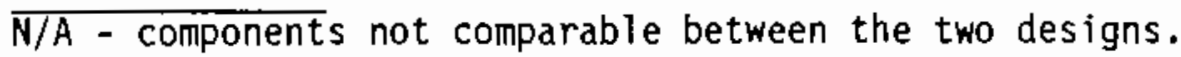


TABLE G.1. (contd)

\begin{tabular}{|c|c|c|}
\hline $\begin{array}{l}\text { Parasitic Mode } 1 \\
\text { Component }\end{array}$ & $\begin{array}{c}\text { Differential } \\
\text { Between } \\
\text { Bowl and } \\
\text { Central Receiver } \\
\text { (hp, 5Mwe plant) }\end{array}$ & Comments \\
\hline Controls & +0.63 & $\begin{array}{l}\text { Approximately } 30 \% \text { was added to } \\
\text { the central receiver design to } \\
\text { account for the extra controls } \\
\text { necessary for the bowl field. }\end{array}$ \\
\hline Lighting & $N / A$ & $\begin{array}{l}\text { Lighting requirements vary } \\
\text { significantly between designs for } \\
\text { the bowl and central receiver } \\
\text { (primarily due to the size of the } \\
\text { field). Lighting requirements } \\
\text { were obtained from the TTU design. }\end{array}$ \\
\hline Compressed Air & +0.25 & $\begin{array}{l}\text { Approximately } 30 \% \text { was added to } \\
\text { the central receiver design to } \\
\text { account for additional controls } \\
\text { necessary for the bowl field. }\end{array}$ \\
\hline
\end{tabular}

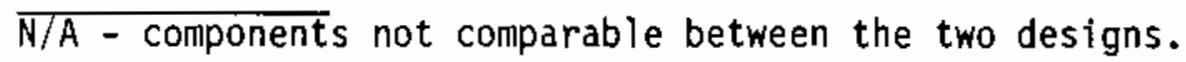

\section{G.2 CALCULATIONS}

The 5-MWe Crosbyton design was used as the base case for the bowl design. In order to directly use the size of plant equipment specified in the crosbyton design, the Solar-100 plant was scaled from 100 to 5 Mwe.

For components that were not comparable between the bowl and central receiver designs, and were not accounted for in another piece of equipment or sub-system, calculations were made based on information from the crosbyton design. When no information was avallable from the Crosbyton design, estimates were made based on engineering judgement and prior experience with similar systems. Each case is individually discussed below. Sources of information and assumptions are also listed. 


\section{G.2.1 Concentrator Tracking Power}

The functional form of the tracking power equation is as follows:

$$
\text { AUXTR = TR1 + (TR2) (AC) }
$$

where $A C$ is the aperture area of the concentrator.

The tracking system for the bowl design is comprised of two sub-systems: the hour angle drive unit and the declination drive unit; both units are hydraulically operated (Simpson, 0'Hair and Reichert 1982). It was estimated that the $12 \mathrm{~V}$ hydraulic pumps that energize the hour angle and declination drives operate 25 and 2 minutes per day, respectively. Given these assumptions, the energy consumption during the operating mode in a 5 MWe plant (10 bowls) is $3.36 \mathrm{kwh}$ per day. This load is entirely dependent on the number of bowls in the field, and therefore is represented in TR2. Based on a gross aperture area of $3007 \mathbb{m}^{2} /$ bow1, TR2 is $1.13 E-04 \mathrm{~kW} / \mathbb{m}^{2}$. There are no fixed power requirements for the bow1 (TR1 $=0$ ).

For the 5-Mwe plant, tracking power consumes less than $0.07 \%$ of the gross output of the plant.

\section{G.2.2 Fixed Operating Power Requirements}

The input into the SOLSTEP model for the fixed operating power requirements is in the form of the constant AUXOP. All equipment in this category is sized independently of the field size (i.e., the number of bowls).

Power requirements for the following items were obtained directly from the central receiver analysis (i.e., no adjustments were necessary to adapt these components to the bowl design):

- turbine control/lube pump

- bearing cooling water pump

- gland seal condenser fan

- water treatment system

- hVAC. 
In addition to the components 1 isted above, there were items common to both designs, but adjustments were necessary to accommodate for the differences between the bowl and central receiver designs.

Controls - To account for the controls necessary regulate the mass flow of the working fluid to the receivers, $30 \%$ was added to the existing control system for the central receiver design. The $30 \%$ was an estimate made on engineering judgment.

Lighting - The lighting requirements are significantly different between the bowl and central receiver design. The difference is primarily because of the intensity of use in the shop/rehab facility. The lighting load was calculated using the design parameters specified in the TTU document. The details of the plant lighting analysis are given in Table G.2.

\section{TABLE G.2. Lighting Requirement for Crosbyton 5-MWe Design (10 Bowls)}

\begin{tabular}{|c|c|c|c|c|c|c|c|c|}
\hline \multirow[b]{2}{*}{ Use } & \multirow{2}{*}{$\begin{array}{c}\text { Number } \\
\text { of } \\
\text { Fixtures }\end{array}$} & \multirow{2}{*}{$\begin{array}{c}\text { Watts } \\
\text { per } \\
\text { Fixture }\end{array}$} & \multirow{2}{*}{$\begin{array}{l}\text { Total } \\
\text { (kW) }\end{array}$} & \multirow{2}{*}{$\begin{array}{c}\text { Equiv. } \\
\mathrm{hp}\end{array}$} & \multicolumn{2}{|c|}{ Operating } & \multicolumn{2}{|c|}{ Standby } \\
\hline & & & & & usage & $\mathrm{hp}$ & usage & $\mathrm{hp}$ \\
\hline \multicolumn{9}{|l|}{ Solar Gridiron } \\
\hline Above & 40 & 400 & 16000 & 21.44 & $0 \%$ & & $10 \%$ & 2.14 \\
\hline Below & 160 & 70 & 11200 & 15.01 & $0 \%$ & & $10 \%$ & 1.5 \\
\hline Street Lighting & 36 & 250 & 9000 & 12.06 & $0 \%$ & & $100 \%$ & 12.06 \\
\hline \multicolumn{9}{|l|}{ Power Plant } \\
\hline Exterior & $13^{*}$ & 400 & 5200 & 6.97 & $0 \%$ & & $100 \%$ & 6.97 \\
\hline High Bay & 12 & 250 & 3000 & 4.02 & $100 \%$ & 4.02 & $100 \%$ & 4.02 \\
\hline Control Room & 18 & 40 & 2160 & 2089 & $100 \%$ & $\frac{2.89}{6.91}$ & $100 \%$ & $\begin{array}{r}2.89 \\
29.58\end{array}$ \\
\hline
\end{tabular}

* Based on 60-ft-spacing around the entire mirror rehab/control, room/power plant building [perimeter $=760 \mathrm{ft}$ (approx.)].

Source: Crosbyton 5MWe Design (Volume VIII) - Page 3.2, 5.46, 6.6

Compressed Air - In addition to the controls needed to regulate the mass flow of the working fluid to the receivers, additional compressed air will be required to operate the pneumatic valves. The compressed air station was 
scaled upward $30 \%$ (the same as the controls) to account for this requirement. Air pressure required for the efector vacuum pump used instead of an electrically powered pump is accounted for in this load.

For a 5 MWe plant, the fixed loads (AUXOP) sum to $45.4 \mathrm{~kW}$, which is approximately $0.9 \%$ of the gross plant output.

\section{G.2.3 Standby Power Requirements}

The functional form of the standby power requirements equation is

$$
\mathrm{AUXSB}=\mathrm{SB} 1+(\mathrm{SB} 2)(\mathrm{AC})
$$

where, $A C$ is the aperture area of the concentrator.

By definition, the facility is in standby mode when the turbine is not operating.

Equipment that is directly comparable between the bowl and central receiver designs includes:

- turbine control/lube pump

- bearing cooling water pump

- gland seal condenser fan

- water treatment system

- HVAC

- service water pumps

- cooling water fans.

In addition to those items listed above, there are pieces of equipment that are either unique to the bowl design or that require some modification from the central receiver design to work in the bowl design. Equipment of this type is discussed below on a case by case basis.

Controls - To account for the controls necessary to regulate the mass flow of feed water to the receivers, $30 \%$ was added to the existing control system for the central receiver design. The $30 \%$ was an estimate made on engineering judgment.

Compressed Air - In addition to the controls needed to regulate the mass flow feed water to the receivers, additional compressed air will be required 
to operate the pneumatic valves. The compressed air station was scaled upward $30 \%$ (the same as the controls) to account for this requirement.

Lighting - The lighting requirements are significantly different between the bowl and central receiver designs. The difference is because of two offsetting factors: the size of the field (central receiver field has a much lower packing factor and the area is larger) and the intensity of the lighting necessary on each bowl relative to that required for the heliostat field (higher intensity for the bowl). The lighting load was calculated using the design parameters specified in the TTU document. The details of the plant lighting analysis are given in Table G.2.

Lighting requirements were sub-divided into two components: 1) generating facility lighting, and 2) field lighting. Generating facility lighting refers to the exterior and interior lighting for the generating facility, and is scaled on plant output (SB1). Thts is the same as for the central receiver. In contrast, field lighting refers to all lighting in the receiver field (bowl and roadway lighting), and is scaled on collector area (SB2).

Cold Weather Heater - The in-line cold weather heater is unique to the water/steam bowl design (Simpson, 0'Hair, and Reichert 1982); trace heating is required when molten salt is used as the heat transfer medium for both the bowl and central receiver designs.

Use of the cold weather heater was based on weather data for the Barstow, California area. From this information it was determined that the coldest temperature recorded in 1976 was $23^{\circ} \mathrm{F}$, and during the same year there were approximately 45 hours of freezing weather. This was conservatively converted to 10 cold nights per year, with 5 hours of freezing weather per night (50 hours of freezing weather per year).

The Crosbyton design did not require a heater because it used the waste heat from the fossil fuel boiler, but the design report did provide information that was useful in sizing the cold weather heater. According to their calculations (page 5.17), a temperature drop (per pass) of $2^{\circ} \mathrm{F}$ resulted at a flow rate of 50,000 pounds per hour for an ambient temperature of $20^{\circ} \mathrm{F}$. The 
calculation below assumes that feed water was not circulated through the receivers. Based on this information the following calculation was made:

power requi rement $=\frac{50,000 \mathrm{lb}}{\mathrm{hr}} \times 1.25^{\circ} \mathrm{F} \times \frac{1 \mathrm{btu}}{{ }^{0} \mathrm{~F}-\mathrm{lb}} \times \frac{0.000293 \mathrm{kWh}}{\mathrm{btu}}=18.31 \mathrm{kwh}$

daily consumption $=18.31 \mathrm{~kW} \times \frac{50 \mathrm{hr}}{\mathrm{yr}} \times \frac{\mathrm{yr}}{366 \text { days }}=2.5 \frac{\mathrm{kWh}}{\text { day }}$

power averaged over standby period $=\frac{2.5 \mathrm{kWh}}{\text { day }} \times \frac{\text { day }}{15 \mathrm{hrs}}=0.167 \mathrm{~kW}$

for 10 bowls (3007 $m^{2}$ gross aperture area per bow 1 )

average power per $\mathrm{m}^{2}(\mathrm{SB} 2)=\frac{0.167 \mathrm{~kW}}{3007 \mathrm{~m}^{2}}=5.56 \mathrm{E}-06 \frac{\mathrm{kW}}{\mathrm{m}^{2}}$.

Bow] Cleaning System - The drive mechanism for the cleaning system is powered by the wash water pressure. The wash water pressure is supplied by the excess capacity of the $5 \mathrm{hp}$ sump pump, which also provides power for the circulation of the wash water. Assuming a weekly, 12 hour cleaning cycle for each bowl, the average standby power requirement is $1.42 \mathrm{E}-04 \mathrm{~kW} / \mathrm{m}^{2}$ (SB2) for a 5-Mwe plant (10 bowls).

In aggregate for a 5-MWe plant, the standby loads that vary with aperture area (SB2) have a coefficient of 4.876-04 kW/ $\mathrm{m}^{2}$, and those that are independent of field size (SB1) sum to $72 \mathrm{~kW}$. For the 5-MWe plant with 10 bowls the standby load is $86.7 \mathrm{~kW}$, which is approximately $1.7 \%$ of the gross plant output.

\section{G.2.4 Heat Tracing Power Requirements}

Because of the high freezing point of salt, heat tracing is necessary when molten salt is used as the medium for heat transfer from the collector field to the heat engine. The trace heating is used when the potential exists for the molten salt in the piping system to freeze (i.e., when the solar plant is not operating). By definition, trace heating is used when the solar plant is 
not operating. The functional form of the heat tracing power requirement is given as

$$
\text { AUXHT }=\text { SBHT1 }+(\text { SBHT2) (AC) })^{\text {SBHT3 }}
$$

where, $A C$ is the aperture area of the concentrator.

Power requirements for trace heating were derived from ETRANS output. 
.

, 
APPENDIX H

IRIS CONCENTRATOR WITH ORGANIC RANKINE CYCLE ENERGY CONVERSION 
APPENDIX H

\section{IRIS CONCENTRATOR WITH ORGANIC RANKINE CYCLE ENERGY CONVERSION}

This appendix provides a general discussion of another proposed configuration for the bowl technology; an iris bowl using an organic rankine cycle (ORC) distributed heat engine. This concept was proposed by Texas Tech University (TTU) during the course of this study, but it could not be included in the analysis of other systems because of schedule and cost constraints.

The objective of this appendix is to provide a discussion of the possible performance, cost, and levelized energy cost (LEC) of the iris/ORC concept to contribute to an understanding of whether it could promise sufficient advantages over the other concepts to be worthy of further analysis.

Although numerical results are provided in this appendix, the values shown are based on qualitative judgments; component performances have not been analyzed (as they were for Cases I through $V$ ), and annual simulations using the SOLSTEP computer code have not been conducted. For these reasons, the estimates of performance, cost, and LEC found in this appendix should not be directly compared with other results in this study, and all values reported in this appendix should be perceived as uncertain. They are intended to provide a range to indicate whether further systems analysis is warranted.

The performance and cost of the system were based on the analysis done for the five bowl configurations considered in this study. Each subsystem is discussed separately. Estimated design-point information is given when available (i.e., the same as a case previously analyzed) and component annual performance and cost estimates are presented. The estimated annual average performance of the system is the product of the individual component efficiencies less the parasitics.

This appendix provides a first order approximation of the LEC of a 100-MW (200 bowls) plant using iris concentrators with full-length receivers and ORC engines. The results of this analysis indicate an expected range for the LEC of $\$ 0.11-0.16 / \mathrm{kWh}$. Although the lower bound of this range is below the 
estimate for the 60-degree $\mathrm{W} / \mathrm{S}$ system, the upper bound is higher than the 60-degree W/S system. The lower bound is also more than twice as high as LEC projections for central receiver systems at the same power level. Based on this first-order evaluation, Pacific Northwest Laboratory's (PNL) recommendation is that the iris/ORC concept does not offer sufficient promise to warrant additional systems analyses studies.

\section{H. 1 CONCENTRATOR SUBSYSTEM}

The iris concentrator subsystem consists of a field of fixed 30-degree concentrators with sun-tracking mirror units called irises. The fixed portion of the concentrator is identical to the concentrator used in Cases III and IV except that the reflective surface is Mylar instead of glass/metal mirror. The moveable portion of the concentrator (iris) has a width of 90 degrees of the concentrator aperture circumference and a height of 15 degrees of the concentrator curvature. The iris is able to circumscribe 270 degrees of the concentrator; therefore, the center of the iris is able to move from due west to due east in a day. The addition of the iris increases the gross aperture area of the concentrator by $25 \%$ to $40,459 \mathrm{ft}^{2}\left(3758.6 \mathrm{~m}^{2}\right)$. The non-tracking portion of the iris concentrator is assumed to make up a contiguous surface; therefore there are no gaps in this portion. Gaps between the mirror panels of the tracking iris do exist. TTU estimates that the gaps will account for $0.9 \%$ of the entire concentrator's theoretical surface area. (a) This results in a net aperture area of $40,093 \mathrm{ft}^{2}\left(3724.7 \mathrm{~m}^{2}\right)$.

\section{H.1.1 Design-Point Performance}

The primary figure of merit for characterizing concentrator performance is concentrator efficiency. Concentrator efficiency includes the impact of cosine losses, shadowing, blocking, reflectivity losses, atmospheric attenuation, and spillage. Because the bowl system is a modular concept, the design-point performance will be the same for all concentrators of the same kind. The following is a discussion of how each of the losses listed above contributes to the design-point performance of the iris concentrator.

(a) TTU correspondence to T. Williams on October 14, 1986. 
- cosine losses-Because the angle of incidence is equal to zero at the design point there are no cosine losses.

- shadowing-The shadowing from the receiver support structure/legs, piping, and "cleaning snake" was estimated by TTU to be approximately 0.9946 (a) for the iris concentrator. Without knowing the basis of this estimate it was assumed to be the same on an annual basis. This value is considerably less than the 0.912 associated with the 65 -foot-diameter test bowl at TTU, but the receiver support structure has a radically different design. It should be noted that the shadowing of the reflector caused by its own "lip" is a loss accounted for by the cosine loss. The shadowing of one concentrator by the adjacent concentrator's receiver support structure is not considered, even though it could be significant with this design. One should also note that the iris portion of the concentrator will not shadow the fixed portion of the concentrator because the iris is always on the side of the concentrator away from the sun.

- blocking-This design has no blocking of the reflected flux because the receiver support structure is all located outside of the concentrator. Additionally, the iris does not block any reflected flux.

- reflectivity losses-As with the 60-degree and 30-degree concentrators a clean, new reflectivity of 0.94 was assumed for the concentrator reflectors. This value is very optimistic because this concept assumes a Mylar reflector for the fixed portion of the concentrator. A concentrator cleaning system is incorporated into the concentrator. Weekly cleaning will help to maintain the highest possible reflectivity. It is assumed that the average reflectivity is 0.93 ; therefore the reflectivity degradation factor is $0.93 / 0.94=0.9894$. The average reflectivity $(0.93)$ was used for both the design-point and annual performance estimates.

(a) TTU correspondence to T. Williams, PNL, on optical efficiency of an iris concentrator, dated October 14, 1986. 
- atmospheric attenuation-A very small fraction of the reflected solar flux is absorbed by the atmosphere before it reaches the receiver. This value was not measured or calculated by TTU. It is estimated that the atmospheric transmission loss for the bowl collector is much less than that for the central receiver. Although this value would actually be larger for the iris concentrator than for the 60-degree concentrator, the same value was assumed $(0.995)$.

- spillage-The spillage is determined by reflector quality, tracking accuracy, receiver size and geometry, and receiver structural integrity. For the iris concentrator, the same values for the optical loss (0.98) and deflection Toss (0.98) were assumed as were used for the 60-degree concentrator. Because the receiver for this case is full length (one-half the radius of curvature) there are no end losses. The overall design-point spillage loss factor is therefore estimated to be:

0.98 (optical loss) $\times 0.98$ (deflection loss) $=0.9604$.

The design-point concentrator efficiency is the product of the various efficiency factors listed above. This is the percentage of the available flux that impinges on the receiver surface; where the available flux is defined as the product of the design-point direct normal insolation $\left(950 \mathrm{~W} / \mathrm{m}^{2}\right)$ and the gross aperture area (3007 $\left.\mathrm{m}^{2}\right)$. Therefore, the design-point efficiency for the iris concentrator is:

$$
(0.9946)(0.93)(0.995)(0.98)(0.98)=.884
$$

And the amount of flux impinging on the receiver at the design point is:

$$
\left(950 \mathrm{~W} / \mathrm{m}^{2}\right)\left(3725 \mathrm{~m}^{2}\right)(0.884)=3128 \mathrm{~kW}
$$

\section{H.1.2 Average Annual Concentrator Performance}

The annual average iris concentrator efficiency for a full-length receiver as determined by SOLSTEP in the Case $V$ analysis is $60.9 \%$. (a) The efficiency would be constant with power level because of the modular nature of the concept.

(a) This value was for a sensitivity analysis receiver. The actual receiver used in Case 5 was only $20 \%$ of full length, resulting in an annual concentrator efficiency of $38.5 \%$. 
This efficiency is the highest among the concentrator configurations analyzed because the receiver is full length (no end loss) and the tracking portion of the concentrator allows for lower annual cosine losses.

\section{H.1.3 Concentrator Cost}

The concentrator cost per square meter is identical to the Case $V$ concentrator cost. Therefore, the total concentrator cost is:

$(200$ bowls $) *\left(3725 m^{2} /\right.$ bow 1$) *\left(\$ 89 / m^{2}\right)=\$ 66.13 M$

\section{H.2 RECEIVER SUBSYSTEM}

The receiver/boiler is a cylinder with a length approximately equal to one-half the concentrator radius of curvature $(101.5=203 / 2)$. It is assumed to have a design similar to the Case III receiver (a two-phase water/steam receiver) and to consist of a stainless steel support tube, which is spirally wrapped with twenty parallel tubes. The bottom $60 \%$ of the receiver (low flux area) uses 316 stainless steel tubes and the top $40 \%$ of the receiver uses Incone 1617 tubes of the same size. The receiver diameter is the same as that of the Case III receiver. The receiver tubes are assumed to be painted with black Pyromark paint to reduce reflection and to aid in the absorption of the concentrated solar flux.

\section{H.2.1 Design-Point Performance}

The receiver performance is estimated based on the Case III analysis. The results of this analysis consist of receiver optical and thermal losses. The receiver absorption and emittance are determined by the receiver geometry, angle of incident flux, and receiver tube material and coating. Because the receiver is a cylinder and the tubes are painted with black Pyromark paint, the absorptivity and emissivity were assumed to be 0.96 , the same as that of a central receiver (Williams et al. 1987). The much greater average incident angle of the flux (which would lower the absorptivity) was not considered because of the lack of experimental data.

The total receiver thermal loss for the Case III receiver was estimated to be $155.7 \mathrm{~kW}$. Since this receiver is $66.7 \%$ longer $(101.5 / 60.9)$ than the 
Case III receiver, the thermal losses are assumed to be higher by the same percentage.

$$
(155.7) \star(1.667)=260 \mathrm{~kW}
$$

Because at the design point there is $3128 \mathrm{~kW}$ incident on the receiver and $96 \%$ is assumed to be absorbed into the working fluid, an estimate of the design-point receiver efficiency can be made:

$$
\frac{(3128 * 0.96)-(260)}{3128}=88 \%
$$

This represents a rough approximation because what the actual temperature profile of the receiver would be is not known.

\section{H.2.2 Average Annual Receiver Efficiency}

The average annual receiver efficiency is less than the design-point efficiency because of off-design conditions and the addition of nighttime cooldown losses. The nighttime cool-down loss for Case III was estimated to be $303.3 \mathrm{kWh}$ per day. Therefore, the estimated nighttime cool-down loss is:

$$
(303.3) *(1.667)=510 \mathrm{kWh}
$$

If the plant is assumed to operate for 3158 hours a year (the number of hours the optimal Case I plant operated) the total annual thermal loss per receiver would be:

$$
\left(259.5^{\star 3158)}+(510 \star 366)=1,006 \mathrm{MWh} /\right. \text { year }
$$

Because the annual insolation is $2848 \mathrm{kWh} / \mathrm{m}^{2}$ and the annual concentrator efficiency is $60.3 \%$ the annual receiver efficiency can be estimated as:

$$
\frac{(2848 * 3725 \star 0.609) *(0.96)-(1006 * 1000)}{\left(2848 \star 3725^{\star} 0.609\right)}=80 \%
$$

Because of the modular nature of the concept, recejver efficiency is constant with plant size. Therefore, the estimated field efficiency (combined concentrator/receiver efficiency) is $48.7 \%\left(0.609^{*} 0.80\right)$, which is also constant with field size. 


\section{H.2.3 Receiver Cost}

The receiver is assumed to cost $66.7 \%$ more than the Case III receiver in absolute dollars or $33.3 \%$ more on a dollars per square meter of aperture basis. Therefore, the cost for 200 receivers is:

$$
(200) *(1.67) *(\$ 390,800)=\$ 130.27 M
$$

\section{H.3 TRANSPORT SUBSYSTEM}

The transport subsystem is an ac power transmission network, and consists of the cables, transformers, circuit breakers, and miscellaneous equipment necessary for transmitting power from numerous large ORC engines to the central distribution facility.

\section{H.3.1 Design-Point Performance}

Losses in the transport system for this concept represent losses in transmission lines and electrical components. The optimal field size for the Case $V, 100-M W$ system was $774,000 \mathrm{~m}^{2}$; the design-point transport efficiency for this field size was $95.9 \%$. This same value will be assumed for the organic Rankine cycle (ORC) system.

\section{H.3.2 Average Annual Transport Performance}

The annual average transport performance for the optimal Case V, 100-MW system was $95.9 \%$. This result is the same as for the design-point results because losses are a percentage of output.

\section{H.3.3 Transport System Cost}

The transport cost is assumed to be identical to the Case $V$ transport cost $(\$ 6.24 M)$.

\section{H.4 STORAGE SUBSYSTEM}

There was no storage considered with this case. 


\section{H.5 ENERGY CONYERSION SUBSYSTEM}

The energy conversion subsystem takes thermal energy supplied from the receiver and converts it to electrical energy. The energy conversion subsystem for each bowl consists of the ORC engine, the generator, and heat rejection unit.

\section{H.5.1 Design-Point Performance}

The gross energy conversion efficiency of the ORC engines was estimated to be $28.0 \%^{(a)}$.

\section{H.5.2 Average Annual Energy Conversion Efficiency}

The average annual gross energy conversion efficiency for the ORC heat engine, including part-load and ambient temperature corrections, was determined by taking the ratio of the $0.5-\mathrm{MW}$ steam Rankine engine annual gross energy conversion efficiency and design-point efficiency from Case $I$, and multiplying by the ORC design-point efficiency. Therefore, the annual average gross energy conversion efficiency for the ORC heat is estimated to be:

$$
\frac{(0.28) *(0.304)}{(0.314)}=27.1 \%
$$

This value ignores the parasitic power requirements of the heat engine, as well as the pumping power required to overcome the head loss of the receiver. Therefore, it grossly overestimates the net conversion efficiency.

Another factor which affects the electrical output of the plant is the mismatch between the receiver output and the maximum heat engine input. This factor was $97 \%$ for Case $V$ and that value will be assumed here.

\section{H.5.3 Energy Conversion Cost}

The cost of the energy conversion system was assumed to be $\$ 300 / \mathrm{kW}_{\mathrm{e}}^{(\mathrm{b})}$. Therefore, for two-hundred 0.5-Mwe engines the total cost is:

$$
(200)^{\star}(500)^{\star}(300)=\$ 30 M
$$

(a) SERI internal memorandum from R. J. Copeland to J. Thornton dated November $26,1986$.

(b) SERI internal memorandum from R. J. Copeland to J. Thornton dated November 26, 1986. 


\section{H.6 BALANCE OF PLANT, PARASITICS, AND OPERATING AND MAINTENANCE}

The balance-of-plant and parasitics were assumed to be the same as for Case $V$. The operating and maintenance (O\&M) costs were assumed to be the midpoint between the Case I and Case $V$ costs.

\section{H.6.1 Parasitics}

The annual parasitics estimated for the 200-bowl system in Case $V$ were $27,240 \mathrm{MWh}$; this value will be assumed for this configuration as well.

\section{H.6.2 Balance-of-Plant Costs}

Balance-of-plant includes costs for: power conditioning equipment, structures, instrumentation and control, spare parts, and service facilities. The total for these items from case $V$ was $\$ 5.30 M$. In addition, land costs from Case $V$ were $\$ 5.66 \mathrm{M}$ and the present value of the collector replacement capital cost from Case $V$ was $15.54 M$.

\section{H.6.3 O\&M Costs}

The annual 0\&M costs for Case $V$ were estimated to be $\$ 9.65 / \pi^{2}$ of aperture area. For Case I the annual $0 \& M$ costs were estimated to be $\$ 7.31 / m^{2}$ of aperture area. The average of these two cases $\left(\$ 8.48 / \mathrm{m}^{2}\right)$ will be used as an estimate. Therefore, the annual O\&M is:

$$
(200)^{\star}(3725.56) \star(8.48)=\$ 6.32 \mathrm{M} / \text { year }
$$

\section{H.7 SYSTEM PERFORMANCE AND ANNUAL OUTPUT}

The system performance is calculated by multiplying together the component efficiencies, the heat engine mismatch, and the avaflable energy. Then the parasitics are subtracted and the net energy output is multiplied by the availability.

\section{H.7.1 Optimistic Case Estimate}

The estimated gross annual output is:

$\left(744,947 \pi^{2}\right) *\left(2848 \mathrm{kWh} / \pi^{2}\right) *(0.609) *(0.804) *(0.959) *(0.271) *(0.97)=$ $261,651 \mathrm{MWh}=$ gross annual output 
The annual output net of parasitics is:

$$
261,652 \mathrm{MWh} \text { - 27,240 Mwh }=234,412 \mathrm{MWh}
$$

And finally, the accounting for availability, the amount of energy estimated to be put on the grid is:

$$
234,412 \text { MWh * } 0.97=227,380 \text { WWh }
$$

This would result in a system efficiency of:

$$
\frac{227,380 \mathrm{MWh}}{744,947 \pi^{2} * 2.848 \mathrm{MWh} / \pi^{2}}=10.7 \%
$$

This system efficiency is comparable to the 100-MW Case I efficiency even though the Case I gross turbine efficiency is $35 \%$ higher than the ORC gross efficiency.

\section{H.7.2 Realistic Case Estimate of Annual Output}

The above value represents an optimistic, best case estimate. Pumping losses were ignored, the specularity of the Mylar bowl was assumed to be the same as the glass/metal bowls, and the droop factor was assumed to be the same even though the receiver was $67 \%$ longer than in Cases I through IV, and the absorptivity was assumed to be .96 . To arrive at a more realistic estimate of the annual output these items should be considered.

The pumping parasitics for Case I (same estimated operating time) with one bowl were $23,474 \mathrm{kwh} /$ year. Therefore, for 200 bowls this would increase the parasitics by $4,695 \mathrm{MWh} /$ year.

The specularity of new Mylar is less than that of a glass/metal mirror and $i t$ will degrade over time (it is assumed that it will need to be replaced every five years). For the realistic case the specularity of the Mylar is assumed to be four percentage points less than that of the glass/metal. Since the Mylar portion of the bowl is just over three-quarters of the surface area, a reduction in total specularity of three percentage points would be reasonable.

The droop factor was assumed to be the same for this receiver even though the receiver was $67 \%$ longer than in cases I through IV. At a minimum, it could be expected that this loss factor would double. 
Receiver absorptivity was assumed to be .96 ; at the very large incident angles that the flux impinges on the receiver a value lower than this would be expected. The absorptivity of a full-length receiver painted with flat black Pyromark paint was found to have a reflection loss of $10 \%^{(\mathrm{a})}$.

Including these factor would result in a design-point concentrator efficiency of:

$$
(0.9946)(0.90)(0.995)(0.98)(0.96)=.838
$$

And the amount of flux impinging on the receiver at the design point is:

$$
\left(950 \mathrm{~W} / \pi^{2}\right)\left(3725 \pi^{2}\right)(.838)=2964 \mathrm{~kW}
$$

The estimated annual average concentrator efficiency would then be:

$$
\frac{(0.609) *(0.838)}{(0.884)}=.577
$$

By including the effect of the lower assumed absorptivity, the design-point receiver efficiency would be:

$$
\frac{(2964 * 0.90)-(259.5)}{2964}=81.2 \%
$$

The estimated annual average receiver efficiency would then be:

$$
\frac{(2848 * 3725 \star 0.577) \star(0.90)-\left(1006^{\star} 1000\right)}{(2848 * 3725 * 0.577)}
$$

Therefore, the estimated gross annual output would be:

$$
\left(744,947 \pi^{2}\right) *\left(2848 \mathrm{kWh} / \pi^{2}\right) \star(0.77) \star(0.736) \star(0.959) *(0.271) *(0.97)=
$$

$227,1321 \mathrm{MWh}=$ gross annual output

By including the pumping parasitics, the total parasitics would be:

$$
27,240+4,695=31,935
$$

(a) The Crosbyton Solar Power Project, Vol. VII: Performance and Cost of Solar Gridiron Electric Power Plants p. 2.44. 
The annual output net of parasitics is:

$$
\text { 227,132 MWh - 31,935 MWh }=195,197 \text { MWh }
$$

And finally, accounting for avallability, the amount of energy estimated to be put on the grid would be:

$$
195,197 \text { WWh * } 0.97=187,341 \mathrm{MWh}
$$

This would result in a system efficiency for the realistic case of:

$$
\frac{189,341 \mathrm{MWh}}{744,947 \mathbb{\pi}^{2} * 2.848 \mathrm{MWh} / \pi^{2}}
$$

\section{H.8 SYSTEM COST}

The onty cost that is really in question is the receiver cost. If it is assumed that the receiver cost is the same as for Case III (even though it is $67 \%$ longer), it would cost $\$ 390,800$ per receiver. Table H.1 presents the estimated cost of a 200-bow1 (100-MW) ORC plant. The total estimated system cost for the low cost receiver is shown in the column labeled optimistic, and the system cost using the higher cost receiver is shown in the column labeled base case.

\section{H.9 LEVELIZED ENERGY COST}

Using the method in SOLSTEP the LEC was determined. The results of each combination of performance and cost are shown the Table H.2.

Even under the most optimistic assumptions the ORC has only an estimated LEC of $11 \nsubseteq / \mathrm{kWh}$. Although this is better than any of the other bowl systems, it is still a factor of 2 higher than the estimated LEC of 100-MW central receiver systems. 
TABLE H.1. ORC Estimated Cost

\begin{tabular}{|c|c|c|}
\hline Component & $\begin{array}{l}\text { Base Case } \\
\text { Cost (\$M) }\end{array}$ & $\begin{array}{l}\text { Optimistic } \\
\text { Cost }(\$ M)\end{array}$ \\
\hline Concentrators & 66.30 & 66.30 \\
\hline Receivers & 130.27 & 78.16 \\
\hline Transport & 6.24 & 6.24 \\
\hline Conversion & 30.00 & 30.00 \\
\hline Balance of Plant & 5.30 & 5.30 \\
\hline Land & 5.66 & 5.66 \\
\hline Total Direct Cost & 243.77 & 191.66 \\
\hline $\begin{array}{c}\text { Indirects and Contingencies } \\
(035 \% \text { of Direct Cost) }\end{array}$ & 85.32 & 67.08 \\
\hline Total Capital Investment & 329.09 & 258.74 \\
\hline $\begin{array}{l}\text { Present Value of Replacement } \\
\text { Capital Costs }\end{array}$ & 15.54 & 15.54 \\
\hline O\&M Costs (Annual) & 6.32 & 6.32 \\
\hline
\end{tabular}

TABLE H.2. Levelized Energy Cost of ORC System

\begin{tabular}{llll} 
& & \multicolumn{2}{c}{ Cost } \\
\cline { 3 - 4 } & & Base Case & Optimistic \\
$\mathrm{P}$ & & & \\
$\mathrm{e}$ & & & \\
$\mathrm{r}$ & Realistic & $16 \$ / \mathrm{kWh}$ & $14 \$ / \mathrm{kWh}$ \\
0 & & & \\
$\mathrm{r}$ & & $11 \$ / \mathrm{kWh}$ \\
$\mathrm{m}$ & & & \\
$\mathrm{a}$ & 0 0ptimistic & $13 \$ / \mathrm{kWh}$ & \\
$\mathrm{n}$ & & & \\
$\mathrm{c}$ & & &
\end{tabular}


$+$ 


\section{APPENDIX I}

CAPITAL COST ESTIMATES FOR INNOVATIVE BOWL CONCENTRATORS 


\section{APPENDIX I}

\section{CAPITAL COST ESTIMATES FOR INNOVATIVE BOWL CONCENTRATORS}

Many alternative designs are possible for fixed mirror distributed focus (FMDF) bowl concentrators. In addition to the 60-degree and 30-degree concentrators evaluated in Cases I through IV, a number of innovative bow] concentrator designs were investigated as a sensitivity analysis. The levelized energy cost (LEC) results of the sensitivity analysis are reported in chapter 8. This appendix provides additional documentation on the capital cost estimates for the innovative bowl concentrators evaluated.

The innovative concentrator designs are aimed at finding ways to dramatically reduce the initial capital cost of the bowl concentrator, and thereby reduce the LEC. The designs assessed in this study included:

- glass on cast-in-place concrete concentrator

- glass on pre-cast concrete cConcentrator

- Mylar concentrator

- membrane concentrator.

Very limited design information exists for any of these concentrators, as they have been developed at only a preliminary, conceptual level. The cost estimates developed for the concentrators do not account for the uncertainty inherent in the designs; therefore the uncertainties associated with the cost estimates for these concentrators are much higher than the uncertainties in the cost estimates for the 60- and 30-degree concentrators. The cost estimates were developed under the assumption that the basic construction techniques, as envisioned by Texas Tech University (TTU), could be accomplished. This appendix also does not address the performance uncertainties associated with the concentrators.

The costs for the alternative concentrators were developed with an approach that is similar to that used for the 60- and 30-degree concentrators. In each of the estimates Pacific Northwest Laboratory (PNL) used the unit costs associated with Cases I through IV when estimating elements of the alternative concentrators, which are similar to the Case I through IV elements. For unique 
aspects of the alternative concentrators cost estimating, manuals and vendors were consulted regarding the estimates.

The following sections present, for each alternative concentrator design, a short design description, both PNL's and TTU's cost estimates for the concentrator capital cost, a discussion of why differences exist between PNL's and TTU's estimates, and particular aspects of the concentrator that substantially increase the uncertainty in the cost estimates.

\section{I.1 GLASS ON CAST-IN-PLACE CONCRETE CONCENTRATOR}

The glass on cast-in-place concrete concentrator consists of a bowl-shaped concrete slab poured on a roughly-formed soil bowl upon which mirror facets are glued. The soil bowl is formed by a rough cut, fill, and compact operation. The finish grading/compacting is completed by a receiver-mounted pneumatic tool. To achieve an accurately formed slab, steel guide rafls are mounted in the soil bowl to act as tracks for a screeding trolley, which finishes the concrete. The mirror facets are similar to those found in the baseline concentrator, except that they don't require metal backing for support because the concrete provides the necessary support.

The PNL and TTU estimates for the cast-in-place concentrator are presented in Table I.1. PNL's earthwork estimate is greater than TTU's because charges for a compaction operation by heavy equipment are included, where the TTU estimate included only the cut and fill operation. PNL's estimate for the installed steel support cost is $\$ 15,200$ lower than TTU's, because PNL used a lower unit cost per pound of installed steel. With respect to the concrete operations, PNL itemized the materials and labor involved, which resulted in an estimated cost lower than that derived by TTU's use of a $\$ 200 / \mathrm{yd}^{3}$ unit cost. PNL included the cost for a cleaning system (using the same cost as was used in cases III and IV), and TTU did not include this item. For mirror facets PNL used a cost similar to Cases I through IV, with appropriate adjustments of the cost for design differences. The largest discrepancy between estimates arises in the mirror placement cost. PNL deemed the installation man-hours as being greater than TTU and used a higher field labor rate. This resulted in PNL's estimate being higher. 
TABLE I.1. Cast-in-Place Concentrator Estimate

\begin{tabular}{lrr}
\multicolumn{1}{c}{ Subcomponent } & TTU est. & PNL est. \\
\cline { 1 - 1 } Earthwork & 61,500 & 88,700 \\
Steel Supports & 28,900 & 13,700 \\
Concrete & 83,000 & 54,000 \\
Cleaning System & - & 20,200 \\
Mirrors & 33,700 & 89,000 \\
Mirror Placement & 6,700 & 41,300 \\
Total & $\$ 213,300$ & $\$ 306,900$ \\
$\$ / \mathrm{m}^{2}$ & 75 & 109
\end{tabular}

The principal difficulty in estimating the cost of this concentrator is the lack of design and construction definition. There is some concern as to how the concrete would be poured at grades exceeding $100 \%$ (45 degrees). This factor alone could greatly increase the total cost, should the concerns be realized when developing a definitive design. This factor constitutes the major point of uncertainty associated with the glass on cast-in-place concrete.

\section{I.2 GLASS ON PRE-CAST CONCRETE CONCENTRATOR}

The glass on pre-cast concrete concentrator is similar in nature to the cast-in-place concentrator. The primary difference between the two designs is the method of concrete placement. To construct a pre-cast concentrator, 8-foot by 8 -foot molds would be set up at the construction site. The mirror facets would be laid face down in the molds, and concrete poured over them. After curing, the pre-cast panel with the mirrors attached would be removed from the mold and placed into the bowl, where it would be grouted in place.

Table I.2 shows PNL's and TTU's subcomponent estimates for the concentrator component. PNL's estimate of earthwork and cleaning system charges were more than TTU's estimate for the same reasons as explained for the cast-in-place concentrator estimate. PNL's cost for the pre-cast panels is greater than TTU's primarily because of PNL's higher mirror cost and field-labor rate. The mirror cost and field-labor rate used by PNL were identical to that used for 
TABLE I.2. Pre-Cast Concrete Concentrator Cost Estimate

\section{Subcomponent}

Earthwork

Pre-Cast Panels

Panel Installation

cleaning System

Total

$\$ / m^{2}$
TTU est.

61,000

85,000

20,400

$\$ 166,900$

59
PNL est.

88,700

140,500

83,300

20,200

$\$ 332,700$

118

other bowl concentrators (and other solar concepts in the previous PNL study), so that any changes in these unit costs would also affect the concentrator costs for other concepts. For panel installation, PNL believes the handling, aligning, and grouting man-hours, and the associated labor rates are higher than does TTU, which results in PNL's higher estimated cost. As for the castin-place concentrator, PNL includes the cost of a concentrator cleaning system.

\section{I.3 MYLAR CONCENTRATOR}

The Mylar concentrator is quite different from the previous concentrators. It consists of a soil-formed bowl, upon which a gunite bowl is sprayed and finished. After curing, a reflective Mylar liner would be placed inside the gunite bowl.

8oth PNL's and TTU's estimates on this concept are presented in Table I.3. PNL again included compaction in its earthwork charges, which resulted in PNL's estimate for earthwork being higher than TTU's. With respect to forming the gunite bowl, PNL used estimating manuals to itemize the materials and application hours, PNL also added the cost to finish grade the gunite. PNL presumed the cleaning system for this concentrator would cost the same as the Cases III and IV cleaning systems.

The Mylar is a unique aspect of this concentrator. To arrive at its cost, Mylar vendors and fabricators were consulted. The estimated cost includes the cost of the reflective Mylar coated with a UV stabilizer (to prevent degradation by the sun's rays), the cost to cut and weld seams, and the cost 
TABLE I.3. Mylar Concentrator cost Estimate

\begin{tabular}{lrrr}
\cline { 1 - 1 } Subcomponent & TTU est. & PNL est. \\
\cline { 3 - 4 } Earthwork & 61,000 & 88,700 \\
Gunite & 18,800 & 45,600 \\
Mylar & 2,900 & 34,000 \\
Cleaning System & - & 20,200 \\
Total & $\$ 82,700$ & $\$ 188,500$ \\
$\$ / \mathrm{m}^{2}$ & 28 & 65 \\
\hline 5 year life on Mylar & &
\end{tabular}

of installation. With respect to this subcomponent, on the advice of a Mylar manufacturer, the life of the Mylar was estimated at five years. This requires the inclusion of replacement capital every five years in the SOLSTEP cost model.

The Mylar concentrator estimate has a great amount of uncertainty, most of which pertains to the Mylar itself. There are currently a wide range of grades and thicknesses of Mylar on the market. Since there is no detail in the conceptual design, the material with the lowest cost (which was deemed as minimally acceptable for use) was chosen. Therefore, the cost of the Mylar subcomponent is viewed as optimistic, and could easily increase $50 \%$ or more once a more definitive design is available. Also, the true performance of the Mylar concentrator is uncertain. It may be necessary to modify the design to bring the perfomance to an acceptable level, which could greatly increase the capital costs.

\section{I.4 MEMBRANE CONCENTRATOR}

The membrane concentrator consists of a shallow soil bowl with a concrete ring surrounding it. Over the ring a polyester/Mylar membrane is attached. A large blower applies suction to the reverse side of the membrane, which is supposed to result in a uniformly curved concentrator.

The concentrator costs for this concept estimated by PNL and TTU are shown in Table I.4. Once again, the difference in the earthwork estimates can 
be ascribed to PNL's inclusion of compaction in addition to cut and $f(11$. PNL's itemized concrete estimate is higher by $\$ 18,000$ than ITU's unit cost estimate. PNL's itemized estimate accounted for the increased labor involved in building circular forms. Although not defined, the ring may have a sloped inner face, access doors, clamps set in the concrete, etc. This could further complicate the pouring. PNL's membrane estimate was derived from the cost of a circular air-supported polyester tank cover and blower system to which the Mylar cost was added. Because the Mylar/polyester membrane is heavier and more durable than the Mylar used in the Mylar-on-gunite concentrator, it was assumed to have a ten year life as opposed to a five year life assumed for the Mylar concentrator.

\section{IABLE I.4. Membrane Concentrator Cost Estimate}

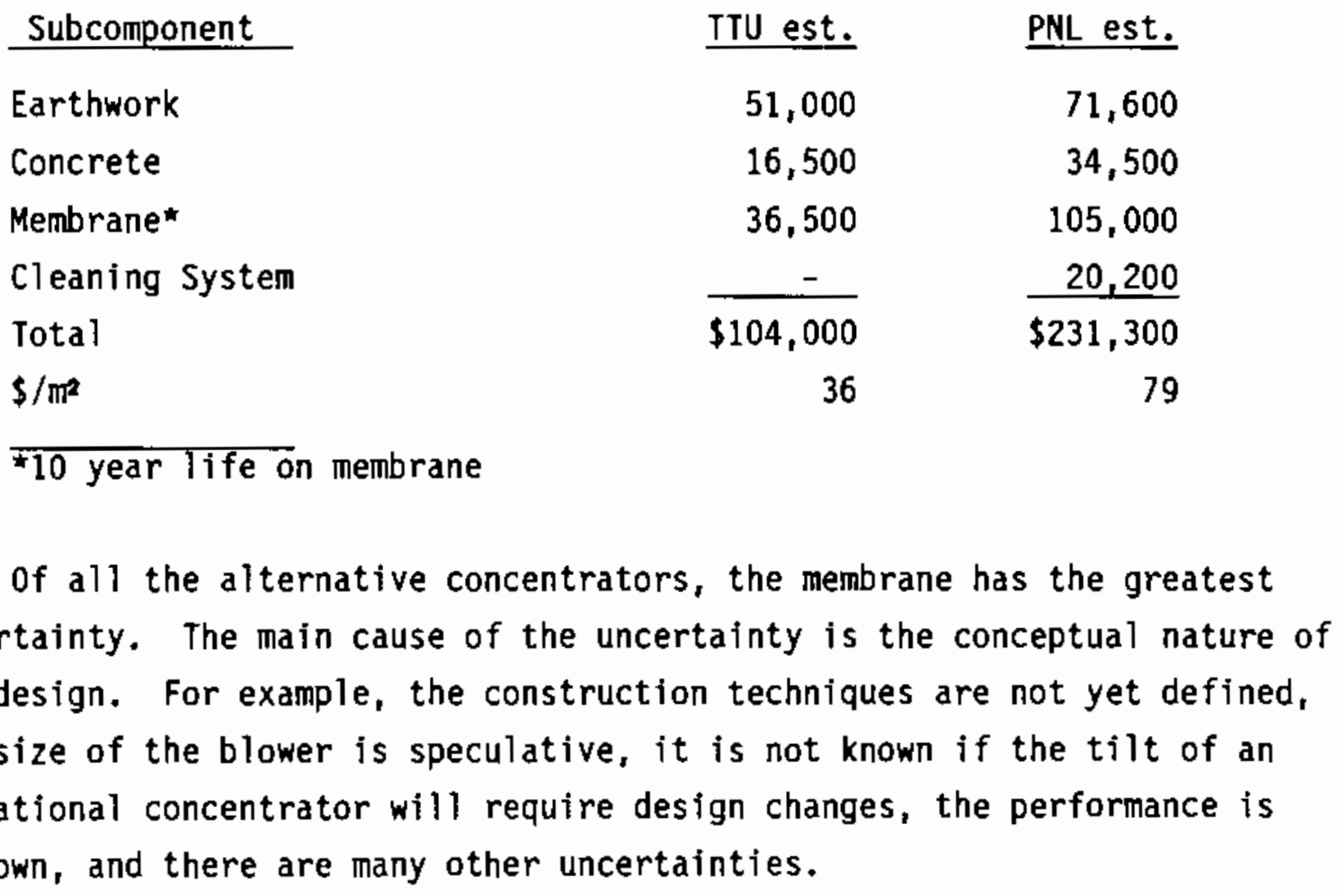




\section{REFERENCES AND BIBLIOGRAPHY}

Anderson, R. M., and W. T. Ford. 1984. Rosa: A Computer Model for Optical Power Ratio Calculations. Department of Mathematics, Texas Tech University, Lubbock, Texas.

Anderson, R. M., and R. W. Barnard. 1986. "Mathematical Techniques for Generating Mirror Panel Layouts on a Spherical Bowl." In Proceedings of the ASME Solar Energy Conference, pp. 210-216, Anaheim, California.

Anderson, R. M., R. W. Barnard, and W. T. Ford. 1986. Mirror Panel Layouts for an Icosahedral Solar Bowl. Department of Mathematics, Texas Tech University, Lubbock, Texas.

Apley, W. J., et al. 1980. Analysis of Electric Power Generating Costs for Systems Larger than 10 MWe. In Vol. I of Assessment of Generic Solar Thermal Systems for Large Power Applications. PNL-3533, Pacific Northwest Laboratory, Richland, Washington.

Bechte1 Group, Inc. 1985. Water-Steam Rankine Cycle Solar Central Receiver Power Plant: Cost Estimate. EPRI-AP-3801, Bechtel Group, Inc., San Francisco, California.

Barnhart, J. S. 1980. ETRANS: An Energy Transport System Optimization Code for Distributed Networks of Solar Collectors. PNL-3327, Pacific Northwest Laboratory, Richland, washington.

Bethea, R. M., and A. M. Cooper, 1985. Dust Storm Simulation on Carolina Glass Mirrors. Department of Chemical Engineering, Texas Tech University, Lubbock, Texas.

Bethea, R. M., and A. M. Cooper. 1986. Redesign and Evaluation of Dust Storm Simulator of Solar Mirror Survivability. Department of Chemical Engineering, Texas Tech University, Lubbock, Texas.

Bethea, R. M., et al. 1986. Reflectance Loss of Prospective Solar Concentrator Mirrors in Erosive Environments. Department of Chemical Engineering, Texas Tech University, Lubbock, Texas.

Bird, S. P. 1980. SOLSTEP-A Computer Model for Solar Plant System Simulations. In Vol. V. of Assessment of Solar Options for Small Power Systems Applications. PNL-4000, Pacific Northwest Laboratory, Richland, Washington.

Bird, S.P., et al. 1981. Analysis of Thermal Energy Production Costs for Systems from 50 to $600 \mathrm{MWt}$. In Vol. II of Assessment of Generic Solar Thermal Systems for Large Power Applications. PNL-3533, Pacific Northwest Laboratory, Richland, Washington. 
Carper, H. J., and J. D. Reichert. 1980. The Crosbyton Solar Power Project. In Vol. VI: Analog Design Verification system Preliminary Performance Results. Texas Tech University, Lubbock, Texas.

Clausing, A. M. 1976. Optical and Thermal Characteristics of a Solar Collector With a Stationary Spherical Reflector and a Tracking Absorber. Sandia Laboratories, Albuquerque, New Mexico.

Clements, L. D. 1977. "Design Considerations for the Energy Receiver in a Fixed Mirror-Distributed Focus (FMDF) Solar Energy System." From Alternative Energy Sources: An International Compendium, Volume 1, Solar Energy 1, Hemisphere Publishing, Washington, D.C.

Clements, L. D., and J. D. Reichert. 1979. "Optical-Thermal Performance Analysis for a Fixed Mirror-Distributed Focus Solar-Thermal-Electric Power System." In Proceedings of the 14th Intersociety Energy Conversion Engineering Conference, Boston, Massachusetts.

Cooper, A. M., and R. M. Bethea. 1986. Evaluation of Second-Surface Glass Mirrors Proposed for Use in a Fixed-Mirror Distributed-Focus Solar Collector. Department of Chemical Engineering, Texas Tech University, Lubbock, Texas.

Copeland, R. J. 1980. Preliminary Requirements for Thermal Storage Subsystems in Solar Thermal Applications. SERI-RR-731-364, Solar Energy Research Institute, Golden, Colorado.

Crane Company. 1974. Flow of Fluid Through Valves, Fittings, and Pipes. Crane Company, New York, New York.

Crocker, S. 1973. Piping Handbook. 5th Edition, McGraw Hill, New York, New York.

Darne11, J. R., et al. 1985. Studies on Water-Steam Rankine-Cycle Solar Central Receiver Power Plants, EPRI-AP-3982, Electric Power Research Institute, Palo Alto, California.

Doane, J. W., et al. 1976. The Cost of Energy from Utility-0wned Solar Electric systems. ERDA/JPL-1012-76/3, Jet Propulsion Laboratory, Pasadena, California.

Dunn, J. R., R. K. Foran, and U. Gunasena. 1986. "Aerodynamic Loading Characteristics of a Hemispherical Solar Concentrator." In Proceedings of the ASME Solar Energy Conference, pp. 233-237, Anaheim, California.

E-Systems. 1976. Fixed Mirror/Distributed Focus Solar Thermal Power System Study. In Volume III: Concentrator Structural Analysis and Costs. Energy Technology Center, Dallas, Texas.

E-Systems. 1981. Fixed Mirror Distributed Focus (Solar Bowl). E-Systems Energy Technology Center Technical Bulletin, Dallas, Texas. 
Electric Power Research Institute (EPRI). 1983. VIPRE-01: A ThermalHydraulic Analysis Code for Reactor Cores, Vol. 1: Mathematical Modeling. EPRI-NP-2511-CCM, Electric Power Research Institute, Palo Alto, California.

Electric Power Research Institute (EPRI). 1985. "Design Characteristics." From a Solar Thermal Workshop on Technical Problems and Issues sponsored by Electric Power Research Institute, Overland Park, Kansas.

Ford, W. T., and R. M. Anderson. 1985. Solvag: Radially Averaged Optical Power Ratio Calculations. Department of Mathematics, Texas Tech University, Lubbock, Texas.

Goodman, J. 1985. Construction Sequence Study. Texas Tech University, Lubbock, Texas.

Goodman, J. 1985. 16 December 1985 Study: Out 7 ine Construction Sequence of Membrane (Textile) Pneumatic Vacuum-Film Reflector and Tower-Jib Type Receivers (.2 R. of C.) Support Structure for 4 Shallow $(30)$ Bowls, circular Rims of 100 Feet $(30 \mathrm{~m})$ 0la. at 10 Incline Module for Level Terrain. Texas Tech University, Lubbock, Texas.

Goodman, J. 1985. 17 December 1985 Study: Out 7 ine Construction Sequence of R.C.- "Dirt" Bowls 4 Receivers (.2 R. of C.) Module Reinforced Concrete Spherical Segment Substrate on Excavated and Excavation Compacted with $\mathrm{N}-\mathrm{S}$ Guide (Rails) for Construction Trolley and Washing System. Texas Tech University, Lubbock, Texas.

Goodman, J. 1985. Selected Configuration of Multiple Spherical Segment Reflectors and Receiver-Assembly Support Structures. Texas Tech University, Lubbock, Texas.

Guven, N. 1985. SEM and EDS Analysis of Glasses. Department of Geosciences, Texas Tech University, Lubbock, Texas.

Guven, N. 1984. Scanning Electron Microscopic Examination of Mirror Glasses. Department of Geosciences, Texas Tech University, Lubbock, Texas.

Jones, W. B., T. Clark, and J. Wright. 1986. "Low-Cost Membrane Solar Concentrator Demonstration." In Proceedings of the ASME Solar Energy Conference, Pp. 229-232, Anaheim, California.

Jonish, J. E., and E. A. O'Hair. 1986. The Crosbyton Solar Power Project Economic Analysis of Alternate Uses and Design. Texas Tech University, Lubbock, Texas.

Jonish, J. E., and E. A. O'Hair. 1986. "Crosbyton Solar Power Concept: Economic Sensitivity Analysis." In Proceedings of the ASME Solar Energy Conference, pp. 245-249, Anaheim, California. 
Laity, W. W., et al. 1979. Assessment of Solar Options for Small Power System Applications, Volume I: Executive Summary. PNL-4000, Vol. I, Pacific Northwest Laboratory, Richland, Washington.

Laity, W. W., et. al. 1980. Identification and Characterization of Concepts for Analysis. In Vol. II of Assessment of Solar options for Small Power System Applications. PNL-4000, Vol. II, Pacific Northwest Laboratory, Richland, Washington.

Lodhi, M.A.K., and E. A. O'Hair. 1986. "The Solar Bowl Technology Transfer to Developing Nations: A Case Study of Pakistan." In Proceedings of the ASME Solar Energy Conference, pp. 250-253, Anaheim, California.

Maxwell, T. T., M. E. Davenport, G. B. Ferrel1, and M. Semrad. 1986. "Design Study of a Gas Cooled Receiver for a Hemispherical Solar Bowl." In Proceedings of the ASME Solar Energy Conference, pp. 238-244, Anaheim, California.

Means, R. S., Co. 1985. Building Construction Cost Data 1986. R. S. Means Company, Inc., Kingston, Maine.

Northrup, Inc. 1981. Second Generation Heliostat Development For Sodium Central Receiver Systems. Northrup, Inc., Hutchins, Texas.

O'Hair, E. A., and T. L. Simpson. 1984. Solar Bowl Results (Feb. 1983 - May 1984) - Results on Solar Bowl Technology. Department of Electrical Engineering, Texas Tech University, Lubbock, Texas.

O'Hair, E. A., T. L. Simpson, and R. Green. 1986. "Results from Operation of the Crosbyton Solar Bow1." In Proceedings of the ASME Solar Energy Conference, pp. 205-209, Anaheim, California.

0'Neill, M. J. 1977. "Optical Analysis of the Fixed Mirror/Distributed Focus (FMDF) Solar Energy Collector." In Proceedings of the International Solar Energy Society Annual Meeting, Orlando, Florida.

Page, J. S., and J. G. Nation. 1976. Estimator's Piping Man-Hour Manual. Gulf Publishing Company, Houston, Texas.

Percival, W., D. Wells, C. Bratt, K. Rosenqvist, and J. Berntell. 1982. "Stirling Engines for Solar Power Generation in the 50 to $500 \mathrm{~kW}$ Range." In Proceedings of the 17th Intersociety Energy Conversion Engineering Conference. Society of Automotive Engineers, Warrendale, Pennsylvania.

Peterson, R. E., and D. J. Smalley. 1985. A Cloud Shading Direct Solar Radiation Model. Atmospheric Science Group, Texas Tech University, Lubbock, Texas. 
Reichert, J. D., and S. R. Liberty. 1977. "An Interim Technical Report of Work Accomplished." In The Crosbyton Solar Power Project (Phase 1). Texas Tech University, Lubbock, Texas.

Reichert, J. D,, et al. 1984. "Analytical Optical Power Concentration Calculations for Reflection for Spherical Mirrors." American Society of Mechanical Engineers, New York, New York.

Richardson. 1983. Process Plant Construction Estimating Standards. Engineering Services, Inc., San Marcos, California.

Rockwell International, Pacific Gas and Electricity, and ARCO Solar Industries. 1983. Preliminary Design of the Carrisa Plains Solar Central Receiver Power Plant. ESG-DOE-13404. Prepared for the Department of Energy by Rockwell International, Pacific Gas and Electricity, and ARCO Solar Industries, San Francisco, California.

Simpson, T. L., E. A. O'Hair, and J. D. Rejchert. 1981. The Crosbyton Solar Power Project. In Vol. VII: Performance and cost of Solar Gridiron Electric Power Plants. Texas Tech University, Lubbock, Texas.

Simpson, T. L., E. A. O'Hair, and J. D. Reichert. 1981. The Crosbyton Solar Power Project. In Volume VIII: Preliminary Design of 5 MWe Solar-Fossil Hybrid Electric Power Plant at Crosbyton, Texas. Texas Tech University, Lubbock, Texas.

Southern California Edison, McDonnell Douglas Corporation, and 8echtel Power Corporation. 1982. Solar 100 Conceptual Study Final Report. Southern California Edison, Los Angeles, California.

Stearns-Rodgers. 1979. Tower Cost Data For Solar Central Receiver Studies. SAND78-818SV-1, Stearns-Rodgers Engineering, Denver, Colorado.

Urban, L. V., K. M. Trauth, and J. E. Loveless. 1986. Environmental Analysis of Solar Bowl Technology. Water Resources Center, Texas Tech University, Lubbock, Texas.

U.S. Department of Energy (DOE). 1984. Five Year Research and Development Plan, 1985-1989. U.S. Department of Energy, Washington, D.C.

U.S. Department of Energy (DOE). 1986. Five Year Research and Development Plan, 1986-1990. U.S. Department of Energy, Washington, D.C.

Vallabhan, C.V.G., K. Vungutur, and R. Selvam. 1984. Nonlinear Thermoelastic Stress Analysis of Spherically Curved Solar Panels. Department of Civil Engineering, Texas Tech University, Lubbock, Texas.

Vallabhan, C.V.G., K. Vungutur, and R. P. Selvam. 1986. "Thermal Stresses in Curved Solar Panels." In Proceedings of the ASME Solar Energy Conference, pp. 217-222, Anaheim, Cali fornia. 
Vann, W. P., B. E. Seth, and V. N. Gudivada. 1986. "Structural Design of Solar Bowl Receivers." In Proceedings of the ASME Solar Energy Conference, pp. 223-22B, Anaheim, California.

Walters, R., M. O'Neill, and Y. Gupta. 1976. Fixed Mirror/Distributed Focus Solar Thermal Electric Power Systems Development. E-Systems, Dallas, Texas.

Walters, R. R. 1983. "E-Systems Fixed Mirror Distributed Focus (Bowl) Collector Technology Summary." Paper presented at the Distributed Solar Collector Summary Conference--Technology and Applications, Albuquerque, New Mexico.

Williams, T. A., and J. A. Dirks. 1985. Economic Evaluation of Solar Thermal Energy Systems Using a Levelized Energy Cost Approach. Paper presented at Seventh Miami International Conference on Alternative Energy Systems, PNLSA-13507, Pacific Northwest Laboratory, Richland, Washington.

Williams, T. A., J. A. Dirks, and D. R. Brown. 1985. Long-Term Goals for Solar Thermal Technology. PNL-5463, Pacific Northwest Laboratory, Richland, Washington.

Williams, et al. 1987. Analyses and Evaluation. Vol. I of Characterization of Solar Thermal Concepts for Electricity Generation. PNL-6128, Vol. I, Pacific Northwest Laboratory, Richland, Washington.

Williams, T. A., J. A. Dirks, and D. R. Brown. 1987. Appendices. Vol. II of Characterization of Solar Thermal Concepts for Electricity Generation. PNL-6128, Vol. II, Pacific Northwest Laboratory, Richland, Washington.

Winslow, T. F. 1980. Construction Industry Production Manual. Craftsman Book Company, Solana Beach, California.

Wood, C. S. 1980. Mechanical Estimators Handbook. Craftsman Book Company, Solana Beach, California. 


\section{DISTRIBUTION}

No. of

Copies

OFFSITE

10 DOE/Office of Scientific and Technical Information

H. Coleman

U.S. Department of Energy Code CE-314

Forrestal Building, Rm. 5H021 1000 Independence Avenue, S.W. Washington, D.C. 20585

S. Gronich

U.S. Department of Energy Code CE-314

Forrestal Building, Rm. 5H021 1000 Independence Avenue, S.W. Washington, D.C. 20585

F. H. Morse

U.S. Department of Energy Code CE-314

Forrestal Building, Rm. 5H021 1000 Independence Avenue, S.W. Washington, D.C. 20585

C. C. Mangold

U.S. Department of Energy Code CE-314

Forrestal Building, Rm. 5H021 1000 Independence Avenue, S.W. Washington, O.C. 20585

M. R. Scheve

U.S. Department of Energy Code CE-314

Forrestal Building, Rm. 5H021 1000 Independence Avenue, S.W. Washington, D.C. 20585
No. of

Copies

R. W. Shivers

U.S. Department of Energy

Code CE-314

Forrestal Building, Rm. 5H021

1000 Independence Avenue, S.W. Washington, D.C. 20585

F. Wilkins

U.S. Department of Energy

Code CE-314

Forrestal Building, Rm. 5H021 1000 Independence Avenue, S.W. Washington, D.C. 20585

C. Carwile

U.S. Department of Energy

Code CE-33

Forrestal Building, Rm. 5H095

1000 Independence Avenue, S.W. Washington, D.C. 20585

M. Lopez

U.S. Department of Energy

1333 Broadway

Oakland, CA 94612

R. W. Hughey

U.S. Department of Energy

1333 Broadway

0akland, CA 94612

J. Weisiger

U.S. Department of Energy

Albuquerque Operations office

P.0. Box 5800

Albuquerque, NM 87115

D. Graves

U.S. Department of Energy

Albuquerque Operations Office

P.0. Box 5800

Albuquerque, NM 87115 
No. of

Copies

E. Weber

Arizona Public Service Company

P.0. Box 21666

Phoenix, AZ 85036

G. Grant

Babcock and Wilcox

91 Stirling Avenue

Barberton, $\mathrm{OH} 44203$

P. DeLaquil III

Bechtel Corporation

50 Beale Street

San Francisco, CA 94150

J. C. Grosskreutz

Black \& Veatch Consulting

Engineers

P.0. Box 8405

Kansas City, MO 64114

California Energy Commission

1516 North Street

$\mathrm{M} / \mathrm{S} 40$

Sacramento, CA 95814

E. DeMeo

Electric Power Research Institute

P.0. Box 10412

Palo Alto, CA 94303

Foster Wheeler Development Corp.

12 Peach Tree Hill Road

Livingston, NJ 07039

R. A. Cassanova

Georgia Institute of Technology

Atlanta, GA 30332

IEA/SSPS Project

Apartado 649

Almeria, Spain

R. L. Gervais

McDonnell Douglas Astronautics

Company

5301 Bolsa Avenue

Huntington Beach, CA 92647
No. of

Copies

J. J. Iannuci

Pacific Gas \& Electric

3400 Crow Canyon Road

San Ramon, CA 94583

R. E. Potthoff

San Diego Gas \& Electric Company

Mechanical Engineering

P.0. Box 1831

San Diego, CA 92112

L. Radosevich

Sandia National Laboratory

7011 East Avenue

Livermore, CA 94550

P. K. Falcone

Sandia National Laboratory

7011 East Avenue

Livermore, CA 94550

A. C. Skinrood

Sandia National Laboratory

7011 East Avenue

Livermore, CA 94550

J. T. Holmes

Sandia National Laboratory

1515 Eubank SE

Albuquerque, NM 87115

J. A. Leonard

Sandia National Laboratory

1515 Eubank SE

Albuquerque, NM 87115

J. V. 0tts

Sandia National Laboratory

1515 Eubank SE

Albuquerque, NM 87115

D. G. Schueler

Sandia National Laboratory

1515 Eubank S.E.

Albuquerque, NM 87115 
No. of

Copies

C. LaPorta

Solar Energy Industries

Association

Suite 503

Washington, D.C. 20035

B. Gupta

Solar Energy Research Institute 1617 Cole Boulevard

Golden, CO 80401

M. Murphy

Solar Energy Research Institute

1617 Cole Boulevard

Golden, C0 80401

J. Thornton

Solar Energy Research Institute

1617 Cole Boulevard

Golden, CO 80401

R. J. Copeland

Solar Energy Research Institute

1617 Cole Boulevard

Golden, C0 80401

P. Munjal

Solar Thermal Projects

Energy Systems Group

P.0. Box 92957

Los Angeles, CA 90009

E. A. O'Hair

Texas Tech University

Crosbyton Solar Power Project

Lubbock, TX 79409

T. L. Simpson

Texas Tech University

Crosbyton Solar Power Project

Lubbock, TX 79409
No. of

Copies

A. M. Clausing

University of Illinois

1206 W. Green Street

Urbana, IL 61820

A. F. Hilderbrandt

University of Houston

Solar Energy Laboratory

4800 Calhoun

Houston, TX 77004

A. J. Hunt

University of California 90-2024

Lawrence Berkeley Laboratory

1 Cyclotron Road

Berkeley, CA 94720

\section{ONSITE}

1 DOE-Richland Operations

J. J. Sutey/D. R. Segna

27 Pacific Northwest Laboratory

Z. A. Antoniac

D. R. Brown

J. A. Dirks

W. H. Doggett

M. K. Drost

B. A. Garrett-Price

R. A. Hutchinson

B. A. Ross

E. J. Westergard

T. A. Williams (10)

P. W. Zimmerman

Publication Information (2)

Technical Report Files 
